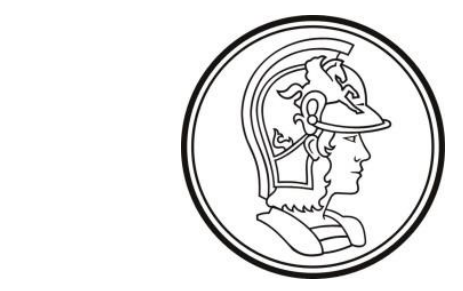

UNIVERSIDADE DE SÃO PAULO

ESCOLA POLITÉCNICA

BRUNA CASTANHEIRA

SÍNTESE, CARACTERIZAÇÃO E AVALIAÇÃO DE NOVOS MATERIAIS À BASE DE SÍLICAS MESOPOROSAS PARA DEGRADAÇÃO FOTOCATALÍTICA DE CONTAMINANTES DE INTERESSE EMERGENTE 
BRUNA CASTANHEIRA

\section{SÍNTESE, CARACTERIZAÇÃO E AVALIAÇÃO DE NOVOS MATERIAIS À BASE DE SÍLICAS MESOPOROSAS PARA DEGRADAÇÃO FOTOCATALÍTICA DE CONTAMINANTES DE INTERESSE EMERGENTE}

Tese apresentada à Escola Politécnica da Universidade de São Paulo para obtenção do título de Doutor em Ciências.

Área de Concentração: Engenharia Química

Orientador: Prof. Dr. Antonio Carlos Silva Costa Teixeira

Co-orientador: Prof. Dr. Sergio Brochsztain (Universidade Federal do ABC)

São Paulo 
Autorizo a reprodução e divulgação total ou parcial deste trabalho, por qualquer meio convencional ou eletrônico, para fins de estudo e pesquisa, desde que citada a fonte.

Este exemplar foi revisado e corrigido em relação à versão original, sob responsabilidade única do autor e com a anuência de seu orientador.

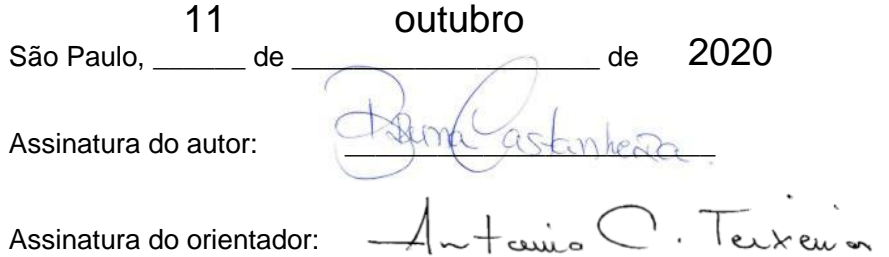

\section{Catalogação-na-publicação}

Castanheira, Bruna

SÍNTESE, CARACTERIZAÇÃO E AVALIAÇÃO DE NOVOS MATERIAIS À BASE DE SÍLICAS MESOPOROSAS PARA DEGRADAÇÃO FOTOCATALÍTICA DE CONTAMINANTES DE INTERESSE EMERGENTE /

B. Castanheira -- versão corr. -- São Paulo, 2020. $205 \mathrm{p}$.

Tese (Doutorado) - Escola Politécnica da Universidade de São Paulo. Departamento de Engenharia Química.

1.processos avançados de oxidação 2.fotocatálise heterogênea 3.organosílicas periódicas mesoporosas 4.sílicas mesoporosas 5.contaminantes de interesse emergente I.Universidade de São Paulo. Escola Politécnica. Departamento de Engenharia Química II.t. 
As minhas famílias do Brasil e de Portugal.

Com amor 


\section{AGRADECIMENTOS}

Foram quatro anos nessa jornada chamada Doutorado. Posso dizer, com muita certeza, que a Bruna de quatro anos atrás é totalmente diferente da Bruna de agora. Aprendi, vivi, sorri e chorei muito. Em resumo, esses anos foram altamente significativos para me tornar uma pessoa melhor. E tenho a agradecer muito por isso.

Primeiramente aos meus orientadores, Prof. Dr. Antonio Carlos S. C. Teixeira e o Prof. Dr. Sergio Brochsztain pela constante orientação, apoio e incentivo para realizar essa pesquisa da melhor forma possível.

Agradeço ao apoio do $\mathrm{CNPq}$ pelas bolsas de doutorado no país (processo $\mathrm{n}^{\circ}$ 870243/1997-7) e doutorado sanduíche (processo $n^{\circ}$ 204891/2018-3) concedidas. Meus agradecimentos também ao Programa de Pós-Graduação de Engenharia Química da Escola Politécnica da USP e à Universidade Federal do ABC (UFABC) pelo apoio e estrutura física.

A minha família, sem o apoio da qual eu não teria chegado aonde cheguei. Ao meu pai Reinaldo Castanheira, que é, sempre foi e sempre será o meu maior exemplo de pessoa. A minha mãe Rosana Fátima de Melo pelo carinho e o apoio de que eu sempre precisei. Ao meu irmão Marco Antônio Castanheira, que foi meu companheiro de casa e a pessoa que acompanhou de perto esses meus anos de pesquisa e que sempre me apoiou quando eu precisei. Agradeço também a meus irmãos gêmeos Aline M. Castanheira e Davi M. Castanheira, a quem eu tanto admiro, pelo constante incentivo e amor.

As minhas amigas queridas de laboratório da UFABC Luana Andrade e Bruna Tosco, pela amizade, risadas, trabalhos e cervejas geladas. Vocês sempre serão um grande exemplo para mim. Ao Prof. Dr. Thiago Branquinho pela amizade e exemplo de profissionalismo.

Ao grupo de laboratório da USP (AdOx) Arlen Lastre-Acosta, Bruno Ramos e Leonardo Diniz, sei que durante quase todo o doutorado fui distante do grupo, mas sempre pude contar com essas pessoas queridas. Ao técnico Rodrigo Ricardo Ramos que sempre me ajudou quando precisei e pelos cafés.

Um agradecimento especial a Priscila Palharim, que se tornou muito especial pra mim em pouco tempo e que sem ela eu não teria concluído metade desse trabalho.

As minhas amigas queridas de Atibaia. Manuela Cherfem, Thais Cardilli, Isa Brisa e Priscila Aguiar. Que me acompanham por muitos anos nessa jornada da vida e sei que vão me acompanhar por muito mais.

Atravessando o oceano Atlântico, agradeço imensamente quem participou da minha jornada de viver um ano em Portugal para realizar o estágio sanduíche. Começando pelo meu orientador, Dr. Vitor Vilar, pela constante orientação e poderoso conhecimento. Agradeço a 
todos os meus colegas de trabalho e membros do grupo do laboratório LCRE-LCM de Portugal, em especial Sara Santos, que me ajudou muito e não teria feito nada do trabalho se não fosse ela. A Joana Monteiro, Karen Batista, Bruna Porto, Jéssica Xavier e Reynel Castellanos pelos almoços, cafés, papos, amizade e companhia. Agradeço a Cátia Graça, minha amiga portuguesa mais querida do mundo, que foi uma grande companheira e parceira nas terras lusitanas.

A família que construí em tão pouco tempo: a família da comunidade. Os Cerqueiras: Sandra, Gell, Ursula e Carol e Alexandre Maximino, agradeço pela amizade, pelo amor, companheirismo, pelo carinho, experiência e por me deixar fazer parte desta família linda. Sei que minha vida em Portugal não teria sido tão boa sem vocês nela.

Agradeço também as lindas surpresas que apareceram no final dessa jornada de quatro anos de doutorado, meu namorado Jorge Madureira, pelo amor e companheirismo que até então achei que não existia, vivemos muitas aventuras e sei que teremos muitas outras pela frente. E a Maria Flor que carrego dentro de mim e que ainda não conheço, mas já amo muito.

Enfim, o doutorado me proporcionou conhecimento tanto na pesquisa quanto na vida e só tenho a agradecer esse período intenso de expêriencia na minha vida.

E que venham novas etapas!

Muito obrigada. 

It always seems impossible until it is done Nelson Mandela 


\section{RESUMO}

CASTANHEIRA, Bruna. Síntese, caracterização e avaliação de novos materiais à base de sílicas mesoporosas para degradação fotocatalítica de contaminantes de interesse emergente. Tese (Doutorado em Engenharia Química) - Escola Politécnica, Universidade de São Paulo, São Paulo, 2020.

A presente Tese visou estudar a preparação e aplicação de novos materiais à base de sílicas mesoporosas como fotocatalisadores heterogêneos em processos de oxidação avançada (POA). Para isso, foram sintetizadas, em um primeiro momento, sílicas mesoporosas do tipo SBA-15 via sol-gel, em que a fonte de sílica (tetraetilortosilicato - TEOS) foi condensada em condições ácidas na presença das micelas do surfactante Pluronic (P123) como template para formação dos mesoporos. Em seguida, a SBA-15 foi funcionalizada com composto semicondutor $\mathrm{TiO}_{2}$ pelo método pós-síntese sol-gel. Neste método, impregnaram-se 10\%, $16 \%, 20 \%$ e $30 \%$ em massa de $\mathrm{TiO}_{2}$ na sílica, originando os materiais $10 \% \mathrm{TiO}_{2} / \mathrm{SBA}-15$, $16 \% \mathrm{TiO}_{2} / \mathrm{SBA}-15,20 \% \mathrm{TiO}_{2} / \mathrm{SBA}-15$ e $30 \% \mathrm{TiO}_{2} / \mathrm{SBA}-15$, respectivamente. Em um segundo momento, foram preparadas as organosílicas periódicas mesoporosas (PMO) contendo as imidas aromáticas 1,4,5,8-naftalenodiimidas (NDI) como moléculas orgânicas, pelo método de co-condensação. Neste método, TEOS é condensado nas mesmas condições de síntese da SBA-15 juntamente com o grupo organossilano: N,N'-bis[3(trietoxisil)propil]1,4,5,8-naftalenodiimida (TESP-NDI), tendo sido utilizadas diferentes porcentagens em massa de NDI (8\% e 16\%) originando os materiais PMONDI-8 e PMONDI16 , respectivamente. A caracterização das estruturas mesoporosas empregando SAXS, MET e adsorção de $\mathrm{N}_{2}$ mostraram a obtenção de materiais porosos extremamente organizados com alta área superficial específica $\left(\sim 500 \mathrm{~m}^{2} \mathrm{~g}^{-1}\right)$ e diâmetro de poros entre 5,2-6,3 $\mathrm{nm}$ para $\mathrm{TiO}_{2} / \mathrm{SBA}-15$ e entre 10,2-12,6 nm para as PMONDI. A presença de partículas com dimensões entre 5 e $7 \mathrm{~nm}$ de $\mathrm{TiO}_{2}$ anatase nas amostras $\mathrm{TiO}_{2} / \mathrm{SBA}-15$ pôde ser confirmada através das análises de difração de raios-X, enquanto a presença de NDI nas paredes dos poros das PMONDI foi confirmada através de análise elementar (CHN), de RMN e espectroscopia na região UV-visível. Por fim, avaliou-se o desempenho desses materiais como fotocatalisadores heterogêneos para degradação de um contaminante-modelo de interesse emergente, o antibiótico sulfadiazina (SDZ). Para tal, foram utilizados sistemas fotocatalíticos com diferentes configurações: (i) batelada; (ii) microrreator empacotado; e (iii) fotorreator anular FluHelik. No sistema batelada obtiveram-se 100\% de degradação da SDZ após 45 minutos de irradiação na presença da suspensão de PMONDI-16. No microrreator empacotado, operado em escoamento contínuo e empacotado com PMONDI-16, obteve-se diminuição de $60 \%$ da concentração inicial de SDZ. Em ambos os sistemas, foi possível propor um mecanismo de degradação da SDZ e averiguar que um dos intermediários formados corresponde à extrusão de $\mathrm{SO}_{2}$ seguido do rearranjo da molécula de SDZ. Por fím, no reator FluHelik, foi possível eliminar a SDZ inicialmente presente após $120 \mathrm{~min}$ de irradiação na presença de suspensão do $30 \% \mathrm{TiO}_{2} / \mathrm{SBA}-15$. Nesse caso, experimentos realizados em matriz de águas residuais urbanas mostraram que $90 \%$ da SDZ foram removidos após 180 min de irradiação.

Palavras-chave: processos avançados de oxidação, fotocatálise heterogênea, organosílicas periódicas mesoporosas, imidas aromáticas, sílicas mesoporosas, $\mathrm{TiO}_{2}$, contaminantes de interesse emergente, sulfadiazina, fotorreatores. 


\begin{abstract}
The present Thesis aimed to study the synthesis and application of novel materials based on mesoporous silicates as heterogeneous photocatalysts in advanced oxidation processes (AOP). With this purpose, SBA-15 mesoporous silicates were synthesized via the sol-gel method, in which the source of silica (tetraethylorthosilicate - TEOS) was condensed under acidic conditions in the presence of Pluronic surfactant (P123) micelles, acting as a template for mesopore formation. Then, the SBA-15 material was functionalized with the semiconductor $\mathrm{TiO}_{2}$ by the post-synthesis sol-gel method, in which $10 \%, 16 \%, 20 \%$, and $30 \% \mathrm{w} / \mathrm{w} \mathrm{TiO}_{2}$ were impregnated on the silica framework, giving rise to the materials $10 \% \mathrm{TiO}_{2} / \mathrm{SBA}-15$, $16 \% \mathrm{TiO}_{2} / \mathrm{SBA}-15,20 \% \mathrm{TiO}_{2} / \mathrm{SBA}-15$ and $30 \% \mathrm{TiO}_{2} / \mathrm{SBA}-15$, respectively. In a second step, periodic mesoporous organosilicas (PMO) containing aromatic 1,4,5,8-naphthalenediimides (NDI) were prepared by the co-condensation method. According to this method, TEOS was condensed under the same SBA-15 conditions together with the organosilane group: $\mathrm{N}, \mathrm{N}^{\prime}$-bis [3-(triethoxyisyl) propyl] 1,4,5,8-naphthalenediimide (TESP-NDI); 8\% and 16\% of NDI w/w were used, resulting in the materials PMONDI-8 and PMONDI-16, respectively. The characterization of the mesoporous structures using SAXS, TEM and $\mathrm{N}_{2}$ adsorption showed extremely organized porous frameworks of high surface area $\left(\sim 500 \mathrm{~m}^{2} \mathrm{~g}^{-1}\right)$ and pore diameters in the range 5.2-6.3 nm for $\mathrm{TiO}_{2} / \mathrm{SBA}-15$ and 10.2-12.6 nm for PMONDI. The presence of anatase $\mathrm{TiO}_{2}$ particles with $5-7 \mathrm{~nm}$ in $\mathrm{TiO}_{2} / \mathrm{SBA}-15$ samples was confirmed through X-ray diffraction analyzes, while the presence of NDI in the PMONDI materials was confirmed through elemental analysis (CHN), NMR and UV-vis spectroscopy. The performance of these materials as heterogeneous photocatalysts was then investigated for the degradation of the antibiotic sulfadiazine (SDZ). With this aim, three different photocatalytic systems were employed: (i) slurry batch reactor; (ii) micro packed-bed reactor ( $\mu \mathrm{BPR}$ ); and (iii) the FluHelik photoreactor. In the batch system, a high-pressure vapor Hg UV lamp was used, achieving total SDZ degradation after 45 minutes irradiation in the presence of PMONDI-16. In the continuous flow $\mu \mathrm{BPR}, 60 \%$ decrease of the intlet SDZ concentration was obtained in the presence of PMONDI-16 and a UV-A LED radiation source. In both systems, the intermediate compounds formed were characterized, making possible to propose a degradation mechanism for SDZ. Finally, in the annular FluHelik photoreactor, it was possible to eliminate the SDZ initially present after $120 \mathrm{~min}$ of irradiation in the presence of the $30 \% \mathrm{TiO}_{2} / \mathrm{SBA}-15$ photocatalyst. In this case, experiments using an urban wastewater matrix resulted in $90 \%$ SDZ removal after 180 min of irradiation.
\end{abstract}

Keywords: advanced oxidation processes, heterogeneous photocatalysis, periodic mesoporous organosilicas, aromatic imides, mesoporous silicates, $\mathrm{TiO}_{2}$, contaminants of emerging concern, sulfadiazine, photoreactors. 


\section{LISTA DE FIGURAS}

Figura 1.1 Mecanismo de formação de materiais mesoporosos, tomando como exemplo a formação da MCM-41 (mobil composition of matter $n^{\circ} 41$ ).

Figura 1.2 Estrutura molecular de dois surfactantes comumente utilizados para a síntese de sílicas mesoporosas: (A) brometo de cetiltrimetilamônio (CTAB) utilizado na síntese da MCM-41. (B) Pluronic P123 formado por blocos de óxido de etileno e óxido de propileno $\left(\mathrm{EO}_{20} / \mathrm{PO}_{70} / \mathrm{EO}_{20}\right)$ utilizado na síntese da SBA-15.

Figura 1.3 Métodos para funcionalizar a SBA-15 com óxidos metálicos, sendo (A) impregnação simples e (B) impregnação hidrotérmica. O precursor consiste em uma solução salina do metal (Me) de interesse.

Figura 1.4 Método sol-gel para a funcionalização de sílicas mesoporosas com óxidos metálicos.

Figura 1.5 As três estruturas de $\mathrm{TiO}_{2}$ (a) rutilo e (b) anatase (c) brookita. Ti: esferas rosas; O: esferas vermelhas.

Figura 1.6 Número de publicações encontradas nos últimos dez anos utilizando as palavraschave de busca: SBA-15 $+\mathrm{TiO}_{2}$ (שu ) e SBA-15 $+\mathrm{TiO}_{2}+$ fotocatálise

Figura 1.7 Representação do método de funcionalização pós-síntese, sendo $\mathrm{R}=$ grupo orgânico.

Figura 1.8 Esquema representando o método de co-condensação ou síntese direta, sendo R o grupo funcional orgânico.

Figura 1.9 Síntese de PMO. Onde, R representa o grupo funcional orgânico.

Figura 1.10 Estruturas moleculares de algumas diimidas aromáticas. 46

Figura 1.11 Grupamento imida. 46

Figura 1.12 Numeração dos derivados naftalênicos e perilênicos.

Figura 1.13 Síntese das imidas aromáticas (A) 1,8-naftalimida (NI) (B) 1,4,5,8naftalenodiimidas.

Figura 1.14 Redução das NDI em duas etapas.

Figura 1.15 (A) Espectro de absorção em $\mathrm{CH}_{2} \mathrm{Cl}_{2}$ e (B) espectro de fluorescência normalizado $\left(\lambda_{\text {ex }}=360 \mathrm{~nm}\right)$ em $\mathrm{CH}_{2} \mathrm{Cl}_{2}$ e (C) em tolueno da $\mathrm{N}$, N-difenil 1,4,5,8-naftalenodiimida.

Figura 1.16 Estrutura cristalina de derivado da NDI (N, N-difenil 1,4,5,8-naftalenodiimida) mostrando uma forte ordenação devido à capacidade de empilhamento $\pi-\pi$ do núcleo de naftaleno. 
Figura 1.17 Estrutura das PPDI empilhadas nos canais da MCM-41

Figura 1.18 Sílicas mesoporosas modificadas com imidas aromáticas preparadas pelo grupo de pesquisa da UFABC, via método da funcionalização pós-síntese. Na primeira etapa as sílicas mesoporosas são reagidas com 3-aminopropiltrietoxisilano (APTES), gerando superfícies aminadas. Os grupos amino são então reagidos com anidridos aromáticos, gerando imidas aromáticas covalentemente ligadas à parede dos poros. .52

Figura 1.19 Representação do processo de transferência de energia entre a 1,8-naftalimidas (NI) e as 3,4,9,10- perilenodiimidas (PDI). Inserto: ajuste de cor de emissão de fluorescência através do incremento da dopagem de PDI nos materiais SBANI.....

Figura 1.20 Esquema de preparação dos filmes finos PMO-SBA-15. (A) Sistema sol de partida. (B) PMO-SBA-15. (C) Mesocanais hexagonais. A imagem obtida pela microscopia eletrônica de transmitância (TEM) mostra ordenação hexagonal para PMO-SBA15. (D) PTCDBS ligado covalentemente dentro dos poros de PMO-SBA-15 puro (100 \% BTSE). ...54 Figura 1.21 Processos de transferência de energia e de elétrons em filmes de PMO contendo tetrafenil pireno (TPPy-Si) como doador e uma perilenodiimida como aceptora de elétrons e de energia.

Figura 1.22 Estruturas moleculares dos derivados das PDI utilizados como aceptores de elétrons e energia. 55

Figura 1.23 PMO preparados por Mizoshita e colaboradores com 3,4,9,10-perilenodiimida (PDI). (A) representação dos empilhamentos moleculares do tipo $\pi$ ( $\pi$ stacking). (B) Molécula PDI utilizada com grupos silanos presentes nas quatro extremidades. .56

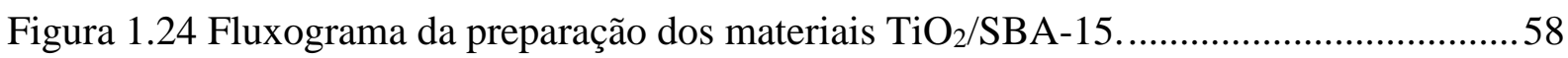

Figura 1.25 Esquema do método sol-gel para a síntese dos materiais $\mathrm{TiO}_{2} / \mathrm{SBA}-15$.............58

Figura 1.26 Representação de cada passo para a síntese das PMONDI...................................60

Figura 1.27 Espectros de absorção no UV-visível das soluções de TESP-NDI utilizadas na síntese das PMONDI. Para obter os espectros, alíquotas de $1 \mu \mathrm{L}$ das soluções de TESP-NDI em acetona (vide texto) foram diluídas em $3 \mathrm{~mL}$ de $\mathrm{CHCl}_{3}$ em uma cubeta de quartzo. As concentrações foram obtidas com a lei de Lambert-Beer (Equação 1.6), utilizando um valor de $\varepsilon=20000 \mathrm{~L} \mathrm{~mol}^{-1} \mathrm{~cm}^{-1}$ (para $\lambda_{\text {máx }}=380 \mathrm{~nm}$ ), típico das NDI (BARROS et al., 1997).

Figura 1.28 Difratogramas das amostras $\mathrm{TiO}_{2} / \mathrm{SBA}-15$ e da sílica não funcionalizada SBA-15 (lotes 1 e 2).

Figura 1.29 Imagens de miscroscopia eletrônica de transmissão de alta resolução (HRTEM) das amostras SBA-15 (lote 1) (A e B) e 16\% $\mathrm{TiO}_{2} / \mathrm{SBA}-15$ (C e D). 
Figura 1.30 Imagens de miscroscopia eletrônica de transmissão de alta resolução (HRTEM) das amostras SBA-15 (lote 2) (A e B); $10 \% \mathrm{TiO}_{2} / \mathrm{SBA}-15$ (C e D) 20\% TiO $/ \mathrm{SBA}^{-15}$ (E e F) e $30 \% \mathrm{TiO}_{2} / \mathrm{SBA}-15(\mathrm{G}$ e $\mathrm{H})$

Figura 1.31 (A) Isotermas de adsorção de $\mathrm{N}_{2}$ e (B) distribuição do tamanho de poros (BJH) das SBA-15 originais pertencentes ao lote $1(--)$ e lote $2(--)$. Os símbolos vazios representam a etapa de dessorção de $\mathrm{N}_{2}$.

Figura 1.32 (A) Isotermas de adsorção de $\mathrm{N}_{2}$ e (B) distribuição do tamanho de poros (BJH) das amostras (-•-) SBA-15 (lote 1) e (一representam a etapa de dessorção de $\mathrm{N}_{2}$.

Figura 1.33 (A) Isotermas de adsorção de $\mathrm{N}_{2}$ e (B) distribuição do tamanho de poros (BJH)

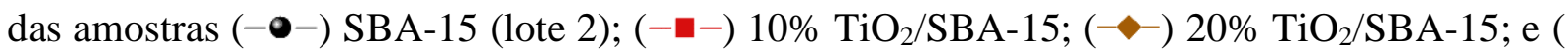
- $\star-$ ) $30 \% \mathrm{TiO}_{2} / \mathrm{SBA}-15$. Os símbolos vazios representam a etapa de dessorção de $\mathrm{N}_{2} \ldots \ldots . . .72$ Figura 1.34 SAXS em escala logarítmica das amostras (A) SBA-15 (lote 1) e 16\% $\mathrm{TiO}_{2} / \mathrm{SBA}-$ 15 e (B) SBA-15 (lote 2); $10 \% \mathrm{TiO}_{2} / \mathrm{SBA}-15 ; 20 \% \mathrm{TiO}_{2} / \mathrm{SBA}-15 ; 30 \% \mathrm{TiO}_{2} / \mathrm{SBA}-15 \ldots \ldots . . .74$ Figura 1.35 Diagrama da estrutura das sílicas mesoporosas, em que $d(100)$ é a distância interplanar no plano (100), $w$ é a espessura de parede da sílica e a0, o parâmetro de rede mesoporosa. 75

Figura 1.36 Espectros de absorção na região do UV-visível das amostras $\mathrm{TiO}_{2} / \mathrm{SBA}-15 \ldots . . .76$ Figura 1.37 Estrutura, fórmula molecular e massas molar de TESP-NDI condensada presente nas paredes dos poros das PMONDI.

Figura 1.38 Espectros de infravermelho (FTIR) das amostras PMONDI-8 e PMONDI-16... 79 Figura 1.39 (A) Estrutura molecular do precursor organosilano TESP- NDI com os átomos de hidrogênio em destaque (B) Espectro de ${ }^{1} \mathrm{H}-\mathrm{RMN}$ em $\mathrm{CDCl}_{3}$ do TESP-NDI. Os prótons significativos são mostrados em diferentes cores, e relacionados tanto na estrutura molecular quanto no espectro de RMN.

Figura 1.40. (A) De baixo para cima: espectro de 13C-NMR da solução de TESP-NDI em $\mathrm{CDCl}_{3}$; espectro de ${ }^{13} \mathrm{C}-\mathrm{NMR}$ da amostra PMONDI-16 no estado sólido. As bandas marcadas com "p" correspondem aos carbonos da cadeia de propil. (B) estrutura molecular da TESPNDI mostrando os carbonos $\alpha, \beta$ e $\gamma$ da cadeia propil.

Figura 1.41 Espectros de RMN ( $\left.{ }^{29} \mathrm{Si}\right)$ das amostras PMONDI-8 e PMONDI-16 no estado sólido.

Figura 1.42 (A) Isotermas de adsorção de $\mathrm{N}_{2}$. (B) distribuição de tamanho de poros determinado pelo método BJH durante a dessorção das amostras PMONDI-8 e PMONDI-16 e da sílica não funcionalizada SBA-15. 
Figura 1.43 SAXS em escala logarítmica das amostras (A) SBA-15 com e sem surfactante e (B) PMONDI.

Figura 1.44 Imagens de microscopia eletrônica de transmissão (TEM) das PMONDI-8 (A, B); PMONDI-16 (C, D)

Figura 1.45 Espectro de refletância difusa convertido em unidades de absorbância das amostras PMONDI. Foi adicionado o espectro de absorção da solução homogênea do intermediário TESP-NDI $\left(0,04 \mathrm{~mol} \mathrm{~L}^{-1} \mathrm{em} \mathrm{CHCl}_{3}\right)$ para comparação.... 87

Figura 2.1 Caráter anfótero das sulfonamidas. .90

Figura 2.2 Estrutura molecular da SDZ. 90

Figura 2.3 (A) Equilíbrio de dissociação ácido-base da SDZ (B) Porcentagem molares das diferentes espécies de SDZ (forma catiônica, neutra e aniônica) em função do pH.

Figura 2.4 Alguns semicondutores e sua energia de gap de banda (eV) contra o potencial de hidrogênio padrão (EPH). 93

Figura 2.5 Representação esquemática dos eventos existentes na fotocatálise heterogênea....94 Figura 2.6 Esquema geral das vias de degradação por radicais $\mathrm{HO}$ • sofridas pelas sulfonamidas.

Figura 2.7 Representação esquemática dos processos de transferência de energia a partir de uma molécula orgânica sensibilizadora (sens). $S_{0}$ é seu estado fundamental, $S_{1}$ e $S_{2}$ são os estados excitados singletes ( ${ }^{1}$ sens*) e $\mathrm{T}_{1}$ e $\mathrm{T}_{2}$ são os respectivos estados excitados tripletes $\left({ }^{3}\right.$ sens*). 102

Figura 2.8 Possíveis vias (mecanismos tipo I e tipo II) originárias a partir da absorção de energia radiante pelo sensibilizador orgânico. No esquema, $\mathrm{P}$ corresponde ao poluente, ISC representa o cruzamento intersistemas e sens, o sensibilizador. 103

Figura 2.9 Primeiro produto fotogerado oriundo da extrusão de $\mathrm{SO}_{2}$ pela interação de $\mathrm{SDZ}$ com matéria orgânica dissolvida cromofórica (CDOM). 104

Figura 2.10 (A) representação do aparato experimental utilizado e (B) Fotografia do béquer irradiado.

Figura 2.11 Espectros de (a) emissão da lâmpada de alta pressão de vapor de mercúrio (100 W) de arco curto Ominicure $S 1000$ associada a uma fibra óptica com filtro com janela 320500 nm, juntamente com os espectros de absorção (b) da PMONDI-16 (c) da SDZ e (d) $16 \% \mathrm{TiO}_{2} / \mathrm{SBA}-15$. 
Figura 2.12 Fotodegradação de SDZ em pH natural e $25^{\circ} \mathrm{C}$. (A) $\mathrm{I}=3 \mathrm{~mW} \mathrm{~cm}^{-2}$ e $C_{0, \mathrm{SDZ}}=7,5$ $\mathrm{mg} \mathrm{L}^{-1}$; (B) I $=3 \mathrm{~mW} \mathrm{~cm}^{-2}$ e $C_{0, \mathrm{SDZ}}=12,5 \mathrm{mg} \mathrm{L}^{-1}$; (C) $\mathrm{I}=3 \mathrm{~mW} \mathrm{~cm}^{-2}$ e $C_{0, \mathrm{SDZ}}=5 \mathrm{mg} \mathrm{L}^{-1}$; (D) $\mathrm{I}=8 \mathrm{~mW} \mathrm{~cm}^{-2}$ e $C_{0, \mathrm{SDZ}}=10 \mathrm{mg} \mathrm{L}^{-1}$; (E) I $=8 \mathrm{~mW} \mathrm{~cm}^{-2}$ e $C_{0, \mathrm{SDZ}}=15 \mathrm{mg} \mathrm{L}^{-1}$; (F) I $=13 \mathrm{~mW}$ $\mathrm{cm}^{-2}$ e $C_{0, \mathrm{SDZ}}=7,5 \mathrm{mg} \mathrm{L}^{-1} ;(\mathrm{G}) \mathrm{I}=13 \mathrm{~mW} \mathrm{~cm}^{-2}$ e $C_{0, \mathrm{SDZ}}=12,5 \mathrm{mg} \mathrm{L}^{-1}$. Fotólise (一- - )

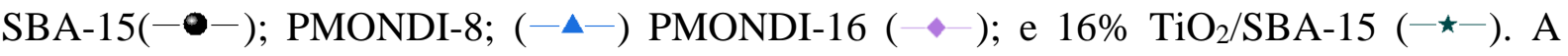
linha tracejada indica o instante em que se deu início à irradiação após 24 h na ausência de luz. Erro experimental avaliado a partir das triplicatas dos experimentos realizados nas condições do ponto central.

Figura 2.13 Efeito da irradiância $\left(I=3\right.$ e $\left.13 \mathrm{~mW} \mathrm{~cm}^{-2}\right)$ na fotodegradação catalítica de SDZ. (A) $C_{0, \mathrm{SDZ}}=7,5 \mathrm{mg} \mathrm{L}^{-1}$; (B) $C_{0, \mathrm{SDZ}}=12,5 \mathrm{mg} \mathrm{L}^{-1}$. Nesses experimentos: ( $\square$ ) fotólise; (\$\&)

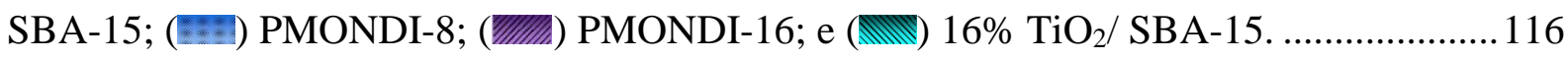
Figura 2.14 Efeito da concentração inicial de $\operatorname{SDZ}\left(C_{0, \mathrm{SDZ}}=7,5 \mathrm{mg} \mathrm{L}^{-1}\right.$ e $\left.12,5 \mathrm{mg} \mathrm{L}^{-1}\right)$ na fotodegradação catalítica de SDZ. (A) $3 \mathrm{~mW} \mathrm{~cm}^{-2}$; (B) $8 \mathrm{~mW} \mathrm{~cm}^{-2}$; (C) $13 \mathrm{~mW} \mathrm{~cm}{ }^{-2}$. Nesses

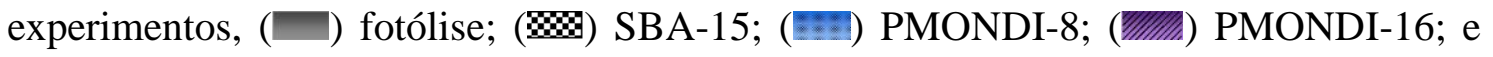
$16 \% \mathrm{TiO}_{2} / \mathrm{SBA}-15$.

Figura 2.15 Experimentos de reutilização dos fotocatalisadores (제) PMONDI-16 e $16 \% \mathrm{TiO}_{2} / \mathrm{SBA}-15$ quanto à degradação fotocatalítica de SDZ. Condições: $C_{0, \mathrm{SDZ}}=12,5 \mathrm{mg}$ $\mathrm{L}^{-1} ; \mathrm{I}=3 \mathrm{~mW} \mathrm{~cm}{ }^{-2} ; \mathrm{pH}$ natural $; 25^{\circ} \mathrm{C}$. 118

Figura 2.16 Experimentos de fotodegradação de pCBA $\left(C_{0, \mathrm{pCBA}}=22,5 \mu \mathrm{mol} \mathrm{\textrm {L } ^ { - 1 }}\right) \mathrm{em}$ meio aquoso $(50 \mathrm{~mL})$ contendo $16 \% \mathrm{TiO}_{2}$ SBA-15 $\left(0,5 \mathrm{~g} \mathrm{~L}^{-1}\right)$. (--) ausência de SDZ e (-^-) com SDZ $\left(C_{0, \mathrm{SDZ}}=12,5 \mathrm{mg} \mathrm{L}^{-1}\right)$. Condições: $\mathrm{I}=13 \mathrm{~mW} \mathrm{~cm}{ }^{-2} ; \mathrm{pH}$ natural; $25^{\circ} \mathrm{C}$.

Figura 2.17 Experimentos de fotodegradação de FFA $\left(C_{0, \mathrm{FFA}}=10^{-4} \mathrm{~mol} \mathrm{~L}^{-1}\right)$ em meio aquoso $\left(50 \mathrm{~mL}\right.$ ) contendo (A) PMONDI-8 e (B) PMONDI-16 (C) 16\% $\mathrm{TiO}_{2} / \mathrm{SBA}-15$, ambos a 0,5 g $\mathrm{L}^{-1}$. (--) ausência de SDZ; e $\left(-\boldsymbol{\Delta}^{-}\right)$com SDZ $\left(C_{0, \mathrm{SDZ}}=12,5 \mathrm{mg} \mathrm{L}^{-1}\right)$. Condições: $\mathrm{I}=13$ $\mathrm{mW} \mathrm{cm}{ }^{-2} ; \mathrm{pH}$ natural; $25^{\circ} \mathrm{C}$.

Figura 2.18 Ajuste linear de $\ln \left(C_{\mathrm{pCBA}} / \mathrm{C}_{0, \mathrm{pCBA}}\right)$ versus tempo (s) para determinação da quantidade estacionária de radicais hidroxila $\left(\left[\mathrm{HO}^{*}\right]_{\mathrm{ss}}\right)$ na irradiação de solução $(50 \mathrm{~mL})$ contendo pCBA $\left(C_{0, \mathrm{pCBA}}=22,5 \mu \mathrm{mol} \mathrm{L}{ }^{-1}\right)$ na presença do fotocatalisador $16 \% \mathrm{TiO}_{2} / \mathrm{SBA}-15$ $\left(0,5 \mathrm{~g} \mathrm{~L}^{-1}\right)$. (A) ausência de SDZ (B); com SDZ $\left(C_{0, \mathrm{SDZ}}=12,5 \mathrm{mg} \mathrm{L}^{-1}\right)$. Condições: $\mathrm{I}=13 \mathrm{~mW}$ $\mathrm{cm}^{-2}$; pH natural; $25^{\circ} \mathrm{C}$ 
Figura 2.19 Ajuste linear de $\ln \left(C_{\mathrm{FFA}} / C_{0, \mathrm{FFA}}\right)$ versus tempo para determinação da quantidade estacionária de oxigênio singlete $\left(\left[{ }^{1} \mathrm{O}_{2}\right]_{\mathrm{ss}}\right)$ na irradiação de solução $(50 \mathrm{~mL})$ contendo FFA $\left(C_{0, \mathrm{FFA}}=10^{-4} \mathrm{~mol} \mathrm{~L}^{-1}\right)$ na presença do fotocatalisador PMONID-8 $\left(0,5 \mathrm{~g} \mathrm{~L}^{-1}\right)$. (A) ausência de $\operatorname{SDZ}(\mathrm{B})$; com SDZ $\left(C_{0, \mathrm{SDZ}}=12,5 \mathrm{mg} \mathrm{L}^{-1}\right)$, e PMONDI-16 $\left(0,5 \mathrm{~g} \mathrm{~L}^{-1}\right)$. (C) ausência de SDZ (D); com SDZ $\left(C_{0, \mathrm{SDZ}}=12,5 \mathrm{mg} \mathrm{L}^{-1}\right)$. Condições: $\mathrm{I}=13 \mathrm{~mW} \mathrm{~cm}{ }^{-2} ; \mathrm{pH}$ natural; $25^{\circ} \mathrm{C} \ldots \ldots . .122$ Figura 2.20 Mecanismos tipo I e tipo II possíveis para a degradação de SDZ induzida pelo sensibilizador orgânico 1,4,5,8-naftalenodiimidas (NDI), em que $h v$ representa a absorção de radiação UV pela NDI; ${ }^{1} \mathrm{NDI} *,{ }^{3} \mathrm{NDI}^{*}$ correspondem aos estados excitado singlete e triplete, enquanto ISC corresponde ao cruzamento intersistemas.

Figura 2.21 Cromatogramas (LC-MS) das soluções de SDZ. (A) não irradiada; (B) irradiada por 180 min na presença de $16 \% \mathrm{TiO}_{2} / \mathrm{SBA}-15\left(0,5 \mathrm{~g} \mathrm{~L}^{-1}\right)$; (C) irradiada por $180 \mathrm{~min}$ na presença de PMONDI-16 (0,5 $\left.\mathrm{g} \mathrm{L}^{-1}\right)$. Condições: $C_{0, \mathrm{SDZ}}=12,5 \mathrm{mg} \mathrm{L}^{-1} ; \mathrm{I}=3 \mathrm{~mW} \mathrm{~cm}{ }^{-2} ; \mathrm{pH}$ natural; $25{ }^{\circ} \mathrm{C}$.

Figura 2.22 Relação massa/carga $(\mathrm{m} / \mathrm{z})$ dos fragmentos correspondentes aos picos obtidos pelas análises de cromatografia líquida acoplada à espectrometria de massas das alíquotas de SDZ após 180 min de fotodegradação catalítica.

Figura 2.23 Mecanismo proposto para a fotodegradação catalítica de SDZ. ......................... 127

Figura 3.1 Configuração do primeiro micro reator utilizado em fotocatálise em 2004 ........ 131 Figura 3.2 Fotografia do microrreator fotocatalítico. Por clareza, o microcanal foi preenchido com solução aquosa de azul de metileno. 132

Figura 3.3 Esquema da configuração do reator de leito empacotado (PBR) trabalhando em modo batelada com recirculação.

Figura 3.4 Esquema da configuração do micro reator de leito empacotado (em cima). Posição da fonte de luz em relação ao corpo do reator (em baixo).

Figura 3.5 (A) Micro- reator de leito fixo ( $\mu$ PBR). (B) Fonte de LEDs UV-A e arranjo do $\mu \mathrm{PBR}$. 136

Figura 3.6 (a) Espectro de emissão da fonte de LEDs na região do UV-A, sobreposto aos espectros de absorção dos fotocatalisadores (b) PMONDI-16 e (c) PMONDI-8, juntamente com (d) espectro de absorção da solução de $\operatorname{SDZ}\left(C_{0, S D Z}=10 \mathrm{mg} \mathrm{L}^{-1}\right)$. 138 Figura 3.7 Experimentos de adsorção e fotodegradação da SDZ conduzidos no microrreator empacotado (micro-packed bed reactor) com escoamento contínuo (20 $\mu \mathrm{L} \mathrm{min}^{-1}$ ). Experimentos na presença dos fotocatalisadores PMONDI-8 ( $\bullet$ ), PMONDI-16 ( $)$ e $\mathrm{TiO}_{2}$ P25 ( ) e controles: fotólise ( $\bullet$ ) e SBA-15 ( $\bullet$ ), utilizando fonte radiante uma placa de LEDs UV-A. 
Figura 3.8 Concentrações de SDZ à saída do reator, normalizadas com relação à concentração de entrada $\left(C_{\mathrm{SDZ}} / \mathrm{C}_{0, \mathrm{SDZ}}\right)$ para os experimentos de fotocatálise conduzidos no microrreator empacotado (micro-packed bed reactor) com escoamento contínuo $\left(20 \mu \mathrm{L} \mathrm{min}^{-1}\right)$, na presença dos materiais PMONDI-8 (^), PMONDI-16 (•), $\mathrm{TiO}_{2} \mathrm{P} 25(\bullet)$ e SBA-15 (• ) após 180 min de irradiação.

Figura 3.9 Decaimento exponencial da irradiância versus a distância do microrreator em relação à fonte radiante utilizada nos experimentos fotocatalíticos $(x, \mathrm{~cm})$. $\mathrm{O}$ ajuste da curva de calibração corresponde a $R^{2}=0,9999$.

Figura 3.10 Taxa especifica de degradação de SDZ $\left(r_{S D Z}\right)$ em estado estacionário e base

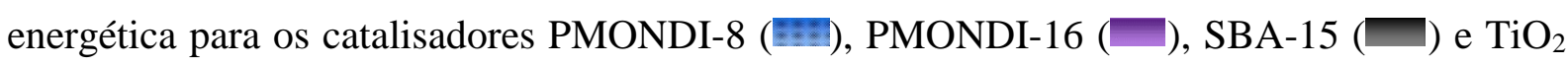
P25

Figura 3.11 Experimentos de adsorção e fotodegradação da SDZ conduzidos no microrreator empacotado (micro-packed bed reactor) para vazões $20(\square), 25(\bigcirc), 30(\triangle)$ e $40(\succsim) \mu \mathrm{L}$ $\min ^{-1}$ na presença do fotocatalisador PMONDI-16. 144

Figura 3.12 Cromatogramas obtidos nas análises de cromatografia líquida de alta eficiência (HPLC) da solução aquosa de $\operatorname{SDZ}\left(C_{0, \mathrm{SDZ}}=10 \mathrm{mg} \mathrm{L}^{-1}\right)$ após $300 \mathrm{~min}$ de irradiação, na presença dos catalisadores PMONDI-8, PMONDI-16 e $\mathrm{TiO}_{2} \mathrm{P} 25$. 146

Figura 3.13 Razão entre a área dos picos de $\operatorname{SDZ}\left(t_{\mathrm{R}} \sim 4,75 \mathrm{~min}\right)(-\bullet-)$ e do segundo pico $\left(t_{\mathrm{R}}\right.$ 2,06 min) (--) em função do tempo de irradiação nos experimentos fotocatalíticos na presença dos materiais PMONDI-8 (A) e PMONDI-16 (B).

Figura 3.14 Picos e relação massa carga $(\mathrm{m} / \mathrm{z})$ obtidos através cromatografia líquida acoplado à espectrometria de massas (LCMS-IT-TOF) para as amostras irradiadas com (A) PMONDI-8 e (B) PMONDI-16 ( $t=300 \mathrm{~min})$.

Figura 3.15 Relação massa/carga $(\mathrm{m} / \mathrm{z})$ dos fragmentos correspondentes aos picos obtidos pelas análises de cromatografia líquida acoplada à espectrometria de massas das alíquotas de SDZ após 300 min de fotodegradação catalítica. 148

Figura 3.16 Mecanismo proposto para a fotodegradação catalítica de SDZ no microrreator operando a modo contínuo.

Figura 4.1 Vista em corte transversal e vista superior de A: Fotorreator tubular de escoamento contínuo com lâmpada em posição coaxial. B: posição externa da lâmpada com refletor $(\mathrm{R})$. RV: vaso do reator; Q: camisa de quarto para lâmpada. 152

Figura 4.2 Simulação CFD do movimento helicoidal do fluido no interior do reator FluHelik. 
Figura 4.4 (A) Diagrama esquemático da configuração experimental (B) Foto do sistema utilizado, em que: (i) fonte de energia para ligar a lâmpada UV-A; (ii) fotorreator FluHelik; (iii) bomba de recirculação; (iv) vaso de recirculação com 2 L de capacidade; (v) agitador magnético; (vi) medidor de $\mathrm{pH}$. 156

Figura 4.5 Experimentos de adsorção e de fotodegradação da sulfadiazina (SDZ) conduzidos no fotorreator FluHelik. Experimentos de controle por fotólise (-^-), adsorção em SBA-15 ( --) e fotodegradação na presença dos fotocatalisadores $10 \% \mathrm{TiO}_{2} / \mathrm{SBA}-15(-\bullet), 20 \%$ $\mathrm{TiO}_{2} / \mathrm{SBA}-15(-\bullet), 30 \% \mathrm{TiO}_{2} / \mathrm{SBA}-15(-\bullet-)$. Condições: $150 \mathrm{mg}$ de fotocatalisador, $V_{\text {sol }}=$ $1,5 \mathrm{~L} ; C_{0, \mathrm{SDZ}}=2 \mathrm{mg} \mathrm{L}^{-1} ; \mathrm{pH}_{\text {inicial }}=7,0 ; \mathrm{T}=25^{\circ} \mathrm{C}$.

Figura 4.6 Experimentos de fotodegradação de sulfadiazina conduzidos na presença de diferentes quantidades do fotocatalisador 30\% $\mathrm{TiO}_{2} / \mathrm{SBA}-15: 50 \mathrm{mg}(-\mathbf{-}), 150 \mathrm{mg}(-\mathbf{-}-)$, $200 \mathrm{mg}\left(\bullet^{-}\right), 300 \mathrm{mg}\left(-{ }_{-}\right), 500 \mathrm{mg}\left(--_{-}\right)$e $600 \mathrm{mg}\left({ }^{\bullet}\right)$. Condições: 1,5 L de solução de SDZ; $C_{0, \mathrm{SDZ}}=2 \mathrm{mg} \mathrm{L}^{-1} ; \mathrm{pH}_{0}=7,0 ; \mathrm{T}=25^{\circ} \mathrm{C}$. 162

Figura 4.7 Experimentos de reutilização do fotocatalisador $30 \% \quad \mathrm{TiO}_{2} / \mathrm{SBA}-15$ para a degradação de SDZ no fotorreator FluHelik. Condições $\mathrm{C}_{\mathrm{TiO} 2}=100 \mathrm{mg} \mathrm{L}^{-1} ; 1,5 \mathrm{~L}$ de solução de SDZ; $C_{0, \mathrm{SDZ}}=2 \mathrm{mg} \mathrm{L}^{-1} ; \mathrm{pH}_{0}=7,0 ; \mathrm{T}=25^{\circ} \mathrm{C}$.

Figura 4.8 Experimentos de adsorção e fotodegradação da sulfadiazina (SDZ) em (A) água pura e (B) água residual urbana conduzidos no fotorreator FluHelik. Experimentos na presença dos fotocatalisadores 30\% $\mathrm{TiO}_{2} / \mathrm{SBA}-15$ (-๑) e $\mathrm{TiO}_{2} \mathrm{P} 25$ (--). Condições: $\left[\mathrm{TiO}_{2}\right]=100 \mathrm{mg} \mathrm{L}^{-1} ; 1,5 \mathrm{~L}$ de água residual fortificada com $\operatorname{SDZ}\left(C_{0, \mathrm{SDZ}}=2 \mathrm{mg} \mathrm{L}^{-1}\right) ; \mathrm{pH}_{0}=$ 7,$0 ; \mathrm{T}=25^{\circ} \mathrm{C}$. 164

Figura 4.9 Gráficos de radar das relações de concentração $\left(C / C_{0}\right)$ presentes inicialmente ) e após a adsorção (-) e irradiação (-) utilizando o fotocatalisador $30 \% \mathrm{TiO}_{2} / \mathrm{SBA}-15$, considerando os microcontaminantes detectados na ARU que são fármacos utilizados em (A) medicamentos de uso neurológico; (B) medicamentos de uso cardiovascular, respiratório e urinário (C) medicamentos de uso dermatológico, outros e substancias não usadas como medicamentos. 


\section{LISTA DE TABELAS}

Tabela 1.1 Principais trabalhos publicados que utilizaram os materiais $\mathrm{TiO}_{2} / \mathrm{SBA}-15$ em sistemas de fotocatálise heterogênea (todos os sistemas em reator batelada).

Tabela 1.2 Quantidade molar de TTIP adicionada durante a síntese, porcentagem mássica de $\mathrm{TiO}_{2}$ e proporção $\mathrm{TiO}_{2} / \mathrm{SiO}_{2}$ teórica presente em cada material.

Tabela 1.3 Quantidades dos precursores inorgânico (TEOS) e orgânico (TESP-NDI) empregadas na síntese das PMONDI.

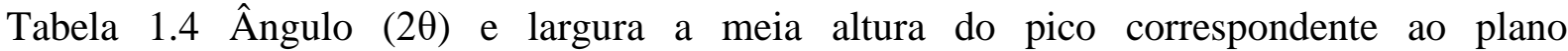
cristalográfico (101) com seu respectivo coeficiente de correlação $\left(R^{2}\right)$ para a determinação do tamanho de cristal anatase presente em cada amostra de $\mathrm{TiO}_{2} / \mathrm{SBA}-15$ através da Equação de Scherrer

Tabela 1.5 Parâmetros obtidos pelas análises de SAXS e isotermas de adsorção de $\mathrm{N}_{2}$ para as amostras SBA-15 pura e $\mathrm{TiO}_{2} / \mathrm{SBA}-15$.

Tabela 1.6 Porcentagens de carbono $(\mathrm{C})$, hidrogênio $(\mathrm{H})$ e nitrogênio $(\mathrm{N})$ de cada PMONDI sintetizada, obtidas pela analise elementar.

Tabela 1.7 Quantidades dos precursores inorgânicos e orgânicos utilizados na síntese das PMONDI.

Tabela 1.8 Parâmetros obtidos pelas análises de SAXS e isotermas de adsorção de $\mathrm{N}_{2}$ para as amostras PMONDI.

Tabela 2.1 Características físico-químicas da SDZ.

Tabela 2.2 Principais trabalhos publicados utilizando diferentes materiais em sistemas de fotocatálise heterogênea para a degradação de SDZ.

Tabela 2.3 Distribuição eletrônica nos orbitais moleculares $(\pi)$, energia de excitação e tempo de vida do oxigênio molecular no estado fundamental triplete $\left({ }^{3} \Sigma_{\mathrm{g}}{ }^{-}\right)$e nos estados excitados singlete $\left({ }^{1} \Delta_{\mathrm{g}} \mathrm{e}^{1} \Sigma_{\mathrm{g}}{ }^{+}\right)$ 101

Tabela 2.4 Concentração inicial de SDZ $\left(C_{0, \mathrm{SDZ}}\right)$ e irradiâncias (I) utilizadas em cada experimento de fotodegradação catalítica de SDZ. 106

Tabela 2.5 Mistura de eluente e comprimento de onda para a detecção dos compostos SDZ, álcool furfurílico (FFA), ácido p-clorobenzóico (pCBA) nas análises de cromatografia líquida de alta eficiência (HPLC).

Tabela 2.6 Resultados das curvas de calibração para análise de HPLC dos compostos álcool furfurílico (FFA), ácido $p$-clorobenzoico (pCBA) e sulfadiazina (SDZ).

Tabela 2.7 Constantes cinéticas de pseudo-primeira ordem para degradação fotocatalítica de $\mathrm{SDZ}\left(k_{\mathrm{SDZ}}\right)$ e seus respectivos coeficientes de determinação $\left(R^{2}\right)$ 
Tabela 2.8 Resultados da formação das espécies reativas fotoinduzidas: constante cinética de pseudo-primeira ordem observada $\left(k_{\exp }\right)$, coeficiente de determinação $\left(R^{2}\right)$ e concentração no estado estacionário de radicais hidroxila $\left(\left[\mathrm{HO}^{*}\right]_{\mathrm{ss}}\right)$ e de oxigênio singlete $\left(\left[{ }^{1} \mathrm{O}_{2}\right]_{\mathrm{ss}}\right)$.

Tabela 3.1 Concentração de entrada $\left(C_{0, \mathrm{SDZ}}\right)$, concentração no estado estacionário à saída do microrreator $\left(C_{\mathrm{ss}, \mathrm{SDZ}}\right)$ e porcentagem de degradação $\left(X_{\mathrm{SDZ}}\right)$ de $\mathrm{SDZ}$ nos experimentos de fotocatálise conduzidos no microrreator empacotado (micro-packed bed reactor) com escoamento contínuo $\left(20 \mu \mathrm{L} \mathrm{min}{ }^{-1}\right)$ para diferentes fotocatalisadores

Tabela 3.2 Concentração de entrada $\left(C_{0, S D Z}\right)$, concentração no estado estacionário $\left(C_{\mathrm{ss}, \mathrm{SDZ}}\right)$, porcentagem de degradação $\left(X_{\mathrm{SDZ}}\right)$ e taxa de reação $\left(r_{\mathrm{SDZ}}\right)$ por unidade de massa de catalisador nos experimentos de fotocatálise conduzidos no microrreator empacotado (micropacked bed reactor) a diferentes vazões na presença de PMONDI-16.

Tabela 4.1 Características físico-químicas da água residual urbana secundária. 155 Tabela 4.2 Massa e concentração do fotocatalisador $30 \% \mathrm{TiO}_{2} / \mathrm{SBA}-15$ juntamente com a concentração de $\mathrm{TiO}_{2}$ presentes nos testes de variação de massa do fotocatalisador. Condições: $V_{\text {sol }}=1,5 \mathrm{~L} ; C_{0, \mathrm{SDZ}}=2 \mathrm{mg} \mathrm{L}^{-1} ; \mathrm{pH}_{0}=7,0$ e $\mathrm{T}=25^{\circ} \mathrm{C}$ 162

Tabela 4.3 Porcentagem de adsorção (\%SDZ ads.), porcentagem de fotodegradação (\%SDZ deg.), constante de reação de pseudo-primeira ordem ( $\left.k_{\mathrm{SDZ}}\right)$, coeficiente de determinação do ajuste não linear $\left(R^{2}\right)$ e os parâmetros empregados nos experimentos de degradação de sulfadiazina no fotorreator FluHelik 166 Tabela 4.4 Nomenclatura, abreviatura, fórmula química, tempo de retenção $(R t)$ e aplicação dos micropoluentes encontrados na ARU coletada após tratamento secundário através de análises LC-MS/MS. 170 


\section{LISTA DE SIGLAS}

\begin{tabular}{|c|c|}
\hline APTES & 3-aminopropiltrietoxisilano \\
\hline $\mathrm{BC}$ & Banda de condução \\
\hline BET & Brunauer, Emmett e Teller \\
\hline BJH & Barrett, Joyner e Halenda \\
\hline BV & Banda de valência \\
\hline CEC & Contaminantes emergentes \\
\hline $\mathrm{CP}$ & Cross polarization \\
\hline $\mathrm{CT}$ & Transferência de carga \\
\hline CTAB & Brometo de cetiltrietilamônio \\
\hline DRS & Espectrofotometria de refletância difusa \\
\hline DRX & Difração de raios-X \\
\hline EROS & Espécies reativas de oxigênio \\
\hline FRET & Förster resonance energy transfer \\
\hline FT-IR & Espectroscopia de infravermelho com transformada de Fourier \\
\hline HPLC & Cromatografia líquida de alta eficiência \\
\hline HRTEM & Microscopia eletrônica de transmissão de alta resolução \\
\hline ISC & Cruzamento intersistemas \\
\hline IT & Fonte de ionização por electrospray \\
\hline IUPAC & International Union of Pure Applied Chemistry \\
\hline LCMS & Cromatografia líquida acoplada à espectrometria de massas \\
\hline LED & Diodo emissor de luz \\
\hline MAS & Magic angle spinning \\
\hline MCM- 41 & Mobil Composition of Matter $n^{\circ} 41$ \\
\hline MO & Organosílicas mesoporosas \\
\hline NDI & 1,4,5,8-naftalenodiimida \\
\hline NI & 1,8-naftalimida \\
\hline NTCA & Dianidrido 1,4,5,8-naftalenotetracarboxilíco \\
\hline OLEDs & Diodos orgânicos emissores de luz \\
\hline PDI & $3,4,9,10$-perilenodiimidas \\
\hline PHACs & Pharmaceutical active compounds \\
\hline PMI & Piromelitimidas \\
\hline PMO & Organosilicas periódicas mesoporosas \\
\hline
\end{tabular}


PMONDI

POA

PPDI

PSD

R

RMN

ROS

SAXS

SBA

SDZ

SP

TEOS

TEPNI

TESP-NDI

TMS

TOF

TTIP

UFABC

USP

UV
Organosilicas periódicas mesoporosas com 1,4,5,8-naftalenodiimida Processos oxidativos avançados

N,N'-bis(2-fosfonoetil)-3,4,9,10-perilenodiimida

Pore size distribution

Grupo funcional orgânico

Ressonância magnética nuclear

Reactive oxygen species

Espalhamento de raios-X em baixo ângulo

Santa Barbara Amorphous

Sulfadiazina

Single pulse

Tetraetilortosilicato

$\mathrm{N}$-(3-(trietoxisilil)propil)1,8-naftalimida

N,N'-bis[3-(trietoxisil)propil]1,4,5,8-naftalenodiimida

Tetrametilsilano

Tempo de voo

Isopropóxido de titânio

Universidade Federal do ABC

Universidade de São Paulo

Ultravioleta 


\section{LISTA DE SÍMBOLOS}

A

$\mathrm{a}_{0}$

c

$\mathrm{d}_{\mathrm{hkl}}$

$\mathrm{d}_{100}$

$\mathrm{E}_{\text {red }}^{0}$

hkl

K

1

$\mathrm{P} / \mathrm{P}_{0}$

wt

$\beta$

$\varepsilon$

$\varphi_{\mathrm{f}}$

$\lambda$

$\lambda_{\text {máx }}$

$\lambda_{\text {em }}$

$\lambda_{\text {ex }}$

$\lambda_{\mathrm{CuK} \alpha}$

Absorbância

Parâmetro de arranjo hexagonal da estrutura mesoporosa

Concentração da amostra

Espaçamento interplanar

Distância do plano cristalino (100)

Potencial de redução

Índices de Miller

Constante de proporcionalidade

Caminho óptico

Pressões relativas

Espessura da parede do poro

Largura a meia altura do pico

Coeficiente de absortividade molar

Eficiência de fluorescência

Comprimento de onda

Comprimento de onda máximo

Comprimento de onda de emissão

Comprimento de onda de excitação

Comprimento de onda da radiação de raios- $\mathrm{X}$ 


\section{SUMÁRIO}

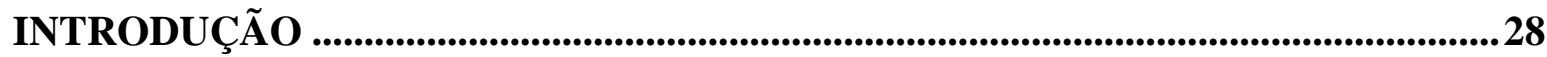

CAPÍTULO 1 PREPARAÇÃO E CARACTERIZAÇÃO DE FOTOCATALISADORES À BASE DE SÍLICAS MESOPOROSAS...................................................................................30

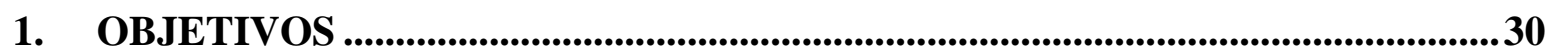

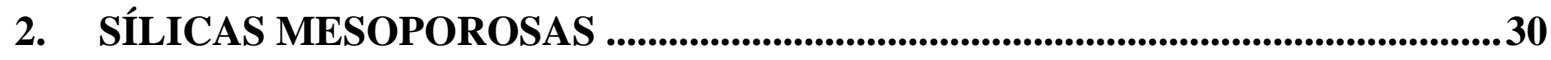

3. MÉTODOS DE FUNCIONALIZAÇÃO DAS SÍLICAS MESOPOROSAS COM ÓXIDOS METÁLICOS ...........................................................................................33

3.1 Sílicas Mesoporosas com Dióxido de Titânio ................................................................36

4. MÉTODOS DE FUNCIONALIZAÇÃO DAS SÍLICAS MESOPOROSAS COM MOLÉCULAS ORGÂNICAS ..........................................................................43

4.1 Organosílicas Periódicas Mesoporosas (PMO) .............................................................45

4.2 Imidas Aromáticas..............................................................................................................46

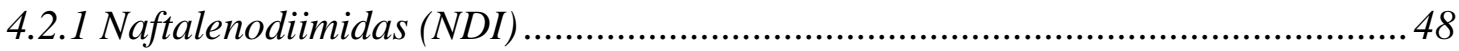

4.3 PMO com Imidas Aromáticas ......................................................................................50

5. SEÇÃO EXPERIMENTAL ........................................................................................56

5.1 Materiais ......................................................................................................................56

5.2 Métodos ............................................................................................................................56

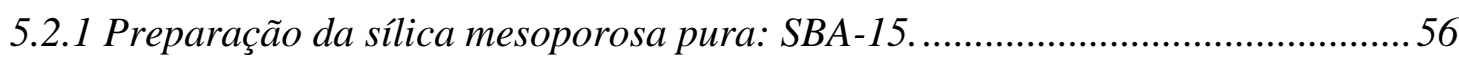

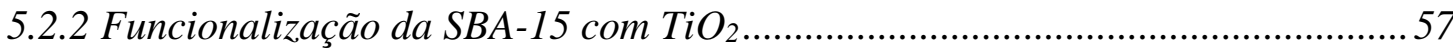

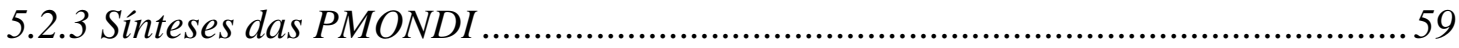

5.3 Técnicas de Caracterização ……….................................................................................62

6. CARACTERIZAÇÃO DOS MATERIAIS TIO 2 /SBA-15 ............................................64

6.1 Estudo da Presença de Cristais de $\mathrm{TiO}_{2}$ nos Materiais $\mathrm{TiO}_{2} / \mathrm{SBA}-15$....................64

6.1 Caracterização da Estrutura Mesoporosa dos Materiais $\mathrm{TiO}_{2} / \mathrm{SBA}-15$................69

6.3 Propriedades Ópticas dos Materiais $\mathrm{TiO}_{2} / \mathrm{SBA}-15$.................................................... 75

7. CARACTERIZAÇÃO DOS MATERIAIS PMONDI ..............................................76 
7.1 Dosagem das NDI

7.2 Caracterização por Espectroscopia na Região do Infravermelho das NDI

Presentes nas PMONDI 78

7.3 Caracterizações por Espectroscopia de Ressonância Magnética Nuclear (RMN) no Estado Líquido $\left({ }^{13} \mathrm{C}\right.$ e $\left.{ }^{1} \mathrm{H}\right)$ e no Estado Sólido $\left({ }^{13} \mathrm{C}\right.$ e $\left.{ }^{29} \mathrm{Si}\right)$. 79

7.4 Caracterização da Estrutura Mesoporosa das PMONDI 82

7.5 Propriedades Ópticas das PMONDI .86

8. CONCLUSÕES DO CAPÍTULO 1 87

CAPÍTULO 2 APLICAÇÃO Dos materiais tiO2/sba-15 e pmondi NA FOTOCATÁLISE HETEROGÊNEA PARA DEGRADAÇÃO DE SULFADIAZINA em REATOR BATELADA 88

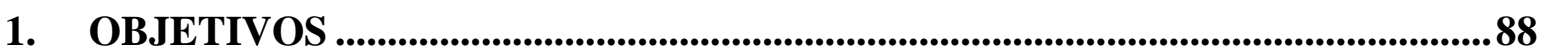

2. CONTAMINANTES DE INTERESSE EMERGENTE (CEC) .............................8

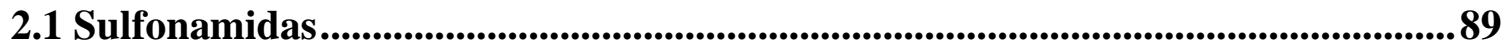

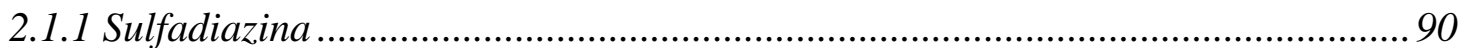

3. PROCESSOS AVANÇADOS DE OXIDAÇÃO (POA): ALTERNATIVA PARA A DEGRADAÇÃO DE POLUENTES DE INTERESSE EMERGENTE ....................92

4. FOTOCATÁLISE HETEROGÊNEA PARA A DEGRADAÇÃO DE

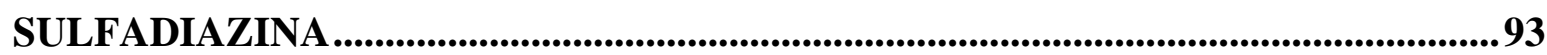

4.1 Fotocatálise Heterogênea com Semicondutores Inorgânicos..................................93

4.2 Fotocatálise com Sensibilizadores Orgânicos ..........................................................100

5. SEÇÃO EXPERIMENTAL ....................................................................................105

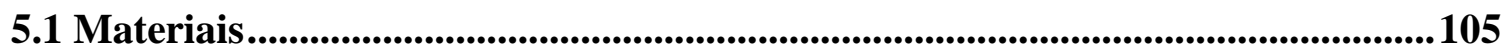

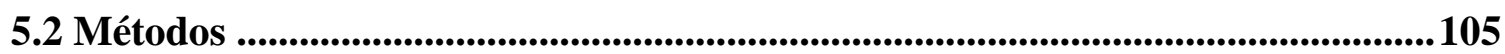

5.2.1 Experimentos de degradação fotocatalítica de sulfadiazina.............................. 105

5.2.2 Reutilização dos fotocatalisadores............................................................... 107

5.2.3 Estudo da cinética de fotodegradação da sulfadiazina ..................................... 107

5.2.4 Quantificação das espécies reativas fotoinduzidas ......................................... 107

5.3 Técnicas Analíticas ....................................................................................................................109

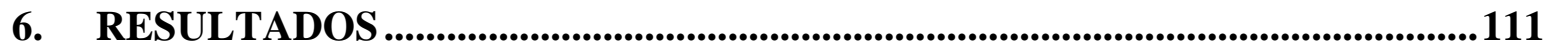


6.1 Fotodegradação Catalítica da Sulfadiazina em Reator Batelada

6.2 Reutilização dos Fotocatalisadores

6.3 Estudo da Geração das Espécies Reativas Fotoinduzidas na Degradação da SDZ

6.4 Identificação dos Intermediários Formados na Fotodegradação da SDZ ........ 124

7. CONCLUSÕES DO CAPÍTULO 2

CAPÍTULO 3 APLICAÇÃO DOS MATERIAIS PMONDI EM UM MICRORREATOR DE LEITO EMPACOTADO OPERANDO EM MODO CONTÍNUO PARA A FOTODEGRADAÇÃO CATALÍTICA DE SULFADIAZINA 129

1. OBJETIVOS 129

2. INTENSIFICAÇÃO DO PROCESSO DE FOTOCATÁLISE 129

3. MICRO REATOR FOTOCATALÍTICO E FOTOREATOR DE LEITO EMPACOTADO. 130

4. SEÇÃO EXPERIMENTAL 135

4.1 Materiais 135

4.2 Métodos 135

4.3 Técnicas Analíticas . 137

5. RESULTADOS 137

5.1 Estudos da Cinética de Fotodegradação Catalítica da SDZ em Modo Contínuo 140

5.2 Caracterização dos Produtos de Fotodegradação da SDZ 145

6. CONCLUSÕES DO CAPÍTULO 3 149

CAPÍtUlo 4 APLICAÇÃO DOS MATERIAIS TiO $2 /$ SBA-15 PARA A DEGRADAÇÃO FOTOCATALÍTICA DE SULFADIAZINA NO FOTORREATOR FLUHELIK 151

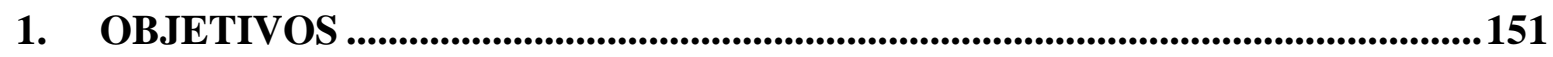

2. FOTORREATOR FLUHELIK.......................................................................151 
3.2 Métodos ..................................................................................................................................155

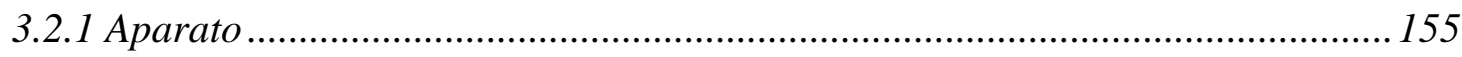

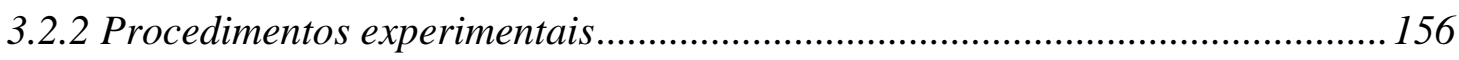

3.2.2.1 Variação na massa de fotocatalisador ........................................................ 157

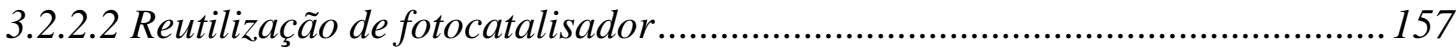

3.2.2.3 Estudo da fotodegradação da sulfadiazina em águas residuais urbanas ...... 158

3.2 Técnicas Analíticas ............................................................................................................. 158

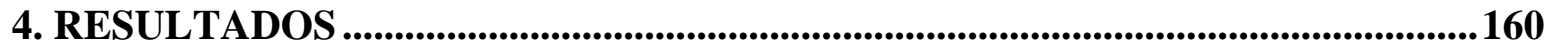

4.1 Avaliação do Fotocatalisador para Degradação da SDZ ........................................160

4.2 Avaliação da Quantidade de Fotocatalisador 30\% $\mathrm{TiO}_{2} / \mathrm{SBA}-15$ para a

Degradação da SDZ.........................................................................................................161

4.3 Reutilização do Fotocatalisador 30\% $\mathrm{TiO}_{2} / \mathrm{SBA}-15$ para a Degradação da SDZ 163

4.4 Estudo da Fotodegradação da SDZ em ARU 163

4.4.1 Estudo da adsorção e fotodegradação de SDZ e dos micropoluentes presentes na $A R U$ 168

5. CONCLUSÕES DO CAPÍTULO 4.....................................................................173

CONCLUSÕES GERAIS .....................................................................................174

PERSPECTIVAS FUTURAS ........................................................................................174

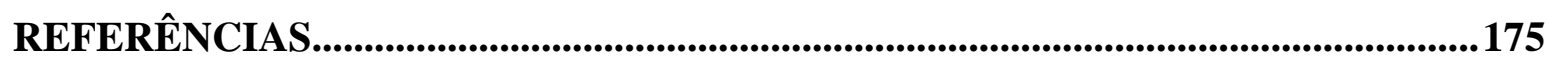

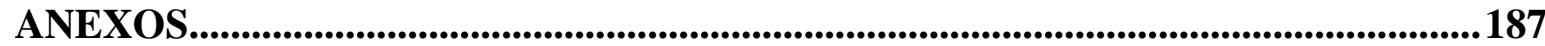




\section{INTRODUÇÃO}

A proteção e conservação dos recursos naturais é uma das principais prioridades da sociedade no século XXI. Indubitavelmente, a água é o nosso mais precioso recurso natural e, quando possível, deve ser reciclada e reutilizada. A preocupação aumenta com o aparecimento de novos contaminantes conhecidos como contaminantes de interesse emergente (contaminants of emerging concern, CEC) (KÜMMERER, 2009a) no meio ambiente. Os CEC são definidos como produtos químicos ou materiais de ocorrência natural, e que podem estar presentes em matrizes sólidas ou líquidas e cujas características podem representar riscos tanto para a biota quanto para o homem (STARLING; AMORIM; LEÃO, 2019).

Dentre os CEC destacam-se os compostos farmacologicamente ativos (pharmaceutical active compounds, PHACs), produtos de cuidados pessoais, hormônios naturais e sintéticos, pesticidas e produtos químicos industriais (drogas ilícitas, plastificantes e outras substâncias) (PETRIE et al., 2016).

Muitas técnicas empregadas para remediar águas poluídas apenas concentram esses contaminantes de uma fase para outra, o que é uma característica aos processos de adsorção ou precipitação química, não ocorrendo sua degradação (DEWIL et al., 2017). Além disso, as técnicas convencionais para o tratamento de água podem não ser suficientes para eliminar tais poluentes devido à alta estabilidade química e/ou baixa biodegradabilidade de suas moléculas (RIZZO et al., 2019). Neste cenário, os processos oxidativos avançados (POA) são provavelmente um dos mais eficientes métodos para o tratamento de efluentes que contêm contaminantes de interesse emergente. Os POA baseiam-se na geração in situ de espécies transitórias de oxigênio (reactive oxygen species, ROS) altamente reativas (ex. radicais hidroxilas, $\mathrm{HO}^{\bullet}$; ânions radicais superóxido, $\mathrm{O}_{2}{ }^{\bullet-}$; oxigênio singlete, ${ }^{1} \mathrm{O}_{2}$; entre outros) que em muitos casos são capazes de mineralizar compostos orgânicos refratários a $\mathrm{CO}_{2}$ e $\mathrm{H}_{2} \mathrm{O}$.

A fotocatálise heterogênea é um exemplo de POA que pode resultar na degradação do poluente orgânico, independentemente de sua estabilidade química e/ou biológica (FOX et al., 1993). Neste processo, um fotocatalisador sólido é ativado fotoquimicamente gerando as ROS.

Grande atenção foi e ainda tem sido dada ao material fotocatalisador semicondutor $\mathrm{TiO}_{2}$ (P25 Degussa $\left.{ }^{\circledR}\right)$ (HOFFMANN et al., 1995) para sistemas de fotocatálise heterogênea. O uso de $\mathrm{TiO}_{2}$ exibe importantes vantagens, incluindo durabilidade, baixo custo, eficiência para fotocatálise etc. No entanto, algumas limitações, como exemplo, alto grau de aglomeração e grande dificuldade na sua separação e recuperação (DONG et al., 2015), dificultam sua 
utilização na prática. Diante destas desvantagens, é de grande relevância o estudo da preparação e aplicação de novos fotocatalisadores heterogêneos.

Através do surgimento da nanociência e nanotecnologia na segunda metade do século $\mathrm{XX}$, se tornou possível a construção de materiais e dispositivos funcionais com base na manipulação controlada de matéria, com ao menos uma dimensão abaixo de $100 \mathrm{~nm}$, para aplicações tecnológicas específicas, explorando fenômenos físicos, químicos ou biológicos a essa escala.

Dentre estes potenciais nanomateriais merecem destaque os materiais porosos, devido as suas importantes características de elevada área superficial específica, estrutura porosa ordenada, alta estabilidade térmica e mecânica e grande disponibilidade de funcionalização com moléculas orgânicas ou inorgânicas (MIZOSHITA; TANI; INAGAKI, 2011), as quais tornam possíveis suas diversas aplicações tecnológicas, bem como em fotocatálise. Os materiais porosos são classificados pela IUPAC de acordo com o tamanho dos poros em microporosos (diâmetro de poros $<2 \mathrm{~nm}$ ), mesoporosos $(2 \mathrm{~nm}<$ diâmetro de poros $<50 \mathrm{~nm}$ ) e macroporosos (diâmetro de poros > $50 \mathrm{~nm}$ ) (SING et al., 1985).

Neste contexto, no presente trabalho foi estudada a preparação e caracterização de materiais mesoporosos, constituídos majoritariamente de sílica inorgânica $\left(\mathrm{SiO}_{2}\right)$, nomeados sílicas mesoporosas, dentre as quais a mais estudada é a SBA-15 (ZHAO et al., 1998).

O Capítulo 1 desta Tese aborda a preparação e caracterização de dois materiais à base de sílicas mesoporosas distintos. O primeiro consiste na sílica mesoporosa funcionalizada com partículas inorgânicas de $\mathrm{TiO}_{2}$. Para isto, empregou-se o método de pós-funcionalização sol-gel da sílica pura (SBA-15) formando os materiais $\mathrm{TiO}_{2} / \mathrm{SBA}-15$. Posteriormente, sintetizaram-se organosílicas periódicas mesoporosas (PMO) contendo como funcionalizador orgânico a imida aromática 1,4,5,8-naftalenodiimida (NDI). Neste caso, o método de síntese das PMO empregado resultou em nanomateriais mesoporosos, altamente organizados e híbridos orgânico/inorgânico, nomeados PMONDI.

Os demais capítulos da Tese abrangem o estudo da aplicação dos materiais preparados como fotocatalisadores para a degradação de um contaminante de interesse emergente, a sulfadiazina (SDZ), antibiótico da classe das sulfonamidas. Assim, no Capítulo 2 a degradação fotocatalítica de SDZ foi estudada em batelada, enquanto no Capítulo 3 são descritos resultados de experimentos em um microrreator empacotado e de fluxo contínuo. No Capítulo 4, último da Tese, o estudo para degradação fotocatalítica de SDZ foi realizado em um fotorreator FluHelik. 


\section{CAPÍTULO 1 PREPARAÇÃO E CARACTERIZAÇÃO DE FOTOCATALISADORES À BASE DE SÍLICAS MESOPOROSAS}

"There is plenty of room at the bottom"

Richard Feynman (físico teórico norte-americano) ao falar sobre nanotecnologia em uma reunião de físicos em 29 de dezembro de 1959.

Parte deste capítulo está embasada no artigo publicado na revista Langmuir (CASTANHEIRA et al., 2018), que se encontra em Anexo 1 no presente trabalho.

\section{OBJETIVOS}

O principal objetivo do trabalho descrito neste capítulo consiste na preparação e caracterização de materiais nanoestruturados à base de sílicas mesoporosas que sejam capazes de atuarem como fotocatalisadores em processos avançados de oxidação (POA) na degradação de contaminantes emergentes (CEC). Para tanto, foram preparados dois tipos distintos de materiais: (i) sílica mesoporosa (SBA-15) funcionalizada com o semicondutor inorgânico $\mathrm{TiO}_{2}\left(\mathrm{TiO}_{2} / \mathrm{SBA}-15\right)$ pelo método sol-gel; (ii) organosílicas periódicas mesoporosas contendo o funcionalizador orgânico 1,4,5,8-naftalenodiimida (PMONDI). Através das caracterizações realizadas foi possível analisar a estrutura mesoporosa, o teor de imida aromática presente (no caso das PMONDI) e a estrutura cristalina de $\mathrm{TiO}_{2}$ (no caso dos $\left.\mathrm{TiO}_{2} / \mathrm{SBA}-15\right)$, bem como as características ópticas de cada material preparado.

\section{SÍLICAS MESOPOROSAS}

Existem diferentes tipos de materiais mesoporosos, dentre os quais se destacam as sílicas mesoporosas, compostas por dióxido de silício $\left(\mathrm{SiO}_{2}\right)$. O dióxido de silício é um dos compostos mais abundantes na crosta terrestre, cuja estrutura amorfa com poros polidispersos pode ser encontrada naturalmente em minerais como o quartzo, topázio, ametista, areia etc.

A sílica também pode ser sintetizada em laboratório, a partir de precursores como o tetraetilortosilicato (TEOS, R= Et) (Equação 1.1). Uma preparação típica é feita através do processo sol-gel, que em geral é caracterizado pela formação de redes de óxidos de metais ou semimetais $\left(\mathrm{SiO}_{2}, \mathrm{TiO}_{2}\right.$, entre outros) a partir da polimerização de sais ou alcóxidos destes metais em solução aquosa/etanólica, que pode ou não ser catalisada com ácido ou base. 
Nesta solução ocorrem dois tipos de reações subsequentes, a hidrólise e a condensação. A hidrólise dos alcoxisilanos na presença de água é caracterizada pela substituição dos alcóxils por grupos silanóis (Equação 1.1). Esta reação gera grupos reativos para dar início à fase de polimerização (ou gelatinização) em baixa temperatura, processo termodinamicamente favorável, que consiste na reação de condensação tendo a água como sub-produto (Equação 1.2).

$$
\begin{gathered}
(\mathrm{RO})_{3} \mathrm{Si}-\mathrm{O}-\mathrm{R}+\mathrm{H}-\mathrm{O}-\mathrm{H} \rightarrow(\mathrm{RO})_{3} \mathrm{Si}-\mathrm{O}-\mathrm{H}+\mathrm{ROH} \\
(\mathrm{RO})_{3} \mathrm{Si}-\mathrm{O}-\mathrm{H}+(\mathrm{RO})_{3} \mathrm{Si}-\mathrm{O}-\mathrm{H} \rightarrow(\mathrm{RO})_{3} \mathrm{Si}-\mathrm{O}-\mathrm{Si}(\mathrm{OR})_{3}+\mathrm{H}-\mathrm{O}-\mathrm{H}
\end{gathered}
$$

No início das reações ocorre a formação do sistema chamado sol, no qual as unidades que sofrem polimerização assumem dimensões de partículas coloidais no fluido, com tamanhos que variam entre 1 e $100 \mathrm{~nm}$. No decorrer da reação, as partículas maiores começam a se agregar ou se interconectar, formando então a fase gel. Essa fase é caracterizada por uma solução viscosa contendo a fase líquida aprisionada nos interstícios das partículas ou estruturas sólidas. O termo gel abraça uma diversidade de combinações de substâncias e que podem ser classificadas em estruturas lamelares bem organizadas, redes poliméricas desorganizadas formadas por agregação física ou estruturas de partículas desordenadas. Nos primeiros trabalhos que utilizaram esta técnica sintetizaram-se materiais vítreos e cerâmicos, contudo não porosos (HENCH; WEST, 1990).

No início dos anos 1990, Beck e colaboradores (BECK et al., 1992) introduziram uma nova metodologia para a síntese de sílicas com poros altamente ordenados (nanoestruturados), com distribuição estreita de tamanho (monodispersidade). O método de Beck faz o uso de micelas de surfactantes como agentes direcionadores de estruturas (template).

Em solução aquosa, as moléculas do surfactante formam micelas cilíndricas que se empacotam com o aumento da concentração de surfactante, formando agregados hexagonais altamente ordenados de cristais líquidos, durante a condensação do precursor da sílica. Em seguida, a parte orgânica formada pelas micelas é removida do material por calcinação ou por extração com solventes, resultando em um sólido à base de $\mathrm{SiO}_{2}$ com mesoporos hexagonais altamente organizados. O mecanismo simplificado deste processo está apresentado na Figura 1.1 (HOFFMANN et al., 2006). Vale ressaltar que o diâmetro de poros das sílicas pode ser facilmente regulado variando o comprimento de cauda do surfactante (BECK et al., 1992). 
Figura 1.1 Mecanismo de formação de materiais mesoporosos, tomando como exemplo a formação da MCM-41 (mobil composition of matter $n^{\circ} 41$ ).

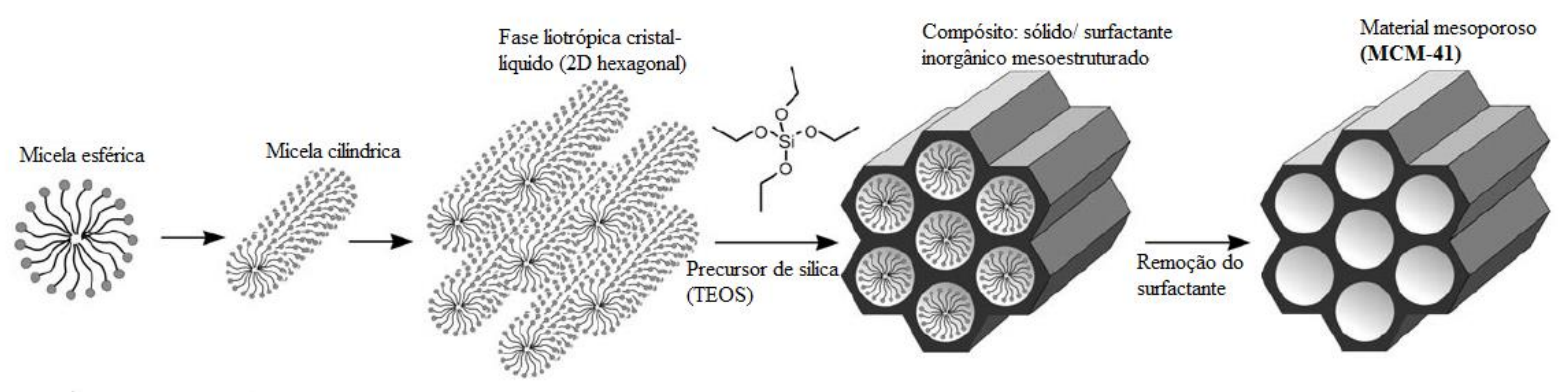

Fonte: (Adaptado de HOFFMANN et al., 2006).

Quando a síntese das sílicas mesoporosas é realizada em condições básicas e na presença de tensoativo do tipo catiônico, sendo o mais comumente utilizado o brometo de cetiltrimetilamônio (CTAB) como direcionador de estruturas (Figura 1.2A), formam-se sílicas com poros da ordem de 1,5-10 nm, conhecidas como MCM-41 (mobil composition of matter $n^{o} 41$ ) (BECK et al., 1992). Por outro lado, no caso da síntese realizada em condições ácidas e na presença do surfactante não iônico copolímero tribloco (oligoetilenoglicols), formam-se silicatos com diâmetro de poros maiores, da ordem de 5-30 nm, conhecidos como SBA-15 (Santa Barbara Amorphous 15) (ZHAO et al., 1998). O surfactante mais utilizado para este procedimento é o Pluronic P123, formado por blocos de óxido de etileno e óxido de propileno $\left(\mathrm{EO}_{20} / \mathrm{PO}_{70} / \mathrm{EO}_{20}\right)$ (Figura 1.2B).

Figura 1.2 Estrutura molecular de dois surfactantes comumente utilizados para a síntese de sílicas mesoporosas: (A) brometo de cetiltrimetilamônio (CTAB) utilizado na síntese da MCM-41. (B) Pluronic P123 formado por blocos de óxido de etileno e óxido de propileno $\left(\mathrm{EO}_{20} / \mathrm{PO}_{70} / \mathrm{EO}_{20}\right)$ utilizado na síntese da SBA-15.

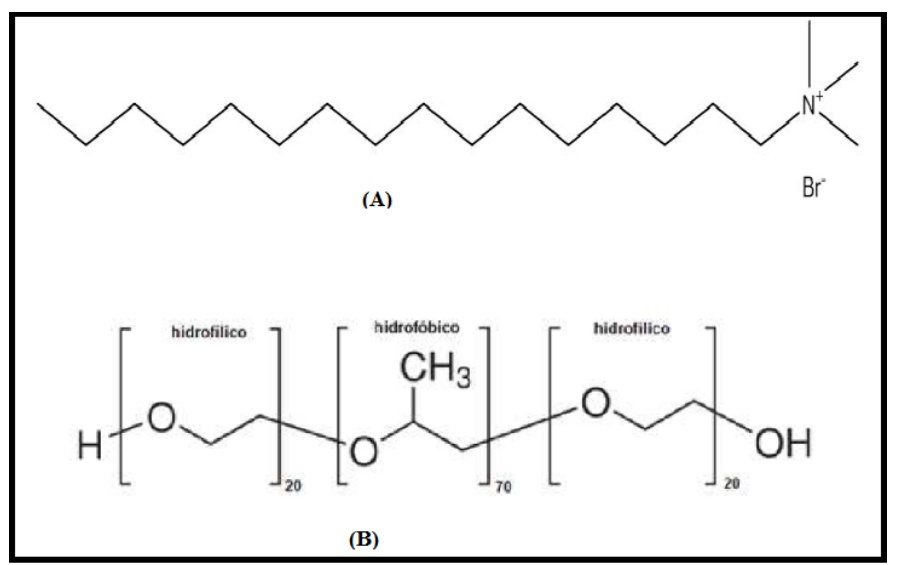

Fonte: (BECK et al., 1992) e (ZHAO et al., 1998). 
No entanto, as sílicas mesoporosas originais são constituídas apenas da matriz inorgânica e inativa de dióxido de silício $\left(\mathrm{SiO}_{2}\right)$ e, também como a grande maioria dos óxidos metálicos, possuem grupos hidroxilas expostos em suas superfícies. Tal característica confere uma vasta possibilidade de funcionalização com outros óxidos metálicos (CHENG et al., 2015) ou com cromóforos orgânicos (HOFFMANN, et al 2006; MIZOSHITA; TANI; INAGAKI, 2011) de interesse, tornando-as materiais extremamente versáteis para múltiplas aplicações. Alguns mecanismos de funcionalização serão vistos a seguir.

\section{MÉTODOS DE FUNCIONALIZAÇÃO DAS SÍlLCAS MESOPOROSAS COM ÓXIDOS METÁLICOS}

A funcionalização de suportes, incluindo sílicas mesoporosas, com óxidos metálicos pode ser feita por diversas técnicas. Na co-precipitação ou síntese direta o agente de acoplamento contendo o precursor do óxido metálico desejado (geralmente uma solução salina) é adicionado durante o processo de síntese da sílica, de modo que o componente metálico se torna presente em toda a estrutura da sílica durante sua condensação.

Esse processo leva à formação do suporte funcionalizado em uma única etapa e fornece uma distribuição mais homogênea dos átomos metálicos ao longo da superfície quando comparado à ancoração pós-sintética. Contudo, a adição de um componente extra (o agente de acoplamento) durante o processo de condensação da sílica mesoporosa altera a química do meio reacional, comprometendo de certa forma sua morfologia. Em geral, sílicas funcionalizadas por síntese direta possuem poros com forma e tamanho menos regulares que as demais (BRÜHWILER, 2010; DA’NA, 2017).

A funcionalização pós-sintética, por outro lado, adiciona uma etapa extra à preparação dos materiais, uma vez que a reação com o agente de acoplamento é realizada na superfície das sílicas previamente sintetizadas. Esse método geralmente não altera a morfologia dos poros do material (forma e tamanho), sendo muito mais versátil que o anterior, visto que há liberdade para síntese e ajuste das características da sílica independentemente do processo de funcionalização. Entretanto, a distribuição dos átomos metálicos ancorados não é uniforme, levando a materiais com mais alta concentração destes átomos nas superfícies externas e nas proximidades das aberturas dos poros que no interior dos mesmos (MEHRABADI et al., 2017).

$\mathrm{Na}$ literatura é mencionado um grande número de métodos pós-sintéticos (BRÜHWILER, 2010), entre os quais merecem destaque: 
(a) Impregnação simples (Figura 1.3A): Como uma fissisorção, a impregnação simples envolve o contato da sílica mesoporosa com uma solução salina precursora do metal desejado (por exemplo, nitrato de zinco) em condições controladas, durante um período de tempo para permitir sua adsorção na superfície de sílica. Após o período de adsorção, o material resultante é calcinado em temperaturas entre 400 e $800{ }^{\circ} \mathrm{C}$ em ambiente aeróbico para a formação dos cristais dos óxidos metálicos. Neste método, algumas variáveis são importantes, tais como a concentração da solução salina precursora, o tempo de contato entre a sílica e a solução salina, o solvente e a temperatura de calcinação (YUAN et al., 2020).

(b) Impregnação hidrotérmica (Figura 1.3B): Este método é similar ao método de impregnação simples, porém a diferença se encontra em utilizar altas pressões $(\mathrm{P}>100 \mathrm{kPa})$ e temperaturas $\left(\mathrm{T}>100{ }^{\circ} \mathrm{C}\right)$ para cristalizar os óxidos na superfície de sílica. Para tanto, a solução salina do precursor metálico e o substrato são acondicionados em uma miniautoclave. Este método é vantajoso por não necessitar da etapa de calcinação para obtenção do produto final, sendo necessária apenas a etapa de secagem. Porém, seu maior desafio se encontra no ajuste de pressão necessária para controlar a solubilidade da solução salina do metal, bem como a taxa de crescimento dos cristais metálicos dentro dos poros ou na superfície externa da sílica, o que pode levar a descontrole no tamanho e morfologia das partículas metálicas (BUSUIOC et al., 2006; SHANDILYA; RAI; SINGH, 2016).

Figura 1.3 Métodos para funcionalizar a SBA-15 com óxidos metálicos, sendo (A) impregnação simples e (B) impregnação hidrotérmica. O precursor consiste em uma solução salina do metal (Me) de interesse.

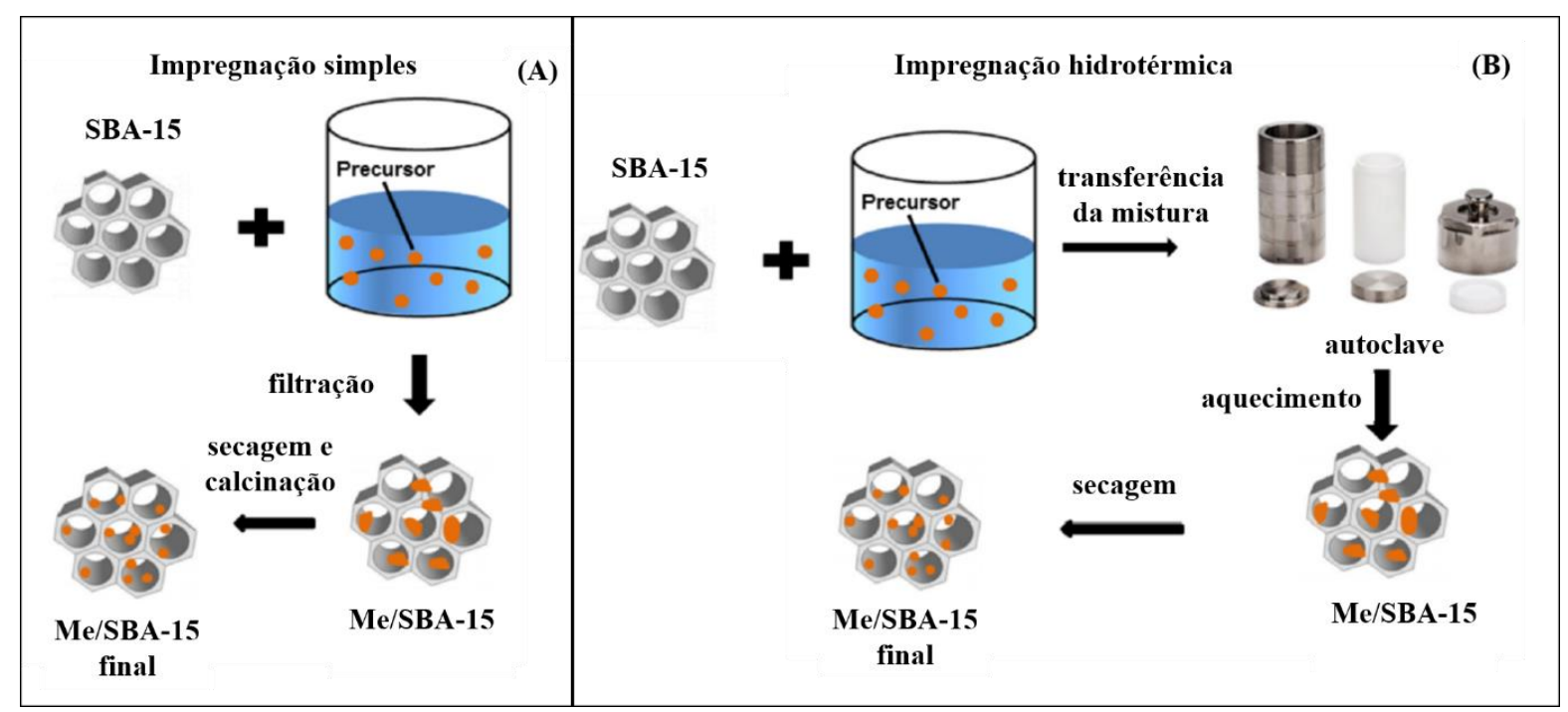

Fonte: Adaptado de YUAN et al., 2020. 
Nesta Tese, o método sol-gel foi utilizado para funcionalizar a sílica mesoporosa SBA-15 com o óxido metálico e semicondutor $\mathrm{TiO}_{2}$ para formar o material $\mathrm{TiO}_{2} / \mathrm{SBA}-15$.

(c) Método sol-gel (Figura 1.4): O processo sol-gel de superfície (SSP) foi originalmente desenvolvido por Kunitake e colaboradores (ICHINOSE; SENZU; KUNITAKE, 1997; YAN et al., 2004). Assim como o processo sol-gel para síntese das sílicas mesoporosas, esse processo consiste nas reações de hidrólise e policondensação de precursores alcóxidos do metal de interesse a um hidróxido ou óxido, em condições específicas de reação.

A partir dos precursores obtém-se a fase sol. O gel é então formado após a evaporação do líquido dispersante. Quando este líquido é removido à pressão ambiente ou próximo à pressão ambiente por evaporação térmica branda (chamada secagem), em temperaturas entre 100 e $180{ }^{\circ} \mathrm{C}$, ocorre encolhimento dos poros, formando um monolito conhecido por xerogel (do grego xero, seco) (ALEMÁN et al., 2007; HENCH; WEST, 1990). Os xerogéis também são sistemas tridimensionais, mas não possuem a plasticidade dos géis. Após passarem por tratamento térmico entre 500 e $800{ }^{\circ} \mathrm{C}$ (calcinação), os xerogéis podem sofrer entre outros processos a densificação pelo colapso de alguns poros e o aumento da cristalinidade das partículas metálicas.

Figura 1.4 Método sol-gel para a funcionalização de sílicas mesoporosas com óxidos metálicos.

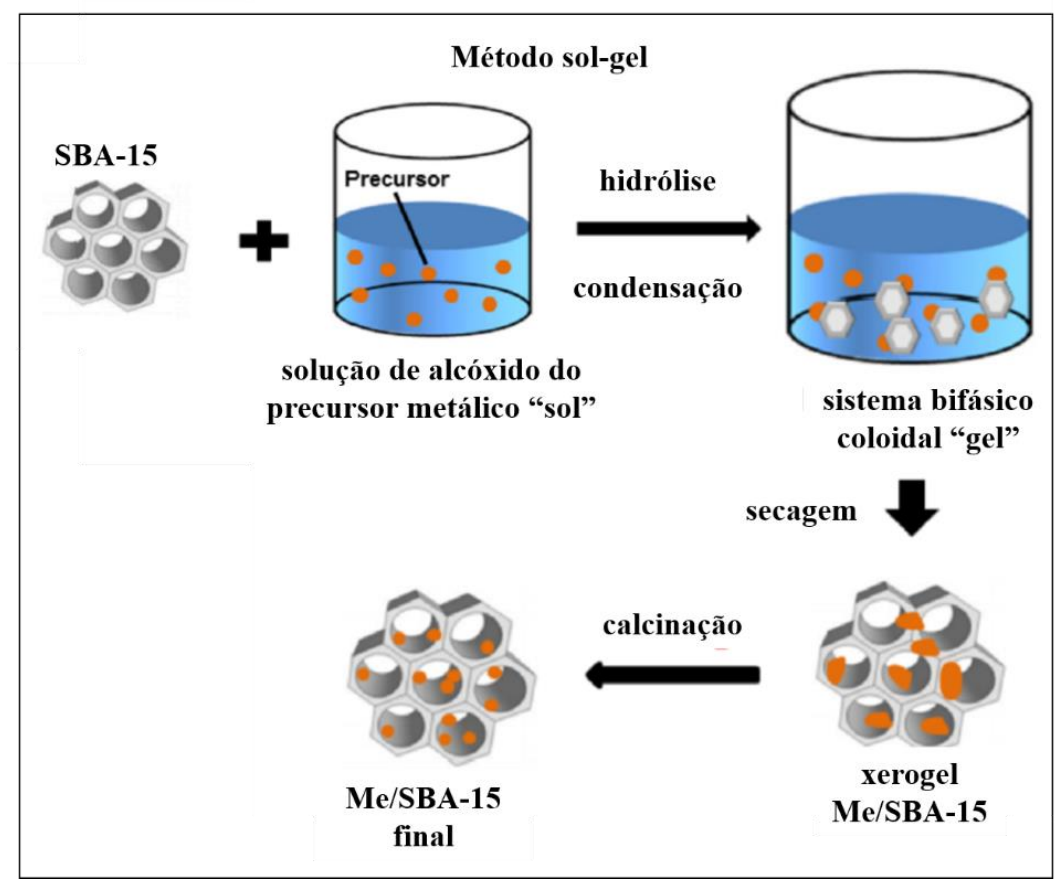

Fonte: Adaptado de YUAN et al., 2020. 


\subsection{Sílicas Mesoporosas com Dióxido de Titânio}

O titânio (Ti) é o nono elemento mais abundante na crosta terrestre. É um elemento litófilo e tem uma forte afinidade por oxigênio, fazendo com que sua maior parte esteja sob a forma de óxido. Devido a sua estabilidade em condições adversas, disponibilidade comercial e excelentes características de semicondutor, o dióxido de titânio $\left(\mathrm{TiO}_{2}\right)$ tem despertado um crescente interesse por apresentar inúmeras possibilidades de aplicações, dentre as quais, em sensores químicos de gás, células solares, dispositivos eletrônicos, pigmentos, além da mais importante: a fotocatálise (HENDERSON, 2011).

Além de algumas fases de alta pressão sem relevância tecnológica significativa, existem três principais fases polimorfas de $\mathrm{TiO}_{2}$ : (1) anatase (tetragonal, $\mathrm{I}_{1} /$ amd); (2) rutilo (tetragonal, $\mathrm{P}_{2} / \mathrm{mnm}$ ); (3) brookita (ortorrômbica, $\mathrm{Pbca}$ ). Tais fases podem ser descritas como um arranjo em octaedro distorcido de $\mathrm{TiO}_{6}$ (Figura 1.5). Nesse caso, os parâmetros de rede para as formas rutilo são $\mathrm{a}=\mathrm{b}=0,4584 \mathrm{~nm}$ e $\mathrm{c}=0,2953 \mathrm{~nm}$; e para a anatase, $\mathrm{a}=\mathrm{b}=$ $0,3782 \mathrm{~nm}$ e c $=0,9502 \mathrm{~nm}$. Devido à forma anatase ser a mais estável, sua transição para a forma rutilo ocorre apenas em temperaturas superiores a $900{ }^{\circ} \mathrm{C}(\mathrm{CORONADO}$ et al., 2013).

Figura 1.5 As três estruturas de $\mathrm{TiO}_{2}$ (a) rutilo e (b) anatase (c) brookita. Ti: esferas rosas; O: esferas vermelhas.
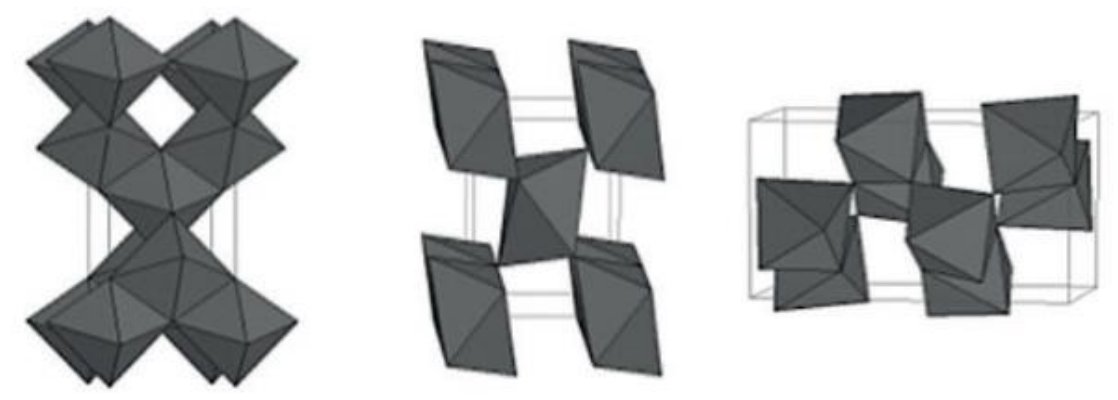

(a)

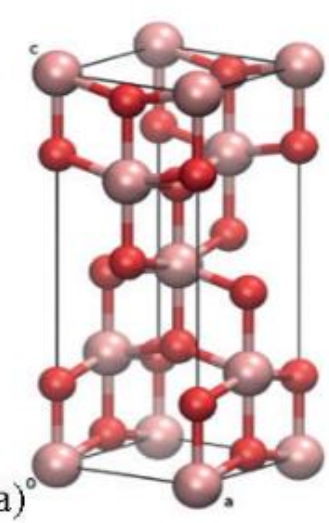

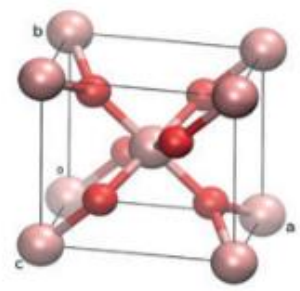

(b)

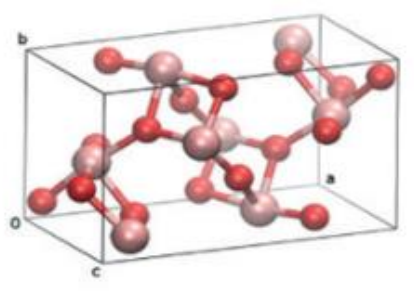

(c)

Fonte: (SCARPELLI et al., 2018). 
Como mencionado, o $\mathrm{TiO}_{2}$ possui interessantes propriedades semicondutoras para aplicação em fotocatálise, sendo o $\mathrm{TiO}_{2}$ P25 Degussa ${ }^{\circledR}$ o mais conhecido comercialmente. Este produto tem como composição $70 \%$ de $\mathrm{TiO}_{2}$ na forma anatase e $30 \%$ na forma rutilo, área superficial específica (BET) de aproximadamente $55 \mathrm{~m}^{2} \mathrm{~g}^{-1}$ e diâmetro de partículas de 25-90 nm, com possíveis formações de aglomerados de até $500 \mathrm{~nm}$.

Por outro lado, o uso de $\mathrm{TiO}_{2} \mathrm{P} 25$ Degussa ${ }^{\circledR}$ como fotocatalisador para degradação de contaminantes orgânicos inclui certas desvantagens que limitam sua aplicação na prática, tais como: baixa área superficial específica, baixa atividade fotocatalítica por excitação restrita na região do ultravioleta. Além disso, quando suspenso em meio aquoso gera turbidez, o que limita a passagem de luz, além de dificultar sua separação e recuperação (DONG et al., 2015). Por este motivo há uma grande motivação para o desenvolvimento de novos fotocatalisadores constituídos de $\mathrm{TiO}_{2}$ imobilizado em diferentes substratos, tais como zeólitas (ANANDAN; YOON, 2003), nanotubos de carbono (TRANG; ALI; KANG, 2015) e sílicas mesoporosas (ZHAO et al., 2010).

Devido às propriedades das sílicas mesoporosas, suportar as nanopartículas de $\mathrm{TiO}_{2}$ na matriz deste substrato gera um vantajoso incremento na superfície de contato entre o $\mathrm{TiO}_{2}$ e o poluente alvo, ou seja, há um aumento ao acesso de sítios fotocatalíticos pelo poluente, resultando em uma maior eficácia de sua degradação; é possível também obter efeitos sinergéticos foto e/ou catalíticos entre $\mathrm{TiO}_{2}$ e a sílica mesoporosa (PERATHONER et al., 2006).

Os primeiros estudos sobre $\mathrm{TiO}_{2} / \mathrm{SBA}-15$ retrataram os diferentes métodos de preparo deste material (LUAN; KEVAN, 2001), enquanto os demais trabalhos publicados investigaram suas possíveis aplicações, tal como em processos fotocatalíticos. Na Figura 1.6, é possível notar que aproximadamente metade dos estudos publicados nos últimos dez anos, com as palavras-chave $\mathrm{SBA}-15+\mathrm{TiO}_{2}$, são voltados para aplicação em fotocatálise heterogênea (SBA-15 $+\mathrm{TiO}_{2}+$ fotocatálise). Uma revisão dos principais trabalhos presentes nesta pesquisa encontra-se na Tabela 1.1. É possível afirmar que o $\mathrm{TiO}_{2} / \mathrm{SBA}-15$ possui grande potencial para ser aplicado nesta área, contudo há poucos estudos neste âmbito. 
Figura 1.6 Número de publicações encontradas nos últimos dez anos utilizando as palavras-chave de busca: $\mathrm{SBA}-15+\mathrm{TiO}_{2}$ ( ) e $\mathrm{SBA}-15+\mathrm{TiO}_{2}+$ fotocatálise (- $)$.

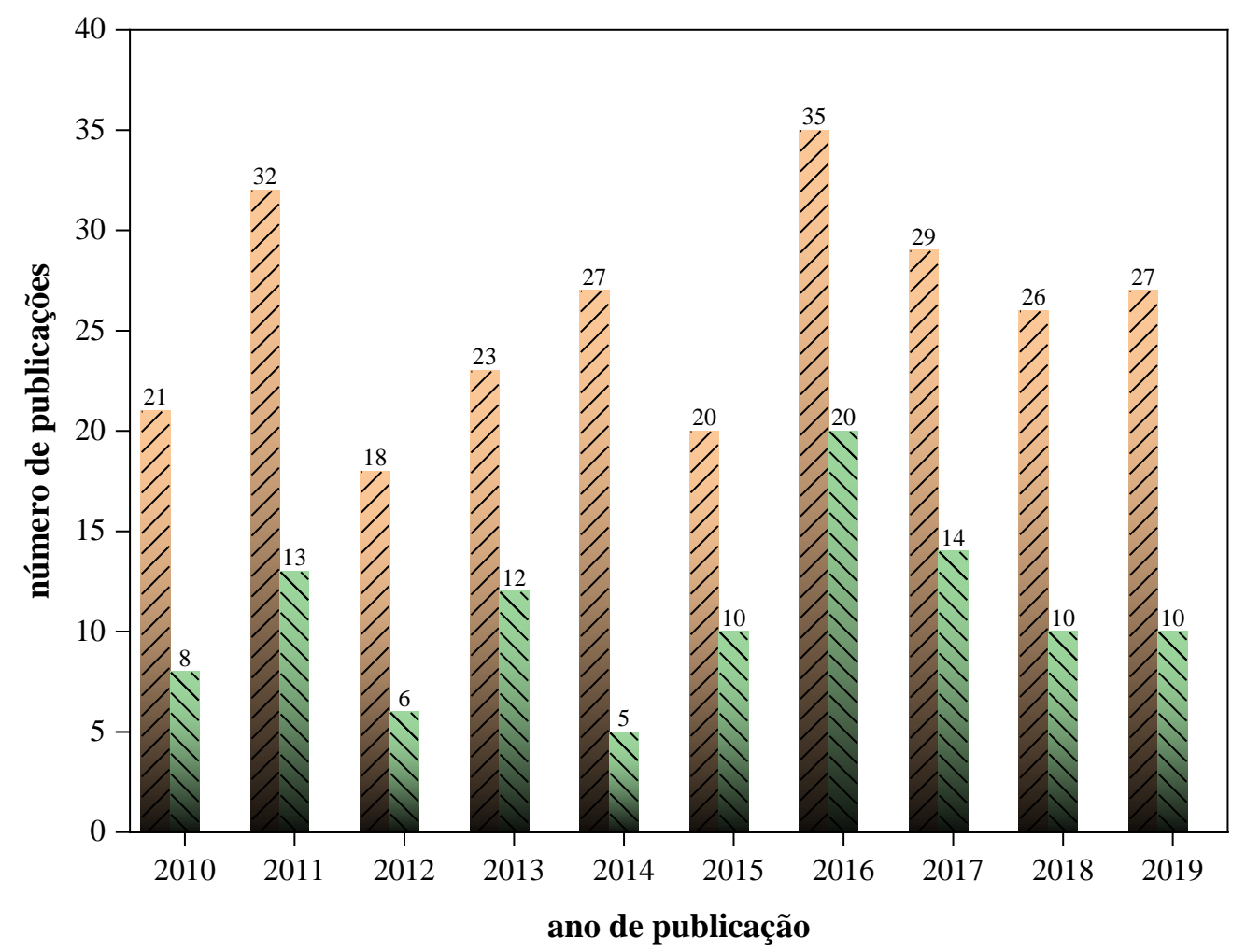

Fonte: Scopus, 2020.

Neste tema, merece destaque o trabalho de Yang e colaboradores (YANG et al., 2006), que observaram melhor desempenho do material 30\% $\mathrm{TiO}_{2} / \mathrm{SBA}-15$ (30\% em massa de $\left.\mathrm{TiO}_{2}\right)$ calcinado à temperatura de $700{ }^{\circ} \mathrm{C}$, para a degradação do corante azul de metileno, quando comparado ao $\mathrm{TiO}_{2} \mathrm{P} 25$ Degussa ${ }^{\circledR}$.

Os autores concluíram que a atividade fotocatalítica do material $\mathrm{TiO}_{2} / \mathrm{SBA}-15$ depende de vários fatores, tais como capacidade de adsorção de poluente em sua superfície, área superficial, estrutura mesoporosa, grau de cristalinidade de $\mathrm{TiO}_{2}$ na superfície da sílica e a razão Ti:Si. O aumento na razão Ti:Si melhora o desempenho quanto à fotodegradação, porém quando esta razão é muito grande, as pequenas partículas de $\mathrm{TiO}_{2}$ se agregam facilmente na superfície da sílica mesoporosa, formando aglomerados, assim parte do titânio pode não ser ativado pela radiação UV, o que leva à diminuição da atividade fotocatalítica. Este resultado também foi observado por Li e colaboradores (LI; ZHAO, 2006).

Em 2017, Conceição et al. mostraram que $\mathrm{TiO}_{2} / \mathrm{SBA}-15$ preparado pelo método de cocondensação é capaz de degradar 100\% o pesticida amicarbazona após 60 min de irradiação. Já em 2019, Calzada e colaboradores (CALZADA et al., 2019) demostraram que o 
fotocatalisador $\mathrm{TiO}_{2} / \mathrm{SBA}-15$ possui melhor desempenho para degradar azul de metileno quando comparado a outros óxidos metálicos $(\mathrm{ZnO}$ e $\mathrm{SnO})$ suportados na SBA-15. Calzada atribui esse resultado ao menor tamanho de cristais de $\mathrm{TiO}_{2}$ quando comparados aos tamanhos de cristais dos demais óxidos metálicos. 
Tabela 1.1 Principais trabalhos publicados que utilizaram os materiais $\mathrm{TiO}_{2} / \mathrm{SBA}-15$ em sistemas de fotocatálise heterogênea (todos os sistemas em reator batelada).

\begin{tabular}{|c|c|c|c|c|c|c|c|c|}
\hline $\begin{array}{l}\text { Catalisador/ } \\
\text { método de } \\
\text { síntese } \\
\end{array}$ & [catalisador] & Poluente & [poluente]o & Fonte radiante & $\begin{array}{c}\text { Tempo/\% } \\
\text { degradação }\end{array}$ & pH & Comentários & Ref. \\
\hline $\begin{array}{l}\mathrm{TiO}_{2} / \mathrm{SBA}-15 ; \\
\mathrm{TiO}_{2} / \mathrm{MCM}^{-41} ; \\
\mathrm{TiO}_{2} / \mathrm{SiO}_{2} \\
\text { método sol-gel }\end{array}$ & $0,5 \mathrm{~g} \mathrm{~L}^{-1}$ & $\begin{array}{l}\text { Cianeto de } \\
\text { potássio } \\
(\mathrm{KCN})\end{array}$ & $100 \mathrm{mg} \mathrm{L}^{-1}$ & $\begin{array}{c}\text { Hg média } \\
\text { pressão }(150 \mathrm{~W})\end{array}$ & $\begin{array}{c}120 \\
\min / 50 \%\end{array}$ & n.a. & $\begin{array}{l}\text { Melhor resultado com } \mathrm{TiO}_{2} / \mathrm{SBA}-15 \text { e } \\
\text { tamanho de partícula de } \mathrm{TiO}_{2} \text { 6-7 nm. }\end{array}$ & $\begin{array}{l}\text { (VAN } \\
\text { GRIEKEN et } \\
\text { al., 2002) }\end{array}$ \\
\hline $\begin{array}{l}\mathrm{TiO}_{2} / \mathrm{Gr} \mathrm{SiO}_{2} \\
\mathrm{TiO}_{2} / \mathrm{SBA}-15 \\
\text { método sol-gel }\end{array}$ & $\begin{array}{c}0,5 \mathrm{~g} \mathrm{~L}^{-1} \\
\left(\mathrm{TiO}_{2}\right)\end{array}$ & $\begin{array}{l}\text { Cianeto de } \\
\text { potássio } \\
(\mathrm{KCN})\end{array}$ & $247,5 \mathrm{mg} \mathrm{L}^{-1}$ & $\begin{array}{c}\text { Hg média } \\
\text { pressão }(150 \mathrm{~W})\end{array}$ & - & 11 & $\begin{array}{l}\text { A fotoxidação aumenta muito quando } \\
\text { complexos de ferro estão presentes, } \\
\text { sendo melhor que Degussa } \mathrm{P} 25^{\circledR} . \mathrm{O} \\
\text { desempenho foi avaliado conforme as } \\
\text { taxas de reação. }\end{array}$ & $\begin{array}{l}\text { (LÓPEZ- } \\
\text { MUÑ̃Z et } \\
\text { al., 2005) }\end{array}$ \\
\hline $\begin{array}{l}\mathrm{TiO}_{2} / \mathrm{SBA}-15 \\
\text { síntese direta }\end{array}$ & $1 \mathrm{~g} \mathrm{~L}^{-1}$ & $\begin{array}{l}\text { Rodamina } \\
\quad(6 G)\end{array}$ & $19,2 \mathrm{mg} \mathrm{L}^{-1}$ & $\mathrm{Hg}(100 \mathrm{~W})$ & $60 \mathrm{~min} / 90 \%$ & n.a. & $\begin{array}{c}\text { O melhor material foi } 0,6 \mathrm{TiO}_{2} / \mathrm{SBA}-15 \text {, } \\
\text { pois houve maior adsorção }(88 \%) \text { do } \\
\text { corante neste material. Porém, a } \\
\text { degradação foi similar à obtida com } \\
\text { Degussa } \mathrm{P}^{2} 5^{\circledR} .\end{array}$ & $\begin{array}{c}\text { (BUSUIOC } e t \\
a l ., 2006)\end{array}$ \\
\hline $\begin{array}{l}\mathrm{TiO}_{2} / \mathrm{SBA}-15 \\
\text { síntese direta }\end{array}$ & $1,25 \mathrm{~g} \mathrm{~L}^{-1}$ & $\begin{array}{l}\text { Corante } \\
\text { Orange II }\end{array}$ & $50 \mathrm{mg} \mathrm{L}^{-1}$ & $\begin{array}{l}\text { Hg alta pressão } \\
(125 \mathrm{~W}) 365 \mathrm{~nm}\end{array}$ & $\begin{array}{c}120 \\
\min / 45 \%\end{array}$ & n.a. & $\begin{array}{l}\text { O material com a razão molar de } 4,5 \mathrm{Ti} / \\
\text { Si é que teve a melhor taxa de } \\
\text { conversão. Se normalizar a } \\
\text { fotodegradação por grama de Ti, os } \\
\text { materiais Ti/SBA-15 mostram melhor } \\
\text { atividade de fotocatálise que o comercial } \\
\text { Degussa P25. Quando aumenta a razão } \\
\text { Ti:Si melhora a atividade fotocatalítica. }\end{array}$ & $\begin{array}{c}\text { (LI; ZHAO, } \\
2006)\end{array}$ \\
\hline $\begin{array}{l}\mathrm{TiO}_{2} / \mathrm{SBA}-15 \\
\text { método sol-gel }\end{array}$ & $\begin{array}{c}0,3 \mathrm{~g} \mathrm{~L}^{-1}(\mathrm{de} \\
\left.\mathrm{TiO}_{2}\right)\end{array}$ & $\begin{array}{l}\text { Azul de } \\
\text { metileno }\end{array}$ & $40 \mathrm{mg} \mathrm{L}^{-1}$ & $\begin{array}{l}\text { Hg média pressão } \\
(125 \mathrm{~W})\end{array}$ & $\begin{array}{l}75 \mathrm{~min} / \\
100 \%\end{array}$ & & $\begin{array}{l}\text { O material com o melhor desempenho } \\
\text { fotocatalítico foi } \mathrm{TiO}_{2} 30 \% / \mathrm{SBA}-15 \\
\text { calcinado a } 700{ }^{\circ} \mathrm{C} \text {. Esse material se } \\
\text { mostrou melhor que o Degussa } \mathrm{P} 25^{\circledR} \text {. }\end{array}$ & $\begin{array}{c}\text { (YANG } \text { et al. } \\
\text { 2006) }\end{array}$ \\
\hline
\end{tabular}


Tabela 1.1 (Cont.) Principais trabalhos publicados que utilizaram os materiais $\mathrm{TiO}_{2} / \mathrm{SBA}-15$ em sistemas de fotocatálise heterogênea (todos os sistemas em reator batelada).

\begin{tabular}{|c|c|c|c|c|c|c|c|c|}
\hline $\begin{array}{l}\text { Catalisador/ } \\
\text { método de } \\
\text { síntese }\end{array}$ & [catalisador] & Poluente & [poluente] 0 & Fonte radiante & $\begin{array}{c}\text { Tempo/\% } \\
\text { degradação }\end{array}$ & pH & Comentários & Ref. \\
\hline $\begin{array}{l}\mathrm{TiO}_{2} / \mathrm{SBA}-15 \\
\text { método sol-gel }\end{array}$ & $0,3 \mathrm{~g} \mathrm{~L}^{-1}$ & $\begin{array}{l}\text { Azul de } \\
\text { metileno }\end{array}$ & $40 \mathrm{mg} \mathrm{L}^{-1}$ & $\begin{array}{c}\text { Hg média } \\
\text { pressão }(125 \mathrm{~W})\end{array}$ & $\begin{array}{c}600 \\
\mathrm{~min} / 100 \%\end{array}$ & n.a. & $\begin{array}{l}\text { Melhor resultado com } 31 \% \text { de } \\
\qquad \mathrm{TiO}_{2} .\end{array}$ & $\begin{array}{l}\text { (ACOSTA- } \\
\text { SILVA et al., } \\
\text { 2011) }\end{array}$ \\
\hline $\begin{array}{l}\mathrm{TiO}_{2} / \mathrm{SBA}-15 \\
\text { método quelante; } \\
\text { impregnação } \\
\text { úmida; } \\
\text { precipitação- } \\
\text { deposição }\end{array}$ & $0,1 \mathrm{~g} \mathrm{~L}^{-1}$ & $\begin{array}{l}\text { Azul de } \\
\text { metileno }\end{array}$ & $100 \mathrm{mg} \mathrm{L}^{-1}$ & $\begin{array}{l}\text { Xe } 300 \mathrm{~W} \\
\text { (Oriel) }\end{array}$ & $\begin{array}{c}120 \\
\mathrm{~min} / 60 \%\end{array}$ & & $\begin{array}{l}\text { O material obtido pelo método } \\
\text { quelante desempenhou melhor } \\
\text { resultado, porque o } \mathrm{TiO}_{2} \text { ficou } \\
\text { mais disperso na superfície da } \\
\text { SBA-15 por esse método. }\end{array}$ & $\begin{array}{l}\text { (JUNG et al., } \\
\text { 2011) }\end{array}$ \\
\hline $\begin{array}{l}\mathrm{TiO}_{2} / \mathrm{SBA}-15 \\
\text { método sol-gel }\end{array}$ & $0,5 \mathrm{~g} \mathrm{~L}^{-1}$ & $\begin{array}{l}\text { Azul de } \\
\text { metileno }\end{array}$ & $30 \mathrm{mg} \mathrm{L}^{-1}$ & $\begin{array}{l}\text { Hg alta pressão } \\
(125 \mathrm{~W}) ; \\
\text { radiação visível } \\
\text { e radiação solar }\end{array}$ & $\begin{array}{c}120 \\
\mathrm{~min} / 100 \%\end{array}$ & n.a. & $\begin{array}{c}\mathrm{O} \text { material com }\left(\mathrm{TiO}_{2}\right)_{8} \mathrm{SBA} \\
\left(9,96 \mathrm{~g} \text { de } \mathrm{TiO}_{2}\right) \text { mostrou melhor } \\
\text { resultado em todas as irradiações. } \\
\text { Esse material foi melhor que } \\
\text { Degussa } \mathrm{TiO}_{2} \mathrm{P}^{\circledR} 5^{\circledR} \text { em luz } \\
\text { visível em diferentes intensidades } \\
\text { radiantes. Houve melhora na } \\
\text { fotodegradação ao se aumentar a } \\
\text { temperatura. }\end{array}$ & $\begin{array}{c}\text { (LACHHEB et } \\
\text { al., 2011) }\end{array}$ \\
\hline $\begin{array}{l}\mathrm{TiO}_{2} / \mathrm{SBA}-15 \\
\text { método do poliol } \\
\text { (etileno glicol } \\
\text { como redutor) }\end{array}$ & $0,5 \mathrm{~g} \mathrm{~L}^{-1}$ & $\begin{array}{l}\text { Vermelho } \\
\text { ácido } 1\end{array}$ & $50 \mathrm{mg} \mathrm{L}^{-1}$ & $\begin{array}{c}2 \text { lâmpadas } \mathrm{Hg} \\
\text { black-light }(20 \\
\mathrm{W}, 366 \mathrm{~nm})\end{array}$ & $13 \mathrm{~h} / 80 \%$ & 5 & $\begin{array}{l}\text { Quanto menor o tamanho da } \\
\text { partícula de } \mathrm{TiO}_{2} \text { melhor o } \\
\text { resultado de fotocatálise. }\end{array}$ & $\begin{array}{l}\text { (TSENG et al., } \\
\text { 2012) }\end{array}$ \\
\hline $\begin{array}{l}\mathrm{TiO}_{2} / \mathrm{SBA}-15 \\
\text { método } \\
\text { impregnação } \\
\text { simples }\end{array}$ & $0,5 \mathrm{~g} \mathrm{~L}^{-1}$ & $\begin{array}{c}\text { Alaranjado } \\
\text { de metila }\end{array}$ & $16 \mathrm{mg} \mathrm{L}^{-1}$ & $\begin{array}{l}\text { Hg baixa pressão } \\
\text { (7 W) emitindo } \\
\text { UV próximo }\end{array}$ & $\begin{array}{c}90 \\
\min / 100 \%\end{array}$ & n.a. & $\begin{array}{c}\text { A fotodegradação utilizando } 28 \% \\
\text { e } 44 \% \mathrm{TiO}_{2} \text { anatase foi similar à } \\
\text { obtida com o material comercial } \\
100 \% \text { anatase; Degussa } \mathrm{P} 25^{\circledR} \text { foi } \\
\text { o melhor catalisador. }\end{array}$ & $\begin{array}{c}\text { (BESANÇON et } \\
a l ., \text { 2016) }\end{array}$ \\
\hline
\end{tabular}


Tabela 1.1 (Cont.) Principais trabalhos publicados que utilizaram os materiais $\mathrm{TiO}_{2} / \mathrm{SBA}-15$ em sistemas de fotocatálise heterogênea (todos os sistemas em reator batelada).

\begin{tabular}{|c|c|c|c|c|c|c|c|c|}
\hline $\begin{array}{l}\text { Catalisador/ } \\
\text { método de } \\
\text { síntese } \\
\end{array}$ & [catalisador] & Poluente & [poluente] 0 & Fonte radiante & $\begin{array}{c}\text { Tempo/\% } \\
\text { degradação }\end{array}$ & $\mathbf{p H}$ & Comentários & Ref. \\
\hline $\begin{array}{l}\mathrm{TiO}_{2} / \mathrm{SBA}-15 \\
\text { deposição ácida } \\
\text { supercrítica por } \\
\text { cristal liquido }\end{array}$ & $1,0 \mathrm{~g} \mathrm{~L}^{-1}$ & $\begin{array}{l}\text { Azul de metileno; } \\
\text { Alaranjado de } \\
\text { metila; Rodamina } \\
\text { 6G; Fenol }\end{array}$ & $\begin{array}{l}20 ; 6 \text { e } 10 \\
\mathrm{mg} \mathrm{L}^{-1}\end{array}$ & $\begin{array}{l}\text { Hg alta pressão } \\
(200 \mathrm{~W} ; 365 \\
\mathrm{nm})\end{array}$ & $\begin{array}{l}180 \mathrm{~min} \\
100 \%\end{array}$ & n.a. & $\begin{array}{l}\text { Temperaturas acima de } 400{ }^{\circ} \mathrm{C} \text { para } \\
\text { a calcinação promovem maior } \\
\text { cristalinidade da fase anatase. A } \\
\text { temperaturas maiores, tem-se } \\
\text { presença de rutilo, que diminui a } \\
\text { eficiência da fotodegradação. }\end{array}$ & $\begin{array}{l}\text { (LIU et al., } \\
\text { 2016a) }\end{array}$ \\
\hline $\begin{array}{l}\mathrm{TiO}_{2} / \mathrm{SBA}-15 \\
\text { técnica assistida } \\
\text { por micro-ondas }\end{array}$ & $1,0 \mathrm{~g} \mathrm{~L}^{-1}$ & $\begin{array}{l}\text { Corante alarizin e } \\
\text { pentaclorofenol } \\
\text { (PCP) }\end{array}$ & $100 \mathrm{mg} \mathrm{L}^{-1}$ & $\begin{array}{c}\text { Hg média } \\
\text { pressão }(125 \mathrm{~W})\end{array}$ & $\begin{array}{c}60 \\
\min / 98 \% \\
\text { (alarizin) } \\
94 \%(\mathrm{PCP})\end{array}$ & n.a. & $\begin{array}{l}\text { O material com razão mássica 1:5 } \\
\left(\mathrm{SBA}-15 / \mathrm{TiO}_{2}-5 \% \text { de } \mathrm{TiO}_{2} \text { em }\right. \\
\text { massa) gerou os melhores } \\
\text { resultados na fotodegradação. }\end{array}$ & $\begin{array}{c}\text { (MEHTA et al., } \\
\text { 2016) }\end{array}$ \\
\hline $\begin{array}{l}\mathrm{TiO}_{2} / \mathrm{SBA}-15 \\
\text { síntese direta }\end{array}$ & $0,5 \mathrm{~g} \mathrm{~L}^{-1}$ & Amicarbazona & $10 \mathrm{mg} \mathrm{L}^{-1}$ & UV-A (15 W) & $\begin{array}{c}60 \\
\min / 100 \%\end{array}$ & 5 & $\begin{array}{c}\mathrm{O} \text { melhor catalisador foi } 0,5 \\
\mathrm{TiO}_{2} / \mathrm{SBA}-15 . \text { Foi medida a } \\
\text { concentração de radicais } \mathrm{HO}{ }^{\bullet} \text { com } \\
\text { pCBA. Avaliou-se que o ZPC de } \\
\mathrm{TiO}_{2} / \mathrm{SBA}-15 \text { está em pH } 3,5-4,5\end{array}$ & $\begin{array}{l}\text { (CONCEIÇÃO } \\
\text { et al., 2017) }\end{array}$ \\
\hline $\begin{array}{l}\mathrm{TiO}_{2} / \mathrm{SBA}-15 \\
\text { método sol-gel }\end{array}$ & $1,75 \mathrm{~g} \mathrm{~L}^{-1}$ & Azul de metileno & $16 \mathrm{mg} \mathrm{L}^{-1}$ & UV (6 W) & $\begin{array}{c}180 \\
\min / 100 \%\end{array}$ & 4 & $\begin{array}{c}\mathrm{TiO}_{2} / \mathrm{SBA}-15 \text { (razão } 3 / 7 \text { ) calcinado } \\
\text { a } 900{ }^{\circ} \mathrm{C} \text { apresentou o melhor } \\
\text { resultado. }\end{array}$ & $\begin{array}{l}\text { (LIOU et al., } \\
\text { 2018) }\end{array}$ \\
\hline $\begin{array}{l}\mathrm{TiO}_{2} / \mathrm{SBA}-15 \\
\mathrm{ZnO} / \mathrm{SBA}-15 \\
\text { método "Sclenk- } \\
\text { line" }\end{array}$ & $0,8 \mathrm{~g} \mathrm{~L}^{-1}$ & $\begin{array}{l}\text { Azul reativo } \\
\text { (RB19) }\end{array}$ & $25 \mathrm{mg} \mathrm{L}^{-1}$ & $\begin{array}{l}\text { Hg alta pressão } \\
(150 W ; 365 \mathrm{~nm})\end{array}$ & $\begin{array}{c}240 \\
\min / 94,7 \%\end{array}$ & 7.0 & $\begin{array}{l}\text { Maior adsorção e degradação do } \\
\text { corante com o material ZnO/SBA- } \\
\text { 15, com a razão molar Zn:Si 1:1 } \\
\text { ZPC SBA-15 = } 2\end{array}$ & $\begin{array}{c}\text { (MAUČEC et } \\
a l ., 2018)\end{array}$ \\
\hline $\begin{array}{l}\mathrm{TiO}_{2}, \mathrm{SnO}_{2} \mathrm{e} \\
\mathrm{ZnO} / \mathrm{SBA}-15 \\
\text { impregnação } \\
\text { úmida }\end{array}$ & $0,13 \mathrm{~g} \mathrm{~L}^{-1}$ & Azul de metileno & $10 \mathrm{mg} \mathrm{L}^{-1}$ & $\begin{array}{c}\mathrm{Hg}(4400 \mu \mathrm{W} \\
\left.\mathrm{cm}^{-2}\right)\end{array}$ & $\begin{array}{c}120 \\
\min / 100 \%\end{array}$ & n.a. & $\begin{array}{l}\mathrm{TiO}_{2} / \mathrm{SBA}-15 \text { apresentou o melhor } \\
\text { resultado. Energia de band gap do } \\
\mathrm{TiO}_{2} / \mathrm{SBA}-15 \text { foi de } 3,3 \mathrm{eV} \text {. }\end{array}$ & $\begin{array}{c}\text { (CALZADA et } \\
\text { al., 2019) }\end{array}$ \\
\hline
\end{tabular}




\section{MÉTODOS DE FUNCIONALIZAÇÃO DAS SÍLICAS MESOPOROSAS COM MOLÉCULAS ORGÂNICAS}

No presente trabalho, além de sintetizar o fotocatalisador $\mathrm{TiO}_{2}$ suportado na sílica mesoporosa SBA-15 para estudos de fotocatálise heterogênea para a degradação de um contaminante emergente, foram também preparadas as PMO que contêm a molécula orgânica 1,4,5,8-naftalenodiimida (NDI) em sua estrutura. Trata-se de uma imida aromática que possui interessantes características ópticas e estabilidade térmica e mecânica, além de poder atuar como um semicondutor do tipo $n$ (ANDRIC et al., 2004). Apresentam-se a seguir o princípio para a síntese deste material, bem como as principais características dessa imida aromática.

A funcionalização de sílicas mesoporosas com cromóforos orgânicos dá origem às organosílicas mesoporosas (MO) (HOFFMANN et al., 2006; MIZOSHITA; TANI; INAGAKI, 2011). Estes materiais, altamente organizados e híbridos inorgânico/orgânico, possuem vasta possibilidade de aplicações, tais como captura e armazenamento de $\mathrm{CO}_{2}$ (LI et $a l ., 2013$ ), entrega seletiva de medicamentos (BALAS et al., 2006), sistemas de coleta de luz por antena (CALZAFERRI et al., 2003), dispositivos fotovoltaicos (BREEZE et al., 2002), diodos emissores de luz (TRINDADE et al., 2015) e em fotocatálise heterogênea (CASTANHEIRA et al., 2017; LIU et al., 2016b; MIZOSHITA; TANI; INAGAKI, 2011).

O ponto-chave de funcionalizar a sílica mesoporosa é combinar as vantagens de sua estrutura inorgânica, tais como, grande área superficial, estrutura porosa ordenada, estreita distribuição de tamanho de poros e alta estabilidade térmica e mecânica, com as interessantes características ópticas e fotônicas dos compostos orgânicos.

Assim como na funcionalização de sílicas mesoporosas com óxidos metálicos, vários métodos têm sido descritos na literatura quanto à funcionalização das sílicas mesoporosas com moléculas orgânicas, sendo os mais conhecidos: (i) fisissorção; (ii) funcionalização póssíntese (grafting); (iii) co-condensação ou síntese direta; e (iv) síntese das organosílicas periódicas mesoporosas (PMO).

A fisissorção (ou difusão simples) é o método mais simples de funcionalização. Neste método, as sílicas mesoporosas são dispersas em soluções do modificador orgânico de interesse, o qual penetra nos poros por simples difusão. No entanto, as interações entre a molécula orgânica e a parede das sílicas envolvem forças intermoleculares fracas (como pontes de hidrogênio ou forças de van der Waals), de modo que o modificador orgânico pode ser facilmente extraído (CASTRO et al., 2007).

No método de funcionalização pós-síntese (grafting) (Figura 1.7), compostos organosilanos $\left[\mathrm{R}-\mathrm{Si}\left(\mathrm{OR}^{\prime}\right)_{3}\right]$ reagem com os grupos silanóis e hidróxidos presentes nas 
paredes dos poros das sílicas, gerando ligações covalentes entre o modificador orgânico e a sílica. A principal desvantagem deste método é que as primeiras moléculas que se ligam podem bloquear a entrada dos poros, impedindo o acesso de outras moléculas ao interior do poro (HOFFMANN et al., 2006).

Figura 1.7 Representação do método de funcionalização pós-síntese, sendo R = grupo orgânico.

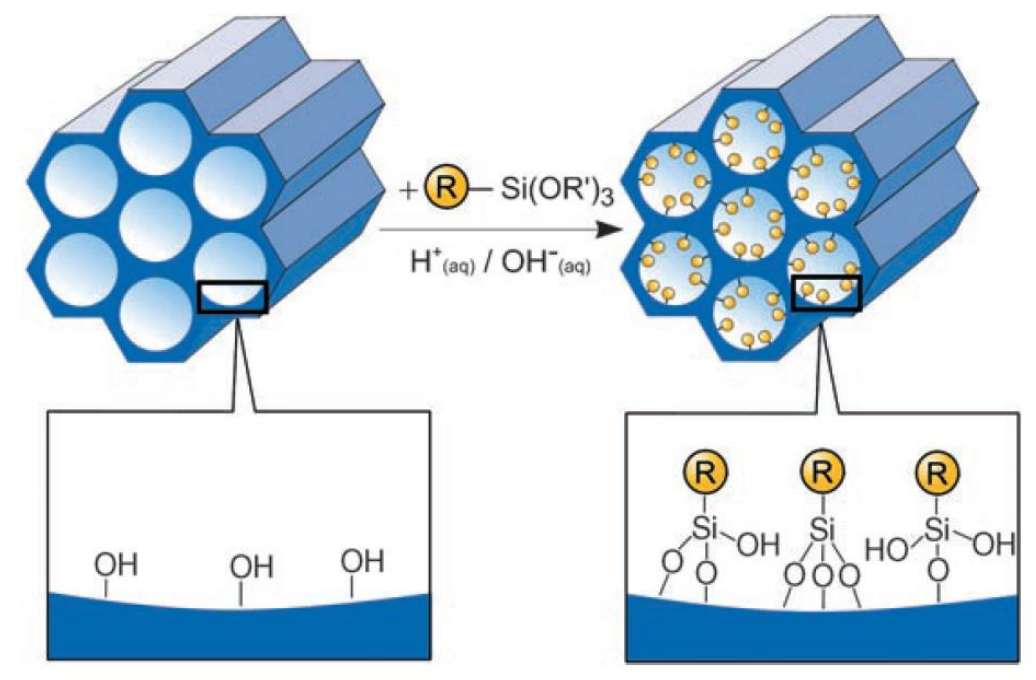

Fonte: (HOFFMANN et al., 2006).

O método de co-condensação ou de síntese direta consiste na co-condensação do precursor de sílica (TEOS-tetraetilortosilicato) na presença do surfactante e de um organosilano [R-Si(OR') $)_{3}$, em um mesmo sistema. Na Figura 1.8 tem-se uma representação do mecanismo simplificado deste método (HOFFMANN et al., 2006). Durante a condensação da fonte de sílica (TEOS), o modificador orgânico (R), que está ligado covalentemente a um átomo de silício, se projeta para o interior dos poros após a extração do surfactante, gerando o material híbrido. Este efeito ocorre porque as ligações $\mathrm{Si}-\mathrm{C}$ (do grupamento $\mathrm{R}$ ) são altamente estáveis, não se quebrando durante a condensação do TEOS.

Dentre as vantagens deste método, destacam-se a homogeneidade na distribuição do grupo funcional orgânico na matriz da sílica, pois não há um bloqueio na entrada dos poros, diferentemente da funcionalização pós-síntese e a versatilidade da técnica, pois a densidade de grupos orgânicos e a organização do sistema de poros podem ser controladas pela concentração do organosilano presente no sistema reacional. 
Figura 1.8 Esquema representando o método de co-condensação ou síntese direta, sendo R o grupo funcional orgânico.

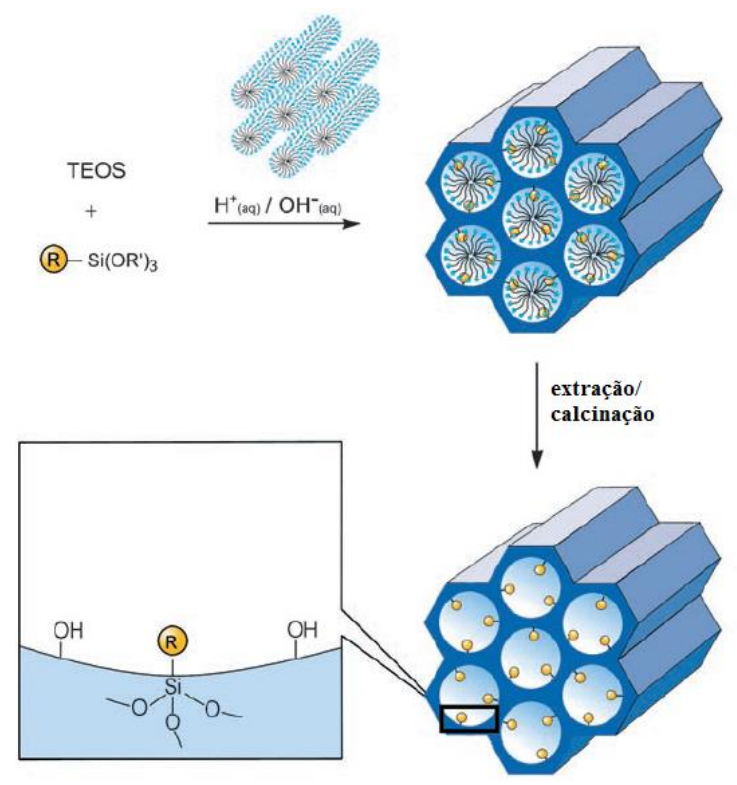

Fonte: Adaptado de HOFFMANN et. al., 2006.

\subsection{Organosílicas Periódicas Mesoporosas (PMO)}

Um terceiro método de funcionalização da sílica mesoporosa com moléculas orgânicas foi desenvolvido e relatado pela primeira vez em 1999 por três grupos de pesquisadores independentes (ASEFA, 1999; INAGAKI et al., 1999; MELDE et al., 1999), o assim chamado método de síntese de organosílicas periódicas mesoporosas (PMO) (Figura 1.9).

Figura 1.9 Síntese de PMO. Onde, R representa o grupo funcional orgânico

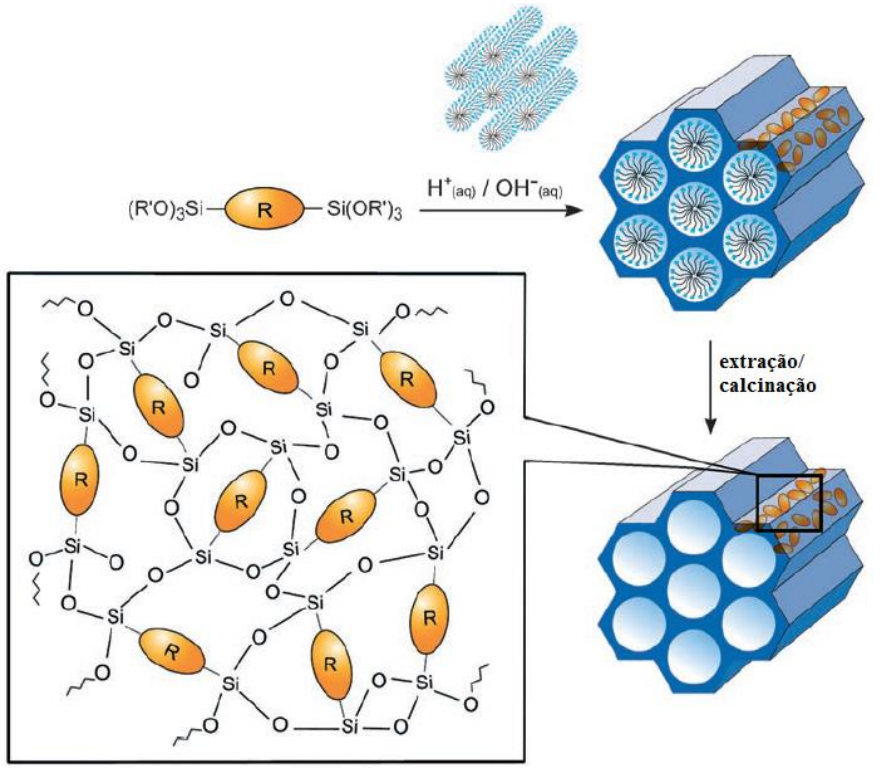

Fonte: Adaptado de HOFFMANN et. al., 2006. 
Este método consiste em utilizar organosilanos bifuncionais do tipo ponte ("bridged") $\left(\mathrm{R}^{\prime} \mathrm{O}\right)_{3} \mathrm{Si}-\mathrm{R}-\mathrm{Si}(\mathrm{OR})_{3}$, nos quais o grupo orgânico R é unido a dois átomos de Si por ligações covalentes, tornando-se parte integral da parede do poro (MIZOSHITA; TANI; INAGAKI, 2011). Dentre suas vantagens, destacam-se a grande homogeneidade na distribuição do grupo funcional orgânico na matriz da sílica, a redução do bloqueio dos poros e a possibilidade de utilizar como fonte única de sílica o grupo $\left(\mathrm{R}^{\prime} \mathrm{O}\right)_{3} \mathrm{Si}-\mathrm{R}-\mathrm{Si}(\mathrm{OR})_{3}(\mathrm{HOFFMANN}$; FRÖBA, 2011). As PMO também apresentam a vantagem de não sofrerem lixiviação dos grupos orgânicos presentes em sua estrutura quando atuam como catalisadores (HOFFMANN; FRÖBA, 2011)

No presente trabalho, os grupos orgânicos funcionais $(\mathrm{R})$ empregados na síntese das PMO são as imidas aromáticas. Suas principais características são discutidas a seguir.

\subsection{Imidas Aromáticas}

As imidas aromáticas (Figura 1.10) são cromóforos orgânicos nitrogenados e aromáticos. Possuem em sua estrutura um anel benzênico, naftalênico ou perilênico e o grupamento imida (Figura 1.11). As imidas aromáticas podem ser classificadas em monoimidas ou diimidas, de acordo com o número de grupamentos imida presentes na molécula. Para nomenclatura de cada imida aromática, a numeração segue de acordo com os respectivos hidrocarbonetos (ex. naftalênico ou perilênico), conforme a Figura 1.12.

Figura 1.10 Estruturas moleculares de algumas diimidas aromáticas.

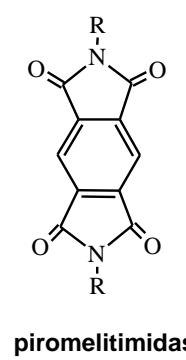

(PMI)
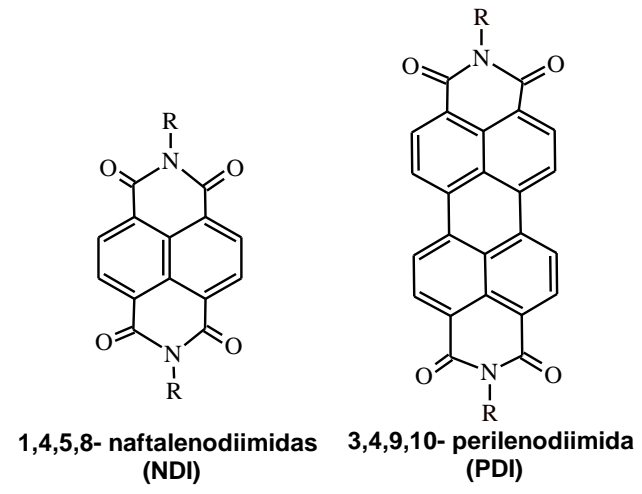

Figura 1.11 Grupamento imida.

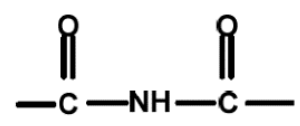


Figura 1.12 Numeração dos derivados naftalênicos e perilênicos.

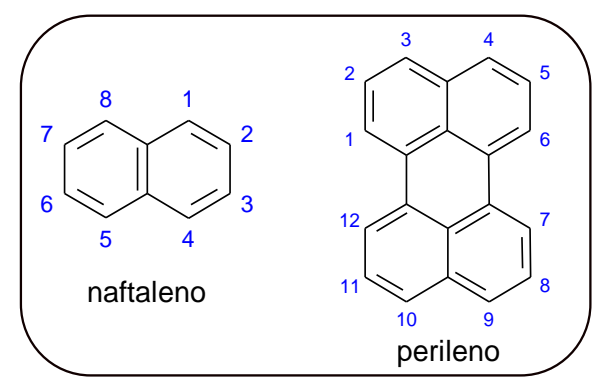

A síntese das imidas aromáticas ocorre através da reação de condensação entre aminas primárias e os compostos anidridos ou dianidridos precursores correspondentes (Figura 1.13). Vale ressaltar que esta reação é extremamente versátil, uma vez que qualquer grupamento $\mathrm{R}$ pode ser incorporado na molécula de imida (MILLER; MANN, 1996; LANGHALS, 1995), desde que este esteja ligado a uma amina primária.

O mecanismo de reação envolve primeiramente a abertura do anel, havendo a formação rápida do ácido âmico como intermediário, seguindo o fechamento do anel com perda de uma molécula de água, para o caso de uma monoimida (Figura 1.13A) ou de duas moléculas de água para as diimidas (Figura 1.13B).

Figura 1.13 Síntese das imidas aromáticas (A) 1,8-naftalimida (NI) (B) 1,4,5,8-naftalenodiimidas.

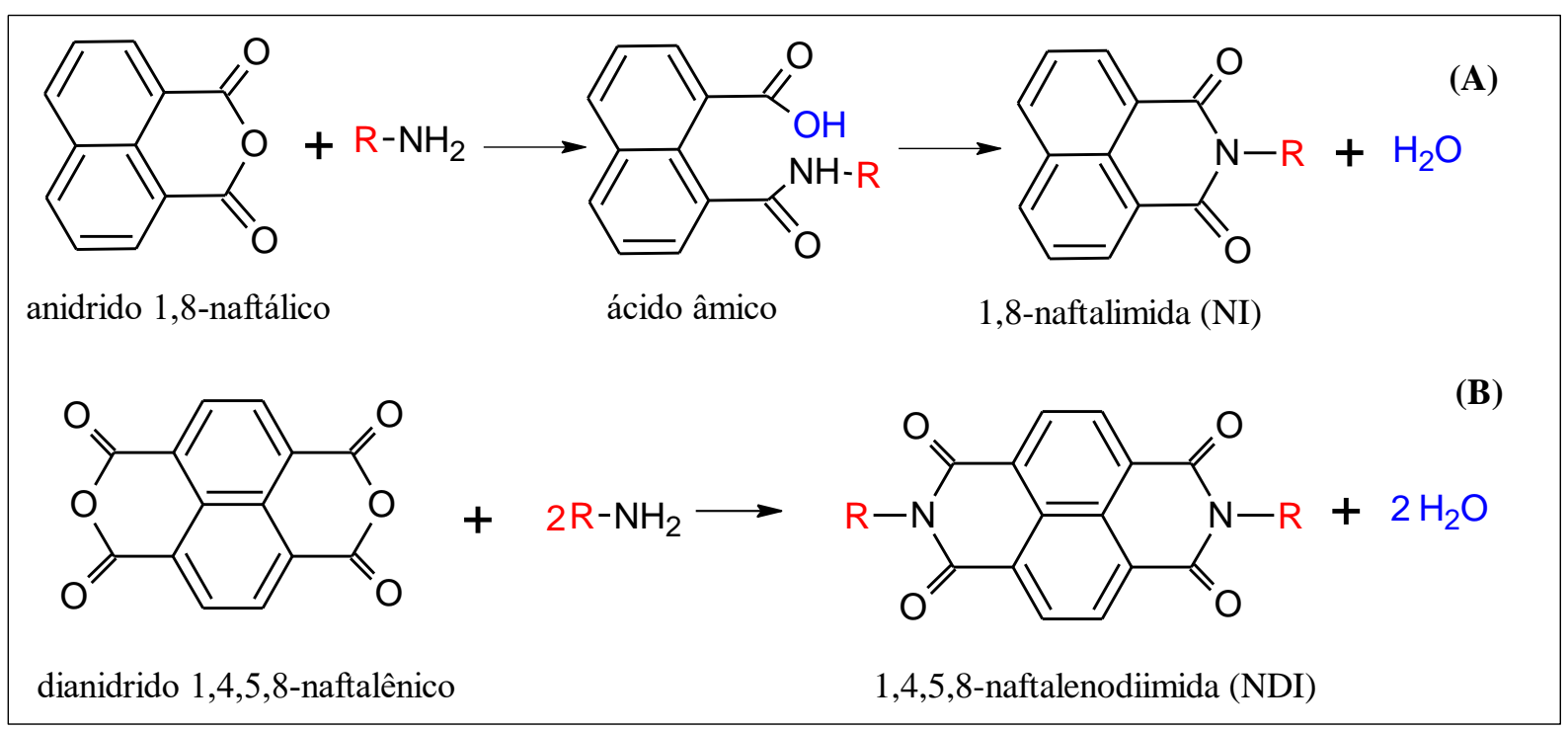

As imidas aromáticas apresentam interessantes características fotofísicas, fotoquímicas e eletroquímicas. Como exemplo, o espectro de absorção das imidas aromáticas se desloca para comprimentos de onda maiores à medida que aumenta o número de anéis aromáticos conjugados. Por exemplo, as 1,4,5,8-naftalenodiimidas (NDI) absorvem na região do 
ultravioleta do espectro eletromagnético e, portanto, são incolores, ao passo que as 3,4,9,10perilenodiimidas (PDI) absorvem na região do visível, sendo coloridas (vermelhas). Quanto à fluorescência, as NDI são fracamente fluorescentes e as PDI, fortemente fluorescentes (GREENFIELD et al., 1996).

As imidas aromáticas também são conhecidas entre os melhores semicondutores orgânicos do tipo $n$ (MARCON; BROCHSZTAIN, 2007), devido a sua fácil redução originando espécies ânions radicais relativamente estáveis. O caráter aceitador de elétrons é uma propriedade comum das diimidas aromáticas e decorre do forte poder sacador de elétrons dos grupos imidas.

Devido a essas características, as imidas aromáticas e seus derivados têm sido utilizados não apenas como componentes para dispositivos eletrônicos e optoeletrônicos, a exemplo de diodos orgânicos emissores de luz (TRINDADE et al., 2015), corantes a lasers e fotodetectores, mas também como receptores de elétrons para estudar processos fotoinduzidos de transferência de energia e de elétrons (ZHAN et al., 2011), princípio para aplicação em células solares e fotocatálise.

Neste trabalho, as NDI são as principais imidas utilizadas na síntese das PMO, por este motivo a seguir serão vistos mais detalhes desta imida.

\subsubsection{Naftalenodiimidas (NDI)}

Os primeiros estudos relacionados às NDI mostraram que essas moléculas são excelentes aceptoras de elétrons para a formação de complexos de transferência de cargas, podendo ser utilizada uma variedade de compostos doadores, tais como, pireno, fenotiazinas e dietilanilina (BOER, 1978). Foi somente em 1990 que estudos sistemáticos sobre esta classe de compostos começaram a surgir na literatura, tendo havido a publicação de um trabalho abrangente mostrando que as NDI podem ser reduzidas com potenciais relativamente baixos (por exemplo, $E_{\text {red }}^{0}=-0,6 \mathrm{~V} \mathrm{EPC)}$ ), formando radicais livres estáveis (VIEHBECK, 1990). A facilidade de sua redução foi atribuída à presença dos dois grupamentos imidas, localizados nas extremidades opostas desta molécula e que possuem efeito sacador de elétrons, causando assim um déficit na densidade eletrônica no anel aromático estabilizando o radical formado.

Durante a década de 1990, um grande número de trabalhos foi dedicado à redução das NDI e de seus derivados, bem como à descrição das propriedades dos radicais NDI formados. A redução das NDI ocorre na ausência de oxigênio e pode ser realizada tanto via química quanto eletroquímica ou fotoquímica. O método eletroquímico mostrou que as NDI podem 
ser reduzidas em duas etapas, gerando primeiramente um ânion radical e, em seguida, um diânion, como mostrado na Figura 1.14 (MILLER; MANN, 1996; VIEHBECK, 1990).

Figura 1.14 Redução das NDI em duas etapas.

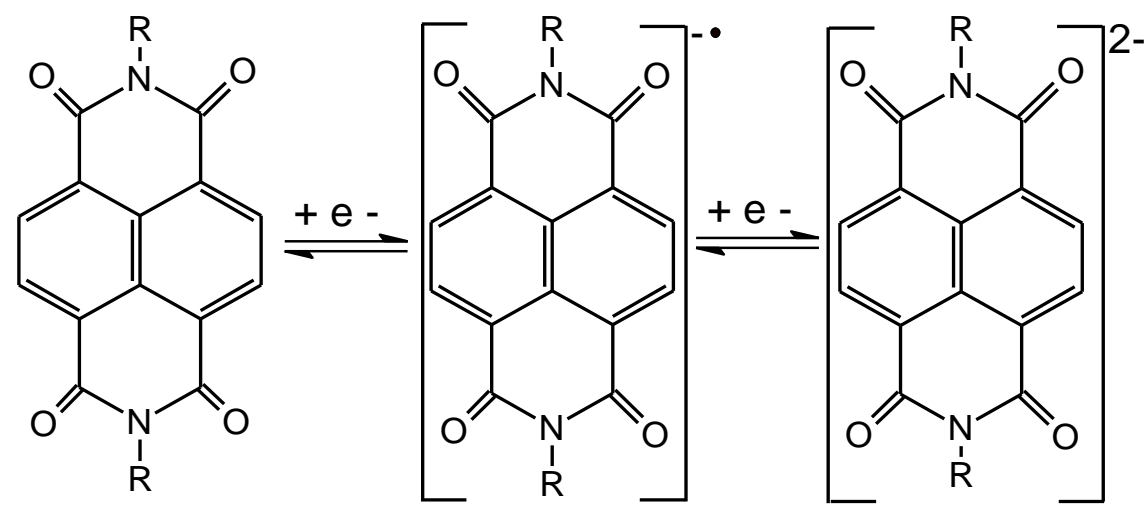

A redução química é realizada geralmente na presença de ditionito de sódio como agente redutor. A redução química e eletroquímica das NDI foi extensivamente estudada pelo grupo de Miller e colaboradores (MILLER; MANN, 1996).

O espectro de absorção de um derivado da NDI (Figura 1.15A) mostra uma banda de estrutura vibracional bem definida com a transição vibracional mais intensa $(0 \rightarrow 0)$ na região de 376-386 nm, e uma banda vibracional menos intensa $(0 \rightarrow 1)$ em $360 \mathrm{~nm}$. Um ombro (transição $0 \rightarrow 2$ ) está geralmente presente em menores comprimentos de onda (próximo a 340 $\mathrm{nm}$ ). A absorção das NDI é típica de cromóforos orgânicos rígidos, o que é esperado, devido ao fato da estrutura da NDI ser similar à do pireno, que possui um espectro de absorção similar. O coeficiente de absorção molar ( $(\varepsilon)$ para a banda vibracional mais intensa é geralmente maior que $20000 \mathrm{~L} \mathrm{~mol}^{-1} \mathrm{~cm}^{-1}$, sugerindo um caráter $\pi \rightarrow \pi^{*}$ para a transição $\mathrm{S}_{0} \rightarrow \mathrm{S}_{1}$.

O espectro de emissão (Figura 1.15B) é imagem especular do espectro de absorção, com um pequeno deslocamento Stokes $(\sim 7 \mathrm{~nm})$, típico de moléculas aromáticas rígidas. Como é bem conhecido, as NDI são fracamente fluorescentes $\left(\varphi_{\mathrm{f}} \sim 0,0008\right)$ (BARROS et al., 1997), mas apresentam fosforescências em baixas temperaturas. $\mathrm{O}$ espectro de fosforescência das NDI possui bandas de emissão típicas em 605 e 665 nm (GREEN; FOX, 1995).

Enquanto moléculas neutras e estrutura aromática planar, as NDI apresentam a capacidade de formar empilhados (tipo $\pi-\pi$ ) entre si ou com outras moléculas aromáticas (Figura 1.16). Esse efeito leva à geração de potenciais vias condutoras de elétrons e/ou a geração de excímeros supramoleculares. De fato, a formação de excímeros no estado 
fundamental da imida pode ser facilmente observada devido ao surgimento de uma banda entre 440-530 nm, característica no espectro de emissão de fluorescência em tolueno (Figura $1.15 \mathrm{C})$.

Figura 1.15 (A) Espectro de absorção em $\mathrm{CH}_{2} \mathrm{Cl}_{2} \mathrm{e}$ (B) espectro de fluorescência normalizado $\left(\lambda_{\mathrm{ex}}=360 \mathrm{~nm}\right) \mathrm{em}$ $\mathrm{CH}_{2} \mathrm{Cl}_{2}$ e (C) em tolueno da $\mathrm{N}$, N-difenil 1,4,5,8-naftalenodiimida.

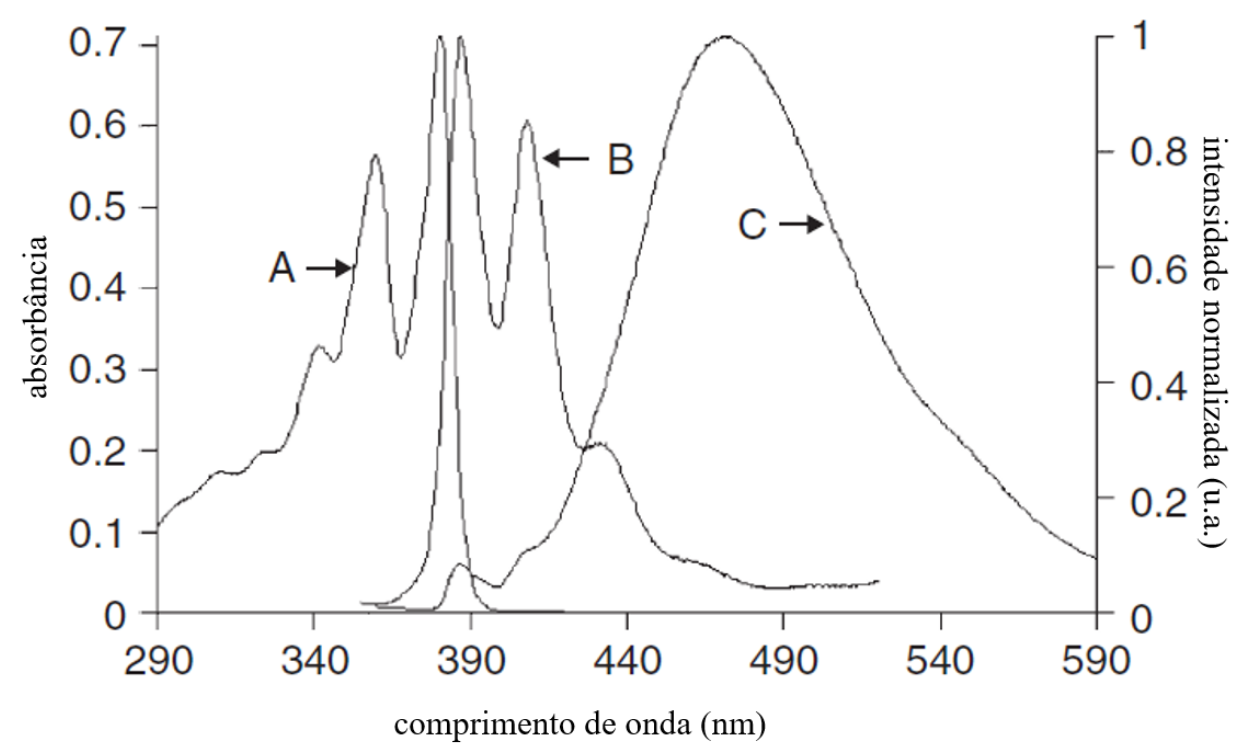

Fonte: Adaptado de ANDRIC et al., 2004.

Figura 1.16 Estrutura cristalina de derivado da NDI (N, N-difenil 1,4,5,8-naftalenodiimida) mostrando uma forte ordenação devido à capacidade de empilhamento $\pi-\pi$ do núcleo de naftaleno.

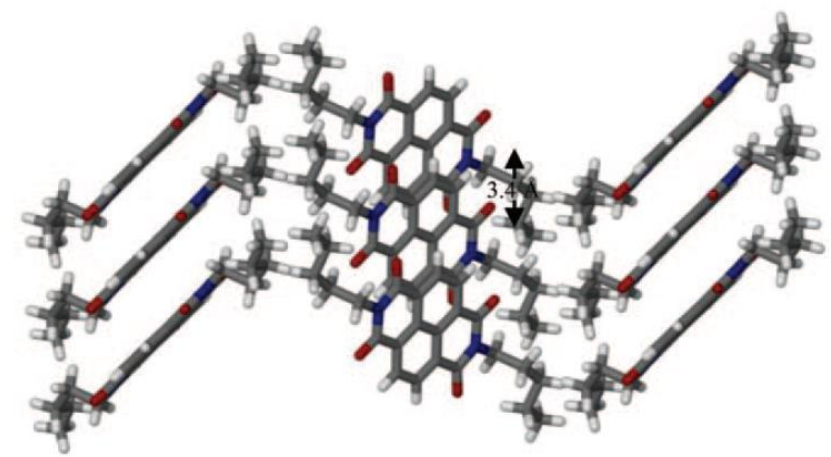

Fonte: (ANDRIC et al., 2004).

\subsection{PMO com Imidas Aromáticas}

O grupo de pesquisa da Universidade Federal do ABC (UFABC), coordenado pelo Prof. Dr. Sergio Brochsztain, co-orientador desta Tese, tem publicado uma série de trabalhos a respeito da funcionalização de sílicas mesoporosas com imidas aromáticas. No primeiro artigo publicado em 2007 (CASTRO et al., 2007), a N,N'-bis(2-fosfonoetil)-3,4,9,10perilenodiimida (PPDI) foi encapsulada via fisissorção nos canais da MCM-41 em soluções 
aquosas de PPDI. O material sólido obtido exibiu fluorescência vermelha, sugerindo um organizado arranjo, com as moléculas de PPDI empilhadas no interior dos canais da sílica mesoporosa (Figura 1.17).

Figura 1.17 Estrutura das PPDI empilhadas nos canais da MCM-41

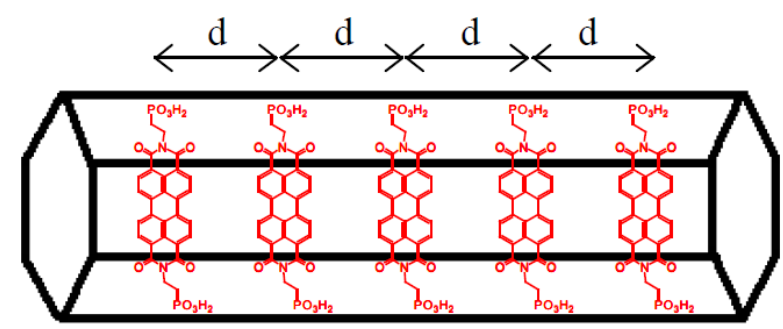

Fonte: (CASTRO et al., 2007).

Na sequência, foi relatada a funcionalização pós-síntese de MCM-41 e SBA-15 com imidas aromáticas diversas - PDI, NDI, ANI e PMI (Figura 1.18) (TRINDADE et al., 2008). A funcionalização covalente gera materiais estáveis, o que impede a lixiviação do cromóforo (TRINDADE; REY; BROCHSZTAIN， 2012; TRINDADE; QUEIRUGA REY; BROCHSZTAIN, 2011). Estes materiais foram preparados através da reação das sílicas originais com 3-aminopropiltrietoxisilano (APTES), gerando superfícies aminadas. Os grupos amino foram então reagidos com anidridos aromáticos, gerando imidas aromáticas covalentemente ligadas à parede dos poros (Figura 1.18). 
Figura 1.18 Sílicas mesoporosas modificadas com imidas aromáticas preparadas pelo grupo de pesquisa da UFABC, via método da funcionalização pós-síntese. Na primeira etapa as sílicas mesoporosas são reagidas com 3-aminopropiltrietoxisilano (APTES), gerando superfícies aminadas. Os grupos amino são então reagidos com anidridos aromáticos, gerando imidas aromáticas covalentemente ligadas à parede dos poros.

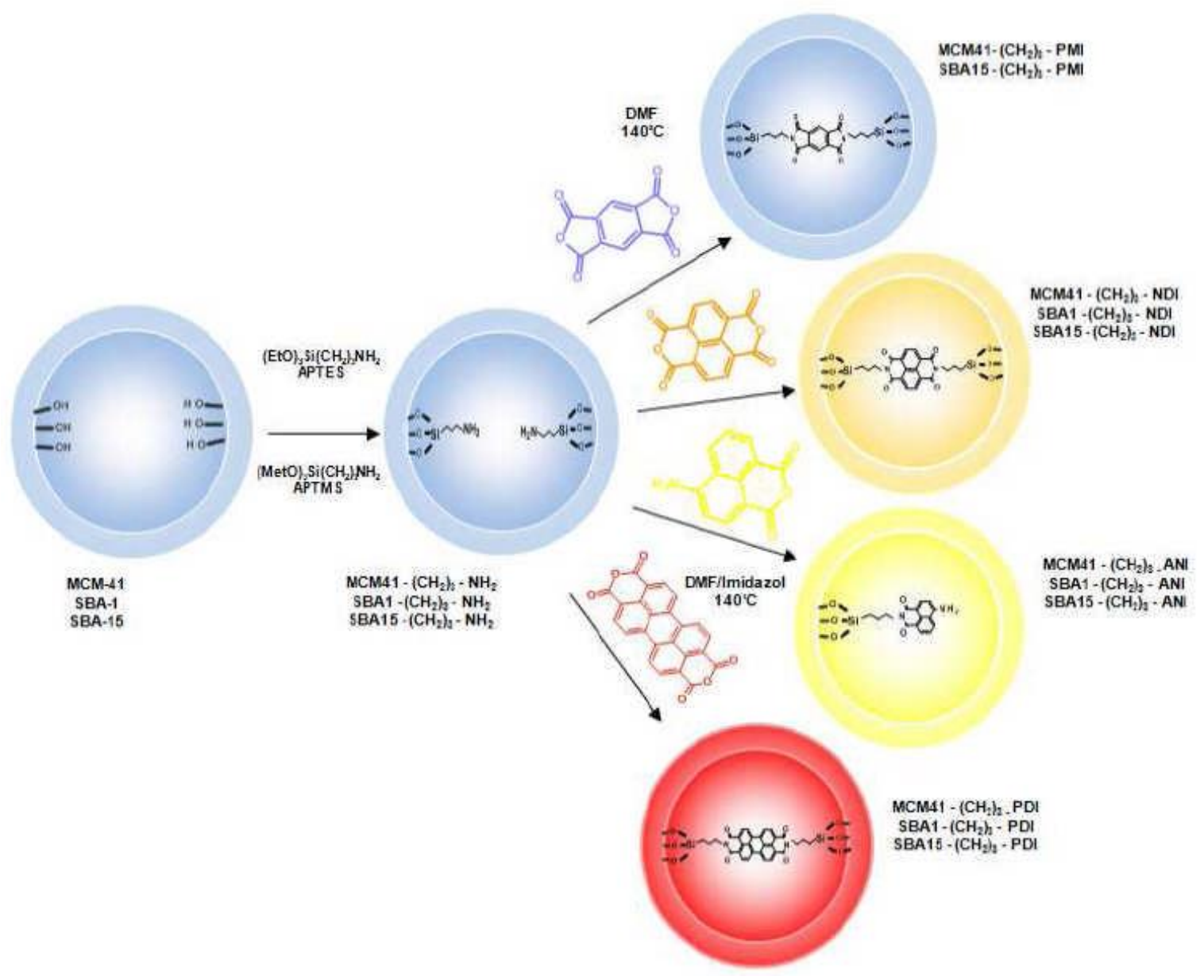

Além do grupo da UFABC, outros autores prepararam MO modificadas com ANI (HOFFMANN; FRÖBA, 2011) por sorção em solução (CHEN et al., 2009) ou por funcionalização pós-síntese (LIANG et al., 2015; MENG et al., 2010; WANG et al., 2005). Em ambos os casos os materiais foram utilizados como sensores fluorescentes para ácidos graxos (WANG et al., 2005) ou para íons metálicos em solução (LIANG et al., 2015).

Em 2015, o grupo de pesquisa da UFABC (TRINDADE et al., 2015) reportou o processo de transferência de energia pelo mecanismo de Föster (FRET- Förster resonance energy transfer) entre duas imidas aromáticas localizadas no interior dos poros da sílica mesoporosa. Os materiais nomeados SBANI foram preparados via co-condesação entre N-(3(trietoxisilil)propil)1,8-naftalimida (TEPNI) e tetraetilortosilicato (TEOS) utilizando o surfactante P123 como agente direcionador de estruturas. As 1,8-naftalimidas (NI) (host) foram ligadas covalentemente às paredes dos poros das SBANI e atuaram como doadoras de energia. Estes materiais foram dopados com as perilenodiimidas (PDI) (guests), que atuaram 
como receptoras de energia (Figura 1.19). Nestes materiais obteve-se emissão de fluorescência de cor branca com o ajuste da concentração da espécie dopante (PDI), ideal para aplicação em OLEDs (diodos orgânicos emissores de luz).

Figura 1.19 Representação do processo de transferência de energia entre a 1,8-naftalimidas (NI) e as 3,4,9,10perilenodiimidas (PDI). Inserto: ajuste de cor de emissão de fluorescência através do incremento da dopagem de PDI nos materiais SBANI.

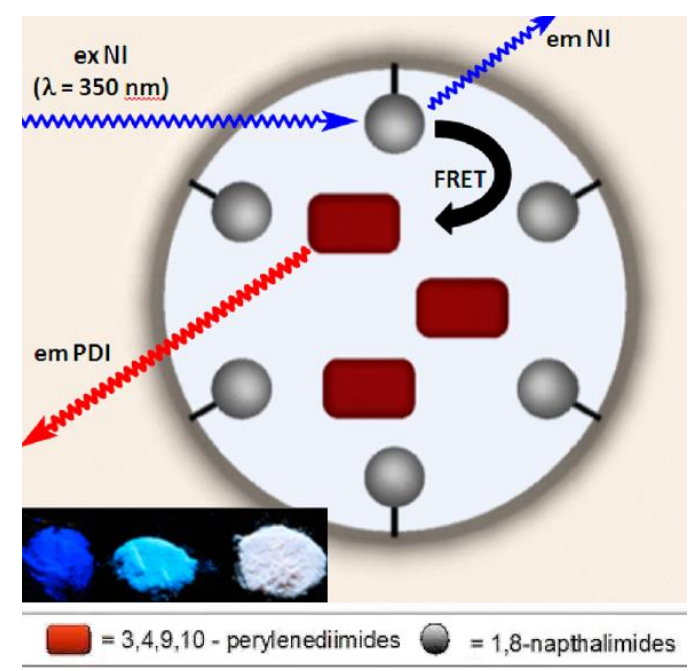

Fonte: (TRINDADE et al., 2015).

Em 2017, a autora desta Tese (CASTANHEIRA et al., 2017) reportou a aplicação dos materiais (SBANI) em processos de fotocatálise heterogênea para a degradação do corante azul de metileno, poluente típico oriundo das indústrias têxteis. Neste trabalho, foi possível alcançar a descoloração total da solução aquosa do corante em 300 min de irradiação com lâmpada UV de vapor de $\mathrm{Hg}$ de $100 \mathrm{~W}$.

Neste levantamento bibliográfico, é possível observar que a maior parte dos trabalhos acerca de sílicas mesoporosas funcionalizadas com imidas aromáticas não compreende a síntese de PMO com as NDI, mostrando assim o caráter inovador do presente trabalho. PMO contendo outras imidas aromáticas também são materiais pouco estudados, uma vez que foi possível encontrar, até o momento, apenas três artigos sobre este tema. Nos dois casos, as PMO foram sintetizadas na presença das 3,4,9,10-perilenodiimidas (PDI).

Em 2009, Wahab e colaboradores (WAHAB; HUSSAIN; HE, 2009) prepararam com sucesso uma PMO utilizando como única fonte de sílica o composto organosilano 1,2-bis (trietoxisilil) etano (BTSE), formando assim, um material 100\% PMO (PMO-SBA-15). Com o objetivo de aumentar a versatilidade deste material foi adicionada junto à condensação do 
BTSE diferentes porções da imida aromática 3,4,9,10-perilenodiimida (PDI) bis-siliada, nomeada PTCDBS (Figura 1.20).

Os filmes finos de PMO-SBA-15 fabricados por Wahab e colaboradores mostraram grande nível de organização (Figura 1.20c). Através da sua funcionalização com a PDI foi possível observar aumento na dureza dos filmes, bem como a atribuição de interessantes características ópticas, pois a PDI possui fluorescência com alto rendimento quântico, sendo ideal para diversas aplicações, a exemplo de células solares.

Figura 1.20 Esquema de preparação dos filmes finos PMO-SBA-15. (A) Sistema sol de partida. (B) PMO-SBA15. (C) Mesocanais hexagonais. A imagem obtida pela microscopia eletrônica de transmitância (TEM) mostra ordenação hexagonal para PMO-SBA15. (D) PTCDBS ligado covalentemente dentro dos poros de PMO-SBA15 puro (100\% BTSE).

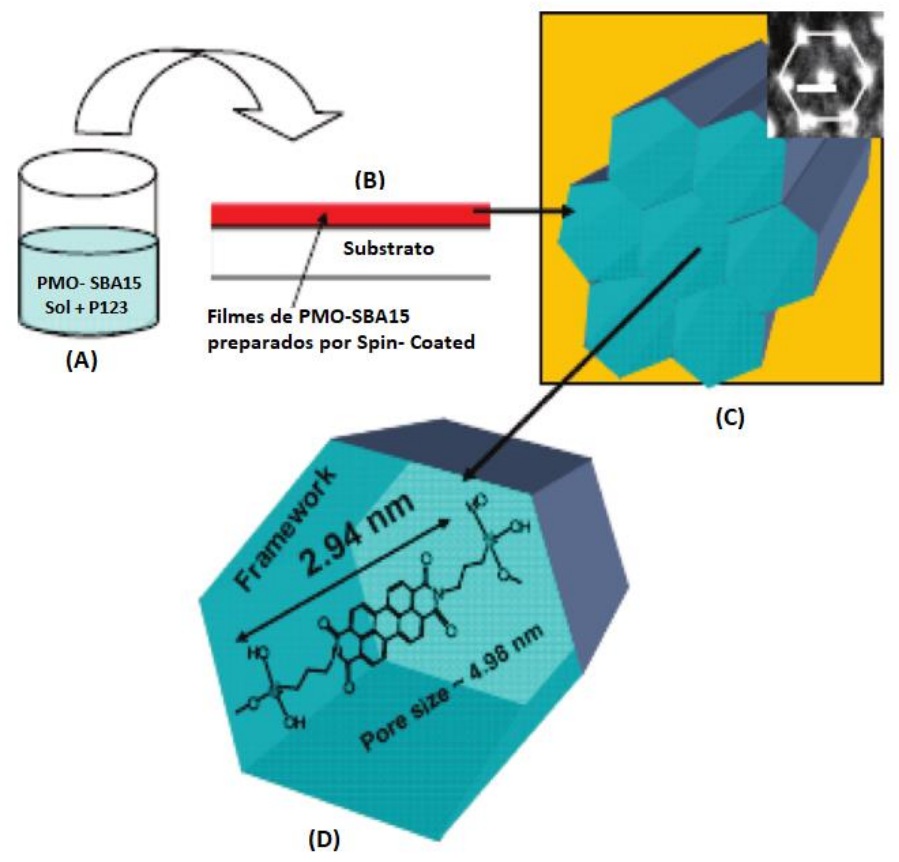

Fonte: (WAHAB; HUSSAIN; HE, 2009).

Um trabalho publicado em 2012 na revista Langmuir por Mizoshita e colaboradores (MIZOSHITA et al., 2012a) mostrou processos de transferência de energia e de elétrons entre perilenodiimidas (PDI), com diferentes grupos substituintes, nos poros de uma PMO contendo grupos de tetrafenil pireno, denominados TPPy-Si (Figura 1.21). Neste trabalho os TPPy-Si atuaram como doadores e as diferentes PDI utilizadas (Figura 1.22) aturam como moléculas aceptoras de elétrons e energia. 
Figura 1.21 Processos de transferência de energia e de elétrons em filmes de PMO contendo tetrafenil pireno (TPPy-Si) como doador e uma perilenodiimida como aceptora de elétrons e de energia.

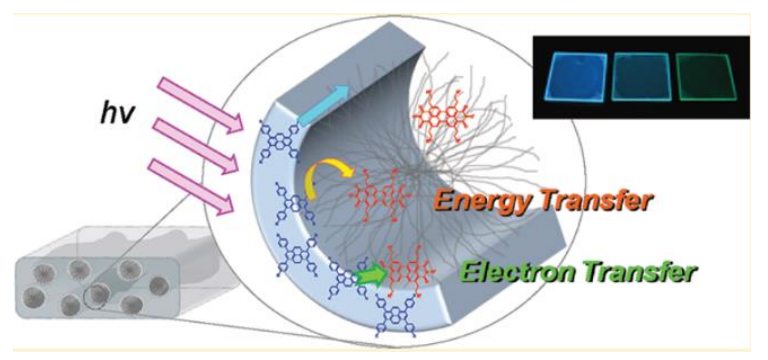

Fonte: (MIZOSHITA, N. et al., 2012).

Figura 1.22 Estruturas moleculares dos derivados das PDI utilizados como aceptores de elétrons e energia.
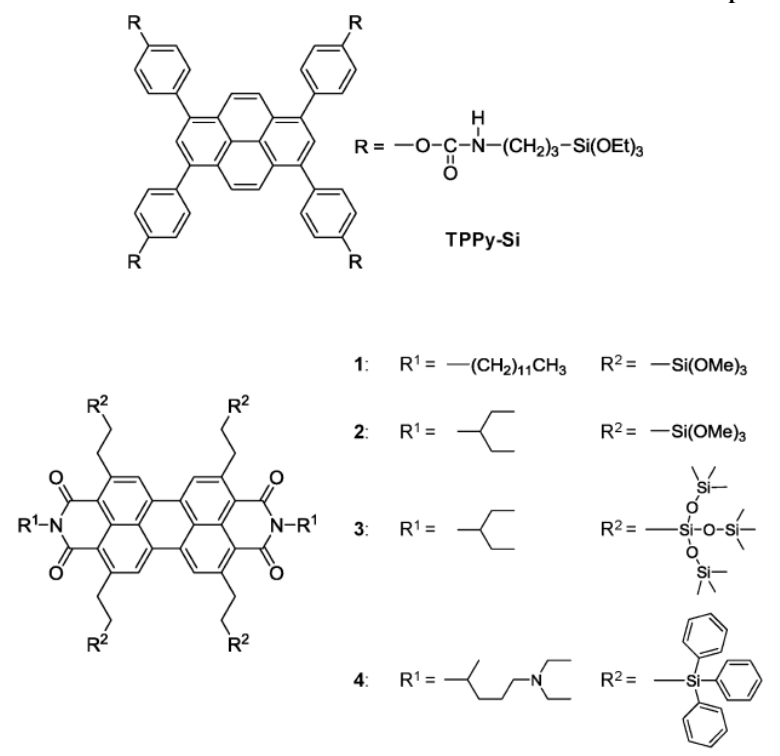

Fonte: (MIZOSHITA, N. et al., 2012).

Também em 2012, Mizoshita e colaboradores (MIZOSHITA et al., 2012b) prepararam PMO funcionalizadas com as PDI, com periodicidade tanto em escala estrutural (mesoporos organizados) quanto em escala molecular, uma vez que as PDI formaram empilhamentos do tipo $\pi$ (“ $\pi$ stacking”) entre si (Figura 1.23A). A ordem molecular cristalina pode permitir o design e controle das propriedades ópticas, elétricas e de superfície das PMO. Para obter esta ordem, Mizoshita e colaboradores utilizaram uma perilenodiimida (PDI) com grupos silanos nas quatro extremidades, ou seja, na posição do oxigênio do grupo imida (Figura 1.23B). 
Figura 1.23 PMO preparados por Mizoshita e colaboradores com 3,4,9,10-perilenodiimida (PDI). (A) representação dos empilhamentos moleculares do tipo $\pi$ ( $\pi$ stacking). (B) Molécula PDI utilizada com grupos silanos presentes nas quatro extremidades.

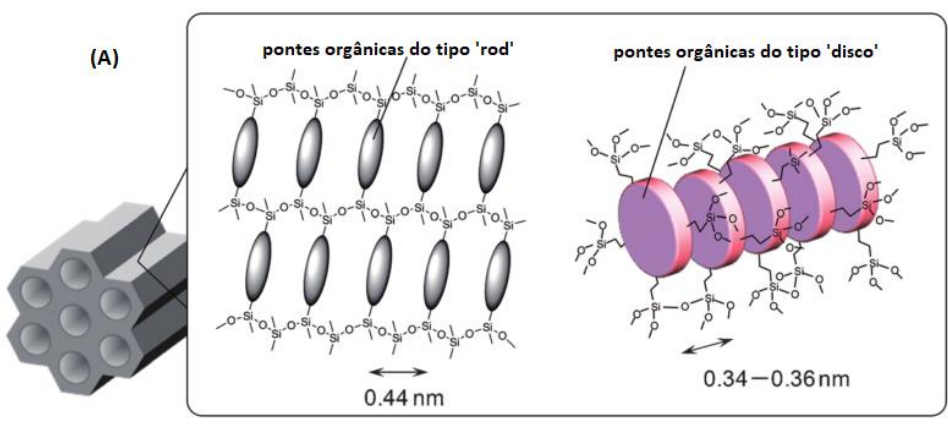

Fonte: (MIZOSHITA et al., 2012b)
(B)

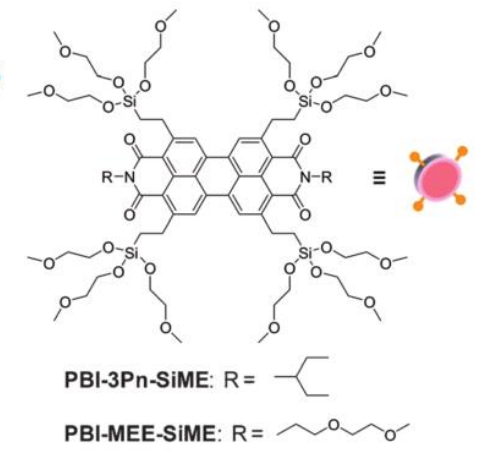

\section{SEÇÃO EXPERIMENTAL}

\subsection{Materiais}

Os seguintes reagentes e solventes foram obtidos da Sigma Aldrich: Pluronic P-123 (copolímerotribloco $\mathrm{EO}_{20} / \mathrm{PO}_{70} / \mathrm{EO}_{20}$ ), tetraetilortosilicato (TEOS), 3-aminopropiltrietoxissilano (APTES), dianidrido 1,4,5,8-naftalenotetracarboxilíco (NTCA) e isopropóxido de titânio (TTIP, 97\% pureza). Etanol (grau HPLC), clorofórmio (grau HPLC) e ácido clorídrico foram adquiridos da Baker. Éter de petróleo $\left(30-70{ }^{\circ} \mathrm{C}\right.$ ) e acetona (ambos de grau analítico) foram fornecidos pela Synth.

\subsection{Métodos}

\subsubsection{Preparação da sílica mesoporosa pura: SBA-15.}

A SBA-15 pura foi preparada utilizando o bem conhecido método descrito na literatura (TRINDADE et al., 2008; ZHAO et al., 1998). Para isso, 4,1 g de Pluronic P123 foram dissolvidas em $30 \mathrm{~mL}$ de água deionizada sob agitação por $2 \mathrm{~h}$ a $35^{\circ} \mathrm{C}$. Em seguida, foram adicionadas $120 \mathrm{~g}$ de $\mathrm{HCl}\left(2 \mathrm{~mol} \mathrm{~L}^{-1}\right)$ a essa solução e deixou-se agitar por mais $2 \mathrm{~h}$. Após esse período, 8,5 g (41 mmol) de tetraetilortosilicato (TEOS) foram adicionados lentamente, e a mistura resultante foi mantida sob agitação constante a $35{ }^{\circ} \mathrm{C}$ por $24 \mathrm{~h}$. O produto formado foi condicionado em uma mini-autoclave para reação hidrotérmica a $100{ }^{\circ} \mathrm{C}$ durante 24 horas. Depois de filtrado, o sólido remanescente foi lavado com $2 \mathrm{~L}$ de água deionizada e $250 \mathrm{~mL}$ de etanol, e secado ao ar durante a noite. 
É Importante salientar que a síntese de SBA-15 por este método foi realizada duas vezes, variando-se o método de extração. Na primeira preparação (lote 1), para a remoção do surfactante, calcinou-se o material a $500{ }^{\circ} \mathrm{C}$ por $6 \mathrm{~h}$ sob atmosfera de nitrogênio (vazão de $100 \mathrm{~mL} \min ^{-1}$ ), com rampa de aquecimento de $1{ }^{\circ} \mathrm{C} \min ^{-1}$. Na segunda preparação (lote 2), o surfactante foi removido pelo sistema de extração em Soxhlet com etanol por $36 \mathrm{~h}$.

\subsubsection{Funcionalização da SBA-15 com $\mathrm{TiO}_{2}$}

Foram preparadas amostras de SBA-15 contendo quatro proporções diferentes de $\mathrm{TiO}_{2}$, conforme a Tabela 1.2 e Figuras 1.24 e 1.25 . Na amostra com $16 \%$ de $\mathrm{TiO}_{2}$, foi utilizada a SBA-15 do lote 1 (extração do surfactante por calcinação). Já para a série de amostras com $10 \% \mathrm{TiO}_{2}, 20 \% \mathrm{TiO}_{2}$ e $30 \% \mathrm{TiO}_{2}$, utilizou-se a SBA-15 do lote 2 (extração do surfactante com solvente).

A funcionalização da SBA-15 pura com a porcentagem em massa desejada de $\mathrm{TiO}_{2}$ foi realizada pelo método sol-gel, de acordo com o procedimento descrito na literatura (ACOSTA-SILVA et al., 2011; YANG et al., 2006), mostrado na Figura 1.25 e detalhado a seguir: deixou-se $1 \mathrm{~g}$ de SBA-15 secar a $150{ }^{\circ} \mathrm{C}$ em estufa por $3 \mathrm{~h}$ para retirar toda a água adsorvida. Após este período, sonicou-se a SBA-15 com $10 \mathrm{~mL}$ de isopropanol até formar uma suspensão coloidal e deixou-se essa mistura em agitação para ser adicionada gota-a-gota a quantidade desejada de isopropóxido de titânio (TTIP), de acordo com o teor de $\mathrm{TiO}_{2}$ desejado em cada material (Tabela 1.2). Esta suspensão foi mantida sob agitação a temperatura ambiente por $45 \mathrm{~min}$. Após este período, adicionou-se água destilada em uma proporção de TTIP 1:10 $\mathrm{H}_{2} \mathrm{O}$ v/v. Esta mistura foi mantida sob agitação por $2 \mathrm{~h}$ para assegurar toda a hidrólise do TTIP. O material resultante foi filtrado sob vácuo, lavado com água destilada e etanol e lentamente secado por 2 dias a $100{ }^{\circ} \mathrm{C}$ em estufa. Para a formação dos cristais de $\mathrm{TiO}_{2}$ na superfície da SBA-15, o material resultante foi calcinado a $700{ }^{\circ} \mathrm{C}$ por $2 \mathrm{~h}$. Os materiais foram nomeados de acordo com a porcentagem em massa (x\%) de $\mathrm{TiO}_{2}$, isto é, $\mathrm{x} \% \mathrm{TiO}_{2} / \mathrm{SBA}-15$, como indicado na Tabela 1.2. 
Figura 1.24 Fluxograma da preparação dos materiais $\mathrm{TiO}_{2} / \mathrm{SBA}-15$.

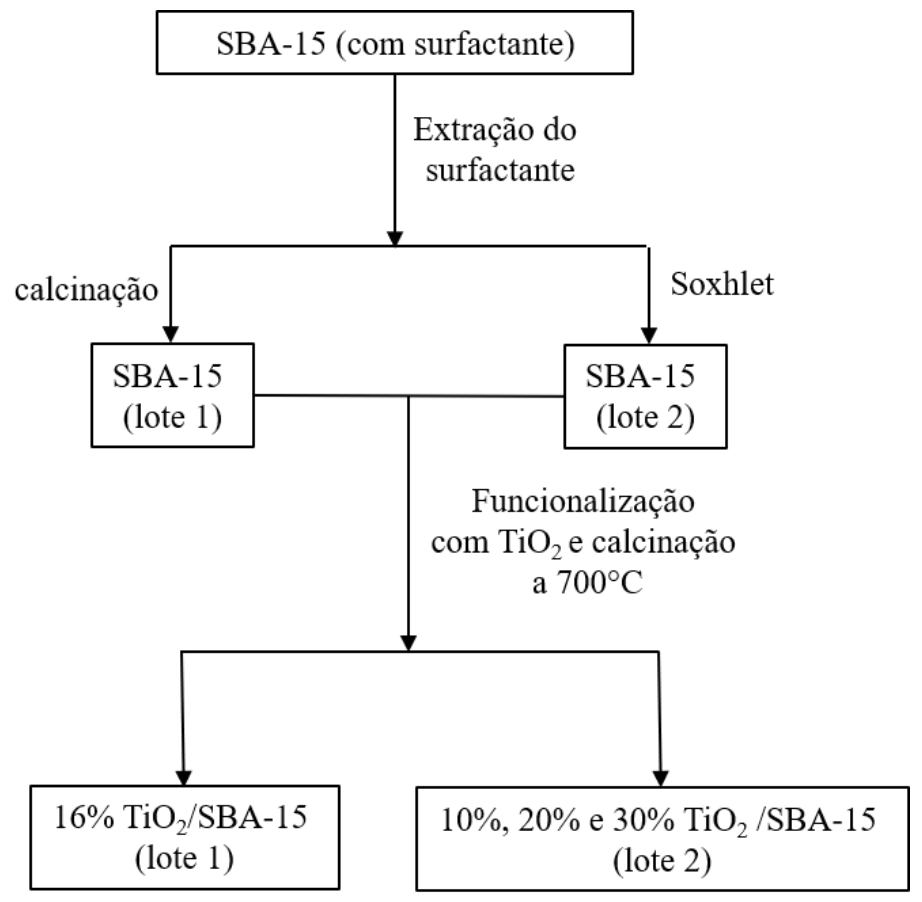

Figura 1.25 Esquema do método sol-gel para a síntese dos materiais $\mathrm{TiO}_{2} / \mathrm{SBA}-15$.

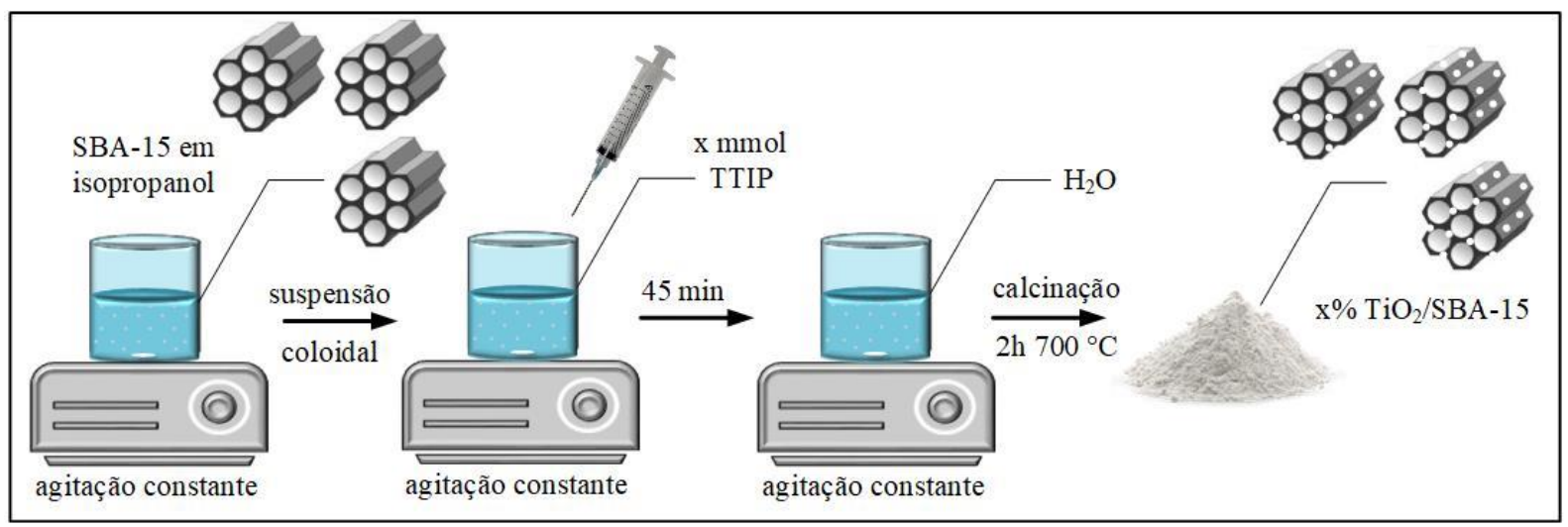


Tabela 1.2 Quantidade molar de TTIP adicionada durante a síntese, porcentagem mássica de $\mathrm{TiO}_{2}$ e proporção $\mathrm{TiO}_{2} / \mathrm{SiO}_{2}$ teórica presente em cada material.

\begin{tabular}{cccccc}
\hline Lote & $\begin{array}{c}\text { Extração do } \\
\text { surfactante } \\
(\text { SBA-15) }\end{array}$ & Amostras & $\begin{array}{c}\text { Volume TTIP } \\
(\mathbf{m L})^{\mathbf{a}, \mathbf{b}}\end{array}$ & $\begin{array}{c}\text { \% massa } \\
\mathbf{T i O}\end{array}$ & $\begin{array}{c}\text { Ti/Si } \\
(\mathbf{m o l a r})\end{array}$ \\
\hline $\mathbf{1}$ & calcinação & $16 \% \mathrm{TiO}_{2} / \mathrm{SBA}-15$ & 0,59 & $16 \%$ & 0,12 \\
\hline & & $10 \% \mathrm{TiO}_{2} / \mathrm{SBA}-15$ & 0,37 & $10 \%$ & 0,08 \\
& & & & & \\
$\mathbf{2}$ & Soxhlet & $20 \% \mathrm{TiO}_{2} / \mathrm{SBA}-15$ & 0,74 & $20 \%$ & 0,15 \\
& & & 1,11 & $30 \%$ & 0,23 \\
\hline
\end{tabular}

adicionada a $1 \mathrm{~g}$ de SBA-15.

${ }^{\mathrm{b}}$ Massa específica do TTIP $=0,96 \mathrm{~g} \mathrm{~mL}^{-1}$.

\subsubsection{Sínteses das PMONDI}

i. Sintese do precursor $N, N^{\prime}$-bis[3-(trietoxisil)propil]-1,4,5,8-naftalenodiimida (TESPNDI): O composto TESP-NDI, precursor das PMO, foi preparado através de reação entre o dianidrido (NTCA) e excesso de APTES (Figura 1.26). O procedimento típico foi reagir, em um balão de fundo redondo, 1,0 mL (4,3 mmol) de APTES com $268 \mathrm{mg}$ (1 mmol) de NTCA a $130{ }^{\circ} \mathrm{C}$ por $5 \mathrm{~min}$. Neste procedimento, o NTCA foi adicionado aos poucos no APTES até sua completa dissolução, resultando em uma solução vermelha escura. Deixou-se a mistura reacional esfriar até temperatura ambiente, quando então foi vertida em $40 \mathrm{~mL}$ de éter de petróleo, resultando em um precipitado. O sólido foi isolado por centrifugação $(5000 \mathrm{rpm}$ durante $5 \mathrm{~min}$ ) e lavado com duas porções, de $40 \mathrm{~mL}$ cada, de éter de petróleo. Entre cada lavagem a solução era centrifugada e o sobrenadante removido para remover o excesso de APTES, o qual é solúvel em éter de petróleo. O sólido resultante foi secado em vácuo durante 10 min. O produto TESP-NDI foi extraído do sólido formado com $10 \mathrm{~mL}$ de acetona. A concentração desta solução foi determinada através de espectroscopia de absorção no UVvisível. Em seguida foi reservada para síntese das PMO. 
Figura 1.26 Representação de cada passo para a síntese das PMONDI.

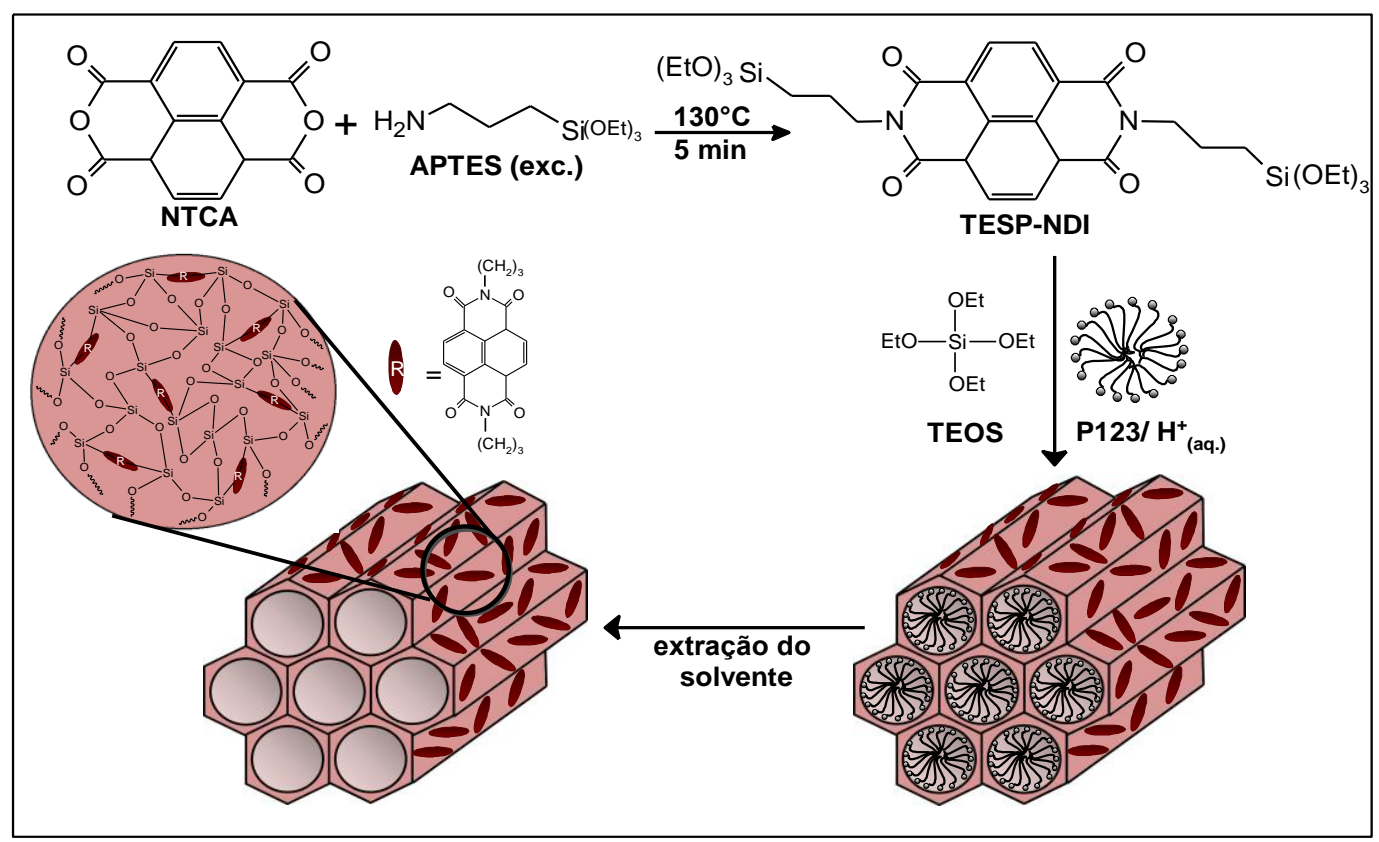

Os espectros de absorção no UV-visível destas soluções são mostrados na Figura 1.27, e condizem com o esperado para derivados da NDI, apresentando a banda de absorção máxima no comprimento de onda $\left(\lambda_{\text {máx. }}\right)$ de $380 \mathrm{~nm}$ e um ombro em $360 \mathrm{~nm}$ (ROGERS; WEISS; KELLY, 2000). As concentrações de TESP-NDI nestas soluções foram determinadas através da lei de Lambert-Beer (Equação 1.3), em que $A$ representa a absorbância no $\lambda_{\text {máx }} ; \varepsilon$ e $c$ representam o coeficiente de absorção molar $\left(\mathrm{L} \mathrm{mol}^{-1} \mathrm{~cm}^{-1}\right)$ e a concentração da amostra (mol $\left.\mathrm{L}^{-1}\right)$, respectivamente, $l$ corresponde ao caminho óptico. A quantidade de mols de TESP-NDI obtida para cada síntese é apresentada na Tabela 1.3.

$$
A=\varepsilon l c
$$


Figura 1.27 Espectros de absorção no UV-visível das soluções de TESP-NDI utilizadas na síntese das PMONDI. Para obter os espectros, alíquotas de $1 \mu \mathrm{L}$ das soluções de TESP-NDI em acetona (vide texto) foram diluídas em $3 \mathrm{~mL}$ de $\mathrm{CHCl}_{3}$ em uma cubeta de quartzo. As concentrações foram obtidas com a lei de Lambert-Beer (Equação 1.6), utilizando um valor de $\varepsilon=20000 \mathrm{~L} \mathrm{~mol}^{-1} \mathrm{~cm}^{-1}$ (para $\lambda_{\text {máx }}=380 \mathrm{~nm}$ ), típico das NDI (BARROS et al., 1997).

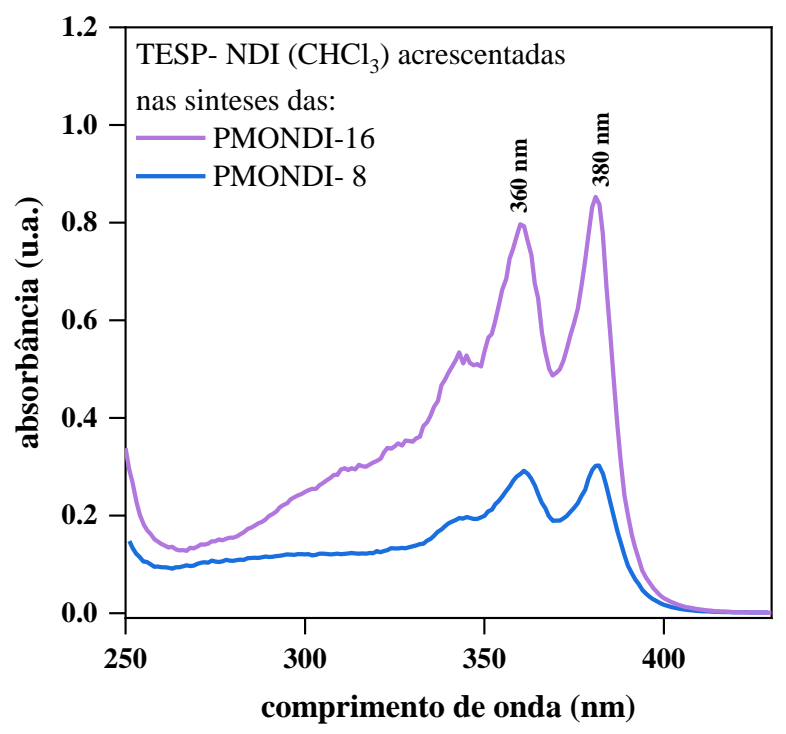

Tabela 1.3 Quantidades dos precursores inorgânico (TEOS) e orgânico (TESP-NDI) empregadas na síntese das PMONDI.

\begin{tabular}{ccc}
\hline Amostra & nTEOS $(\mathbf{m m o l})$ & nTESP-NDI $(\mathbf{m m o l})$ \\
\hline PMONDI-8 & 41 & 0,45 \\
PMONDI-16 & 41 & 1,30 \\
\hline
\end{tabular}

ii. Síntese das PMONDI: Deixaram-se agitar 4,1 g (0,7 mmol) de Pluronic P123 em 30 $\mathrm{mL}$ de água até sua completa dissolução. Logo após adicionaram-se $120 \mathrm{~g}$ de solução aquosa de $\mathrm{HCl}\left(2 \mathrm{~mol} \mathrm{~L}^{-1}\right)$, agitando-se por $1 \mathrm{~h}$. Em seguida, 9,0 mL (41 mmol) de TEOS (Tabela 1.3) foram adicionados à mistura. Como não é possível isolar o composto TESP-NDI por ser muito instável e condensa com facilidade quando seco, a solução de TESP-NDI em $10 \mathrm{~mL}$ de acetona que havia sido reservada (vide seção anterior) foi então adicionada gota a gota durante $30 \mathrm{~min}$.

A quantidade de TESP-NDI adicionada foi variada em cada síntese (Tabela 1.3, Figura 1.27) a fim de se obter materiais com diferentes porcentagens de orgânico (8 e $16 \%$ em massa de NDI, nomeados PMONDI-8 e PMONDI-16, respectivamente). Deixou-se agitar a mistura reacional a $35^{\circ} \mathrm{C}$ por $24 \mathrm{~h}$ e em seguida a mistura foi acondicionada em uma mini autoclave a $100{ }^{\circ} \mathrm{C}$ por $24 \mathrm{~h}$. Após resfriamento da mistura, foram adicionados $2 \mathrm{~L}$ de água deionizada. Por fim, o sólido obtido foi separado por filtração, lavado com $1 \mathrm{~L}$ de água e secado durante 48 h em vácuo. 
iii. Extração do surfactante: Para a remoção do surfactante, as PMONDI foram lavadas com $50 \mathrm{~mL}$ de etanol e $2 \mathrm{~mL}$ de $\mathrm{HCl}$ (37\%) para cada grama de PMONDI. Em seguida, os materiais foram lavados novamente com $500 \mathrm{~mL}$ de etanol e $500 \mathrm{~mL}$ de água e secados em vácuo durante $48 \mathrm{~h}$. Para garantir a retirada de todo o surfactante fez-se a extração em um aparelho de Soxhlet durante $48 \mathrm{~h}$ com etanol.

\subsection{Técnicas de Caracterização}

As seguintes técnicas foram utilizadas para a caracterização dos materiais preparados e descritos no presente capítulo.

(i) Isotermas de adsorção de nitrogênio: As isotermas de adsorção de nitrogênio das amostras sintetizadas foram obtidas em um equipamento da Quantachrome (Modelo Nova 2200e). Para o pré-tratamento, as amostras foram degaseadas a $110^{\circ} \mathrm{C}$, por aproximadamente 24 h. Foi utilizado o método BET (BRUNAUER; EMMETT; TELLER, 1938) em pontos $P / P_{0}<0,3$ para a determinação da área superficial específica de cada amostra. Para a determinação da distribuição de tamanho de poros, foi utilizado o método de cálculo BJH (BARRETT; JOYNER; HALENDA, 1951) nos pontos obtidos de dessorção da isoterma. Os volumes de poros foram obtidos no ponto máximo de saturação de $\mathrm{N}_{2}$ no material, tendo sido escolhido $P / P_{0}=0,97$ como padrão para cada amostra. Essas análises foram realizadas na UFABC.

(ii) Difração de raios-X a baixo ângulo (SAXS): As medidas de SAXS dos sólidos sintetizados foram feitas no equipamento Xeuss 2.0, usando uma fonte geradora Xenocs com radiação $\mathrm{CuK} \alpha(\lambda=0,15406 \mathrm{~nm})$; este equipamento está disponível no Instituto de Física da USP (IF-USP). Todas as amostras foram varridas nas mesmas condições na faixa de $2 \theta=0$ $3^{\circ}$.

(iii) Difração de raios-X (DRX): A morfologia dos nanocristais de $\mathrm{TiO}_{2}$ presentes nos materiais $\mathrm{TiO}_{2} / \mathrm{SBA}-15$ foi determinada através de DRX utilizando um difratômetro de raios$\mathrm{X}$ da Bruker (D8-Discover) com fonte de radiação $\mathrm{CuK} \alpha(\lambda=0,15406 \mathrm{~nm}, 40 \mathrm{kV}$ e $30 \mathrm{~mA})$. O detector foi o LynexEye com um filtro de níquel acoplado, operando na faixa $2 \theta$ de $10^{\circ}$ a $100^{\circ}$ e velocidade de varredura de $0,75^{\circ} \mathrm{min}^{-1}$. As análises foram realizadas no Instituto de Física da USP (IF-USP). 
(iv) Microscopia eletrônica de transmissão de alta resolução (HRTEM): As imagens de HRTEM dos sólidos sintetizados foram obtidas com microscópio JEOL operando a $200 \mathrm{kV}$. As amostras foram preparadas através de uma suspensão aquosa contendo o material a ser analisado, essa suspensão foi gotejada sobre uma grade de cobre revestida com carbono, em seguida deixou-se secar em condições ambientes. As análises foram realizadas no Instituto de Pesquisas Energéticas e Nucleares (IPEN).

(v) Espectroscopia de absorção no UV-visível: Os espectros de absorção na região do UV-visível das soluções homogêneas foram obtidos através do espectrofotômetro Cary 50 (Varian). Foi utilizada uma cubeta de quartzo com $10 \mathrm{~mm}$ de caminho óptico. Os espectros dos materiais sólidos na forma de pós foram obtidos acoplando-se o acessório de refletância difusa Barrelino no equipamento, utilizando como referência a sílica não funcionalizada SBA15. Estas análises foram realizadas na Central Multiusuários da UFABC.

(vi) Ressonância magnética nuclear $(R M N)$ : As análises $\mathrm{RMN}$ no estado sólido ${ }^{29} \mathrm{Si}$ em pulso único ("single pulse" SP) e ${ }^{13} \mathrm{C}\left\{{ }^{1} \mathrm{H}\right\}$ no modo de polarização cruzada ("cross polarization” CP) foram conduzidas em um espectrômetro Varian VNMRS (500 MHz) operando nas frequências de ressonância $99,3\left({ }^{29} \mathrm{Si}\right)$ e $125,7 \mathrm{MHz}\left({ }^{13} \mathrm{C}\right)$, na rotação do ângulo mágico ("magic angle spinning” MAS) de $15 \mathrm{kHz}$ (SP-MAS) e $10 \mathrm{kHz}$ (CP-MAS). Os experimentos de CP-MAS foram realizados para o aumento da razão sinal-ruído nos espectros ${ }^{13} \mathrm{C}$. Os parâmetros típicos de aquisição foram ${ }^{1} \mathrm{H}-\pi / 2$ de comprimento de pulso de $2,5 \mu$ s e ${ }^{29} \mathrm{Si}-\pi / 2$ de 3,5 $\mu$ s, tempo de relaxação de $5 \mathrm{~s}$ (CP-MAS) e $40 \mathrm{~s}$ (SP-MAS), com tempo de contato de 1,5 ms para o CP-MAS.

Para o CP-MAS e SP-MAS, foi utilizada a sequência de pulso de desacoplamento tppm para atenuar o acoplamento dipolar heteronuclear ${ }^{1} \mathrm{H}$. Os desvios químicos em relação ao marcador tetrametilsilano (TMS) foram de $0 \mathrm{ppm}$ para ${ }^{1} \mathrm{H}$ (estado líquido), ${ }^{29} \mathrm{Si} \mathrm{e}{ }^{13} \mathrm{C}$ (estado líquido e sólido). Como referências secundárias foram utilizados o adamantano para o ${ }^{13} \mathrm{C}$ em que o carbono $\mathrm{CH}_{2}$ se encontra em 38,5 ppm e talco para o ${ }^{29} \mathrm{Si}$ com desvio químico isotrópico de $-98,1 \mathrm{ppm}$. As análises de $\mathrm{RMN}$ de ${ }^{1} \mathrm{H}$ e ${ }^{13} \mathrm{C}$ no estado líquido foram conduzidas no mesmo espectrômetro de $500 \mathrm{MHz}$ e foram medidas por pulso único, girando a amostra a $20 \mathrm{~Hz}$. Estas análises foram realizadas na Central Multiusuários da UFABC. 
(vii) Análises elementar $(C H N)$ : As análises elementares de carbono, hidrogênio e nitrogênio $(\mathrm{CHN})$ das amostras sólidas de PMONDI foram realizados na Central Analítica do Instituto de Química da USP (IQ-USP).

(viii) Espectroscopia de infravermelho com transformada de Fourier (FT-IR): As análises FT-IR das amostras sólidas de PMONDI foram realizados na Central Analítica do Instituto de Química da USP (IQ-USP).

\section{CARACTERIZAÇÃO DOS MATERIAIS TiO2/SBA-15}

\subsection{Estudo da Presença de Cristais de $\mathrm{TiO}_{2}$ nos Materiais $\mathrm{TiO}_{2} / \mathrm{SBA}-15$}

A presença de $\mathrm{TiO}_{2}$ cristalino nas sílicas mesoporosas SBA-15 lote 1 e SBA-15 lote 2 pode ser confirmada pela técnica de difração de raios-X em ângulos acima de $10^{\circ}$. Nos difratogramas obtidos (Figura 1.28), é possível notar cinco picos distintos nas amostras $\mathrm{TiO}_{2} / \mathrm{SBA}-15$. Através de comparação com a ficha catalográfica de número JCPDS 21-1272 de dióxido de titânio padrão, foi possível evidenciar que anatase (grupo espacial tetragonal I41/ amd) é a única forma cristalina de $\mathrm{TiO}_{2}$ presente nas amostras. Nenhuma difração característica das formas brookita ou rutilo foi observada, o que era esperado uma vez que essas formas só são evidenciadas para tratamentos térmicos acima de $900{ }^{\circ} \mathrm{C}$ (CORONADO et al., 2013). A difração mais intensa do $\mathrm{TiO}_{2}$ puro encontra-se em $2 \theta=25,3^{\circ}$ (pico 1) e pode ser atribuída ao plano cristalográfico (101). Os demais picos em $2 \theta=37,8^{\circ}$ (pico 2); 48, $1^{\circ}$

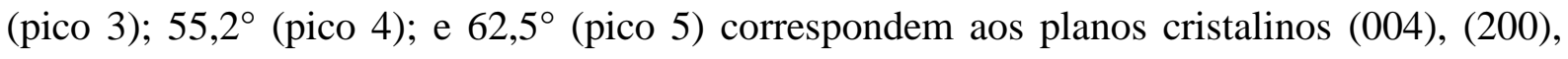
(105) e (204), respetivamente. É possível observar também uma banda na região $2 \theta=20^{\circ}$, característica da estrutura amorfa de sílica $\left(\mathrm{SiO}_{2}\right)$ na amostra de $\mathrm{SBA}-15$ pura e que a intensidade de difração nessa região de $2 \theta$ diminui à medida que se aumenta a carga de cristais de $\mathrm{TiO}_{2}$ em cada amostra, resultado esse característico de uma distribuição homogênea de $\mathrm{TiO}_{2}$ na superfície de sílica. É importante salientar que a SBA-15 lote 1 e 2 apresentaram os mesmos difratogramas 
Figura 1.28 Difratogramas das amostras $\mathrm{TiO}_{2} / \mathrm{SBA}-15$ e da sílica não funcionalizada SBA-15 (lotes 1 e 2).

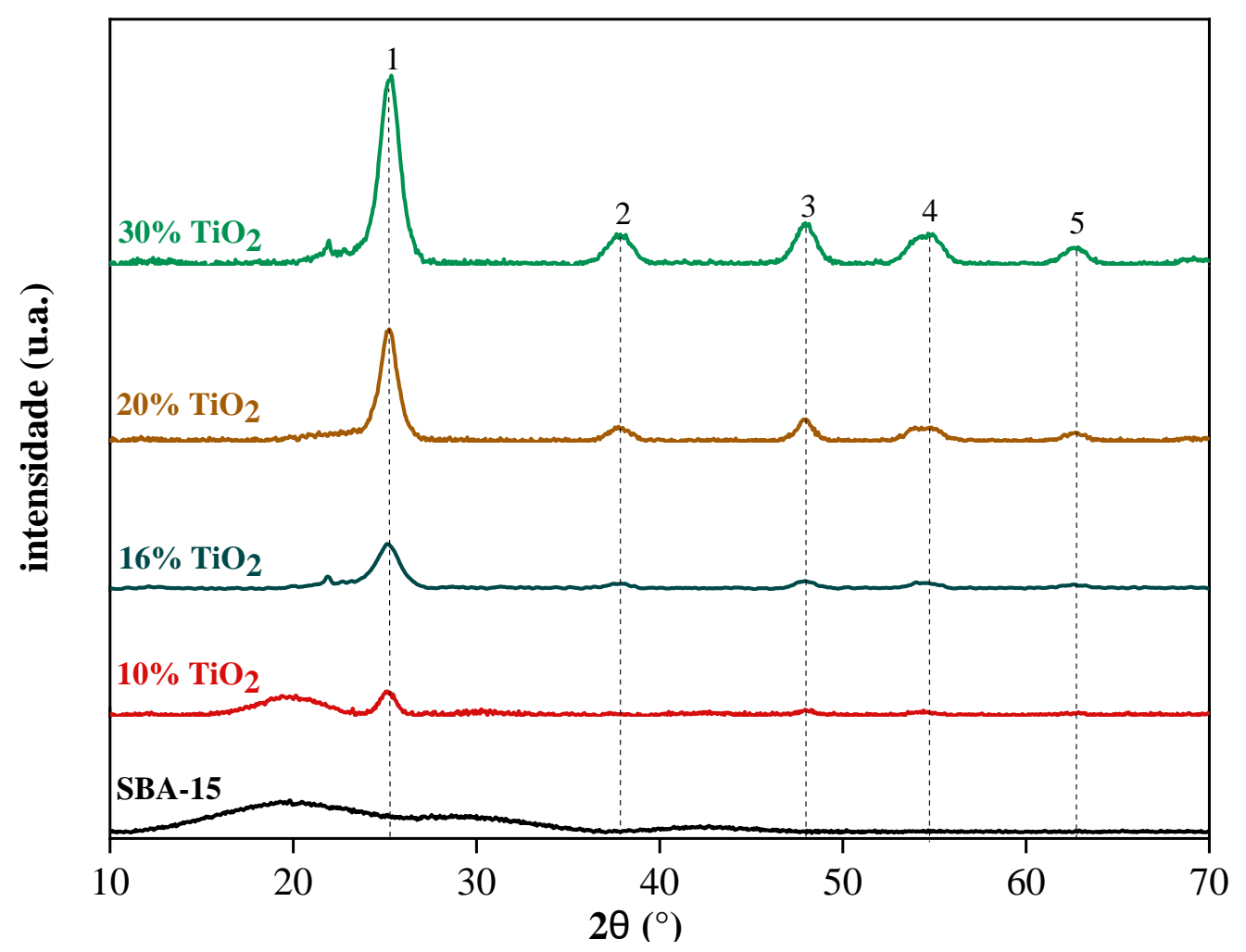

Quando estes cristais são menores que aproximadamente $0,1 \mu \mathrm{m}$, é possível determinar seu tamanho através da equação de Scherrer:

$$
\mathrm{L}=\frac{\mathrm{K} \Lambda}{\beta \cos \theta}
$$

Em que $L$ é o tamanho médio do cristalito em $\mathrm{nm}, \lambda$ é o comprimento de onda característico da radiação de raios-X, $\beta$ é a largura a meia altura do pico correspondente ao principal plano cristalino, $\theta$ é o ângulo de difração deste pico e $K$ é uma constante de proporcionalidade, ou seja, é função da forma geométrica da partícula. Para medidas da largura do pico a meia altura, $K$ apresenta valores entre 0,84 e 0,89 , dependendo da geometria. No caso do $\mathrm{TiO}_{2}$, admite-se a geometria esférica com $K=0,9$. O tamanho de cristal anatase de $\mathrm{TiO}_{2}$ para cada amostra de $\mathrm{TiO}_{2} / \mathrm{SBA}-15$ pode ser determinado através da difração do principal plano cristalino (101), sendo apresentado na Tabela 1.4.

Os resultados obtidos quanto ao tamanho de partículas sugerem que todos os materiais preparados possam apresentar boa eficiência fotocatalítica, uma vez que estudos preliminares (TSENG et al., 2012; VAN GRIEKEN et al., 2002) mostraram que nos materiais $\mathrm{TiO}_{2} / \mathrm{SBA}$ - 
15, que possuem cristais de $\mathrm{TiO}_{2}$ com tamanho entre 6 a $7 \mathrm{~nm}$, podem estar mais dispersos na superfície da sílica e por isso, possuem melhor desempenho para degradação de poluentes orgânicos.

Tabela 1.4 Ângulo (20) e largura a meia altura do pico correspondente ao plano cristalográfico (101) com seu respectivo coeficiente de correlação $\left(R^{2}\right)$ para a determinação do tamanho de cristal anatase presente em cada amostra de $\mathrm{TiO}_{2} / \mathrm{SBA}-15$ através da Equação de Scherrer.

\begin{tabular}{ccccc}
\hline Amostra & $\mathbf{2} \boldsymbol{\theta}_{(\mathbf{1 0 1})}$ & $\boldsymbol{\beta}_{(\mathbf{1 0 1})}$ & $\boldsymbol{R}^{\mathbf{2}}$ & Tamanho do cristal (nm) \\
\hline $10 \% \mathrm{TiO}_{2} / \mathrm{SBA}-15$ & 25,15 & 1,0250 & 0,9825 & 7,94 \\
$16 \% \mathrm{TiO}_{2} / \mathrm{SBA}-15$ & 25,12 & 1,5533 & 0,9676 & 5,24 \\
$20 \% \mathrm{TiO}_{2} / \mathrm{SBA}-15$ & 25,20 & 1,2300 & 0,9809 & 6,62 \\
$30 \% \mathrm{TiO}_{2} / \mathrm{SBA}-15$ & 25,26 & 1,3180 & 0,9888 & 6,18 \\
\hline
\end{tabular}

A presença de nanocristais de $\mathrm{TiO}_{2}$ nos materiais $\mathrm{TiO}_{2} / \mathrm{SBA}-15$ também pode ser verificada nas imagens de microscopia eletrônica de transmissão de alta resolução (HRTEM) (Figuras 1.29 e 1.30). Para os dois lotes de SBA-15 não-modificada (Figuras 1.29A,B e 1.30A,B), é possível observar estrutura mesoporosa hexagonal 2-D altamente organizada, em que cada poro é rodeado por mais seis outros poros e os canais não possuem interconexão, como descrito na literatura para SBA-15 (BECK et al., 1992; BUSUIOC et al., 2006).

Vale ressaltar que os pequenos pontos escuros presentes nas imagens que contêm nanopartículas de $\mathrm{TiO}_{2}$ podem ser associados à presença deste óxido, uma vez que a estrutura da SBA-15 original (Figura 1.29A,B e Figura 1.30A,B) não apresenta tais pontos. A morfologia da sílica é pelo menos parcialmente mantida após a funcionalização com as nanopartículas de $\mathrm{TiO}_{2}$, uma vez que os canais mesoporosos da sílica ainda se mostram presentes, mesmo na amostra com o maior teor de $\mathrm{TiO}_{2}(30 \%)$ (Figuras $\left.1.30 \mathrm{G} \mathrm{e} 1.30 \mathrm{H}\right)$.

Tais pontos negros estão localizados tanto por dentro dos mesoporos quanto por fora da superfície de sílica. Nas Figuras 1.29G observam-se "cachos" de $\mathrm{TiO}_{2}$ (em destaque), que parecem nanopartículas de $\mathrm{TiO}_{2}$ agregadas. Já nas Figuras $1.29 \mathrm{C}, 1.30 \mathrm{C}$ e $1.30 \mathrm{H}$, partículas do semicondutor $\mathrm{TiO}_{2}$ aparecem também dentro dos canais mesoporosos (em destaque). 
Figura 1.29 Imagens de miscroscopia eletrônica de transmissão de alta resolução (HRTEM) das amostras SBA15 (lote 1) (A e B) e 16\% TiO $/$ SBA-15 (C e D).
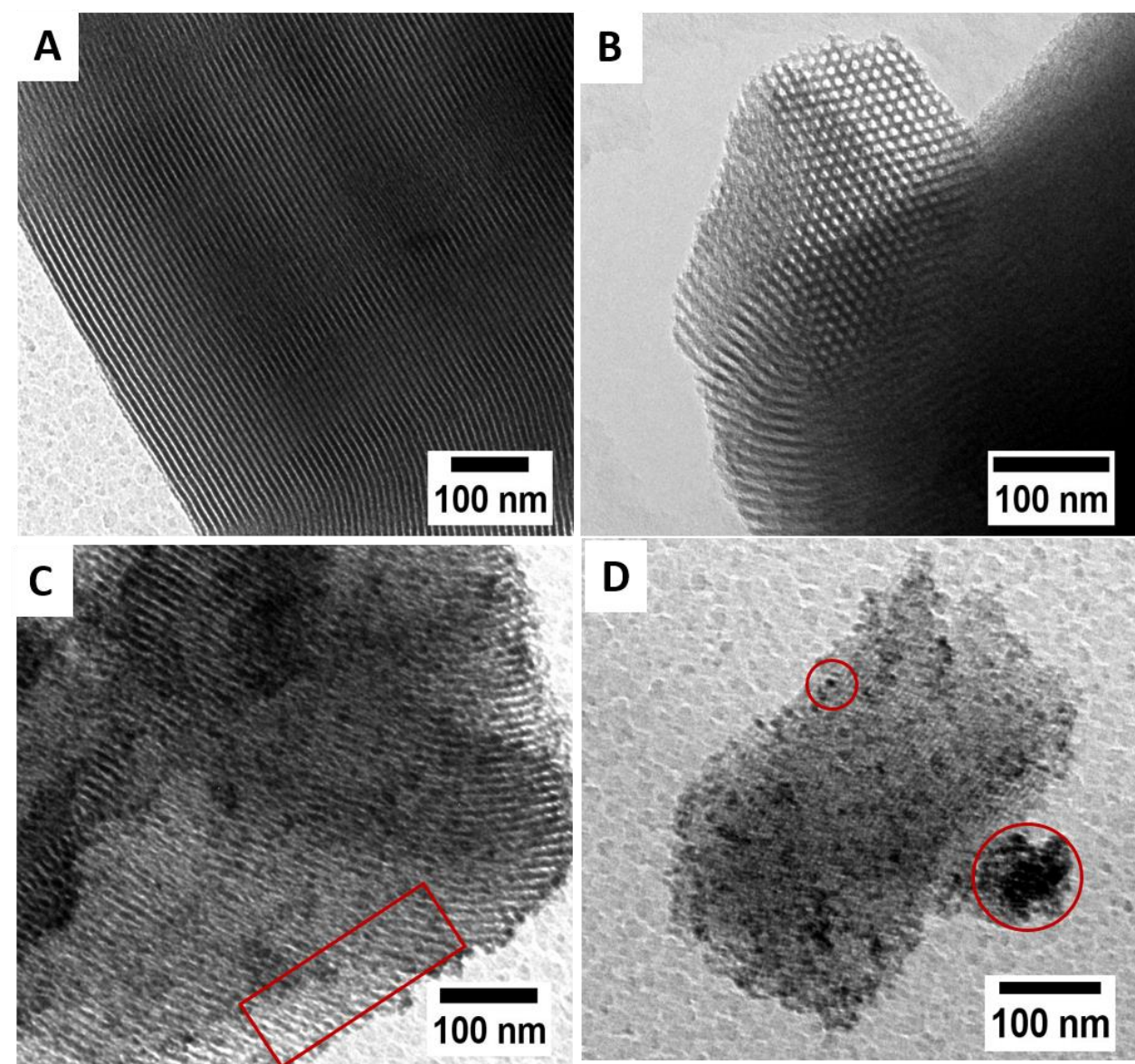
Figura 1.30 Imagens de miscroscopia eletrônica de transmissão de alta resolução (HRTEM) das amostras SBA15 (lote 2) (A e B); $10 \% \mathrm{TiO}_{2} / \mathrm{SBA}-15$ (C e D) 20\% $\mathrm{TiO}_{2} / \mathrm{SBA}-15$ (E e F) e $30 \% \mathrm{TiO}_{2} / \mathrm{SBA}-15$ (G e H).
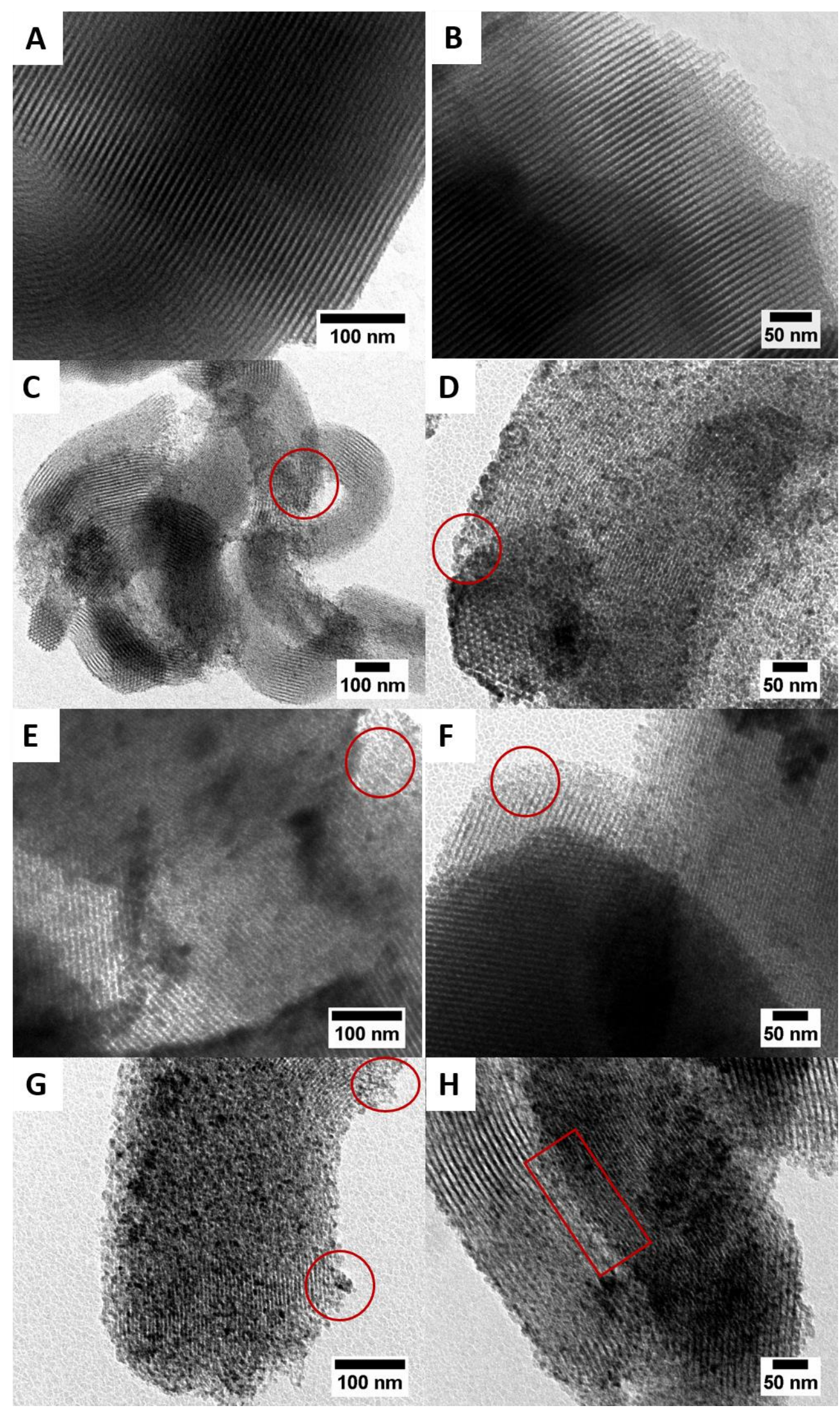


\subsection{Caracterização da Estrutura Mesoporosa dos Materiais TiO2/SBA-15}

As técnicas mais importantes para a caracterização estrutural das sílicas mesoporosas são espalhamento de raios-X a baixo ângulo (SAXS) e isotermas de adsorção de $\mathrm{N}_{2}$ (BET), juntamente com a microscopia eletrônica de transmissão eletrônica (TEM). Tais análises podem provar que o material obtido possui a simetria hexagonal esperada.

A análise de adsorção de $\mathrm{N}_{2}$ é uma técnica amplamente utilizada para a caracterização de sólidos porosos, fornecendo parâmetros como área superficial, volume de poros e distribuição de tamanho de poros. Os principais fundamentos teóricos desta técnica estão descritos no Anexo 2 do presente trabalho.

As SBA-15 originais foram preparadas em dois lotes distintos, sendo a principal diferença entre eles o método de extração do surfactante utilizado. A extração do surfactante no lote 1 deu-se por calcinação, já o surfactante da SBA-15 do lote 2 foi extraído por etanol no sistema Soxhlet. Ambas as isotermas de adsorção/dessorção de $\mathrm{N}_{2}$ são mostradas na Figura 1.31A, em que nota que são do tipo IV com histereses do tipo A, ou seja, os substratos (SBA15) utilizados para funcionalização com $\mathrm{TiO}_{2}$ são mesoporosos com poros de formato cilíndrico (vide classificação no Anexo 2), o que condiz com a formação dos materiais hexagonais a partir de micelas de Pluronic (BECK et al., 1992). Contudo, a diferença no formato das isotermas e na distribuição de tamanho de poros (Figura 1.31B) de ambas as amostras mostram a influência estrutural da sílica resultante dos diferentes procedimentos de extração de surfactante utilizados.

Em baixas pressões relativas $\left(P / P_{0}<0,3\right)$, em que ocorre a etapa da formação da monocamada de $\mathrm{N}_{2}$, a isoterma do primeiro lote adsorveu maior volume de gás, indicando que o valor de área superficial específica é maior que a SBA-15 do lote 2 (mostrados na Tabela 1.5). Após esta etapa, a SBA-15 (lote 1$)$ atingiu a saturação $\left(P / P_{0} \approx 1\right)$ em menor volume de $\mathrm{N}_{2}$, indicando que esse material possui menor volume de poros e apresentou histerese de adsorção em menores pressões relativas $\left(P / P_{0}\right)$ quando comparada com a SBA-15 (lote 2), indicando menor tamanho de poros. De fato, a média da distribuição de tamanho de poros foi de 5,2 nm, enquanto a SBA-15 lote 2 apresentou distribuição com tamanho médio de poros igual a $6,3 \mathrm{~nm}$ (Figura 1.31B). O estreitamento no tamanho dos poros devido à extração do surfactante é característico da retirada das micelas orgânicas de Pluronic com altas temperaturas $\left(\sim 500{ }^{\circ} \mathrm{C}\right)$ e já foi mencionado em alguns trabalhos (KRUK et al., 2000; ZHANG et al., 2013; ZHAO et al., 1998). 
Figura 1.31 (A) Isotermas de adsorção de $\mathrm{N}_{2}$ e (B) distribuição do tamanho de poros (BJH) das SBA-15 originais pertencentes ao lote $1(-\bullet)$ e lote $2(-\mathbf{-})$ ). Os símbolos vazios representam a etapa de dessorção de $\mathrm{N}_{2}$.
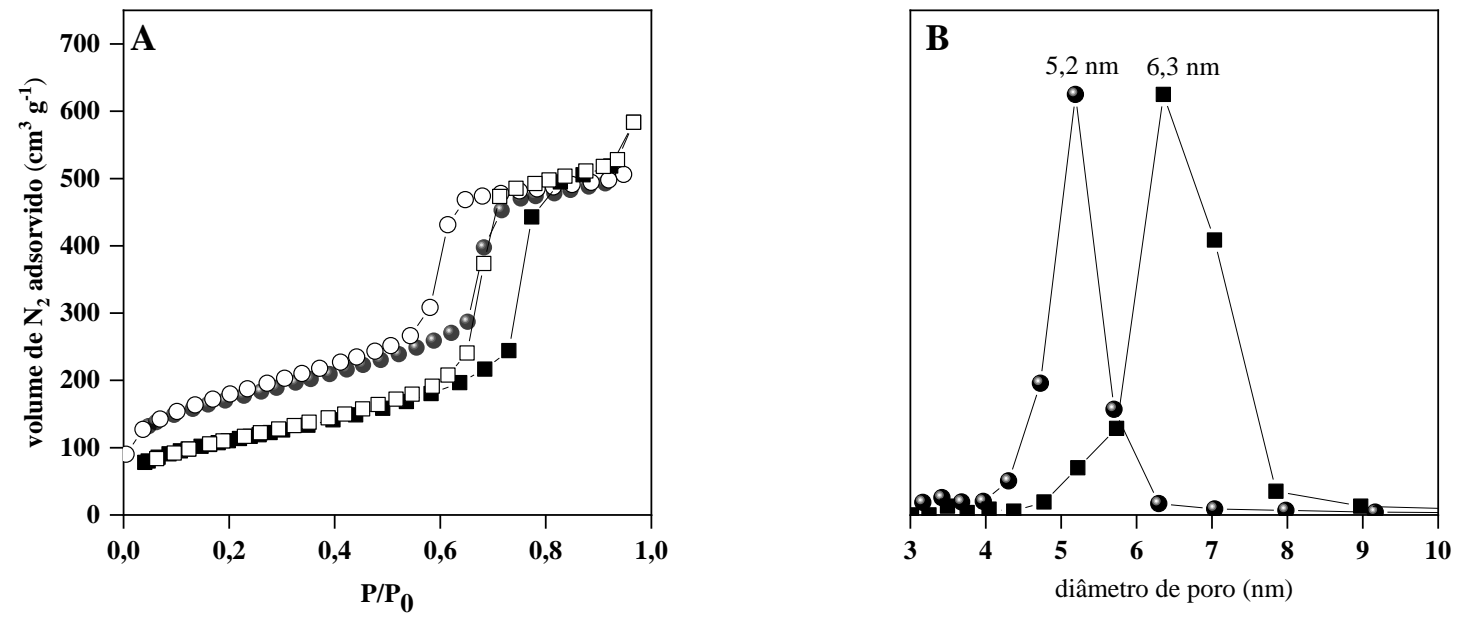

As isotermas de adsorção de $\mathrm{N}_{2}$ das SBA-15 (lote 1) funcionalizadas com $16 \%$ de $\mathrm{TiO}_{2}$ (16\% $\left.\mathrm{TiO}_{2} / \mathrm{SBA}-15\right)$ são mostradas na Figura 1.32A. É possível observar que houve adsorção de menor volume de $\mathrm{N}_{2}$ em pressões de equilíbrio próximas à saturação $\left(P / P_{0} \approx 1\right)$ quando a amostra passa pelo processo de funcionalização e de calcinação a $700{ }^{\circ} \mathrm{C}$, indicando redução no volume de poros devido à formação de cristais aglomerados de $\mathrm{TiO}_{2}$, o que foi confirmado através dos parâmetros obtidos por esta análise (Tabela 1.5).

A isoterma do material $16 \% \mathrm{TiO}_{2} / \mathrm{SBA}-15$ apresenta histerese acentuadamente disforme quando comparada à da sílica original SBA-15 (lote 1). A posição desta inflexão se encontra na faixa de 0,6-0,4 de $P / P_{0}$. De acordo com Busuioc e colaboradores (BUSUIOC et al., 2006), este efeito pode ser atribuído ao bloqueio nos mesoporos da sílica pelo $\mathrm{TiO}_{2}$, originando dessorção do $\mathrm{N}_{2}$ líquido em duas etapas. A primeira parte da dessorção é semelhante à exibida pela SBA-15 pura e é atribuída à dessorção em poros abertos. A segunda parte se deve à formação de nanopartículas (plugs) de $\mathrm{TiO}_{2}$ no interior dos mesoporos. Estes mesoporos podem se tornar mais estreitos ou até bloqueados, dando origem a uma região mesoporosa menor, que pode ser vista na distribuição de tamanho de poros: aparecimento de uma região em 3,5 nm pelo cálculo BJH (Figura 1.32B). Neste caso, a formação de microporosidade e mesoporosidade combinadas pode ser muito benéfica para aplicações deste material em fotocatálise, devido à influência na adsorção e na difusão de moléculas nestes poros menores. Portanto, nestas amostras, as partículas de $\mathrm{TiO}_{2}$ podem estar alocados internamente nos mesoporos da sílica. 
Figura 1.32 (A) Isotermas de adsorção de $\mathrm{N}_{2} \mathrm{e}$ (B) distribuição do tamanho de poros (BJH) das amostras (一- - ) SBA-15 (lote 1) e (一-—) 16\% $\mathrm{TiO}_{2} / \mathrm{SBA}-15$. Os símbolos vazios representam a etapa de dessorção de $\mathrm{N}_{2}$.
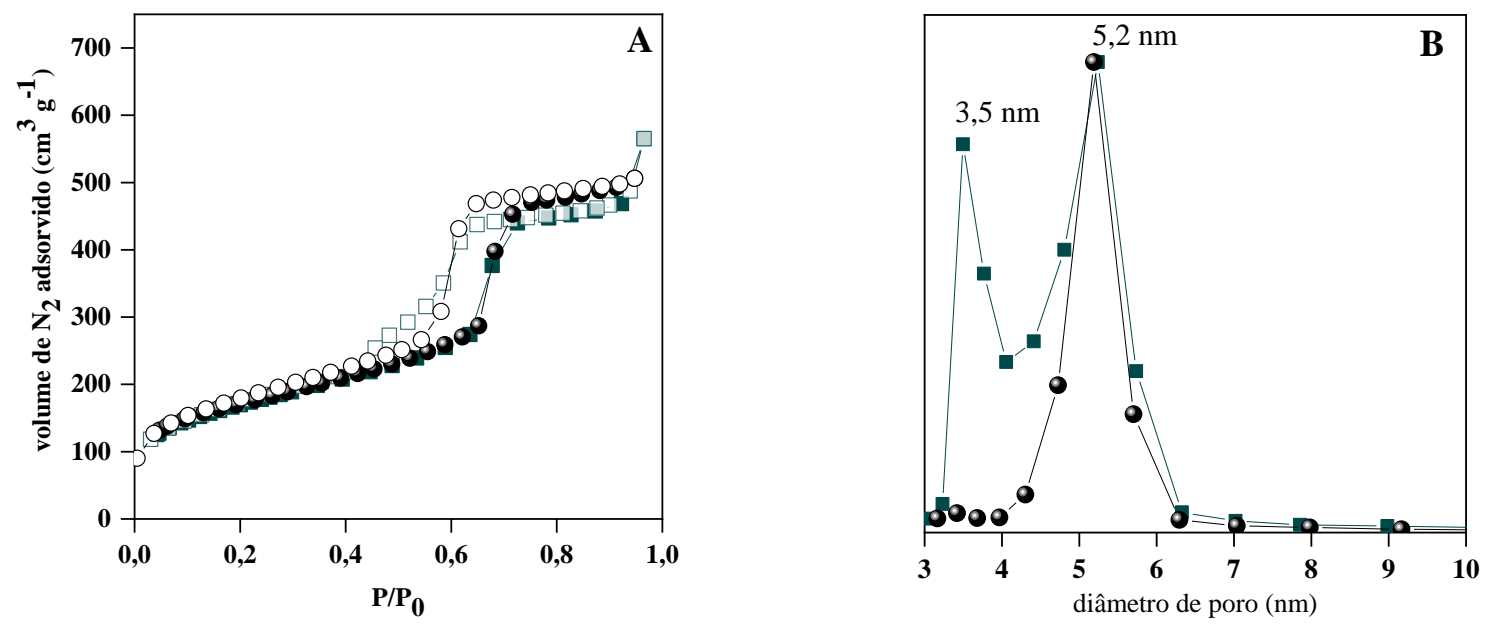

As isotermas de adsorção de $\mathrm{N}_{2}$ obtidas através da funcionalização da SBA-15 (lote 2) com 10\%, 20\% e 30\% de $\mathrm{TiO}_{2}$ são mostradas na Figura 1.33, sendo possível notar neste caso que os cristais de $\mathrm{TiO}_{2}$ não afetaram grandemente a estrutura da SBA-15, pois não se observam mudanças significativas nos formatos das histereses, tendo ocorrido apenas um leve aumento no volume de $\mathrm{N}_{2}$ adsorvido devido à presença do $\mathrm{TiO}_{2}$, indicando um pequeno aumento na área superficial específica e volume de poros. Este resultado pode ser devido à retirada de água localizada nos interstícios da sílica na etapa de calcinação a $700{ }^{\circ} \mathrm{C}$ do xerogel formado entre o $\mathrm{TiO}_{2}$ e a SBA-15. A distribuição de tamanho de poros também não sofreu grande influência devido ao $\mathrm{TiO}_{2}$ (Figura 1.33B). Estes resultados podem ser indicativos de que o $\mathrm{TiO}_{2}$ ficou aglomerado na superfície externa dos poros destes materiais. 
Figura 1.33 (A) Isotermas de adsorção de $\mathrm{N}_{2}$ e (B) distribuição do tamanho de poros (BJH) das amostras (-0-)

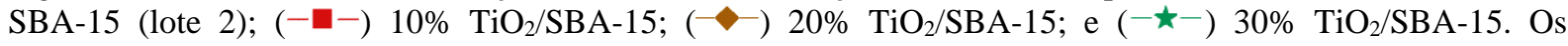
símbolos vazios representam a etapa de dessorção de $\mathrm{N}_{2}$.
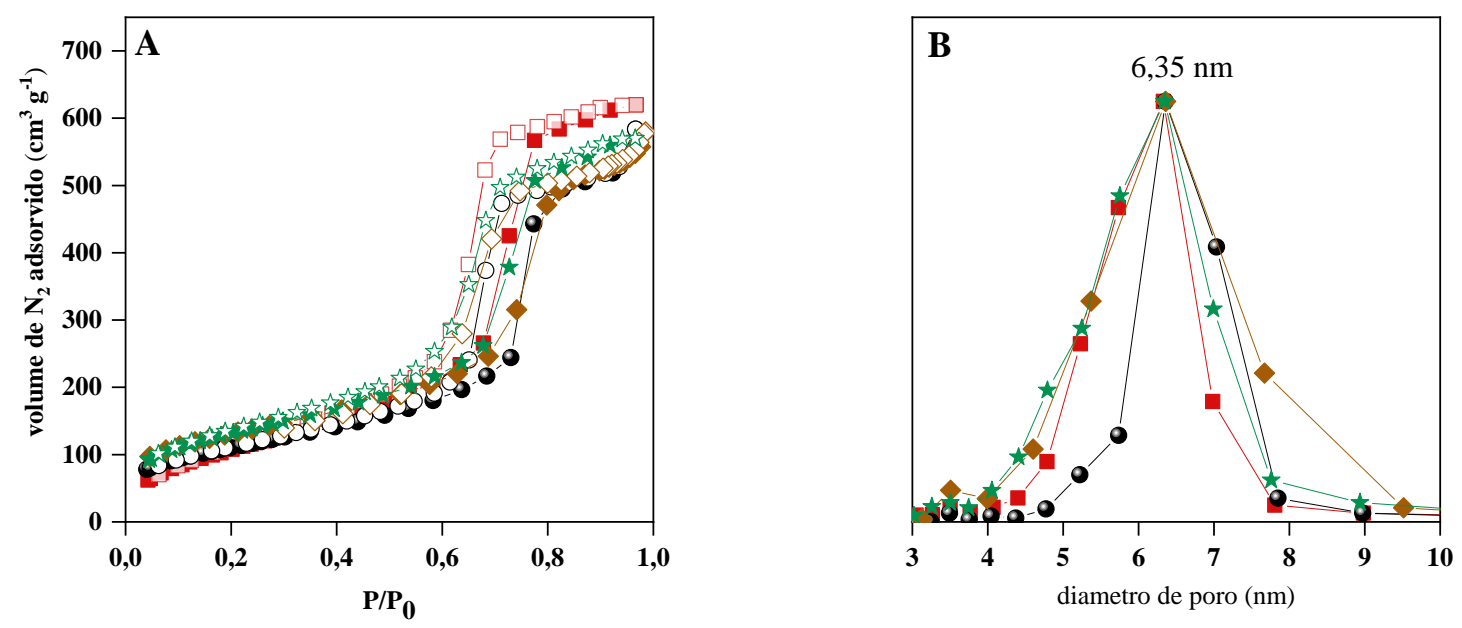

Os parâmetros obtidos através desta técnica são mostrados na Tabela 1.5, na qual é possível notar que a área superficial (BET) aumenta para as amostras contendo $\mathrm{TiO}_{2}$ quando comparadas com a sílica original SBA-15, resultado que pode ser devido ao método póssíntese sol-gel utilizado para a funcionalização da sílica. As espécies de titânio podem reagir com as hidroxilas presentes nas paredes da sílica de forma aleatória, assim as partículas são formadas dentro dos canais dos mesoporos; no entanto, outras são excluídas da entrada dos poros e começam a crescer fora dos mesoporos, aglomerando-se na superfície da sílica, o que pode resultar no aumento da área superficial do material $\mathrm{TiO}_{2} / \mathrm{SBA}-15$.

Também se nota que ocorreu uma leve diminuição no volume de poros ao se adicionar $\mathrm{TiO}_{2}$ na SBA-15. Este efeito pode ser atribuído ao colapso de alguns mesoporos da SBA-15 original devido ao tratamento térmico dos xerogéis, ocorrendo a densificação e o aumento da cristalinidade das partículas metálicas (HENCH; WEST, 1990). 
Tabela 1.5 Parâmetros obtidos pelas análises de SAXS e isotermas de adsorção de $\mathrm{N}_{2}$ para as amostras SBA-15 pura e $\mathrm{TiO}_{2} / \mathrm{SBA}-15$.

\begin{tabular}{cccccc}
\hline Amostra & $\begin{array}{c}\boldsymbol{a}_{\mathbf{0}} \\
(\mathbf{n m})\end{array}$ & $\begin{array}{c}\boldsymbol{S}_{\mathbf{B E T}} \\
\left(\mathbf{m}^{\mathbf{2}} \mathbf{g}^{\mathbf{- 1}} \mathbf{)}^{\mathbf{a}}\right.\end{array}$ & $\begin{array}{c}\text { Volume de } \\
\text { poro } \\
\left(\mathbf{c m}^{\mathbf{3}} \mathbf{g}^{\mathbf{- 1}}\right)^{\mathbf{b}}\end{array}$ & $\begin{array}{c}\text { Diâmetro de } \\
\text { poro BJH } \\
(\mathbf{n m})^{\mathbf{c}}\end{array}$ & $\begin{array}{c}\text { Espessura } \\
\text { da parede } \boldsymbol{w} \\
(\mathbf{n m})^{\mathbf{d}}\end{array}$ \\
\hline $\mathrm{SBA}-15$ (lote 1) & 10,5 & 594 & 0,87 & 5,2 & 5,3 \\
$16 \% \mathrm{TiO}_{2} / \mathrm{SBA}-15$ & 10,3 & 592 & 0,78 & 5,2 & 5,0 \\
$\mathrm{SBA}-15$ (lote 2) & 11,5 & 400 & 1,00 & 6,3 & 5,2 \\
$10 \% \mathrm{TiO}_{2} / \mathrm{SBA}-15$ & 10,8 & 460 & 0,90 & 6,3 & 4,5 \\
$20 \% \mathrm{TiO}_{2} / \mathrm{SBA}-15$ & 10,8 & 460 & 0,90 & 6,3 & 4,5 \\
$30 \% \mathrm{TiO}_{2} / \mathrm{SBA}-15$ & 10,8 & 473 & 0,90 & 6,3 & 4,5 \\
\hline
\end{tabular}

a Área superficial calculada pelo método de Brunauer, Emmett e Teller (BET).

${ }^{\mathrm{b}}$ Calculados em $P / P_{0} \approx 0,97$.

c:Calculado pelo método de Barret, Joyner and Halenda (BJH).

${ }^{\mathrm{d}}$ Calculada através da subtração do parâmetro de arranjo hexagonal $\left(a_{0}\right)$ do diâmetro de poro obtido pelo método de cálculo BJH.

As estruturas das sílicas mesoporosas não possuem cristalinidade a nível atômico, ou seja, as reflexões não podem ser observadas nitidamente em ângulos maiores como os de difração de raios-X (DRX). Isto porque a extensão da periodicidade da estrutura ordenada, da qual se origina o arranjo de poros, é inversamente proporcional ao ângulo de Bragg (Equação 1.8) referente ao plano cristalino principal. Por este motivo, é necessário usar a técnica de raios-X a baixos ângulos (do inglês, Small Angle X-Ray Scattering SAXS), associada a medidas de ângulos de espalhamento de raios-X em torno de $0,1^{\circ}$ a $10^{\circ}$.

Os espalhamentos de SAXS das amostras SBA-15 e $\mathrm{TiO}_{2} / \mathrm{SBA}-15$ (lote 1 e lote 2) são apresentados em escala logarítmica na Figura 1.34 e comprovam a formação da mesofase hexagonal 2-D e grupo espacial p6mm, característicos da sílica mesoporosa SBA-15 (BECK et al., 1992). Após a funcionalização dos materiais com o semicondutor $\mathrm{TiO}_{2}$ e calcinação a $700{ }^{\circ} \mathrm{C}$, a estrutura mesoporosa se manteve, ou seja, os materiais obtidos apresentam grande estabilidade térmica.

Na Figura 1.34A é possível observar a presença de quatro picos que correspondem a quatro planos cristalinos (100), (110), (200) e (300), caraterísticos de materiais mesoporosos (BECK et al., 1992) para a amostra SBA-15 (lote 1) e a amostra com 16\% de $\mathrm{TiO}_{2}$. A amostra SBA-15 (lote 2) e as funcionalizadas com 10\%, 20\% e 30\% de $\mathrm{TiO}_{2}$ apresentaram espalhamentos pertencentes a cinco planos cristalinos (100), (110), (200), (210) e (300), mostrando maior organização da mesofase (Figura 1.34B). 
Figura 1.34 SAXS em escala logarítmica das amostras (A) SBA-15 (lote 1) e $16 \% \mathrm{TiO}_{2} / \mathrm{SBA}-15$ e (B) SBA-15 (lote 2); $10 \% \mathrm{TiO}_{2} / \mathrm{SBA}-15 ; 20 \% \mathrm{TiO}_{2} / \mathrm{SBA}-15 ; 30 \% \mathrm{TiO}_{2} / \mathrm{SBA}-15$.
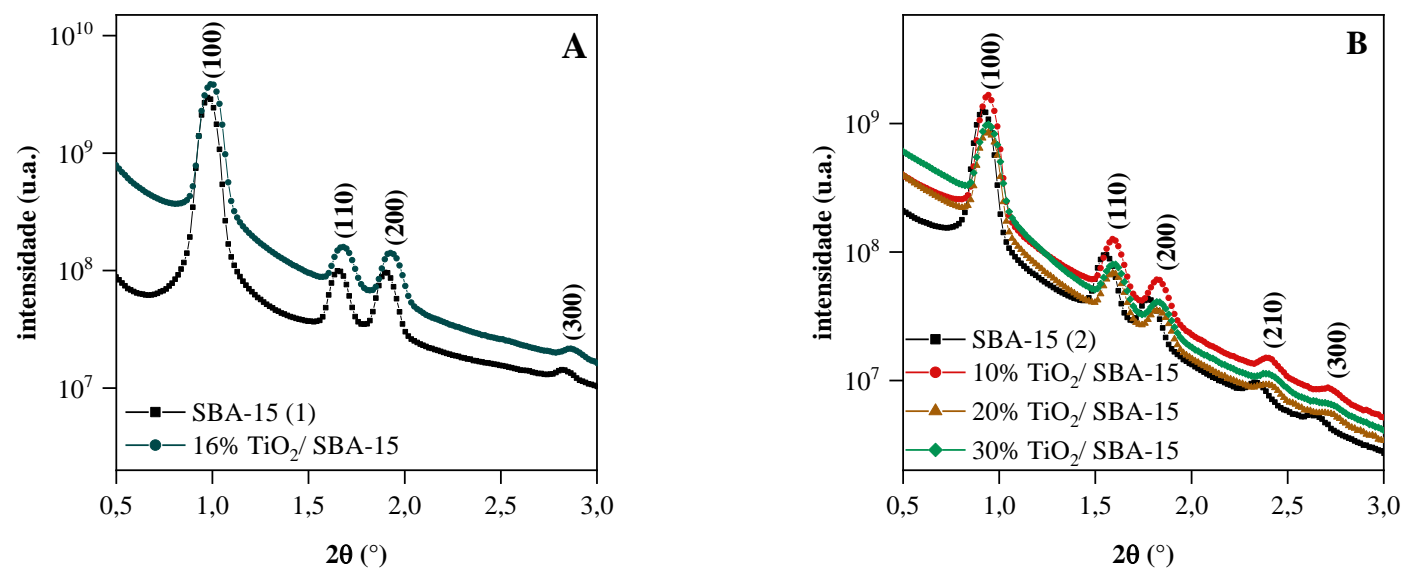

Nesta análise, o espaçamento relacionado ao pico principal $\left(d_{100}\right)$ pode ser obtido com o auxílio da lei de Bragg:

$$
n \lambda_{C u K \alpha}=2 d_{h k l} \operatorname{sen} \theta
$$

Em que $n=1,2,3 \ldots ; \lambda_{C u K \alpha}$ é o comprimento de onda da radiação de raios-X $(C u K \alpha=$ 1,54 Å); $\theta$ é o ângulo de Bragg no pico de maior intensidade e $d_{h k l}$ é o espaçamento interplanar entre os planos que causam interferência construtiva ( $h k l$ são índices de Miller).

De acordo com esta lei a distância respectiva do pico $d(100)$ é inversamente proporcional aos ângulos de difração, ou seja, quanto maior for $d(100)$ menor será o angulo obtido. No caso de materiais mesoporosos, as distâncias $d(100)$ são tipicamente grandes (maiores que $2 \mathrm{~nm}$ ), originando baixos ângulos de difração (menores que $5^{\circ}$ ).

O parâmetro hexagonal $a_{0}$ é corresponde à distância entre os centros de dois poros adjacentes (Figura 1.35) e pode ser obtido de acordo com a Equação 1.6:

$$
a_{0}=\frac{2 d_{100}}{\sqrt{3}}
$$

Consequentemente, a espessura da parede de poro (wt) das amostras pode ser facilmente calculada através da subtração do parâmetro de arranjo hexagonal $\left(a_{0}\right)$ do diâmetro de poro obtido pelo método de cálculo BJH pelas isotermas de adsorção de $\mathrm{N}_{2}$. Esta correlação entre os dois parâmetros pode ser observada na Figura 1.35. 
Figura 1.35 Diagrama da estrutura das sílicas mesoporosas, em que $d(100)$ é a distância interplanar no plano (100), w é a espessura de parede da sílica e a 0 , o parâmetro de rede mesoporosa.

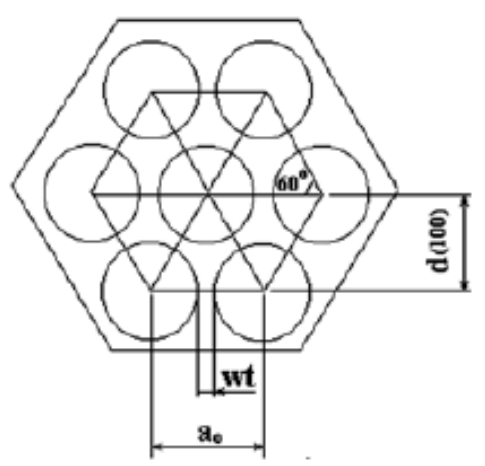

Fonte: (CASTRO et al., 2007).

Na Tabela 1.5 é possível observar que as paredes dos poros ficaram menos espessas com a presença das partículas de $\mathrm{TiO}_{2}$, resultado que se deve à diminuição no parâmetro de rede $\left(a_{0}\right)$; contudo, a distribuição do tamanho de poros se manteve. Esta contração das paredes pode ser devido ao uso de alta temperatura durante o tratamento térmico $\left(700{ }^{\circ} \mathrm{C}\right)$, com saída de água dos interstícios das partículas sólidas (xerogel) para formação do óxido $\mathrm{TiO}_{2}$ sobre a superfície da SBA-15.

\subsection{Propriedades Ópticas dos Materiais $\mathrm{TiO}_{2} / \mathrm{SBA}-15$}

A Figura 1.36 mostra os espectros de refletância difusa UV-visível das amostras $\mathrm{TiO}_{2} / \mathrm{SBA}-15$, que mostram a banda de absorção típica de $\mathrm{TiO}_{2}$, que corresponde a um intervalo de banda de 3,1 eV (YANG et al., 2006). 
Figura 1.36 Espectros de absorção na região do UV-visível das amostras $\mathrm{TiO}_{2} / \mathrm{SBA}-15$.

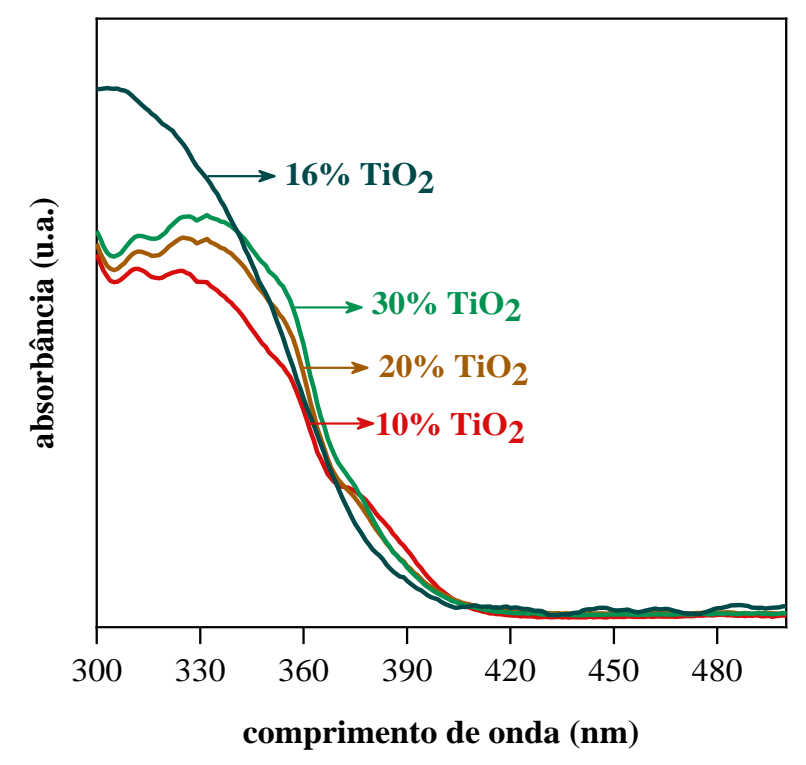

\section{CARACTERIZAÇÃO DOS MATERIAIS PMONDI}

\subsection{Dosagem das NDI}

A dosagem das NDI que estão presentes em cada PMO foi determinada por análise elementar de carbono $(\mathrm{C})$, hidrogênio $(\mathrm{H})$ e nitrogênio $(\mathrm{N})$. A análise elementar de $\mathrm{CHN}$ nas sílicas mesoporosas é um indicativo de que compostos orgânicos estão presentes em suas estruturas, uma vez que as sílicas mesoporosas inorgânicas $\left(\mathrm{SiO}_{2}\right)$ não contém carbono, exceto traços devido a contaminantes ambientais. A Tabela 1.6 mostra as porcentagens obtidas de CHN das amostras de PMONDI antes e após extração do surfactante por Soxhlet. É possível observar significativa diminuição nas porcentagens de carbono e hidrogênio após a extração do surfactante. Este resultado é um indicativo do sucesso da remoção do surfactante nas PMONDI. É importante ressaltar que após a síntese, os filtrados não continham NDI, ou seja, ela foi inteiramente incorporada nos materiais. 
Tabela 1.6 Porcentagens mássicas de carbono $(\mathrm{C})$, hidrogênio $(\mathrm{H})$ e nitrogênio $(\mathrm{N})$ de cada PMONDI sintetizada, obtidas pela analise elementar.

\begin{tabular}{lccc}
\hline \multirow{2}{*}{ Amostra } & & \multicolumn{2}{c}{ Analise Elementar $(\mathbf{C H N})^{\mathbf{a}}$} \\
\cline { 3 - 4 } & & Com surfactante & Surfactante extraído por Soxhlet \\
\hline \multirow{2}{*}{ PMONDI-8 } & $\mathrm{C}$ & $27,2 \%$ & $5,7 \%$ \\
& $\mathrm{H}$ & $4,2 \%$ & $1,7 \%$ \\
& $\mathrm{~N}$ & $0,2 \%$ & $0,45 \%$ \\
\hline \multirow{2}{*}{ PMONDI-16 } & $\mathrm{C}$ & & $11,4 \%$ \\
& $\mathrm{H}$ & $\mathrm{b}$ & $2,6 \%$ \\
& $\mathrm{~N}$ & & $1,2 \%$ \\
\hline
\end{tabular}

${ }^{\text {a }}$ Média de duas análises.

${ }^{\mathrm{b}}$ Amostra perdida.

Figura 1.37 Estrutura, fórmula molecular e massas molar de TESP-NDI condensada presente nas paredes dos poros das PMONDI.

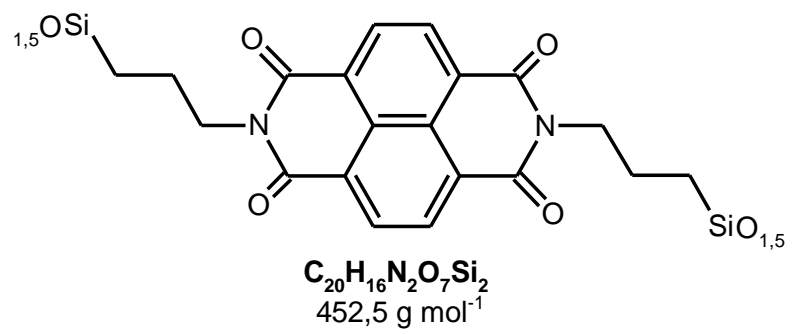

A porcentagem mássica de NDI presentes (obtidas) nas amostras de PMONDI em relação a quantidade de inorgânico $\left(\mathrm{SiO}_{2}\right)$ foi determinada através das análises elementares utilizando como base a porcentagem do elemento carbono (Tabela 1.6). Para estes cálculos, foi utilizada a fórmula e massa molecular da NDI após a etapa de condensação (Figura 1.37). A PMONDI-8 foi assim nomeada, pois se obtiveram 8,3\% em massa de NDI, acima do esperado $(7,7 \%)$ para esta amostra. Este resultado pode ser devido a algum erro na diluição na hora de registrar o espectro no UV-visível. Na amostra PMONDI-16, foi possível encontrar o valor de quantidade em massa de NDI bem próximo ao teórico, ou seja, 16\%. Por este motivo, esta amostra foi nomeada PMONDI-16 (Tabela 1.7). 
Tabela 1.7 Quantidades dos precursores inorgânicos e orgânicos utilizados na síntese das PMONDI.

\begin{tabular}{|c|c|c|c|c|c|}
\hline \multirow{2}{*}{ Amostra } & \multirow{2}{*}{$\begin{array}{c}\text { TESP-NDI } \\
(\mathrm{mmol})^{\mathrm{a}}\end{array}$} & \multirow{2}{*}{$\begin{array}{l}\text { TEOS } \\
\text { (mmol) }\end{array}$} & \multicolumn{2}{|c|}{ NDI adicionada } & \multirow{2}{*}{$\begin{array}{c}\text { NDI obtida } \\
\% \text { massa }^{c}\end{array}$} \\
\hline & & & $\% \mathrm{~mol}$ & $\%$ massa $^{b}$ & \\
\hline PMONDI-8 & 0,45 & 41 & $1,1 \%$ & $7,7 \%$ & $8,3 \%$ \\
\hline PMONDI-16 & 1,30 & 41 & $3,1 \%$ & $19,4 \%$ & $16,5 \%$ \\
\hline
\end{tabular}

\subsection{Caracterização por Espectroscopia na Região do Infravermelho das NDI Presentes nas PMONDI}

A característica mais importante no espectro de infravermelho das imidas aromáticas são as bandas intensas devido aos estiramentos simétricos e assimétricos das carbonilas do grupamento imida. No caso da NDI, que é uma imida com anéis de seis membros, são observadas duas bandas características na região de 1600 e $1700 \mathrm{~cm}^{-1}$ (TRINDADE; REY; BROCHSZTAIN, 2012). Nos espectros presentes na Figura 1.38 essas bandas, 1706 e 1664 $\mathrm{cm}^{-1}$ (marcadas com asterisco), aparecem sobrepostas a uma absorção da estrutura de sílica, pois a banda a $1635 \mathrm{~cm}^{-1}$ se deve à vibração harmônica da rede de $\mathrm{Si}-\mathrm{O}$ em menores frequências. Contudo, as bandas da imida se tornam mais proeminentes à medida que se aumenta a carga de NDI (Figura 1.38).

Além das bandas do grupo carbonila, as bandas claramente observadas em 1584, 1460, 1383 e $1345 \mathrm{~cm}^{-1}$ correspondem a um modo de estiramento do anel aromático da imida NDI. As bandas intensas observadas entre 830 a $1110 \mathrm{~cm}^{-1}$ são vibrações de deformações axiais da rede $\mathrm{Si}-\mathrm{O}$. 
Figura 1.38 Espectros de infravermelho (FTIR) das amostras PMONDI-8 e PMONDI-16.

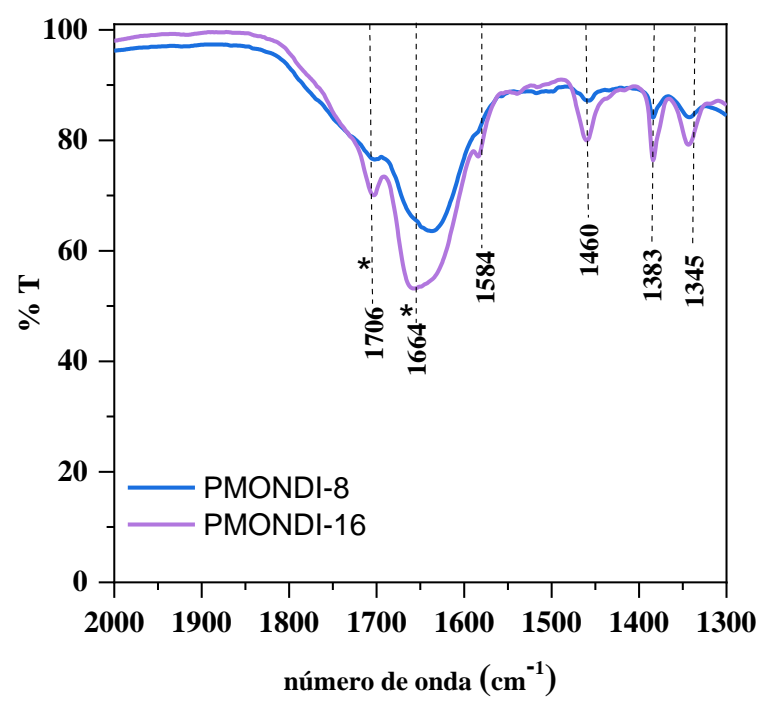

\subsection{Caracterizações por Espectroscopia de Ressonância Magnética Nuclear (RMN) no} Estado Líquido $\left({ }^{13} \mathrm{C}\right.$ e $\left.{ }^{1} \mathrm{H}\right)$ e no Estado Sólido $\left({ }^{13} \mathrm{C}\right.$ e $\left.{ }^{29} \mathrm{Si}\right)$

Ao longo dos últimos 50 anos, a espectroscopia de ressonância magnética nuclear (RMN) tornou-se uma técnica fundamental para determinar a estrutura de compostos orgânicos. Porém, para ter sucesso na sua utilização, é necessário compreender os princípios físicos nos quais este método se baseia, por esse motivo, os principais fundamentos teóricos desta técnica se encontram no Anexo 2 do presente trabalho.

$\mathrm{O}$ espectro de RMN de próton $\left({ }^{1} \mathrm{H}\right)$ da amostra do organosilano TESP-NDI (Figura 1.39A), diluída em clorofórmio deuterado $\left(\mathrm{CDCl}_{3}\right)$, foi registrado antes do organosilano ser colocado na síntese das PMONDI e é mostrado na Figura 1.39B. É possível observar no espectro que todos os prótons característicos da molécula de TESP-NDI foram identificados: em maiores frequências $(8,76 \mathrm{ppm})$ aparece um pico que corresponde aos quatro hidrogênios menos blindados pertencentes ao anel aromático imida; em 4,20 ppm aparecem os hidrogênios da ligação $\mathrm{N}-\mathrm{CH}_{2}$ e em 0,76 ppm, menores frequências, aparecem os hidrogênios mais blindados pertencentes a ligação $\mathrm{CH}_{2}-\mathrm{Si}$. Os demais prótons que compõe a molécula TESP-NDI são mostrados na Figura 1.39B. Este resultado é um indicativo do sucesso de síntese deste precursor organosilano TESP-NDI. 
Figura 1.39 (A) Estrutura molecular do precursor organosilano TESP- NDI com os átomos de hidrogênio em destaque (B) Espectro de ${ }^{1} \mathrm{H}-\mathrm{RMN}$ em $\mathrm{CDCl}_{3}$ do TESP-NDI. Os prótons significativos são mostrados em diferentes cores, e relacionados tanto na estrutura molecular quanto no espectro de RMN.

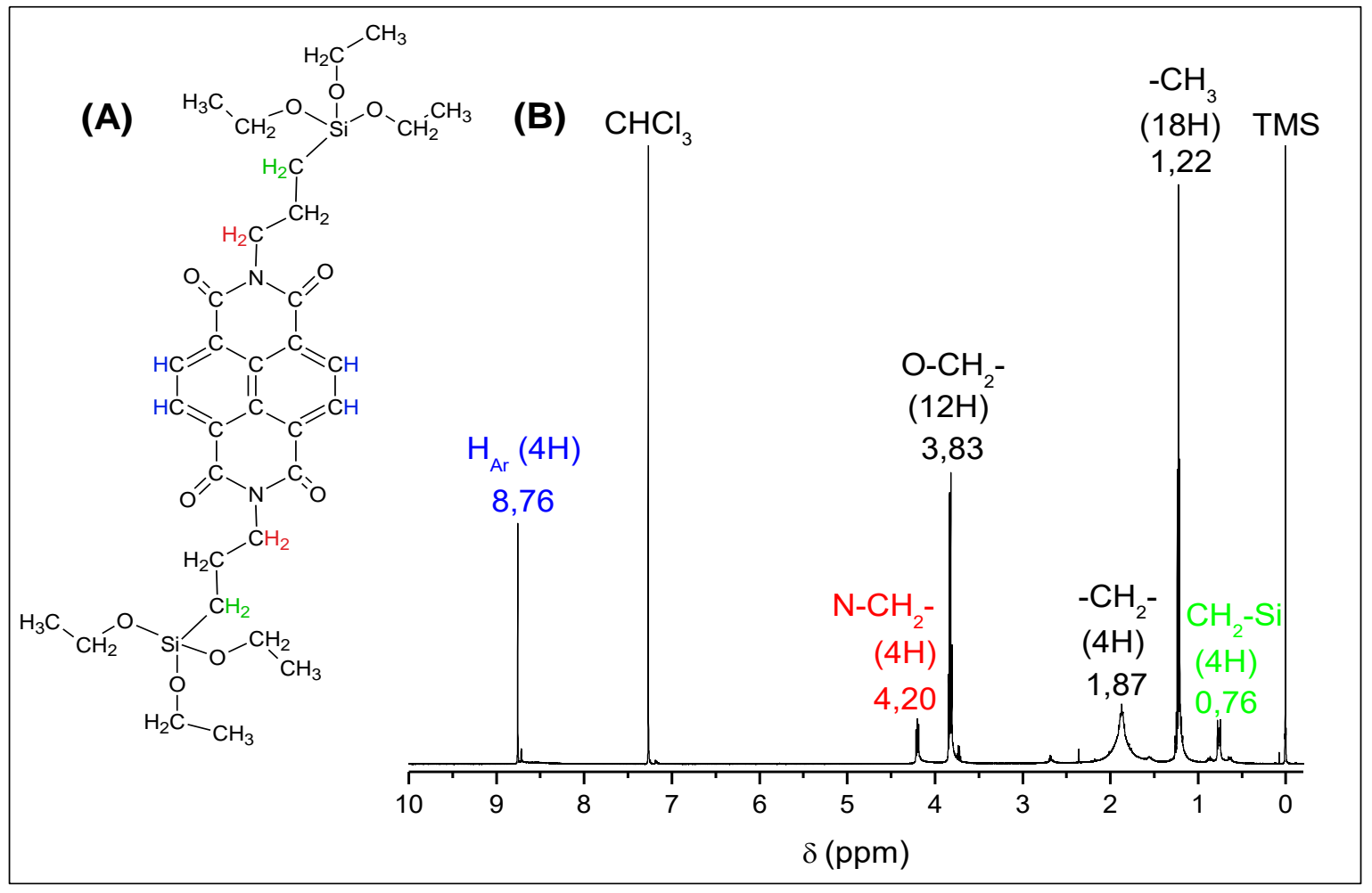

A Figura 1.40A apresenta o espectro de ${ }^{13} \mathrm{C}-\mathrm{RMN}$ da amostra PMONDI-16 no estado sólido comparado ao espectro ${ }^{13} \mathrm{C}-\mathrm{RMN}$ do precursor organosilano TESP-NDI no estado líquido $\left(\mathrm{CDCl}_{3}\right)$ (Figura 1.40B). A amostra PMONDI-16 foi selecionada para esta análise por apresentar maior teor de orgânico (16\% em massa de NDI) em relação às demais.

Na Figura 1.40A é possível notar, em ambas as amostras, um sinal em 163 ppm, referente ao carbono da ligação $\mathrm{C}=\mathrm{O}$ do grupo imida e na região de 131 e 127 ppm os sinais pertencentes aos carbonos do anel aromático em ambas as amostras. As bandas das cadeias propílicas aparecem em 43, 22 e 8 ppm e são referentes aos carbonos $\alpha, \beta$ e $\gamma$ (em relação à carbonila) nas ligações $\mathrm{N}-\mathrm{CH}_{2},-\mathrm{CH}_{2}$ e $\mathrm{CH}_{2}-\mathrm{Si}$, respectivamente (Figura 1.40A,B). Estes resultados corroboram com o resultado obtido nas análises de FTIR, pois indicam que a NDI foi incorporada com sucesso nas PMO, resistindo às condições de síntese.

As bandas que podem ser observadas em 58 e 18 ppm no espectro da amostra PMONDI-16 (marcadas com asterisco) são oriundas do etanol residual da extração do surfactante com o Soxhlet, pois tais bandas são relacionadas aos carbonos dos grupos etoxi. 
Figura 1.40. (A) De baixo para cima: espectro de 13C-NMR da solução de TESP-NDI em $\mathrm{CDCl}_{3}$; espectro de ${ }^{13}$ C-NMR da amostra PMONDI-16 no estado sólido. As bandas marcadas com "p" correspondem aos carbonos da cadeia de propil. (B) estrutura molecular da TESP-NDI mostrando os carbonos $\alpha, \beta$ e $\gamma$ da cadeia propil.

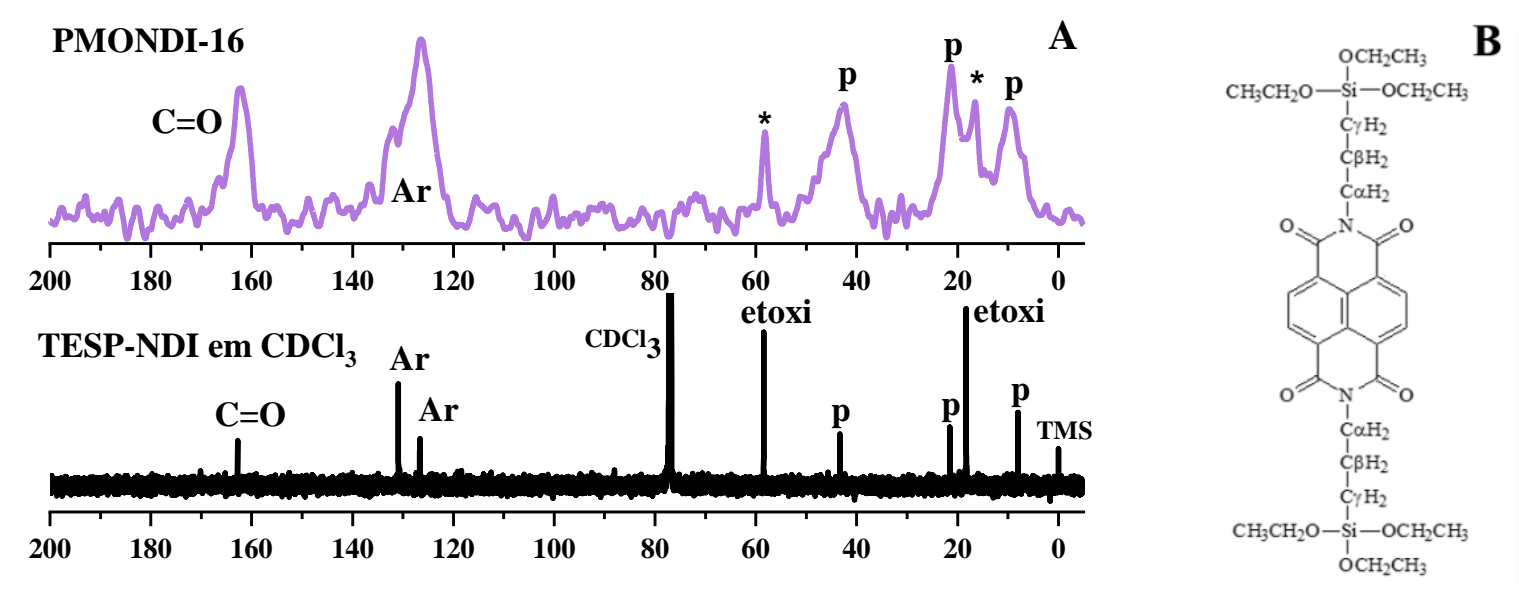

A Figura 1.41 mostra os espectros de ${ }^{29} \mathrm{Si}-\mathrm{RMN}$ das amostras de PMONDI no estado sólido. Os sinais -65 e -60 ppm correspondem às espécies de organo-silício $\mathrm{T}^{3}$ (silício ligado a três unidades oxido-sílica) e $\mathrm{T}^{2}$ (silício ligado a duas unidades oxido-sílica e um grupo hidroxila), respectivamente. No que diz respeito aos silícios inorgânicos, os picos em -110 ppm correspondem a espécies $\mathrm{Q}^{4}$, ou seja, maior grau de polimerização da rede de sílica, enquanto que os ombros em -100 e -90 ppm podem ser atribuídos às espécies $Q^{3}$ (silício ligado a um grupo hidroxila) e $\mathrm{Q}^{2}$ (silício ligado a dois grupos hidroxilas), respectivamente (vide classificação no Anexo 2).

$\mathrm{O}$ aumento na quantidade de espécies de $\mathrm{T}^{\mathrm{n}}$ com o aumento do NDI ocorreu com diminuição das espécies $\mathrm{Q}^{3}$ e $\mathrm{Q}^{2}$ e não de $\mathrm{Q}^{4}$. Como as espécies $\mathrm{Q}^{3}$ e $\mathrm{Q}^{2}$ estão expostas na superfície, em contraste com as espécies $\mathrm{Q}^{4}$, que são inseridas na estrutura da sílica, a maioria dos ligantes NDI pode estar localizada perto da interface parede-poro, que é uma característica desejada para grande parte das aplicações, incluindo fotocatálise. 
Figura 1.41 Espectros de RMN $\left({ }^{29} \mathrm{Si}\right)$ das amostras PMONDI-8 e PMONDI-16 no estado sólido.

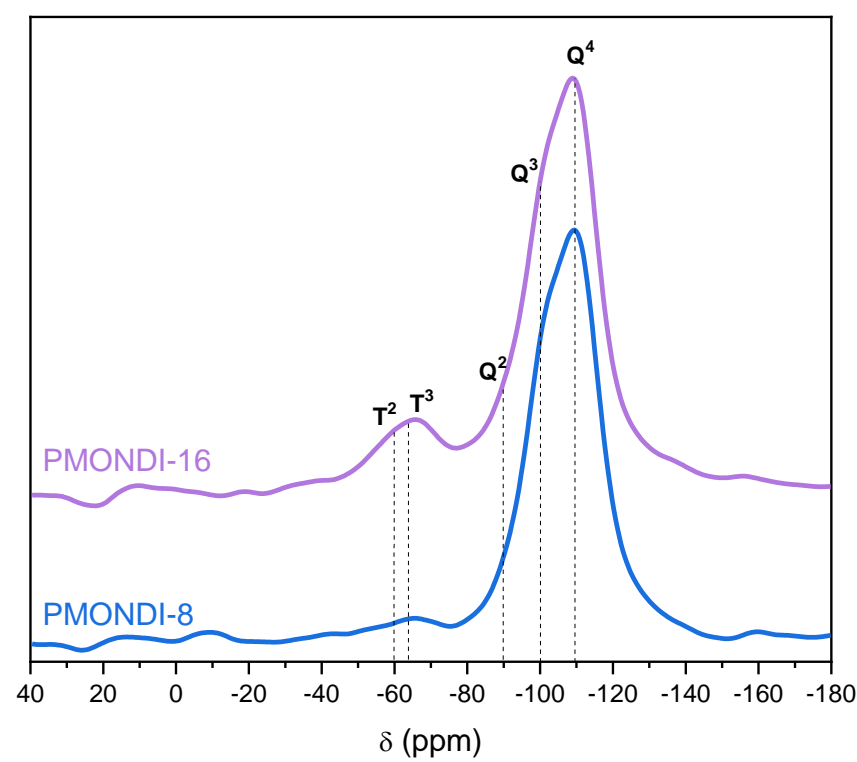

\subsection{Caracterização da Estrutura Mesoporosa das PMONDI}

A Figura 1.42A mostra as isotermas de adsorção/dessorção de $\mathrm{N}_{2}$ das amostras PMONDI-8 e PMONDI-16, juntamente com a sílica inorgânica SBA-15 para melhor comparação. Pode-se notar que, assim como os materiais anteriores, as isotermas são do tipo IV com histereses do tipo A, ou seja, também foram formados os materiais mesoporosos com poros de formato cilíndrico. Nesta figura também é possível observar que houve adsorções de menores volumes de $\mathrm{N}_{2}$ à medida que aumenta a quantidade de NDI nas PMO em pressões de equilíbrio próximas à saturação $\left(P / P_{0} \approx 1\right)$, indicando redução no volume de poros, o que foi confirmado através dos parâmetros obtidos por esta análise (Tabela 1.7).

$\mathrm{Na}$ distribuição de tamanho de poros (Figura 1.42B) obtida pelo método de BJH nas análises de adsorção de $\mathrm{N}_{2}$ é possível notar que a amostra PMONDI-8 possui poros com diâmetro na ordem de $12 \mathrm{~nm}$, enquanto a amostra PMONDI-16 apresentou distribuição um tanto irregular, com diâmetro máximo de $10 \mathrm{~nm}$, equivalente à sílica não funcionalizada SBA15. Estes resultados podem ser um indicativo de que o composto orgânico TESP-NDI se concentrou nas interfaces externas das micelas de Pluronic durante a síntese da PMONDI-8, provocando um aumento no tamanho micelar, atuando como um inchador de poros. 
Figura 1.42 (A) Isotermas de adsorção de $\mathrm{N}_{2}$. (B) distribuição de tamanho de poros determinado pelo método BJH durante a dessorção das amostras PMONDI-8 e PMONDI-16 e da sílica não funcionalizada SBA-15.
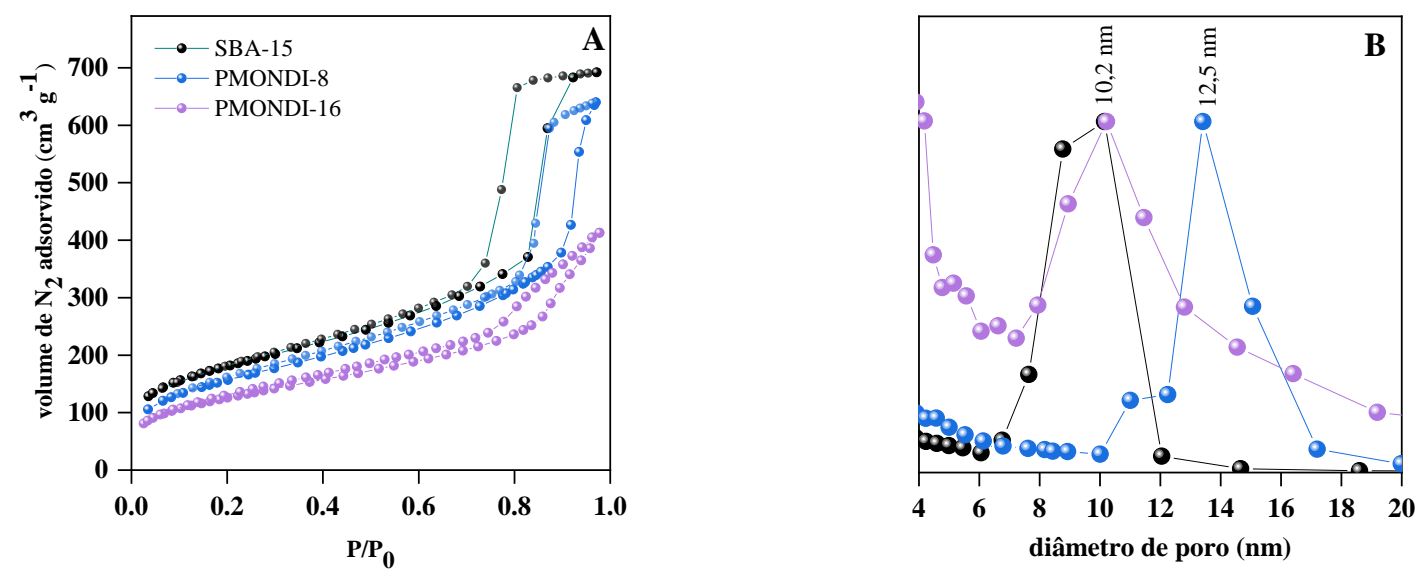

Para complementação da organização hexagonal mesoporosa dos materiais PMODNI e SBA-15, as análises de espalhamento de raios-X a baixo ângulo (SAXS) são apresentadas na Figura 1.43 em escala logarítmica. Os difratogramas obtidos para as amostras SBA-15 pura com surfactante e após a extração do surfactante (Figura 1.43A) indicam cinco planos cristalinos (100), (110), (200), (210) e (300), característicos de sílicas mesoporosas altamente organizadas (ZHAO et al., 1998). É possível observar que ao extrair as micelas do surfactante na SBA-15, os picos se tornam mais intensos, o que é um indicativo de que a extração foi efetiva, uma vez que os espalhamentos são mais intensos quando os mesoporos estão vazios, ou seja, sem as micelas de surfactante.

Outro indicativo da extração de surfactante é o deslocamento dos picos para ângulos

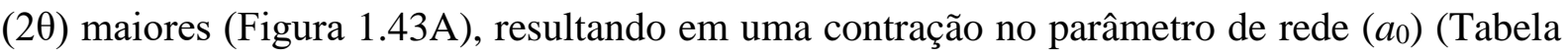
1.7). Esta pequena contração nas paredes de sílica geralmente ocorre devido à extração das micelas de surfactante nos poros de sílica (MELÉNDEZ-ORTIZ et al., 2015).

Na Figura 1.43B é possível observar que a PMONDI-8, material que contém a menor carga orgânica, possui grande organização, uma vez que estão presentes os espalhamentos dos cinco planos cristalográficos como no caso da SBA-15. À medida que o teor de orgânico aumenta nas amostras, os picos dos principais planos (110) e (200) se tornam menos proeminentes e os demais não aparecem. Este resultado é geralmente observado com PMO contendo moléculas orgânicas volumosas. Como exemplo, Wahab e colaboradores (WAHAB; HUSSAIN; HE, 2009) observaram a ausência de picos no SAXS quando a quantidade das 3,4,9,10-perilenodiimidas (PDI) foi de $13 \%$ em massa. Comparando com o resultado obtido por Wahab, as PMO sintetizadas no presente trabalho obtiveram maior nível de organização, 
uma vez que a estrutura permaneceu organizada até na amostra com 16\% em massa de NDI, pois esta apresentou espalhamento do plano (100) (Figura 1.43B).

Figura 1.43 SAXS em escala logarítmica das amostras (A) SBA-15 com e sem surfactante e (B) PMONDI.
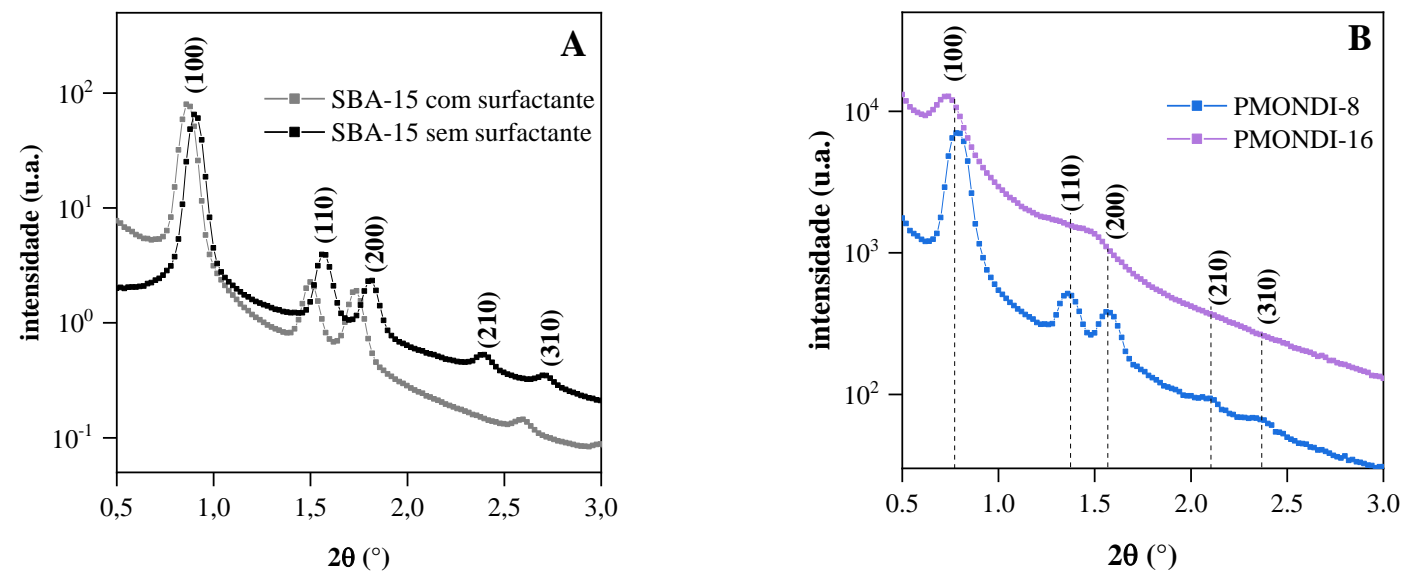

Os dados obtidos através das análises de raios-X e das isotermas de adsorção de $\mathrm{N}_{2}$ e a comparação com a amostra não modificada de SBA-15 estão resumidos na Tabela 1.8. Os parâmetros hexagonais mesoporosos $\left(a_{0}\right)$ aumentam com o aumento no teor de imida NDI. Este resultado pode ser um indicativo de que o precursor TESP-NDI pode ter atuado tanto como fonte de organosílica quanto de agente inchador de poros.

Porém, os tamanhos de poros obtidos a partir da análise BJH parecem estar superestimados para a amostra PMONDI-8, pois os diâmetros dos poros são da mesma ordem que o parâmetro de rede $a_{0}$, de modo que a determinação da espessura parede de poros resultou em valores subestimados (Tabela 1.8). Essa incoerência pode ter sido causada devido à falta de equilíbrio entre o adsorvato e o adsorvente durante as medições das isotermas de adsorção de $\mathrm{N}_{2}$ (CYCHOSZ et al., 2017). Na amostra PMONDI-16 o tamanho de poros diminuiu, enquanto o parâmetro de rede $a_{0}$ aumentou, o que significa que as paredes ficaram mais espessas $(3,8 \mathrm{~nm})$, como esperado para paredes com presença das moléculas de NDI. 
Tabela 1.8 Parâmetros obtidos pelas análises de SAXS e isotermas de adsorção de $\mathrm{N}_{2}$ para as amostras PMONDI.

\begin{tabular}{|c|c|c|c|c|c|c|c|}
\hline Amostra & $2 \theta_{100}$ & $\begin{array}{l}d_{100} \\
(\mathbf{n m})\end{array}$ & $\begin{array}{c}a_{0} \\
(\mathbf{n m})^{\mathrm{a}}\end{array}$ & $\begin{array}{c}S_{\text {BET }} \\
\left(\mathrm{m}^{2} \mathrm{~g}^{-1}\right)^{\mathbf{b}}\end{array}$ & $\begin{array}{c}\text { Volume } \\
\text { de poro } \\
\left(\mathrm{cm}^{3} \mathrm{~g}^{-1}\right)^{\mathrm{c}}\end{array}$ & $\begin{array}{c}\text { Diâmetro } \\
\text { de poro } \\
\text { BJH }(\mathbf{n m})^{d}\end{array}$ & $\begin{array}{c}\text { Espessura } \\
\text { da parede } \\
w(\mathbf{n m})^{\mathrm{e}}\end{array}$ \\
\hline SBA-15 CS & 0,86 & 10,2 & 11,8 & 173 & 0,32 & 5,6 & 6,2 \\
\hline SBA-15 & 0,89 & 9,9 & 11,4 & 631 & 1,07 & 10,2 & 1,2 \\
\hline PMONDI-8 & 0,79 & 11,2 & 12,9 & 562 & 1,08 & 12,6 & 0,3 \\
\hline PMONDI-16 & 0,73 & 12,1 & 14,0 & 441 & 0,64 & 10,2 & 3,8 \\
\hline
\end{tabular}

${ }^{a}$ Determinado através da Equação 1.9.

b Área superficial calculada pelo método de Brunauer, Emmett e Teller (BET).

${ }^{c}$ Calculados em $P / P_{0} \approx 0,97$.

${ }^{\mathrm{d}}$ Calculado pelo método de Barret, Joyner and Halenda (BJH).

${ }^{\text {e }}$ Calculada através da subtração do parâmetro de arranjo hexagonal $\left(a_{0}\right)$ do diâmetro de poro obtido pelo método de cálculo BJH.

${ }^{\mathrm{f}}$ Com surfactante.

Por fim, a ordenação da estrutura mesoporosa das PMO também foi avaliada através de microscopia eletrônica de transmissão (TEM) (Figura 1.44). As PMONDI mostram grande nível de ordenação e são compostas por partículas com formatos que se aproximam a hexágonos (alguns perfeitos) e o comprimento constituído por canais mesoporosos paralelos ao longo do eixo. Na amostra PMONDI-8 a largura das partículas é de aproximadamente 200$400 \mathrm{~nm}$ e cerca de $1,0 \mu \mathrm{m}$ de comprimento.

Contudo, foram obtidas partículas menores, da ordem de $80-150 \mathrm{~nm}$ de largura no material PMONDI-16. É possível notar que a PMONDI-8 mostrou maior grau de ordem em comparação com as demais amostras que possuem maior carga de NDI, estando de acordo com os resultados estruturais obtidos pelos demais métodos (adsorção de $\mathrm{N}_{2}$ e SAXS). 
Figura 1.44 Imagens de microscopia eletrônica de transmissão (TEM) das PMONDI-8 (A, B); PMONDI-16 (C, D).

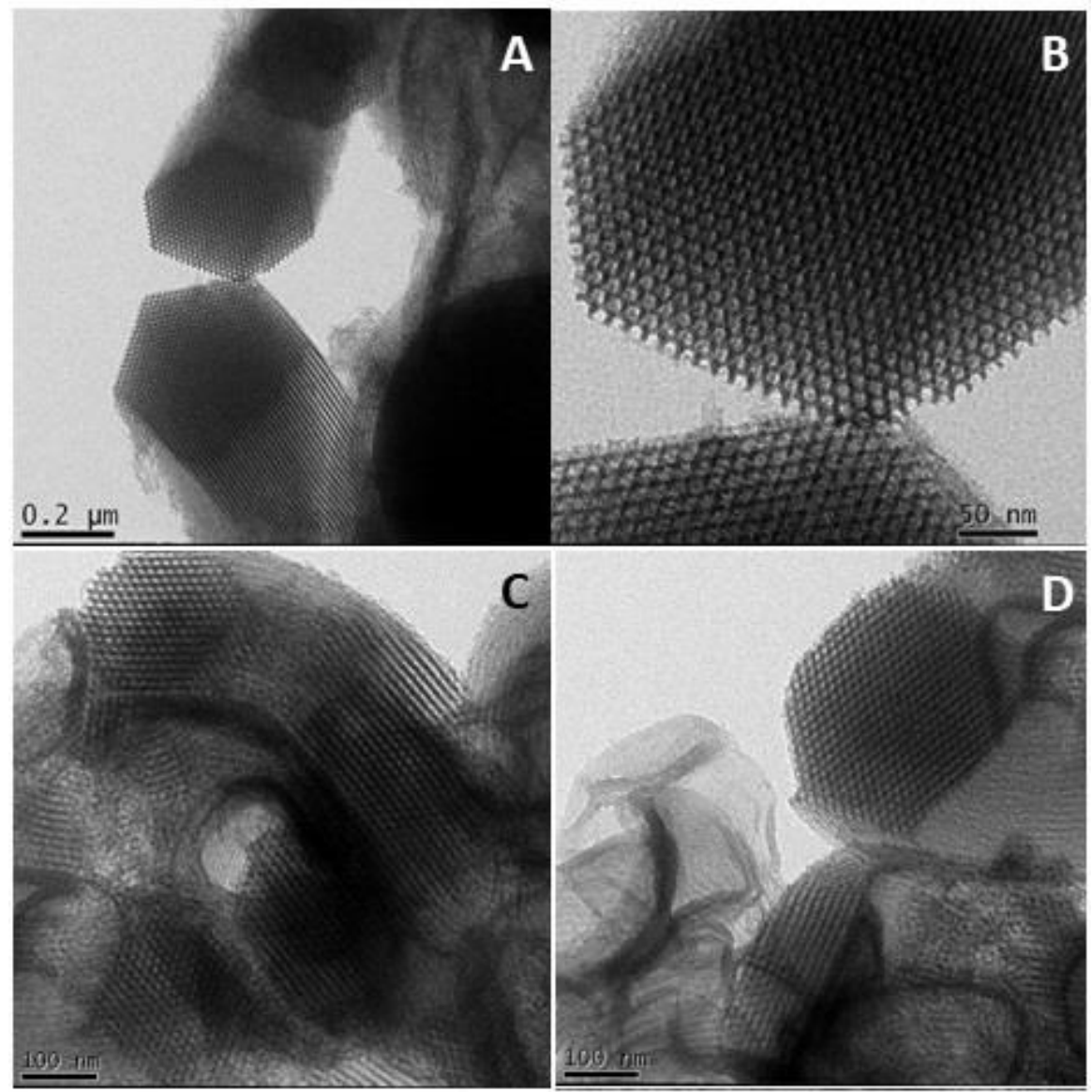

\subsection{Propriedades Ópticas das PMONDI}

Assim como no intermediário organosilano TESP-NDI adicionado à síntese das PMONDI, os espectros de reflectância difusa das amostras sólidas de PMONDI (Figura 1.45) apresentaram a banda de absorção típica dos derivados de NDI, com $\lambda_{\max }=380 \mathrm{~nm}$ (ROGERS; WEISS; KELLY, 2000). Esta banda corresponde à transição eletrônica $0 \rightarrow 0$. A banda vibracional menos intensa aparece em $360 \mathrm{~nm}$ e está relacionada à transição $0 \rightarrow 1$.

Nos espectros de absorção no UV-visível das amostras sólidas de PMONDI (Figura 1.45) é possível observar uma banda larga entre 450-600 nm, que pode ser atribuída à transferência de carga (CT) entre unidades vizinhas de NDI, como usualmente observado em materiais sólidos à base de NDI (BARROS et al., 1997; KOBAISI et al., 2016). 
Figura 1.45 Espectro de refletância difusa convertido em unidades de absorbância das amostras PMONDI. Foi adicionado o espectro de absorção da solução homogênea do intermediário TESP-NDI $\left(0,04 \mathrm{~mol} \mathrm{~L}^{-1} \mathrm{em} \mathrm{CHCl}_{3}\right)$ para comparação.

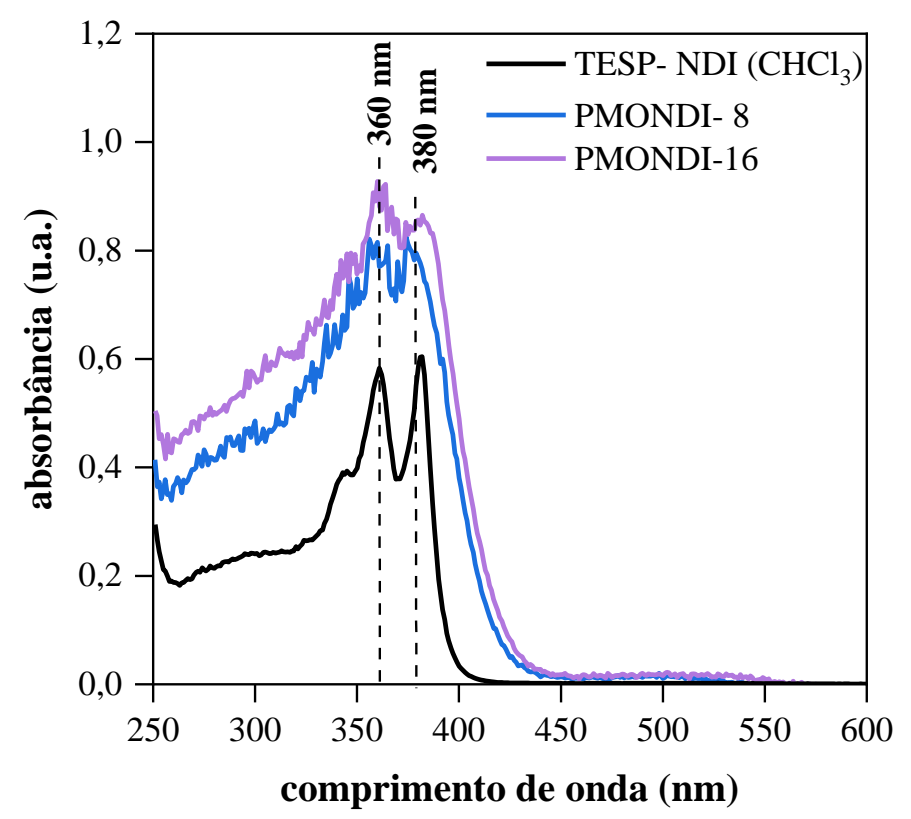

\section{CONCLUSÕES DO CAPÍTULO 1}

No primeiro capítulo desta Tese são apresentados e discutidos resultados que mostram o sucesso na preparação e caracterização dos novos materiais à base de sílicas mesoporosas do tipo SBA-15. Em um primeiro momento prepararam-se $\mathrm{TiO}_{2} / \mathrm{SBA}-15$ e em seguida as PMONDI, ambos por diferentes métodos.

As caracterizações mostraram que estes compostos apresentam características bastante distintas. De fato, como a SBA-15 foi funcionalizada com partículas de $\mathrm{TiO}_{2}$ pelo método pós-síntese, estas se apresentaram localizadas tanto no interior dos poros da sílica, quanto aglomeradas na superfície externa dos poros, formando pequenos aglomerados (“cachos”). Já para as PMONDI, obtidas pelo método de co-condensação, as caracterizações mostraram que as moléculas orgânicas de NDI podem estar tanto inseridas no interior da parede dos poros como próximas à interface parede-poro. É importante ressaltar que em geral ambos os materiais possuem alta organização porosa e elevada área superficial, ideal para aplicação em fotocatálise heterogênea. 


\section{CAPÍtUlO 2 APLICAÇÃO DOS MATERIAIS TiO2/SBA-15 E PMONDI NA FOTOCATÁLISE HETEROGÊNEA PARA DEGRADAÇÃO DE SULFADIAZINA EM REATOR BATELADA}

"So what exactly is this photocatalysis? Let's break it down: "photo" means from the sun, and a catalyst is something that speeds up a reaction. So what photocatalysis is doing is it's just speeding up this solar disinfection process."

Jovem cientista Deepika Kurup em sua palestra (TED talk) de outubro de 2016. Para Deepika, a água é a base da vida, e muitas pessoas ao redor do mundo sofrem de doenças transmitidas através dela. Deepika Kurup está trabalhando para mudar isso.

\section{OBJETIVOS}

O presente capítulo tem como objetivo estudar o desempenho dos materiais preparados e caracterizados, descritos no primeiro capítulo ( $\mathrm{TiO}_{2} / \mathrm{SBA}-15$ e PMONDI) na fotodegradação catalítica de um contaminante de interesse emergente (CEC). Para tanto, foi utilizado um reator batelada e escolhido o contaminante orgânico sulfadiazina, antibiótico de uso humano e veterinário, como contaminante-modelo.

\section{CONTAMINANTES DE INTERESSE EMERGENTE (CEC)}

Contaminantes de interesse emergente (contaminants of emerging concern - CEC), tais como compostos farmacêuticos ativos (PHACs), produtos de higiene pessoal, pesticidas, hormônios sintéticos e naturais e produtos químicos industriais (plastificantes, aditivos alimentares, corantes, entre outros) são continuamente introduzidos no ambiente por diferentes fontes antropogênicas (RIZZO et al., 2019). Com isso, os CEC vêm sendo frequentemente encontrados em águas superficiais como estuários, reservatórios de abastecimento, lagos e rios em concentrações da ordem de $n g \mathrm{~L}^{-1}-\mu \mathrm{g} \mathrm{L}^{-1}$. (TIJANI et al., 2015). No caso de efluentes industriais, podem ser encontrados em concentrações de $\mathrm{mg} \mathrm{L}^{-1}$ (LARSSON; DE PEDRO; PAXEUS, 2007).

Embora até o momento tais contaminantes não estejam, em sua grande maioria, regulamentados pela Legislação Ambiental, apresentam risco potencial para o meio ambiente e para a saúde humana. Os antibióticos, importante exemplo desta classe de microcontaminantes (MARTINEZ, 2009), além de poderem induzir resistência bacteriana, 
também podem causar efeitos tóxicos e atuar como perturbadores endócrinos em diversos organismos vivos e, possivelmente, em humanos (CHATZITAKIS et al., 2008).

Dadas as limitações dos processos convencionais de tratamento de efluentes aquosos e água de abastecimento, tais compostos vêm sendo detectados em água potável em diversas partes do mundo (HIRSCH et al., 1999; JIANG; ZHOU; SHARMA, 2013), incluindo o Brasil (STARLING; AMORIM; LEÃO, 2019). Dessa forma, o estudo da remoção desses contaminantes por meio de processos foto-oxidativos (BARAN; SOCHACKA; WARDAS, 2006; BATISTA; PIRES; TEIXEIRA, 2014) ou por adsorção (PARAMBADATH et al., 2016; WU et al., 2016) ganha importância.

Um dos grupos de antibióticos amplamente utilizados para o tratamento de animais são as sulfonamidas, classe de CEC tratada com mais detalhes a seguir.

\subsection{Sulfonamidas}

As sulfonamidas são um grupo de antibióticos sintéticos amplamente aplicados na atividade pecuária e possuem atividade quimioterápica contra infecções causadas por bactérias gram-negativas e gram-positivas e alguns protozoários (agentes causadores da malária, toxoplasmose etc.) (DMITRIENKO et al., 2014).

A primeira sulfonamida a ser sintetizada foi a $p$-amino benzenosulfonamida pelo químico vienense Paul Gelmo, em 1908, sendo sua propriedade bacteriostática posteriormente descoberta pelo médico alemão Gerhard Johannes Paul Domagk em 1935 (DMITRIENKO et al., 2014). Atualmente, as sulfonamidas representam uma das famílias de antibióticos comumente utilizados na medicina veterinária. Embora tenham sido frequentemente aplicadas na medicina humana para tratar muitos tipos de infecções, hoje em dia quantidades muito superiores são aplicadas para tratar e prevenir doenças infecciosas na pecuária e confinamento de animais (GARCÍA-GALÁN; DÍAZ-CRUZ; BARCELÓ, 2010). Estes antibióticos são predominantemente eliminados na sua forma original, uma vez que mais de $90 \%$ da dose ingerida não são absorvidos pelo organismo (GARCÍA-GALÁN; DÍAZ-CRUZ; BARCELÓ, 2010). Como as sulfonamidas são moléculas polares, em geral solúveis em água, são rapidamente disseminadas no ambiente em matrizes aquosas (BARAN et al., 2011).

As sulfonamidas são compostas por um anel benzênico com um grupo amina $\left(-\mathrm{NH}_{2}\right)$ básico e um grupo sulfonamida ( $\left.-\mathrm{SO}_{2} \mathrm{NH}-\right)$ ácido, apresentando um caráter anfótero, devido à presença destes grupos funcionais que tanto podem doar quanto receber prótons (Figura 2.1). Portanto, essas moléculas possuem dois valores de pKa. Em meio ácido, abaixo do valor do $\mathrm{pKa}_{1}$, a maioria das moléculas está ionizada devido à protonação do grupo amina. Com 
isso, em condições ácidas ou ligeiramente ácidas ( $\mathrm{pH}$ entre 2,5 e 6 aproximadamente) as sulfonamidas estão carregadas positivamente e em condições alcalinas, estão carregadas negativamente (Figura 2.1).

Figura 2.1 Caráter anfótero das sulfonamidas.

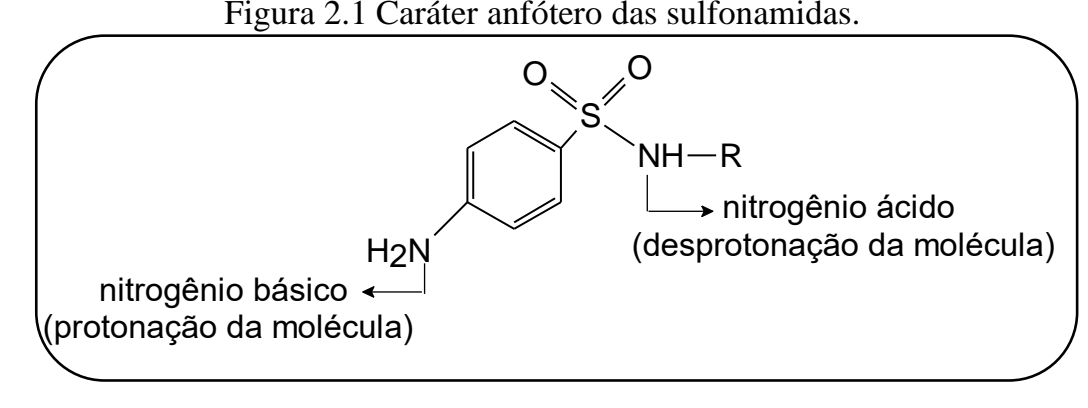

A presente Tese se dedica a estudar a fotodegradação catalítica da sulfonamida sulfadiazina (SDZ), selecionada como CEC modelo, que será descrita mais detalhadamente a seguir.

\subsubsection{Sulfadiazina}

A sulfadiazina (SDZ) (Figura 2.2) é uma das sulfonamidas mais utilizadas como composto bacteriostático sintético para a formulação de antibióticos. Suas principais características físico-químicas estão apresentadas na Tabela 2.1. Assim como as sulfonamidas, a SDZ apresenta diferentes valores de $\mathrm{pKa}$, são solúveis em água, são pequenas moléculas com baixa massa molar e possuem baixa volatilidade (baixos valores da constante de Henry) (Tabela 2.1).

Figura 2.2 Estrutura molecular da SDZ.

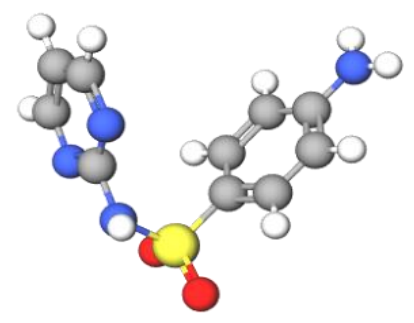


Tabela 2.1 Características físico-químicas da SDZ.

\begin{tabular}{|c|c|c|c|c|c|}
\hline $\mathbf{p K} \mathbf{a}^{\mathbf{a}}$ & $\begin{array}{l}\text { Fórmula } \\
\text { molecular }\end{array}$ & $\begin{array}{c}\log K_{o w} \\
(\text { forma } \\
{\text { neutra })^{b}}^{b}\end{array}$ & $\begin{array}{c}\text { Solubilidade em } \\
\mathrm{H}_{2} \mathrm{O}\left(\mathrm{mg} \mathrm{L}^{-1}\right)\end{array}$ & $\begin{array}{c}\text { Massa molar } \\
\left(\mathrm{g} \mathrm{mol}^{-1}\right)\end{array}$ & $\begin{array}{l}\text { Constante de Henry } \\
\left(\mathrm{Pa} \mathrm{m}^{\mathbf{3}} \mathrm{mol}^{-1}\right)\end{array}$ \\
\hline $\begin{array}{l}2,14 \\
6,34\end{array}$ & $\mathrm{C}_{10} \mathrm{H}_{10} \mathrm{~N}_{4} \mathrm{O}_{2} \mathrm{~S}$ & 0,58 & 77 & 250 & $1,6 \times 10^{-8}$ \\
\hline
\end{tabular}

${ }^{a} \mathrm{~K}_{\mathrm{a}}$ : constante de equilíbrio ácido-base. ${ }^{\mathrm{b}} \mathrm{K}_{\mathrm{ow}}$ : coeficiente de partição octanol/água. Fonte: (BARAN et al., 2011; BATISTA; PIRES; TEIXEIRA, 2014).

Seu equilíbrio de dissociação é mostrado na Figura 2.3A. A constante de equilíbrio $K_{a, 1}$ está relacionada ao equilíbrio de dissociação da espécie carregada positivamente contendo o grupo amina protonado, e sua base conjugada neutra prevalece em meio ácido (Figura 2.3B). A constante de equilíbrio $K_{\mathrm{a}, 2}$ refere-se ao equilíbrio que envolve a perda do próton do grupo sulfonamida para produzir seu conjugado carregado negativamente (Figura 2.3A), espécies predominantes em meio alcalino (Figura 2.3B).

Figura 2.3 (A) Equilíbrio de dissociação ácido-base da SDZ (B) Porcentagem molares das diferentes espécies de $\mathrm{SDZ}$ (forma catiônica, neutra e aniônica) em função do $\mathrm{pH}$.

(A)

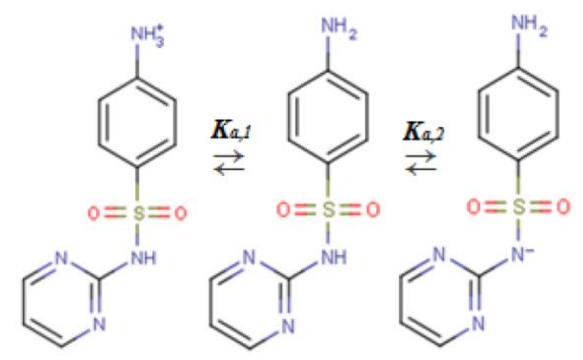

(B)

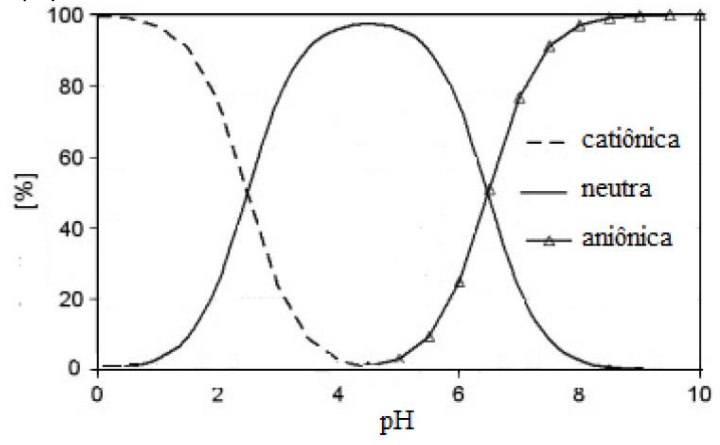

Fonte: ZARFL; MATTHIES; KLASMEIER, 2008.

Em geral, a SDZ apresenta alta reatividade com radicais hidroxila $\left(k_{\mathrm{HO}, \mathrm{SDZ}}=6,14 \pm\right.$ $\left.0,60 \times 10^{9} \mathrm{~L} \mathrm{~mol}^{-1} \mathrm{~s}^{-1}\right)(\mathrm{GE}$ et al., 2019). Com isso, os processos avançados de oxidação (POA) podem ser ideais para sua degradação (BOREEN; ARNOLD; MCNEILL, 2004). 


\section{PROCESSOS AVANÇADOS DE OXIDAÇÃO (POA): ALTERNATIVA PARA A DEGRADAÇÃO DE POLUENTES DE INTERESSE EMERGENTE}

Atualmente, um grande número de trabalhos tem mostrado que os processos convencionais de tratamento de água existentes nas estações de tratamento de esgoto ou efluentes (ETE) apenas reduzem parcialmente a concentração de compostos farmacêuticos (BARAN et al., 2011).

Neste contexto, uma grande variedade de métodos de tratamento está sendo investigada para a remoção de CEC de águas residuais, dentre os quais se destacam como mais consolidados em aplicações em grande escala: adsorção em carvão ativado, ozonização e filtração por membrana, bem como tecnologias consideradas novas, pois ainda estão sendo implementadas, em que estão presentes os processos avançados de oxidação (POA) (RIZZO et al., 2019).

POA são considerados tecnologias limpas para o tratamento de água e efluentes e podem ser definidos como processos baseados na geração e uso de espécies reativas de oxigênio (ERO) altamente oxidantes, sendo o radical hidroxila (HO') a principal delas. Tais radicais podem ser gerados por meio químico ou foto-químico. A vantagem de descontaminação é devida à baixa seletividade dos radicais $\mathrm{HO}^{\circ}$, possibilitando a mineralização de um grande número de compostos orgânicos devido ao seu elevado potencial padrão de redução $\left(E^{0}=2,80 \mathrm{~V} \quad \mathrm{EPH}\right)$, superior ao dos oxidantes convencionais (FERNÁNDEZ-CASTRO et al., 2015).

Os POA convencionais podem ser classificados em homogêneos ou heterogêneos, dependendo se ocorrem em uma única fase ou em fases diferentes. Os processos homogêneos dependem somente da interação entre os reagentes químicos e o composto alvo, enquanto os processos heterogêneos também dependem da adsorção dos reagentes e da dessorção dos produtos que ocorre nos sítios ativos na superfície do catalisador. Enquanto a reação ocorre, os produtos são dessorvidos e novas espécies podem ser adsorvidas nos sítios ativos, assim a característica da superfície e a estrutura dos poros do catalisador afeta fortemente sua eficiência e estabilidade (SOON; HAMEED, 2011).

Após sucessivas etapas, com participação do oxigênio molecular, os POA podem conduzir à total mineralização do poluente orgânico, ocorrendo, em determinadas condições, a formação de dióxido de carbono, água e compostos inorgânicos, além de intermediários orgânicos eventualmente menos nocivos.

Portanto, os POA podem ser especialmente úteis como pré-tratamento a processos biológicos para contaminantes resistentes à biodegradação ou em pós-tratamento de água e 
efluentes aquosos antes de serem distribuídos ou lançados diretamente aos corpos d'água (DEWIL et al., 2017), respectivamente. O POA utilizado no presente trabalho foi a fotocatálise heterogênea para a degradação de SDZ; por esse motivo, um enfoque neste tema será dado a seguir.

\section{FOTOCATÁliSE HETEROGÊNEA PARA A DEGRADAÇÃO DE} SULFADIAZINA

\subsection{Fotocatálise Heterogênea com Semicondutores Inorgânicos}

A fotocatálise heterogênea é baseada no uso de semicondutores sólidos que possuem um largo band-gap $\left(E_{b g}\right)$ (quantidade mínima de energia para excitar o elétron da banda de valência à banda de condução). Alguns exemplos desses semicondutores estão ilustrados na Figura 2.4.

Figura 2.4 Alguns semicondutores e sua energia de gap de banda $(\mathrm{eV})$ contra o potencial de hidrogênio padrão (EPH).

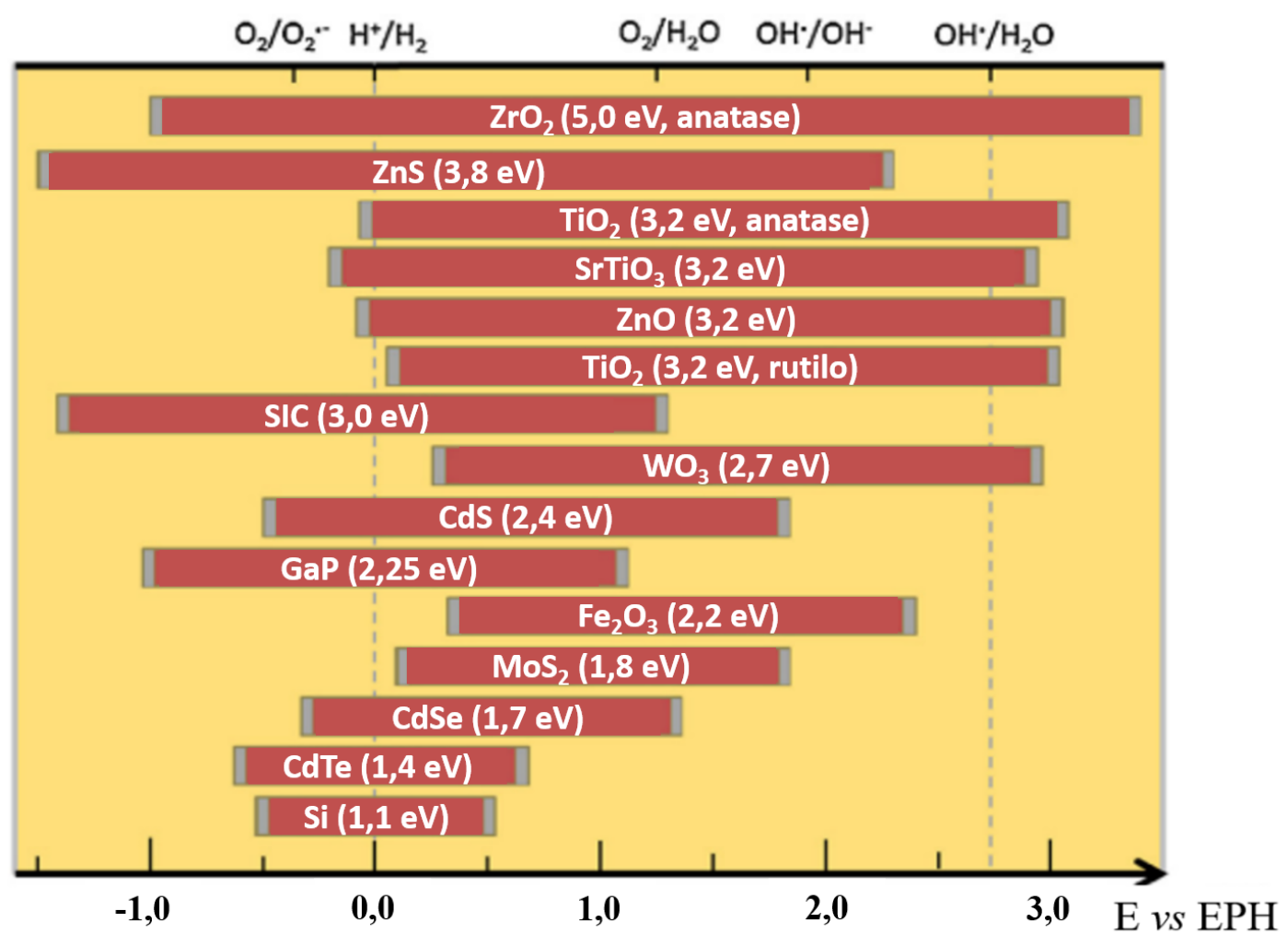

Fonte: Adaptado de AHMAD et al., 2016. 
Quando estes materiais são irradiados com fótons de energia $(h v)$ maior ou igual a sua $E_{b g}$, o elétron é promovido da banda de valência (BV) para a banda de condução (BC), gerando um par elétron $\left(\mathrm{e}^{-}{ }_{\mathrm{BC}}\right)$-lacuna $\left(\mathrm{h}^{+}{ }_{\mathrm{BV}}\right)$ na superfície do material semicondutor (Figura 2.5). Após a fotoexcitação, os processos que podem ocorrer na superfície do semicondutor são (Figura 2.5): (1) transporte do elétron para a superfície; (2) transporte da lacuna para a superfície; (3) recombinação entre elétron e lacuna na superfície; (4), recombinação de elétron e lacuna no interior da partícula; (5) elétrons reduzem moléculas aceptoras (A); e (6) lacunas são reduzidas por moléculas doadoras de elétrons (D), as quais são oxidadas. A eficiência da fotocatálise depende da competição entre os processos de recombinação, oxidação e redução (CORONADO et al., 2013).

Figura 2.5 Representação esquemática dos eventos existentes na fotocatálise heterogênea.

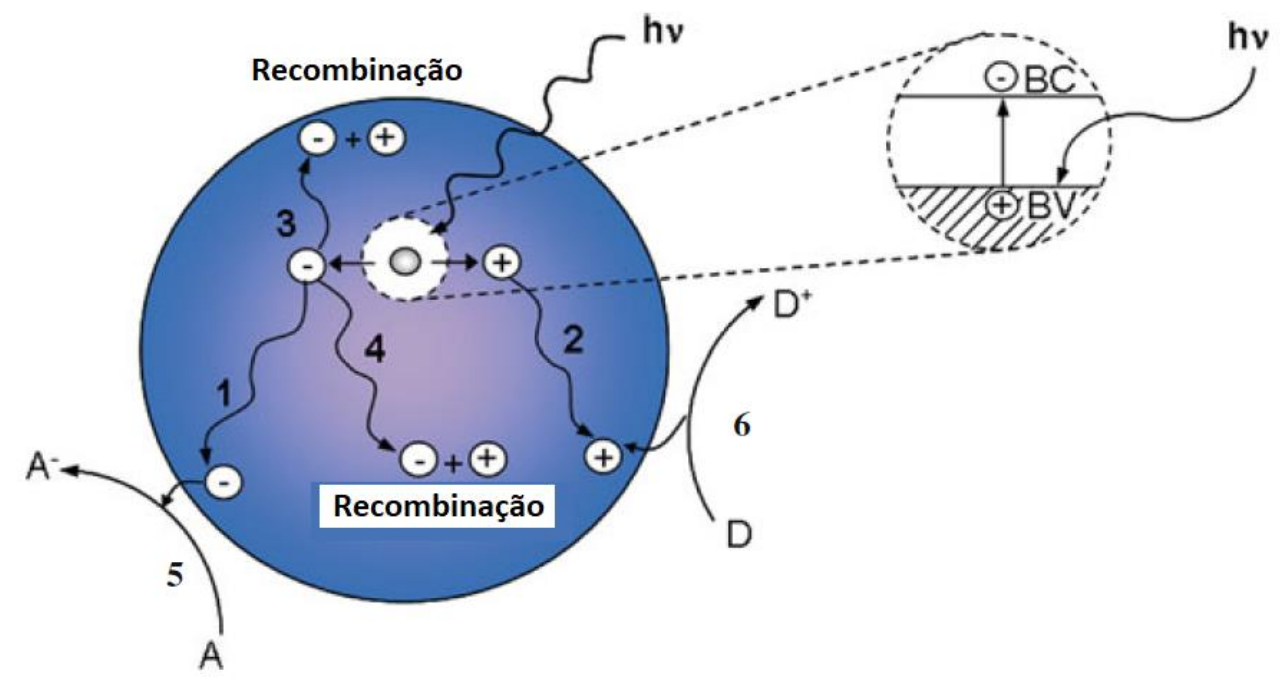

Fonte: Adaptado de CORONADO et al., 2013.

A característica fundamental deste sistema é a capacidade de gerar intermediários reativos (radicais livres) em condições moderadas (RIBEIRO et al., 2015). Em meio aquoso e aerado, as espécies reativas de oxigênio (ERO), tais como radicais hidroxila $\mathrm{HO}^{\bullet}$, entre outras, são formadas pela captura dos elétrons fotogerados e podem subsequentemente oxidar moléculas orgânicas, promovendo sua mineralização para $\mathrm{CO}_{2}, \mathrm{H}_{2} \mathrm{O}$ e espécies inorgânicas (GAYA; ABDULLAH, 2008).

Entre os materiais semicondutores (Figura 2.4), o dióxido de titânio $\left(\mathrm{TiO}_{2}\right)$ é o fotocatalisador mais utilizado para degradação de compostos orgânico presentes em efluentes aquosos. $\mathrm{O} \mathrm{TiO}_{2}$ possui energia de band gap de aproximadamente $3,2 \mathrm{eV}$ na forma cristalina anatase e de 3,0 eV na forma rutilo, sendo o comprimento de onda característico dos fótons responsáveis pela fotoexcitação $\lambda<400 \mathrm{~nm}$. Quando a superfície do $\mathrm{TiO}_{2}$ é ativada por estes 
fótons, ocorre uma série de reações de oxidação e redução em cadeia, como segue (HOUAS et al., 2001; LACHHEB et al., 2002; LAKSHMI; RENGANATHAN; FUJITA, 1995):

$$
\begin{aligned}
& \mathrm{TiO}_{2}+\mathrm{h} v \rightarrow \mathrm{e}_{(\mathrm{BC})}^{-}+\mathrm{h}^{+}(\mathrm{BV}) \\
& \mathrm{h}^{+}(\mathrm{BV})+\mathrm{H}_{2} \mathrm{O}_{(\text {ads. })} \rightarrow \mathrm{H}^{+}+\mathrm{HO}^{\bullet} \\
& \left(\mathrm{O}_{2}\right)_{\mathrm{ads}}+\mathrm{e}_{(\mathrm{BC})}^{-} \rightarrow \mathrm{O}_{2} \bullet^{-} \\
& \mathrm{O}_{2}{ }^{--}+\mathrm{H}^{+} \rightarrow \mathrm{HO}_{2}{ }^{\circ} \\
& \mathrm{HO}_{2}{ }^{\circ}+\mathrm{HO}_{2}{ }^{\circ} \rightarrow \mathrm{H}_{2} \mathrm{O}_{2}+\mathrm{O}_{2} \\
& \mathrm{H}_{2} \mathrm{O}_{2}+\mathrm{e}^{-}{ }_{(\mathrm{BC})} \rightarrow \mathrm{HO}^{-}+\mathrm{HO}^{-} \\
& \mathrm{H}_{2} \mathrm{O}_{2}+\mathrm{O}_{2}{ }^{--} \rightarrow \mathrm{HO}^{-}+\mathrm{HO}^{-}+\mathrm{O}_{2} \\
& \mathrm{P}+\mathrm{HO}^{\bullet} \rightarrow \mathrm{P}^{\bullet}+\mathrm{H}_{2} \mathrm{O} \\
& \mathrm{h}^{+}{ }_{(\mathrm{BV})}+\mathrm{P} \rightarrow \mathrm{CO}_{2}+\mathrm{P}^{\cdot+}
\end{aligned}
$$

A primeira etapa é consiste na formação do par $\mathrm{e}^{-}{ }_{\mathrm{BC}} / \mathrm{h}^{+}{ }_{\mathrm{BV}}$ (2.1). Em seguida, a água adsorvida na superfície pode produzir radicais $\mathrm{HO}^{\bullet}$ (2.2). O oxigênio também adsorvido pode reduzir formando o radical superóxido $\left(\mathrm{O}_{2}{ }^{*}\right)(2.3)$, ocorrendo protonação de $\mathrm{O}_{2}{ }^{\bullet}$, formando $\mathrm{HO}_{2}{ }^{\bullet}$ (2.4). Dois $\mathrm{HO}_{2}{ }^{\bullet}$ podem se combinar formando peróxido de hidrogênio (2.5). A redução do peróxido de hidrogênio ou sua decomposição levam à formação de radicais $\mathrm{HO}^{\bullet}(2.6$ e 2.7, respectivamente). A oxidação da molécula orgânica do poluente $(\mathrm{P})$ pode ocorrer via ataques sucessivos dos radicais $\mathrm{HO}^{\bullet}$ (2.8), ou P pode doar elétrons para a lacuna, sendo oxidado (2.9).

Como pode ser visto, a ativação do $\mathrm{TiO}_{2}$ leva à formação de muitas espécies oxidantes transitórias que degradam o poluente orgânico alvo. Neste contexto, o $\mathrm{TiO}_{2}$ tem sido o material mais estudado para a degradação de SDZ em processo de fotocatálise heterogênea; um resumo esquemático de cada artigo publicado se encontra na Tabela 2.2. 
Tabela 2.2 Principais trabalhos publicados utilizando diferentes materiais em sistemas de fotocatálise heterogênea para a degradação de SDZ.

\begin{tabular}{|c|c|c|c|c|c|c|c|}
\hline Fotocatalisador & [fotocatalisador] & {$[\mathrm{SDZ}]_{0}$} & Fonte radiante & pH & $\begin{array}{c}\text { Tempo/ } \\
\text { \% degradação }\end{array}$ & Comentários & Referência \\
\hline $\mathrm{TiO}_{2}-\mathrm{P} 25$ (Degussa) & $0,2 \mathrm{~g} \mathrm{~L}^{-1}$ & $15 \mathrm{mg} \mathrm{L}^{-1}$ & $\begin{array}{l}\text { Xe } 1500 \mathrm{~W}, 340- \\
400 \mathrm{~nm}\end{array}$ & n.a & $30 \mathrm{~min} / 80$ & $\begin{array}{l}\text { Avaliaram-se os intermediários } \\
\text { formados durante a fotodegradação. O } \\
\text { intermediário contendo nitrogênio é } \\
\text { persistente e não sofreu degradação no } \\
\text { tempo investigado. }\end{array}$ & $\begin{array}{l}\text { (CALZA et al., } \\
\text { 2004) }\end{array}$ \\
\hline $\mathrm{TiO}_{2}(100 \%$ anatase $)$ & $2,5 \mathrm{~g} \mathrm{~L}^{-1}$ & $25 \mathrm{mg} \mathrm{L}^{-1}$ & $\begin{array}{l}\text { UV } 40 \mathrm{~W}, \lambda_{\text {máx }} \\
366 \mathrm{~nm}\end{array}$ & n.a. & $300 \mathrm{~min} / 100$ & $\begin{array}{l}\text { A toxicidade dos intermediários } \\
\text { formados durante a fotodegradação é } \\
\text { significativamente menor que a } \\
\text { sulfadiazina original. }\end{array}$ & $\begin{array}{c}\text { (BARAN; } \\
\text { SOCHACKA; } \\
\text { WARDAS, 2006) }\end{array}$ \\
\hline Degussa P25 & & & & 6,02 & $90 \mathrm{~min} / 52$ & & \\
\hline $\mathrm{TiO}_{2}(100 \%$ anatase $)$ & $2,5 \mathrm{~g} \mathrm{~L}^{-1}$ & $25 \mathrm{mg} \mathrm{L}^{-1}$ & $\begin{array}{l}\text { UV } 40 \mathrm{~W}, \lambda_{\text {máx }} \\
366 \mathrm{~nm}\end{array}$ & 6,60 & $90 \mathrm{~min} / 25$ & $\begin{array}{c}\text { A presença de } \mathrm{FeCl}_{3} \text { acelera a } \\
\text { fotocatálise. }\end{array}$ & $\begin{array}{l}\text { (BARAN et al., } \\
\text { 2009) }\end{array}$ \\
\hline $\mathrm{TiO}_{2}$ anatase $/ \mathrm{FeCl}_{3}$ & & & & 2,95 & $65 \mathrm{~min} / 65$ & & \\
\hline $\mathrm{TiO}_{2}$ & $\begin{array}{l}0,5 \mathrm{~g} \mathrm{~L}^{-1}\left(\mathrm{TiO}_{2}\right) \mathrm{e} \\
0,01 \mathrm{~mol} \mathrm{~L}^{-1}(\mathrm{Fe} \\
\text { IV })\end{array}$ & $500 \mathrm{mg} \mathrm{L}^{-1}$ & $\mathrm{Hg} 254 \mathrm{~nm}$ & 7,0 & $10 \mathrm{~min} / 71,3$ & $\begin{array}{l}\text { Utilizou } \mathrm{Fe}(\mathrm{IV}) \text { como aceptor de } \\
\text { elétrons. A reação depende do } \mathrm{pH} \text { (pH } \\
\text { 7,0 apresentou o melhor resultado). }\end{array}$ & (MA et al., 2015) \\
\hline $\begin{array}{c}\text { Degussa } \mathrm{P} 25 \\
\mathrm{TiO}_{2} / \mathrm{ACF} \text { (fibra de carvão } \\
\text { ativado) }\end{array}$ & $0,20 \mathrm{~g} \mathrm{~L}^{-1}$ & $20 \mathrm{mg} \mathrm{L}^{-1}$ & $\mathrm{Hg} 15 \mathrm{~W}, 365 \mathrm{~nm}$ & 7,0 & $60 \mathrm{~min} / 100$ & $\mathrm{TiO}_{2} / \mathrm{ACF}$ mostrou melhor resultado. & $\begin{array}{l}\text { (HUANG et al., } \\
\text { 2015) }\end{array}$ \\
\hline
\end{tabular}

n.a: não se aplica. 
Tabela 2.2 (Cont.) Principais trabalhos publicados utilizando diferentes materiais em sistemas de fotocatálise heterogênea para a degradação de SDZ.

\begin{tabular}{|c|c|c|c|c|c|c|c|}
\hline Fotocatalisador & [fotocatalisador & {$[\mathrm{SDZ}]_{0}$} & Fonte radiante & pH & $\begin{array}{r}\text { Tempo/ } \\
\text { \%degrada }\end{array}$ & Comentários & Referência \\
\hline $\begin{array}{l}\text { Microfibras de } \mathrm{Bi}_{7} \mathrm{O}_{9} \mathrm{I}_{3} \\
\qquad\left(\mathrm{H}_{2} \mathrm{O}_{2}\right) \\
\text { Nanoesferas BiOI }\end{array}$ & $1 \mathrm{~g} \mathrm{~L}^{-1}$ & $20 \mathrm{mg} \mathrm{L}^{-1}$ & $\begin{array}{l}\text { Irradiação solar } \\
\text { direta (durante o } \\
\text { verão) }\end{array}$ & n.a. & $\begin{array}{l}120 \mathrm{~min} / 96 \\
120 \mathrm{~min} / 87\end{array}$ & $\begin{array}{c}\text { Foi utilizada SDZ-Na como contaminante. } \\
\text { Ao adicionar } 0,5 \mathrm{mg} \mathrm{L}^{-1} \text { de } \mathrm{H}_{2} \mathrm{O}_{2} \text { a } \\
\text { fotocatálise apresentou melhor } \\
\text { desempenho. }\end{array}$ & $\begin{array}{c}\text { (XU; ZHAO; YAN } \\
2015)\end{array}$ \\
\hline $\mathrm{BiOCl}-\mathrm{Au}-\mathrm{CdS}$ & $1 \mathrm{~g} \mathrm{~L}^{-1}$ & $20 \mathrm{mg} \mathrm{L}^{-1}$ & $\mathrm{Xe} 300 \mathrm{~W}$ & n.a. & $\begin{array}{c}180 \\
\min / 100\end{array}$ & $\begin{array}{c}\text { Experimentos utilizando supressor de } \\
\text { radicais indicaram que } \mathrm{HO}^{\bullet}, \mathrm{h}^{+} \mathrm{e} \mathrm{O}_{2}{ }^{\bullet-} \text { são } \\
\text { as principais espécies reativas responsáveis } \\
\text { pela degradação }\end{array}$ & (LI et al., 2017) \\
\hline $\begin{array}{c}\text { MOF magnético MIL- } \\
100(\mathrm{Fe})\end{array}$ & $1 \mathrm{~g} \mathrm{~L}^{-1}$ & $5 \mathrm{mg} \mathrm{L}^{-1}$ & Xe $300 \mathrm{~W}$ & $\begin{array}{c}3,0 \\
( \pm 0,2)\end{array}$ & $90 \mathrm{~min} / 100$ & $\begin{array}{c}\text { Foram adicionados } 0,1 \mathrm{~mol} \mathrm{~L}^{-1} \text { de } \mathrm{H}_{2} \mathrm{O}_{2} \text {. } \\
\text { Foto-Fenton apresentou eficiência três } \\
\text { vezes superior em relação à fotocatálise. }\end{array}$ & (TIAN et al., 2018) \\
\hline $\mathrm{TiO}_{2} /$ Zeólita & $1 g^{-1}-20 g^{-1}$ & $10 \mathrm{mg} \mathrm{L}^{-1}$ & UV $20 \mathrm{~W}, 265 \mathrm{~nm}$ & $2-12$ & $120 \mathrm{~min} / 93$ & $\begin{array}{l}\text { O melhor pH de trabalho foi } 7 \text {. Não foram } \\
\text { observadas grandes diferenças na } \\
\text { fotodegração de SDZ em pH entre } 3 \text { e } 9 . \\
\text { pH acima de } 9 \text { diminui a fotodegradação } \\
\text { (SDZ na forma desprotonada). }\end{array}$ & (LIU et al., 2018) \\
\hline $\mathrm{Ag}-\mathrm{TiO}_{2}(\mathrm{P} 25)$ & $30 \mathrm{~g} \mathrm{~L}^{-1}$ & $20 \mathrm{mg} \mathrm{L}^{-1}$ & $\begin{array}{l}\text { Visível; lâmpada } \\
\text { de halogêneo, } 35 \\
\text { W }\end{array}$ & n.a. & $\begin{array}{c}120 \\
\min / 100\end{array}$ & $\begin{array}{c}\text { O mecanismo de degradação proposto } \\
\text { segue quebra de ligação C-C e oxidação } \\
\text { de grupos amino. }\end{array}$ & (BAO et al., 2018) \\
\hline $\begin{array}{c}\text { Sponja@AgBr-AgCl/Ag } \\
\text { (3D) }\end{array}$ & Pequena porção & $10 \mathrm{mg} \mathrm{L}^{-1}$ & $\begin{array}{l}\text { Visível; lâmpada } \\
\text { de tungstênio } 500 \\
\mathrm{~W}, \lambda>420 \mathrm{~nm}\end{array}$ & n.a. & $60 \mathrm{~min} / 90$ & $\begin{array}{l}\text { Reação em reator tubular de quartzo com } \\
\text { fluxo contínuo. A taxa de degradação de } \\
\text { SDZ quase não muda na presença de um } \\
\text { supressor de } \mathrm{HO}^{\bullet} \text {, o que implica que este } \\
\text { pode não participar da degradação de SDZ. }\end{array}$ & $\begin{array}{c}\text { (KONG et al., } \\
\text { 2019) }\end{array}$ \\
\hline
\end{tabular}

n.a: não se aplica. 
Tabela 2.2 (Cont.) Principais trabalhos publicados utilizando diferentes materiais em sistemas de fotocatálise heterogênea para a degradação de SDZ.

\begin{tabular}{|c|c|c|c|c|c|c|c|}
\hline Fotocatalisador & [fotocatalisador] & {$[\mathrm{SDZ}]_{0}$} & Fonte radiante & pH & $\begin{array}{c}\text { Tempo/ } \\
\text { \%degradação }\end{array}$ & Comentários & Referência \\
\hline $\begin{array}{c}\text { Heterojunção } \\
\mathrm{Cu}_{2} \mathrm{O} / \mathrm{Bi} / \mathrm{Bi}_{2} \mathrm{MoO}_{6}\end{array}$ & n.a. & $10 \mathrm{mg} \mathrm{L}^{-1}$ & $\begin{array}{l}\text { Lâmpada de Xe } \\
\text { visível } 300 \mathrm{~W}, \lambda> \\
420 \mathrm{~nm}\end{array}$ & n.a. & $\begin{array}{c}100 \\
\min / 98,6\end{array}$ & $\begin{array}{l}\text { Os testes foram feitos em conjunto para } \\
\text { remover sais de níquel. Os resultados } \\
\text { sugerem que tanto } \mathrm{h}^{+}, \mathrm{O}_{2}{ }^{-} \text {e } \mathrm{HO} \\
\text { participam da oxidação de SDZ. }\end{array}$ & (XU et al., 2020) \\
\hline $\begin{array}{c}\mathrm{Co}_{3} \mathrm{O}_{4} \text { e } \mathrm{Au} \text { co-modificado } \\
\text { com } \mathrm{BiOBr}\end{array}$ & $1 \mathrm{~g} \mathrm{~L}^{-1}$ & $20 \mathrm{mg} \mathrm{L}^{-1}$ & $\begin{array}{l}\text { Lâmpada de Xe } \\
\text { visível } 300 \mathrm{~W}, \lambda> \\
\quad 420 \mathrm{~nm}\end{array}$ & n.a. & $\begin{array}{c}120 \\
\min / 100\end{array}$ & $\begin{array}{l}\text { A atividade fotocatalítica é melhorada na } \\
\text { presença de Au-BiOBr, pois as } \\
\text { nanopartículas de ouro não apenas } \\
\text { aumentam a absorção da luz visível, mas } \\
\text { também promovem a transferência de } \\
\text { elementos portadores de carga }\end{array}$ & $\begin{array}{l}\text { (GUAN et al., } \\
\text { 2020) }\end{array}$ \\
\hline $\begin{array}{l}\text { Heterojunção de nitreto de } \\
\text { carbono }\left(\mathrm{g}-\mathrm{C}_{3} \mathrm{~N}_{4}\right) \mathrm{em} \\
\text { "dots" de carbono }\end{array}$ & $0,5 \mathrm{~g} \mathrm{~L}^{-1}$ & $2,5 \mathrm{mg} \mathrm{L}^{-1}$ & $\begin{array}{l}\text { Lâmpada de Xe } \\
\text { visível } 500 \mathrm{~W}, \lambda> \\
\quad 420 \mathrm{~nm}\end{array}$ & n.a. & $\begin{array}{c}80 \\
\min / 93,8\end{array}$ & $\begin{array}{l}\text { A melhor atividade fotocatalítica foi } \\
\text { relacionada ao menor gap da banda de } \\
\text { valência e da banda de condução das } \\
\text { heteroestruturas planas. } \mathrm{h}^{+} \text {são os maiores } \\
\text { responsáveis pela degradação da SDZ, } \\
\text { enquanto HO' mostrou uma contribuição } \\
\text { insignificante. }\end{array}$ & $\begin{array}{l}\text { (DUAN et al., } \\
\text { 2020) }\end{array}$ \\
\hline
\end{tabular}

n.a: não se aplica. 
O primeiro trabalho publicado em 2004 por Calza e colaboradores (CALZA et al., 2004) empregou um sistema de batelada utilizando o $\mathrm{TiO}_{2} \mathrm{P} 25$ (Degussa) e uma fonte radiante constituída por uma lâmpada de xenônio de $1500 \mathrm{~W}$ ( $\lambda_{\text {máx }} 340-400 \mathrm{~nm}$ ). Nesse sistema foi possível atingir um total de $80 \%$ de degradação da SDZ após 30 min de irradiação. Os autores verificaram também que a primeira etapa para alcançar a mineralização da SDZ e das demais sulfonamidas ocorre através da quebra da ligação $\mathrm{S}-\mathrm{N}$, bem como através do ataque ao anel aromático pelos radicais $\mathrm{HO}^{\bullet}$ (Figura 2.6).

Figura 2.6 Esquema geral das vias de degradação por radicais $\mathrm{HO} \bullet$ sofridas pelas sulfonamidas.

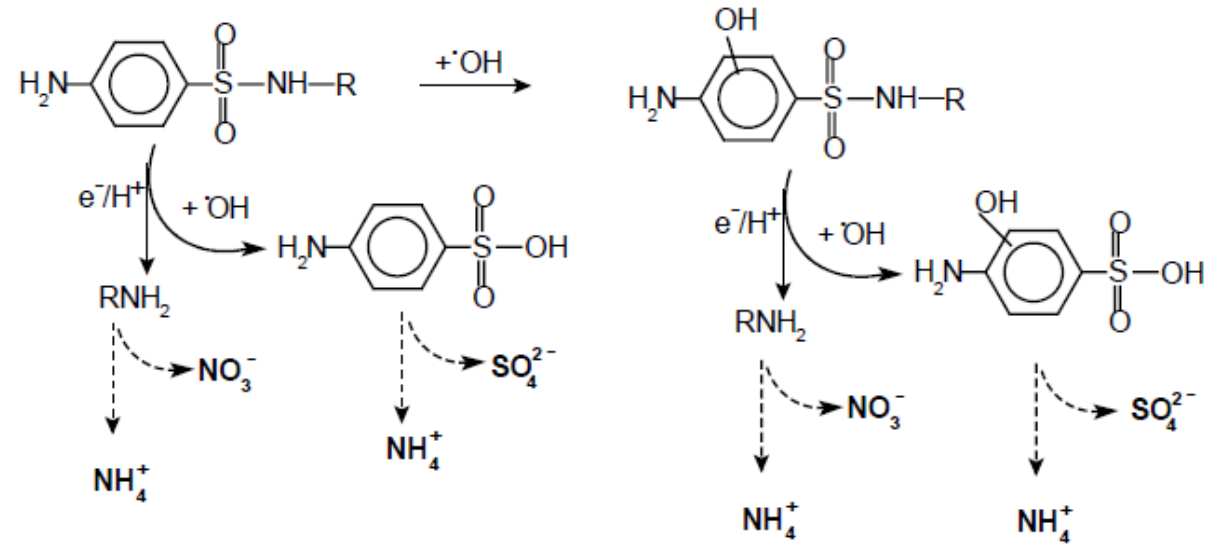

Fonte: (CALZA et al., 2004).

Em 2006, Baran e colaboradores (BARAN; SOCHACKA; WARDAS, 2006) avaliaram a toxicidade e a biodegradabilidade na degradação fotocatalítica de algumas sulfonaminadas, entre elas a SDZ. Para isso, foi empregado um sistema de fotocatálise em batelada em presença do semicondutor $\mathrm{TiO}_{2} \quad 100 \%$ anatase (Riedel-de Haën) utilizando uma lâmpada UV de $40 \mathrm{~W}$ de potência e $\lambda_{\text {máx }}$ em $366 \mathrm{~nm}$. Neste trabalho foi possível verificar que todas as sulfonamidas investigadas eram resistentes à biodegradação e eram tóxicas, e que após a fotodegradação catalítica a toxicidade dos produtos intermediários se tornou significativamente menor. Os autores alcançaram a mineralização das sulfonamidas após 300 min de irradiação.

Assim, pode-se afirmar que $\mathrm{TiO}_{2}$ apresenta potencial altamente promissor de remoção de SDZ em sistemas de fotocatálise heterogênea. Devido a esta eficácia, o foco dos pesquisadores está concentrado em superar demais desafios para aplicação em larga escala, tais como: distribuição da intensidade da luz no reator, doping para estender a gama de ações catalíticas à região visível da luz solar, adesão de substratos para 
imobilizar os semicondutores e recuperação de catalisador para sistemas fotocatalíticos mais sofisticados (AHMAD et al., 2016).

Neste sentindo, LIU et al. (2018) mostraram a eficácia para a degradação de SDZ utilizando o material $\mathrm{TiO}_{2}$ suportado em uma zeólita. Os autores observaram que o aumento na eficiência de remoção de SDZ não pode ser unicamente atribuído à adsorção de SDZ na superfície da zeólita, mas também ao efeito sinérgico obtido pelo uso combinado de $\mathrm{TiO}_{2}$ com o substrato zeólita, formando um compósito. Tal compósito tem o efeito de acelerar a fotodegradação de poluentes orgânicos em água. $\mathrm{O}$ mecanismo fotocatalítico, estudado usando supressão radicalar, indicou que o efeito sinérgico entre radicais $\mathrm{HO}^{\bullet}, \mathrm{h}^{+}, \mathrm{O}_{2}{ }^{\bullet-} \mathrm{e}^{1} \mathrm{O}_{2}$ desempenham importante papel na oxidação fotocatalítica de SDZ.

Trabalhos mais atuais (BAO et al., 2018; DUAN et al., 2020; GUAN et al., 2020; KONG et al., 2019; XU et al., 2020) têm demostrado o uso de novos fotocatalisadores aprimorados, que absorvem no range do visível para a degradação de SDZ. Porém, as limitações para aplicação em escala aumentada estão associadas ao emprego de tecnologias robustas e custosas para sua fabricação bem como no uso de metais, como cobalto, cobre e prata, que podem trazer a necessidade de um novo processo de tratamento devido à formação de resíduos oriundos da síntese em maior escala.

Por este motivo, no presente trabalho estudou-se o emprego de $\mathrm{TiO}_{2}$ imobilizado nas $\mathrm{SBA}-15\left(\mathrm{TiO}_{2} / \mathrm{SBA}-15\right)$ e das organosílicas periódicas mesoporosas contendo as 1,4,5,8-naftalenodiimidas (NDI) nomeadas PMONDI como fotocatalisadores alternativos para a degradação de SDZ.

Como pode ser notado as PMONDI, diferentemente do $\mathrm{TiO}_{2}$, são fotocatalisadores orgânicos. Com isso, a fotocatálise com as PMONDI segue um mecanismo diferente para geração das espécies reativas de oxigênio (ERO) transitórias que degradam o poluente. O mecanismo proposto é detalhado a seguir.

\subsection{Fotocatálise com Sensibilizadores Orgânicos}

O processo de fotossensibilização de sensibilizadores orgânicos ocorre em presença simultânea de radiação eletromagnética de comprimento de onda apropriado e de oxigênio molecular. Dessa maneira, para melhor compreender o mecanismo que envolve a degradação de contaminantes na presença de sensibilizadores orgânicos, é 
importante elucidar sobre os princípios foto-eletrônicos das espécies de oxigênio molecular.

A configuração eletrônica do oxigênio molecular no estado fundamental triplete $\left({ }^{3} \Sigma_{\mathrm{g}}{ }^{-}\right)$é devida ao seu par de elétrons do HOMO que ocupam dois orbitais $\pi^{*}$ degenerados (orbitais diferentes com a mesma energia) apresentarem spins paralelos. Esta característica conferiria ao oxigênio uma alta reatividade, entretanto, sua redução direta por dois elétrons com spins antiparalelos é proibida pela regra de conservação de spin, tornando-o relativamente inerte (ZHANG; YAN; SONG, 2014).

O oxigênio eletronicamente excitado pode apresentar-se em dois estados distintos ${ }^{1} \Delta_{\mathrm{g}} \mathrm{e}^{1} \Sigma_{\mathrm{g}}{ }^{+}$, tendo a primeira energia $22 \mathrm{kcal} \mathrm{mol}^{-1}$ acima do estado fundamental e alto tempo de vida (2 a $4 \mu$ s em meio aquoso), já o segundo tem energia de 37,5 kcal mol ${ }^{-1}$ acima do estado fundamental e tempo de vida muito menor $\left(\sim 10^{-11} \mathrm{~s}\right)$, decaindo rapidamente para o estado ${ }^{1} \Delta_{\mathrm{g}}$. Em ambos os estados eletronicamente excitados os elétrons apresentam spins antiparalelos (Tabela 2.3) (BAPTISTA et al., 2017).

Tabela 2.3 Distribuição eletrônica nos orbitais moleculares $(\pi)$, energia de excitação e tempo de vida do oxigênio molecular no estado fundamental triplete $\left({ }^{3} \Sigma_{\mathrm{g}}{ }^{-}\right)$e nos estados excitados singlete $\left({ }^{1} \Delta_{\mathrm{g}} \mathrm{e}^{1} \Sigma_{\mathrm{g}}{ }^{+}\right)$.

\begin{tabular}{|c|c|c|c|}
\hline Estado & $\begin{array}{l}\text { Spins elétrons (HOMO) } \\
\qquad \begin{array}{ll}\pi_{x} & \pi_{y}\end{array}\end{array}$ & $\begin{array}{c}\text { Energia } \\
\left(\text { kcal mol}^{-1}\right)\end{array}$ & $\begin{array}{c}\text { Tempo de } \\
\text { vida (s) }\end{array}$ \\
\hline Fundamental $\left({ }^{3} \Sigma_{\mathrm{g}}^{-}\right)$ & $\uparrow \uparrow$ & - & - \\
\hline Primeiro excitado $\left({ }^{1} \Delta_{\mathrm{g}}\right)$ & $\uparrow \downarrow-$ & 22,5 & $10^{-6}$ \\
\hline Segundo excitado $\left({ }^{1} \Sigma_{\mathrm{g}}{ }^{+}\right)$ & $\uparrow \quad \downarrow$ & 37,5 & $10^{-11}$ \\
\hline
\end{tabular}

O diagrama de Jablonski simplificado apresentado na Figura 2.7 mostra a absorção de energia radiante por um sensibilizador orgânico (representado por sens) no estado fundamental $\left(\mathrm{S}_{0}\right)$, o que está associado à promoção de um elétron para o próximo nível de energia, produzindo assim o estado excitado singlete $\left(S_{1}\right)$. Dependendo da quantidade de energia absorvida, os estados singletes podem ser $\mathrm{S}_{1}$ ou $\mathrm{S}_{2}$ etc., formando ${ }^{1}$ sens*. O decaimento da energia absorvida pode ocorrer de forma radiativa, fenômeno conhecido como luminescência, através de emissão de fluorescência ou o elétron pode sofrer cruzamento intersistemas (ISC) passando para o estado excitado triplete $\left(\mathrm{T}_{1}\right.$ ou $\mathrm{T}_{2}$ etc.), originando o estado ${ }^{3}$ sens $*$. O decaimento deste estado excitado pode ocorrer na 
forma de fosforescência ou podem ocorrer interações com outras moléculas em processos de transferência de elétrons ou de energia.

Figura 2.7 Representação esquemática dos processos de transferência de energia a partir de uma molécula orgânica sensibilizadora (sens). $\mathrm{S}_{0}$ é seu estado fundamental, $\mathrm{S}_{1}$ e $\mathrm{S}_{2}$ são os estados excitados singletes $\left({ }^{1}\right.$ sens $\left.*\right)$ e $\mathrm{T}_{1}$ e $\mathrm{T}_{2}$ são os respectivos estados excitados tripletes $\left({ }^{3}\right.$ sens*).

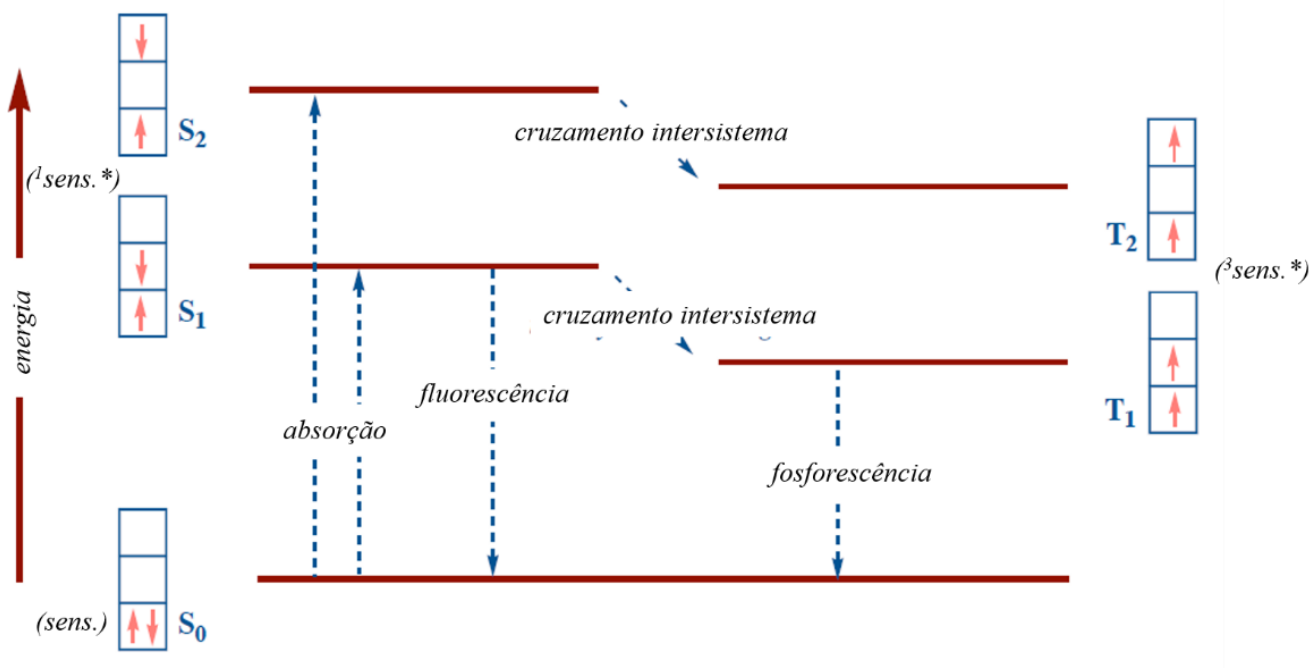

O estado ${ }^{3}$ sens* pode então seguir dois caminhos possíveis. Uma via possível leva ao mecanismo tipo I, em que ocorre transferência de elétrons entre espécies presentes no sistema. Esse processo forma íons radicais que podem interagir com $\mathrm{O}_{2}$ no estado fundamental $\left({ }^{3} \Sigma_{\mathrm{g}}{ }^{-}\right)$, resultando em produtos de degradação. Já no mecanismo tipo II ocorre transferência de energia de ${ }^{3}$ sens* para $\mathrm{O}_{2}\left({ }^{3} \Sigma_{\mathrm{g}}{ }^{-}\right)$, gerando ${ }^{1} \mathrm{O}_{2}\left({ }^{1} \Delta_{\mathrm{g}}\right)$ que pode oxidar o poluente ou ser desativado ao estado fundamental. Esses mecanismos podem ocorrer simultaneamente, sendo influenciados pelo tipo de sensibilizador e de poluente, bem como pela concentração de oxigênio no meio (Figura 2.8) (BAPTISTA et al., 2017). 
Figura 2.8 Possíveis vias (mecanismos tipo I e tipo II) originárias a partir da absorção de energia radiante pelo sensibilizador orgânico. No esquema, P corresponde ao poluente, ISC representa o cruzamento intersistemas e sens, o sensibilizador.

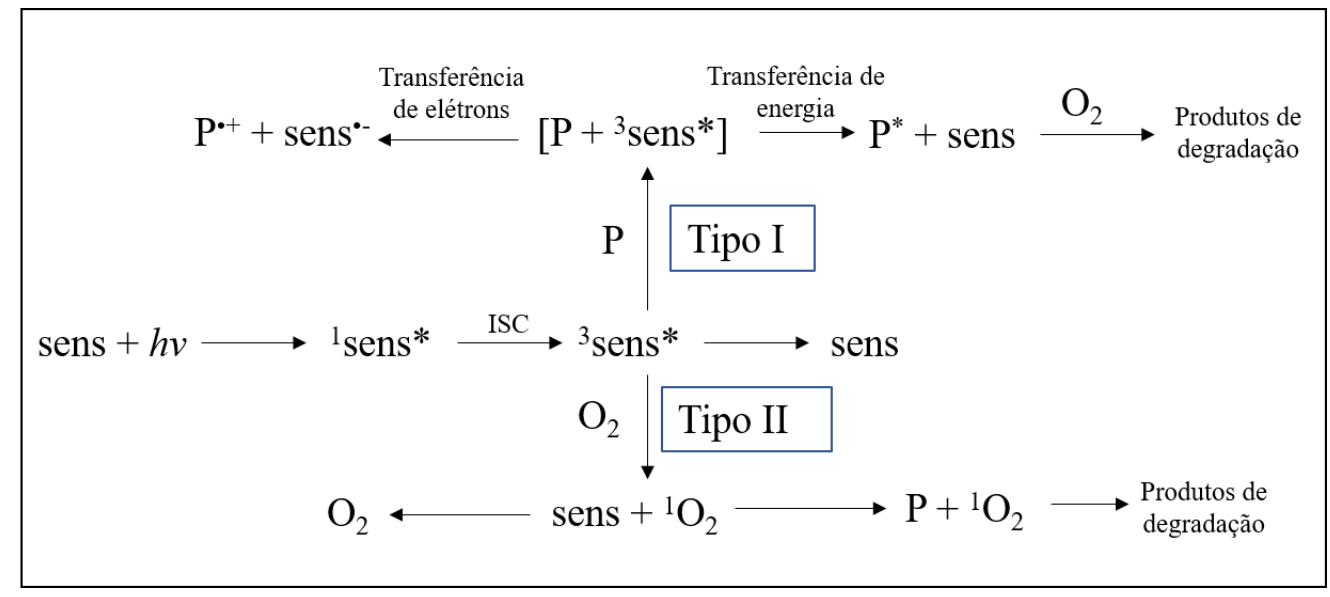

Os trabalhos encontrados na pesquisa bibliográfica sobre a degradação de SDZ por meio de sensibilizadores orgânicos utilizaram processos homogêneos. Nestes trabalhos, a matéria orgânica dissolvida cromofórica ("chromophoric dissolved organic matter” CDOM) em águas superficiais atua como sensibilizador orgânico, capaz de absorver luz solar. Assim, o estado excitado triplete ${ }^{3} \mathrm{CDOM}^{*}$ pode seguir o mecanismo tipo I e interagir com o substrato orgânico formando moléculas eletronicamente excitadas, ou seguir o mecanismo tipo II interagindo com $\mathrm{O}_{2}\left({ }^{3} \Sigma_{\mathrm{g}}{ }^{-}\right)$formando ${ }^{1} \mathrm{O}_{2}\left({ }^{1} \Delta_{\mathrm{g}}\right)$ e seguir as vias de oxidação dos contaminantes orgânicos (CANONICA, 2007; MCNEILL; CANONICA, 2016).

É importante ressaltar que os micropoluentes orgânicos, presentes nas matrizes aquosas também podem formar estados excitados tripletes, porém suas concentrações são muito inferiores em comparação à CDOM. Assim, CDOM em águas naturais pode ser considerada o principal precursor de estados excitados tripletes.

O mecanismo de reações mais aceito que envolve CDOM com o poluente orgânico ocorre da seguinte forma: após a absorção de fótons, CDOM atinge o estado excitado singlete ${ }^{1} \mathrm{CDOM}^{*}$ (Equação 2.10), subsequentemente, através do cruzamento intersistemas ${ }^{1} \mathrm{CDOM}^{*}$ passa para o estado excitado triplete ${ }^{3} \mathrm{CDOM}^{*}$ (Equação 2.11). A desativação deste estado pode ocorrer via fosforescência (Equação 2.12) ou por transferência de energia com oxigênio dissolvido formando oxigênio singlete $\left({ }^{1} \mathrm{O}_{2}{ }^{1} \Delta_{\mathrm{g}}\right)$ (Equação 2.13). Tais processos limitam a vida útil de estados ${ }^{3} \mathrm{CDOM}^{*}$ a no máximo algo em torno de $2 \mu$ s em água aerada a $20^{\circ} \mathrm{C}$. Assim uma fração dos estados tripletes ${ }^{3} \mathrm{CDOM}^{*}$ ainda está disponível para oxidar os contaminantes-alvo P (Equação 2.14) diretamente via transferência de elétrons, formandos radicais $\mathrm{CDOM}^{*}$, que podem ser 
oxidados pelo oxigênio formando o ânion radical superóxido $\mathrm{O}_{2}{ }^{\bullet-}$ (Equação 2.15). $\mathrm{O}$ oxigênio singlete formado pode ser desativado por colisões com moléculas da água (vida útil 3-4 $\mu \mathrm{s}$ ) (Equação 2.16), mas também pode oxidar o contaminante-alvo (Equação 2.17) (CANONICA, 2007).

$$
\begin{aligned}
& \mathrm{CDOM}+h v \rightarrow{ }^{1} \mathrm{CDOM}^{*} \\
& { }^{1} \mathrm{CDOM}^{*} \stackrel{\text { ISC }}{\rightarrow}{ }^{3} \mathrm{CDOM}^{*} \\
& { }^{3} \mathrm{CDOM}^{*} \rightarrow \mathrm{CDOM}+h v^{\prime} \\
& { }^{3} \mathrm{CDOM}^{*}+\mathrm{O}_{2}\left({ }^{3} \Sigma_{\mathrm{g}}^{-}\right) \rightarrow \mathrm{CDOM}^{-1} \mathrm{O}_{2}\left({ }^{1} \Delta_{\mathrm{g}}\right) \\
& { }^{3} \mathrm{CDOM}^{*}+\mathrm{P} \rightarrow \mathrm{CDOM}^{\cdot-}+\mathrm{P}^{\cdot+} \\
& \mathrm{CDOM}^{\cdot-}+\mathrm{O}_{2}\left({ }^{3} \Sigma_{\mathrm{g}}{ }^{-}\right) \rightarrow \mathrm{CDOM}+\mathrm{O}_{2}{ }^{-} \\
& { }^{1} \mathrm{O}_{2}\left({ }^{1} \Delta_{\mathrm{g}}\right) \rightarrow \mathrm{O}_{2} \\
& { }^{1} \mathrm{O}_{2}\left({ }^{1} \Delta_{\mathrm{g}}\right)+\mathrm{P} \rightarrow \mathrm{P}_{\mathrm{ox}}
\end{aligned}
$$

Em 2005 Boreen e colaboradores (BOREEN; ARNOLD; MCNEILL, 2005) avaliaram a fotólise de SDZ e de outras sulfonamidas nas matrizes água deionizada e água natural de rio. Neste trabalho, os autores demonstraram que devido à formação de ${ }^{3} \mathrm{CDOM}^{*}$ na água de rio estimulada pela luz, a fotólise de SDZ e das demais sulfonamindas foi significativamente melhorada. O produto primário formado através da interação entre ${ }^{3} \mathrm{CDOM}^{*}$ e SDZ foi identificado como uma molécula resultante da extrusão de dióxido de enxofre (Figura 2.9). O mesmo resultado foi observado por Batista e colaboradores em 2016 (BATISTA et al., 2016) para outra sulfonamida.

Figura 2.9 Primeiro produto fotogerado oriundo da extrusão de $\mathrm{SO}_{2}$ pela interação de $\mathrm{SDZ}$ com matéria orgânica dissolvida cromofórica (CDOM).

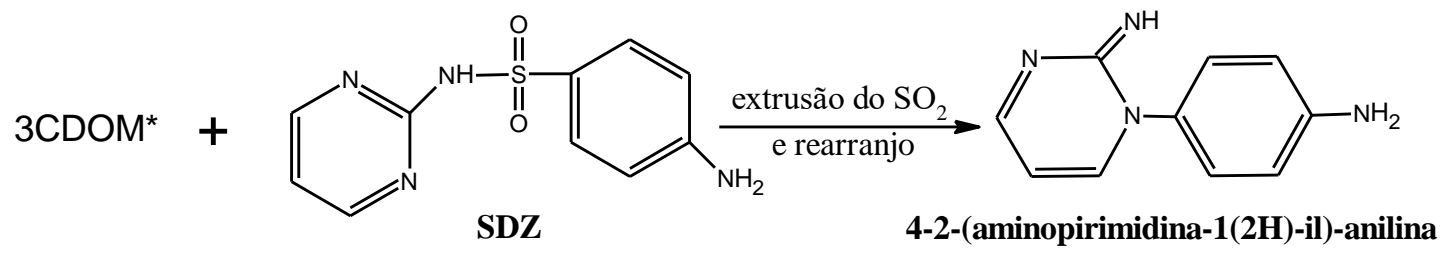

Como sensibilizadores orgânicos, as NDI presentes nas PMONDI e utilizadas como fotocatalisadores no presente trabalho possuem baixa fluorescência, com isso há uma grande tendência do estado excitado singlete ( $\left.{ }^{1} \mathrm{NDI}^{*}\right)$, gerado após absorção de fótons, sofrer cruzamento intersistemas (ISC) para o estado excitado triplete ( ${ }^{3} \mathrm{NDI}^{*}$ ). 
Este estado excitado pode percorrer os mecanismos tipo I e tipo II para a degradação fotocatalítica do contaminante SDZ.

De fato, materiais bastante similares, tais como a SBA-15 funcionalizada com a imida aromática 1,8-naftalimida (SBANI), apresentaram grande potencial para a degradação o azul de metileno, um típico poluente têxtil (CASTANHEIRA et al., 2017).

\section{SEÇÃO EXPERIMENTAL}

\subsection{Materiais}

Sulfadiazina (99\%) foi obtida da Sigma-Aldrich. Etanol (grau HPLC) e ácido acético (grau HPLC) foram adquiridos da Baker. Álcool furfurílico (FFA) e ácido paraclorobenzóico (pCBA) foram obtidos da TCI America e ICN Biomedicals Inc., respectivamente. PMONDI-16, PMONDI-8 e $16 \% \mathrm{TiO}_{2} / \mathrm{SBA}^{-15}$ foram sintetizadas e caracterizadas conforme descrito no Capítulo 1. Todas as soluções aquosas foram preparadas com água deionizada.

\subsection{Métodos}

\subsubsection{Experimentos de degradação fotocatalítica de sulfadiazina}

A preparação da solução estoque de $\operatorname{SDZ}\left(C_{0, \mathrm{SDZ}}=30 \mathrm{mg} \mathrm{L}^{-1}\right)$ foi feita através da dissolução de $30 \mathrm{mg}$ de SDZ em $1 \mathrm{~L}$ de água deionizada a fim de garantir a completa dissolução do fármaco, deixou-se o frasco contendo a solução em banho ultrassônico da Eco Sonics por 2 h. O pH natural ( $\mathrm{pH} \sim 7$ ) não foi alterado e não foi corrigido durante

os experimentos fotocatalíticos. A solução estoque de $\operatorname{SDZ}\left(C_{0, \mathrm{SDZ}}=30 \mathrm{mg} \mathrm{L}^{-1}\right)$ foi armazenada em um frasco âmbar na geladeira e serviu de base para o preparo das demais soluções.

Um béquer encamisado de $250 \mathrm{~mL}$, acoplado a um banho termostático, foi utilizado como reator batelada (Figura 2.10); com isso, os experimentos foram conduzidos à temperatura ambiente $\left(25^{\circ} \mathrm{C}\right)$. Neste béquer eram mantidos sob agitação magnética constante por $24 \mathrm{~h}$ (no escuro) $50 \mathrm{~mL}$ da solução de SDZ, com concentração inicial de acordo com o experimento definido na Tabela 2.4, à qual se adicionaram 25 $\mathrm{mg}$ do catalisador (concentração do catalisador $0,5 \mathrm{~g} \mathrm{~L}^{-1}$ ) para assegurar a total adsorção de SDZ em cada material utilizado: PMONDI-8, PMONDI-16 e 16\% TiO $2 / \mathrm{SBA}^{-15}$. Após este período ligava-se a fonte radiante, constituída por uma lâmpada UV de alta 
pressão de $\mathrm{Hg}$ da marca Omnicure S1000 (100 W), com filtro de janela de 320-500 nm equipada com uma fibra óptica, para dar início ao experimento de fotodegração. $\mathrm{O}$ espectro de emissão da lâmpada UV de alta pressão de Hg utilizada foi obtido por meio de um espectroradiômetro Luzchem SPR-02.

A distância entre a ponta da fibra óptica da lâmpada e a superfície da solução de SDZ foi mantida fixa em $15 \mathrm{~cm}$. A altura do líquido no béquer foi mantida fixa em $5 \mathrm{~cm}$ e a área de secção transversal do recipiente, ou seja, a área de superfície de líquido irradiada era de $36,3 \mathrm{~cm}^{2}$. A irradiação foi variada em cada experimento de acordo com a Tabela 2.4, através do display disponível na fonte eletrônica da lâmpada (Figura 2.10).

Durante a fotodegradação alíquotas de $0,5 \mathrm{~mL}$ eram retiradas a cada $15 \mathrm{~min}$ através de uma seringa de $1 \mathrm{~mL}$, filtradas em filtro de seringa de $0,45 \mu \mathrm{m}$ e armazenadas no congelador para posterior análise em HPLC. O tempo total de cada experimento foi de 180 minutos. Ao final de cada experimento eram armazenadas amostras de SDZ para identificação dos intermediários da SDZ formados através das análises de cromatografia líquida acoplada a um espectrômetro de massas (LC-MS). Experimentos de controle, como fotólise e com a sílica mesoporosa não funcionalizada (SBA-15), também foram realizados nas mesmas condições da Tabela 2.4.

Tabela 2.4 Concentração inicial de SDZ $\left(C_{0, \mathrm{SDZ}}\right)$ e irradiâncias (I) utilizadas em cada experimento de fotodegradação catalítica de SDZ.

\begin{tabular}{ccc}
\hline Exp. & I $\left(\mathbf{m W ~ c m}^{-\mathbf{2}}\right)$ & $\boldsymbol{C}_{\mathbf{0}, \mathbf{S D Z}}\left(\mathbf{m g ~ L}^{\mathbf{- 1}}\right)$ \\
\hline $\mathbf{A}$ & 3 & 7,5 \\
B & 3 & 12,5 \\
$\mathbf{C}$ & 8 & 5 \\
$\mathbf{D}^{*}$ & 8 & 10 \\
$\mathbf{E}$ & 8 & 15 \\
$\mathbf{F}$ & 13 & 7,5 \\
$\mathbf{G}$ & 13 & 12,5 \\
\hline
\end{tabular}

* Realizado em triplicata. 
Figura 2.10 (A) representação do aparato experimental utilizado e (B) Fotografia do béquer irradiado.

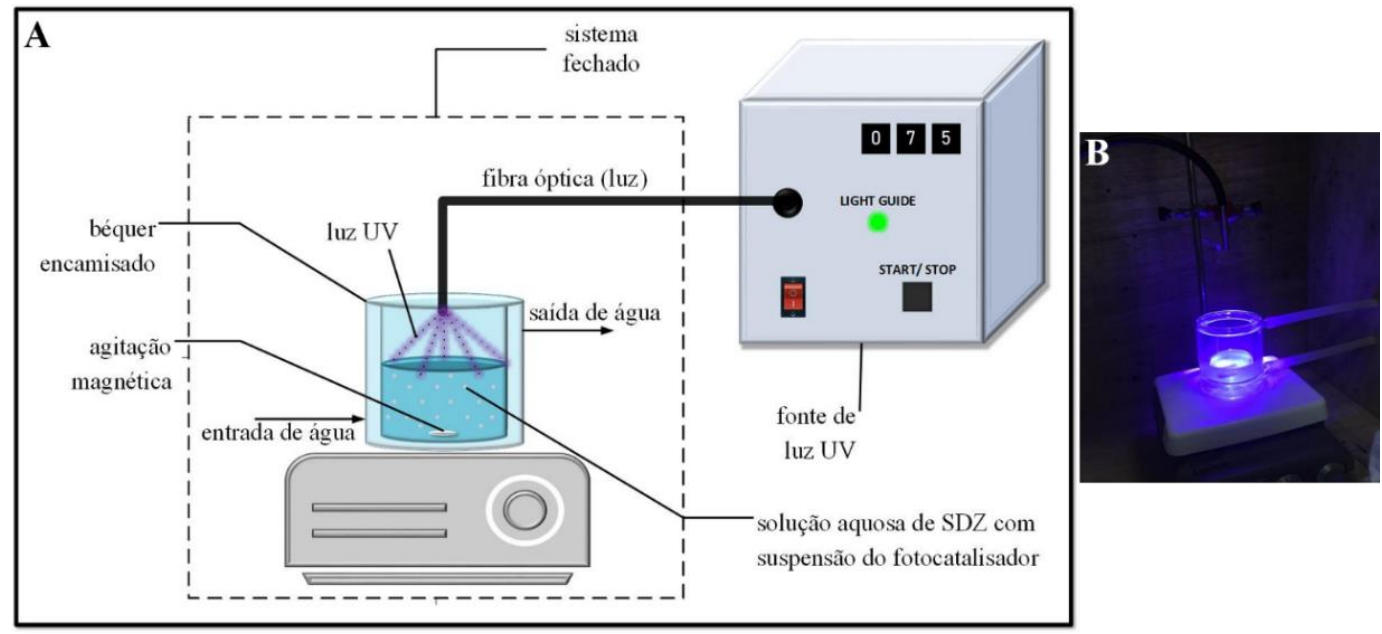

\subsubsection{Reutilização dos fotocatalisadores}

Estudos de reutilização dos fotocatalisadores PMONDI-16 e $16 \% \mathrm{TiO}_{2} / \mathrm{SBA}-15$ na fotodegradação de SDZ foram realizados em três ciclos diferentes. Para isso, ao final de cada experimento, separava-se o fotocatalisador da solução irradiada por filtração, deixava-se secar em estufa $\left(50{ }^{\circ} \mathrm{C}\right)$ por $24 \mathrm{~h}$. Uma vez secado, o material era reutilizado em um novo experimento com outra solução de SDZ. As condições escolhidas para a reutilização foram iguais do experimento B (Tabela 2.4), ou seja, na maior concentração inicial de $\operatorname{SDZ}\left(C_{0, \mathrm{SDZ}}\right)$ de $12,5 \mathrm{mg} \mathrm{L}^{-1}$ e menor irradiância $\left(3 \mathrm{~mW} \mathrm{~cm}{ }^{-2}\right)$.

\subsubsection{Estudo da cinética de fotodegradação da sulfadiazina}

A constante de reação $\left(k_{S D Z}\right)$ de pseudo-primeira ordem pode ser ajustada pelo método de regressão não linear, de acordo com a equação a seguir:

$$
C_{t, S D Z}=C_{0, S D Z} \times e^{-k_{S D Z} t}
$$

\subsubsection{Quantificação das espécies reativas fotoinduzidas}

As concentrações de oxigênio singlete e de radicais hidroxila no estado estacionário $\left(\left[{ }^{1} \mathrm{O}_{2}\right]_{\mathrm{ss}}\right.$ e $\left[\mathrm{HO}^{\circ}\right]_{\mathrm{ss}}$, respectivamente) foram determinadas utilizando álcool furfurílico (FFA) e ácido p-clorobenzoico (pCBA) como compostos-sonda, respectivamente, de acordo com métodos detalhados na literatura (LASTRE-ACOSTA et al., 2018; MOSTAFA; ROSARIO-ORTIZ, 2013; SILVA et al., 2015; ZHANG; 
DING; TANG, 2015). Para tanto, a mesma quantidade de catalisador utilizada nos experimentos foto-irradiados foi dispersa em $50 \mathrm{~mL}$ de solução de FFA $\left(C_{0, F F A}=10^{-4}\right.$ mol L $\left.{ }^{-1}\right)$ ou pCBA $\left(C_{0, p C B A}=22,5 \mu \mathrm{mol} \mathrm{L}^{-1}\right)$, de modo que [catalisador] $=0,5 \mathrm{~g} \mathrm{~L}^{-1}$. A suspensão foi agitada durante 24 horas a $25{ }^{\circ} \mathrm{C}$ para garantir a total adsorção do composto-sonda em cada material fotocatalítico. Empregou-se a mesma fonte radiante dos experimentos, com irradiância $I=13 \mathrm{~mW} \mathrm{~cm}^{-2}$. Alíquotas de $1 \mathrm{~mL}$ da suspensão aquosa eram coletadas do reator e filtradas através de um filtro de membrana de 0,45 $\mu \mathrm{m}$ para remover o catalisador e armazenadas no freezer para análise no HPLC. Cada experimento foi realizado em duplicata.

A concentração no estado estacionário de radicais $\mathrm{HO}^{\bullet}\left(\left[\mathrm{HO}^{\circ}\right]_{\mathrm{ss}}\right)$ foi determinada de acordo com a literatura (CHO et al., 2004; GLIGOROVSKI et al., 2015), com base no balanço molar de pCBA, dado pela Equação 2.19:

$$
\frac{-d[p C B A]}{d t}=k_{\exp }[p C B A]=k_{H O \bullet, p C B A}[H O \bullet]_{s S}[p C B A]
$$

Integrando a equação 2.19 resulta:

$$
-\ln \frac{[p C B A]}{[p C B A]_{0}}=k_{\text {exp }} t
$$

Em que: $k_{\text {exp }}=k_{\text {HO.pCBA }}[H O \bullet]_{s s}$ e $k_{H O . p C B A}=5 \times 10^{9} \mathrm{~L} \mathrm{~mol}^{-1} \mathrm{~s}^{-1}($ ELOVITZ; GUNTEN, 1999).

Como mostrado na Equação 2.22, a constante da taxa de degradação de pCBA obtida experimentalmente $\left(k_{\text {exp }}\right)$ pode ser determinada a partir do coeficiente angular da reta no gráfico $-\ln \frac{[p C B A]}{[p C B A]_{0}}$ versus $t(\min )$ para a degradação de pCBA.

A concentração no estado estacionário de oxigênio singlete $\left[{ }^{1} \mathrm{O}_{2}\right]_{\mathrm{ss}}$ foi determinada através do balanço molar para FFA, dado pela Equação 2.21:

$$
\frac{-d[F F A]}{d t}=k_{r 1 O 2, F F A}\left[{ }^{1} O_{2}\right]_{S S}[F F A]
$$


Em que $\left[{ }^{1} \mathrm{O}_{2}\right]_{\mathrm{ss}}$ e $[\mathrm{FFA}]$ são as concentrações de ${ }^{1} \mathrm{O}_{2}$ no estado estacionário e de FFA no tempo $t$, respectivamente, e $k_{r 1 O 2, F F A}$ representa a constante de segunda ordem da reação entre ${ }^{1} \mathrm{O}_{2}$ e FFA, com o valor de $1,2 \times 10^{8} \mathrm{~L} \mathrm{~mol}^{-1} \mathrm{~s}^{-1}$ (MOSTAFA; ROSARIO-ORTIZ, 2013).

Experimentalmente, obtêm-se os valores de constante de reação de pseudoprimeira ordem $\left(k_{o b s}\right)$ para a reação entre ${ }^{1} \mathrm{O}_{2}$ e FFA conforme equação a seguir:

$$
\frac{-d[F F A]}{d t}=k_{o b s}[F F A]
$$

Assim, a concentração do estado-estacionário $\left[{ }^{1} \mathrm{O}_{2}\right]_{\mathrm{ss}}$ pode ser determinada de acordo com a expressão:

$$
\left[{ }^{1} O_{2}\right] \mathrm{SS}=\frac{k_{o b s}}{k_{r, 1 O 2 F F A}}
$$

\subsection{Técnicas Analíticas}

As concentrações de SDZ, pCBA e FFA foram determinadas por cromatografia líquida de alta eficiência (HPLC), usando o equipamento Shimadzu (LC 20AD) com um detector UV-visível (SPD 20A) e uma coluna C18 (Phenomenex Synergi Fusion-RP $80 \mathrm{~A}, 150 \mathrm{~mm} \times 4,60 \mathrm{~mm}, 4 \mu \mathrm{m})$. A temperatura do forno e o volume de injeção da amostra foram de $40{ }^{\circ} \mathrm{C}$ e $50 \mu \mathrm{L}$, respectivamente. Todas as análises foram conduzidas em modo isocrático de eluente com uma vazão de $1,0 \mathrm{~mL} \mathrm{~min}^{-1}$. A mistura de eluente e o comprimento de onda de detecção de cada composto analisado são mostrados na Tabela 2.5. 
Tabela 2.5 Mistura de eluente e comprimento de onda para a detecção dos compostos SDZ, álcool furfurílico (FFA), ácido $p$-clorobenzóico (pCBA) nas análises de cromatografia líquida de alta eficiência (HPLC).

\begin{tabular}{|c|c|c|c|c|c|}
\hline Composto & Eluente A & Eluente B & $\begin{array}{c}\text { Proporção } \\
\text { (A:B) }\end{array}$ & $\begin{array}{c}\text { Tempo de } \\
\text { analise (min) }\end{array}$ & $\lambda_{\text {detecção }}$ \\
\hline SDZ & $\begin{array}{c}\text { ácido acético } \\
1,0 \%\end{array}$ & metanol & $20: 80$ & 10 & $266 \mathrm{~nm}$ \\
\hline $\mathrm{pCBA}$ & $\begin{array}{c}\text { ácido acético } \\
1,0 \%\end{array}$ & metanol & $30: 70$ & 20 & $219 \mathrm{~nm}$ \\
\hline FFA & $\begin{array}{c}\text { ácido acético } \\
1,0 \%\end{array}$ & metanol & $50: 50$ & 8 & $234 \mathrm{~nm}$ \\
\hline
\end{tabular}

A obtenção das curvas de calibração foi feita a partir do preparo de soluções de cada composto em diferentes concentrações com água Milli- $\mathrm{Q}^{\circledR}$. As equações lineares obtidas, os limites de detecção (LD) e os limites de quantificação (LQ) obtidos para cada composto são mostrados na Tabela 2.6.

Tabela 2.6 Resultados das curvas de calibração para análise de HPLC dos compostos álcool furfurílico (FFA), ácido $p$-clorobenzoico (pCBA) e sulfadiazina (SDZ).

\begin{tabular}{|c|c|c|c|c|c|}
\hline Composto & Equação & $R^{2 c}$ & $\begin{array}{l}\text { Tempo de } \\
\text { retenção } \\
(\text { min) }\end{array}$ & $\begin{array}{c}\mathbf{L D} \\
\left(\mu \mathrm{g} \mathrm{L^{-1 }}\right)\end{array}$ & $\begin{array}{c}\mathbf{L Q} \\
\left(\mu \mathrm{g} \mathbf{L}^{-1}\right)\end{array}$ \\
\hline SDZ & $\mathrm{A}^{\mathrm{a}}=116948,06 \times[\mathrm{SDZ}]^{\mathrm{b}}$ & 0,9999 & 6,4 & 2,6 & 8,6 \\
\hline pCBA & $\mathrm{A}=146590,96 \times[\mathrm{pCBA}]$ & 0,9999 & 10,0 & 0,4 & 1,2 \\
\hline FFA & $\mathrm{A}=8245842,32 \times[\mathrm{FFA}]$ & 0,9917 & 3,7 & 1,2 & 4,6 \\
\hline
\end{tabular}

${ }^{\mathrm{a} A}$ : área da curva obtida. ${ }^{\mathrm{b}}[\mathrm{c}]$ : concentração do composto $\left(\mathrm{mg} \mathrm{L}^{-1}\right) .{ }^{\mathrm{c}} R^{2}$ : coeficiente de determinação.

Os intermediários formados na degradação fotocatalítica da SDZ foram identificados em um equipamento de cromatografia líquida acoplado a um espectrômetro de massa Super Speed Shimadzu (LCMS-IT-TOF) operado com configuração tandem (MS/MS). A amostra foi ionizada em pressão atmosférica em uma sonda do tipo electrospray no modo positivo (ESI), com detecção de acordo com o tempo de voo (TOF). A secagem da amostra foi realizada com nitrogênio gasoso com pureza mínima de $99 \%$, pressão de $180 \mathrm{kPa}$ e vazão de $11 \mathrm{~L} \mathrm{~min}^{-1}$. A sonda de eletropulverização (ESI) foi operada a 4,5 kV. A interface da curva de linha de solvatação (CDL) foi operada a $200{ }^{\circ} \mathrm{C}$. A fragmentação das moléculas em modo de massa em 
tandem (MSn) foi realizada por dissociação induzida por colisão com $\operatorname{Ar}(>99,99 \%)$, com energia de dissociação induzida por colisão (CID) de $50 \%$. O erro entre as razões massa/carga experimentais e calculadas $(\mathrm{m} / z)$ foi menor que $1 \mathrm{mg} \mathrm{L}^{-1}$ para todos os compostos identificados. A coluna e o eluente utilizados foram idênticos aos da análise de HPLC, porém a vazão utilizada foi de $0,3 \mathrm{~mL} \mathrm{~min}^{-1}$.

\section{RESULTADOS}

\subsection{Fotodegradação Catalítica da Sulfadiazina em Reator Batelada}

A Figura 2.11 (a) mostra o espectro de emissão da lâmpada de $\mathrm{Hg}$ (equipada com filtro-janela de $320-500 \mathrm{~nm}$ ) utilizada no presente trabalho, juntamente com os espectros de absorção de (b) PMONDI-16, (c) SDZ e (d) $16 \% \mathrm{TiO}_{2} / \mathrm{SBA}-15$ nesta região. É possível observar uma maior sobreposição da emissão da lâmpada na região de comprimentos de ondas de absorção da sílica contendo a imida aromática NDI que com a sílica que contém o semicondutor $\mathrm{TiO}_{2}$, sendo um indicativo que o fotocatalisador PMONDI-16 apresenta maior excitação na faixa de emissão da fonte que o $16 \%$ $\mathrm{TiO}_{2} / \mathrm{SBA}-15$. É importante lembrar que, assim como a PMONDI-16, a PMONDI-8 absorve na mesma faixa de comprimentos de onda ( $\lambda_{\text {máx }}$ entre 360 e $380 \mathrm{~nm}$ ), porém em menor intensidade, devido ao menor teor de imida.

Vale ressaltar que há uma pequena sobreposição no espectro de absorção do contaminante SDZ com a emissão da lâmpada (entre 300-350 nm), o que pode resultar em fotólise do antibiótico. 
Figura 2.11 Espectros de (a) emissão da lâmpada de alta pressão de vapor de mercúrio (100 W) de arco curto Ominicure $S 1000$ associada a uma fibra óptica com filtro com janela 320-500 nm, juntamente com os espectros de absorção (b) da PMONDI-16 (c) da SDZ e (d) $16 \% \mathrm{TiO}_{2} / \mathrm{SBA}^{-15 .}$

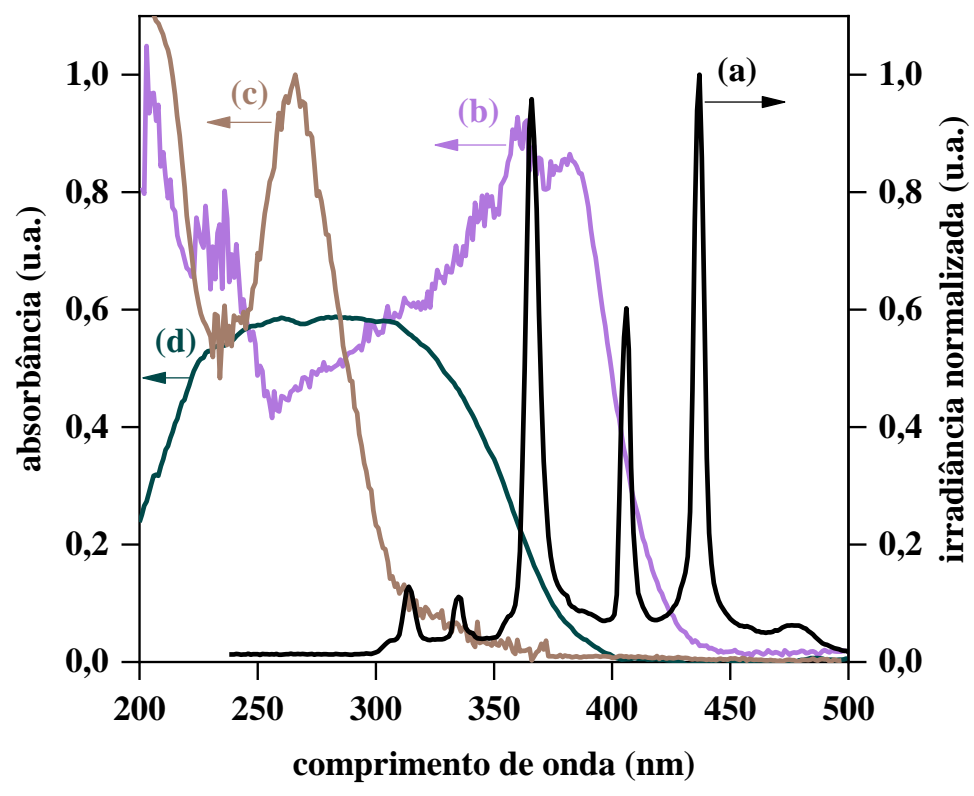

A Figura 2.12 apresenta a fotodegradação de SDZ $\left(C_{\mathrm{SDZ}} / C_{0, \mathrm{SDZ}}\right)$ de acordo com o tempo de reação e em presença dos catalisadores PMONDI-8, PMONDI-16 e 16\% $\mathrm{TiO}_{2} / \mathrm{SBA}-15$, juntamente com os experimentos controles: fotólise e em presença da sílica não funcionalizada SBA-15. Em cada gráfico, a linha tracejada marca o instante $(t$ = 0 min) em que foi dado início à irradiação decorrido o tempo de adsorção de $24 \mathrm{~h}$ na ausência de irradiação. Observa-se que o efeito de adsorção é relativamente baixo entre as moléculas de SDZ e a superfície dos fotocatalisadores.

O efeito fotocatalítico é notado quando a solução contendo o contaminante é irradiada em presença dos materiais sintetizados. Em todos os experimentos, houve quase total degradação de SDZ; no experimento F, houve degradação deste composto em apenas 40 min de irradiação em presença da PMONDI-16.

Ao aumentar a irradiância de $3 \mathrm{~mW} \mathrm{~cm}^{-2}$ para 8 e $13 \mathrm{~mW} \mathrm{~cm}^{-2}$, ocorre fotólise de SDZ (Figura $2.12 \mathrm{C}-\mathrm{G}$ ). O aumento da irradiância para $13 \mathrm{~mW} \mathrm{~cm}^{-2}$ também resulta na degradação da SDZ na presença da sílica não funcionalizada (SBA-15), este efeito pode ser atribuído ao efeito de espalhamento de luz no meio reacional devido à presença de suspensão das partículas brancas desta sílica (Figura 2.12F,G).

Os materiais fotocatalíticos se mostraram mais eficientes quando foto-excitados em maiores irradiâncias e menor concentração inicial de SDZ (Figura 2.12F). Tal resultado está em conformidade com o esperado, uma vez que pode ocorrer maior 
formação de espécies reativas de oxigênio, que degradam em menor tempo a pequena quantidade de moléculas de SDZ presentes no meio.

Figura 2.12 Fotodegradação de SDZ em pH natural e $25^{\circ} \mathrm{C}$. (A) $\mathrm{I}=3 \mathrm{~mW} \mathrm{~cm}^{-2}$ e $C_{0, \mathrm{SDZ}}=7,5 \mathrm{mg} \mathrm{L}^{-1}$; (B) $\mathrm{I}=3 \mathrm{~mW} \mathrm{~cm}^{-2}$ e $C_{0, \mathrm{SDZ}}=12,5 \mathrm{mg} \mathrm{L}^{-1}$; (C) I $=3 \mathrm{~mW} \mathrm{~cm}^{-2}$ e $C_{0, \mathrm{SDZ}}=5 \mathrm{mg} \mathrm{L}^{-1}$; (D) I $=8 \mathrm{~mW} \mathrm{~cm}^{-2}$ e $C_{0, \mathrm{SDZ}}$ $=10 \mathrm{mg} \mathrm{L}^{-1}$; (E) I $=8 \mathrm{~mW} \mathrm{~cm}^{-2}$ e $C_{0, \mathrm{SDZ}}=15 \mathrm{mg} \mathrm{L}^{-1}$; (F) I $=13 \mathrm{~mW} \mathrm{~cm}^{-2}$ e $C_{0, \mathrm{SDZ}}=7,5 \mathrm{mg} \mathrm{L}^{-1} ;(\mathrm{G}) \mathrm{I}=13$

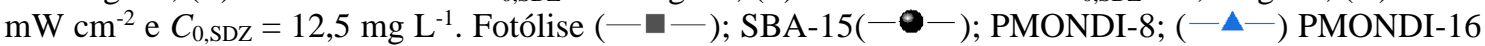
$(-)$; e $16 \% \mathrm{TiO}_{2} / \mathrm{SBA}-15(-\star-)$. A linha tracejada indica o instante em que se deu início à irradiação após $24 \mathrm{~h}$ na ausência de luz. Erro experimental avaliado a partir das triplicatas dos experimentos realizados nas condições do ponto central.
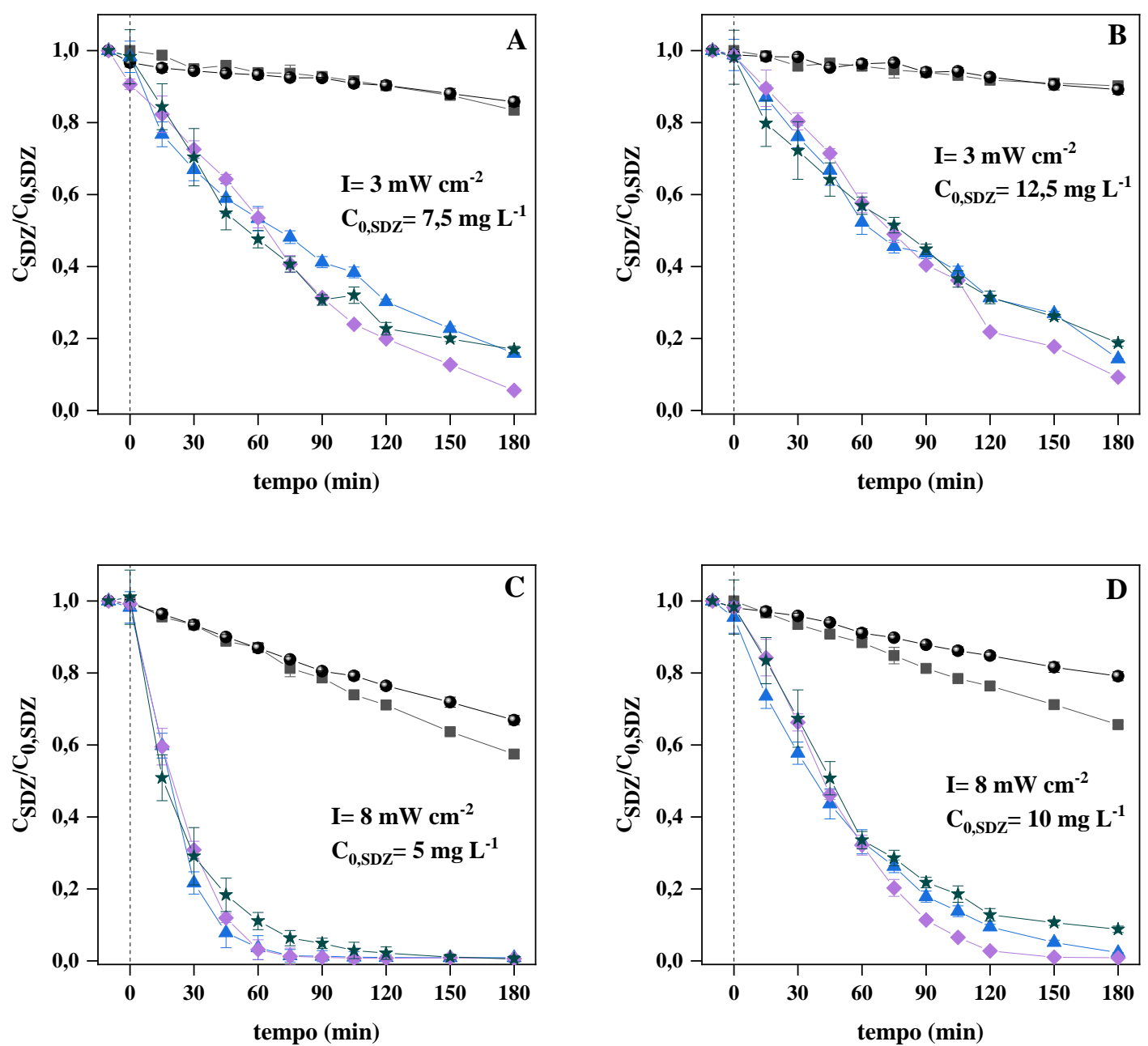
Figura 2.12 (Cont.) Fotodegradação de SDZ em pH natural e $25^{\circ} \mathrm{C}$. (A) $\mathrm{I}=3 \mathrm{~mW} \mathrm{~cm}{ }^{-2}$ e $C_{0, \mathrm{SDZ}}=7,5 \mathrm{mg}$ $\mathrm{L}^{-1}$; (B) $\mathrm{I}=3 \mathrm{~mW} \mathrm{~cm}^{-2}$ e $C_{0, \mathrm{SDZ}}=12,5 \mathrm{mg} \mathrm{L}^{-1}$; (C) $\mathrm{I}=3 \mathrm{~mW} \mathrm{~cm}^{-2}$ e $C_{0, \mathrm{SDZ}}=5 \mathrm{mg} \mathrm{L}^{-1}$; (D) $\mathrm{I}=8 \mathrm{~mW} \mathrm{~cm}^{-2}$ e $C_{0, \mathrm{SDZ}}=10 \mathrm{mg} \mathrm{L}^{-1}$; (E) $\mathrm{I}=8 \mathrm{~mW} \mathrm{~cm}^{-2}$ e $C_{0, \mathrm{SDZ}}=15 \mathrm{mg} \mathrm{L}^{-1}$; (F) I $=13 \mathrm{~mW} \mathrm{~cm}^{-2}$ e $C_{0, \mathrm{SDZ}}=7,5 \mathrm{mg} \mathrm{L}^{-1}$;

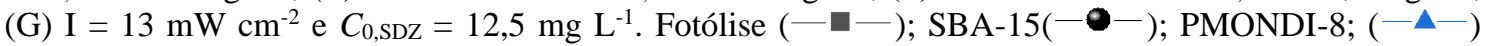
PMONDI-16 (-); e 16\% $\mathrm{TiO}_{2} / \mathrm{SBA}-15(-\star-)$. A linha tracejada indica o instante em que se deu início à irradiação após $24 \mathrm{~h}$ na ausência de luz. Erro experimental avaliado a partir das triplicatas dos experimentos realizados nas condições do ponto central.
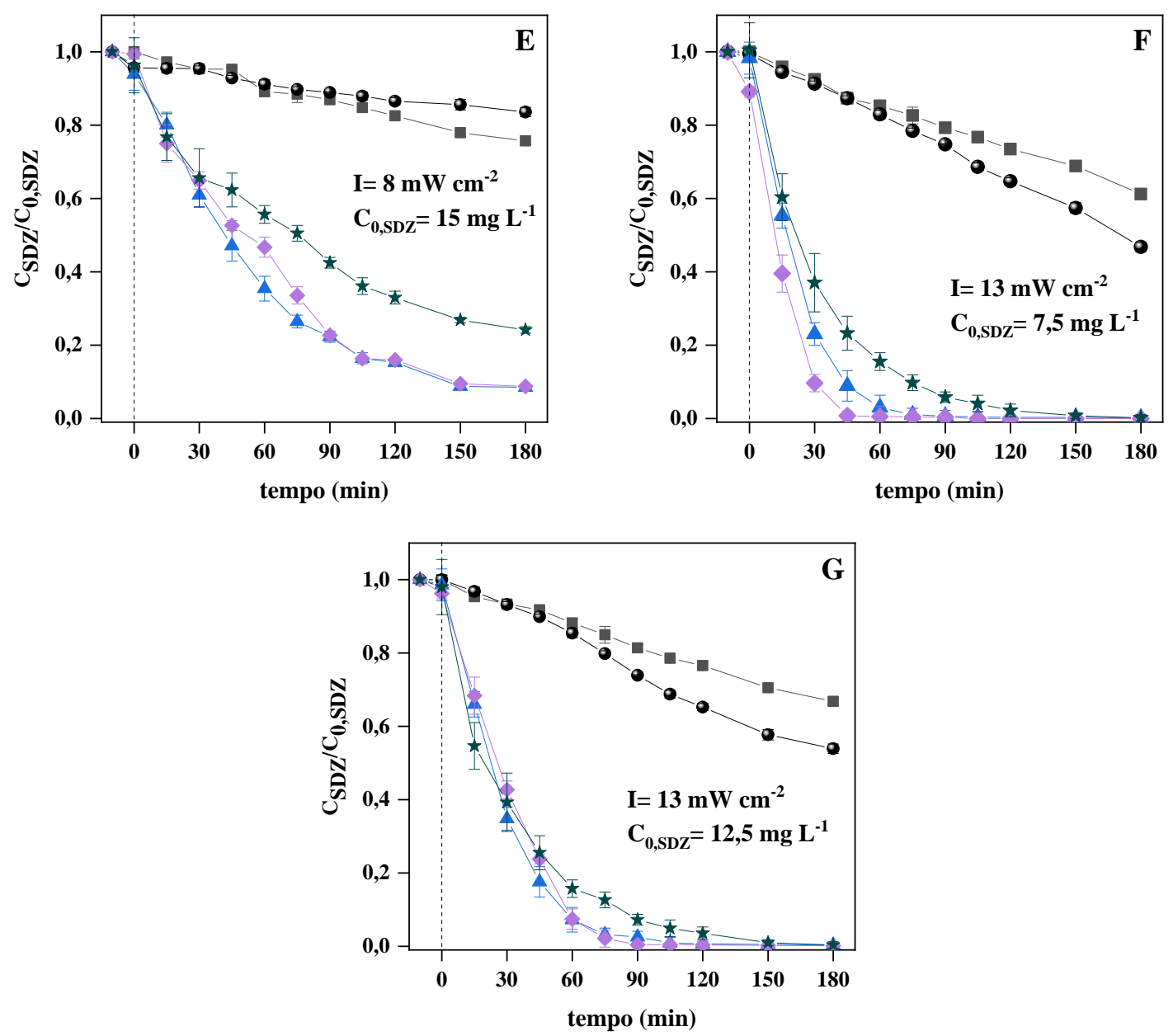

A Tabela 2.7 apresenta as constantes cinéticas de pseudo-primeira ordem $\left(k_{\mathrm{SDZ}}\right)$ obtidas pela Equação 2.18, com os respectivos coeficientes de determinação $\left(R^{2}\right)$, para cada experimento de fotodegradação de SDZ. 
Tabela 2.7 Constantes cinéticas de pseudo-primeira ordem para degradação fotocatalítica de SDZ $\left(k_{\mathrm{SDZ}}\right)$ e seus respectivos coeficientes de determinação $\left(R^{2}\right)$.

\begin{tabular}{|c|c|c|c|c|c|}
\hline Experimento & Fotocatalisador & $\begin{array}{c}I \\
\left(\mathrm{~mW} \mathrm{~cm}^{-2}\right)\end{array}$ & $\begin{array}{c}C_{0, \mathrm{SDZ}} \\
\left(\mathrm{mg} \mathrm{L}^{-1}\right)\end{array}$ & $\begin{array}{c}k_{S D Z} \\
\left(10^{-2} \mathrm{~min}^{-1}\right)\end{array}$ & $R^{2}$ \\
\hline \multirow{7}{*}{$\begin{array}{l}\text { Homogêneo } \\
\text { (Fotólise) }\end{array}$} & \multirow{7}{*}{-} & 3 & 7,5 & 0,086 & 0,9900 \\
\hline & & 3 & 12,5 & 0,068 & 0,9836 \\
\hline & & 8 & 5 & 0,265 & 0,9704 \\
\hline & & 8 & 10 & 0,220 & 0,9900 \\
\hline & & 8 & 15 & 0,161 & 0,9926 \\
\hline & & 13 & 7,5 & 0,231 & 0,9788 \\
\hline & & 13 & 12,5 & 0,203 & 0,9798 \\
\hline \multirow{28}{*}{$\begin{array}{l}\text { Heterogêneo } \\
\text { (Fotocatálise) }\end{array}$} & \multirow{7}{*}{ SBA-15 } & 3 & 7,5 & 0,062 & 0,9732 \\
\hline & & 3 & 12,5 & 0,060 & 0,9924 \\
\hline & & 8 & 5 & 0,197 & 0,9823 \\
\hline & & 8 & 10 & 0,109 & 0,9665 \\
\hline & & 8 & 15 & 0,077 & 0,9659 \\
\hline & & 13 & 7,5 & 0,357 & 0,9773 \\
\hline & & 13 & 12,5 & 0,332 & 0,9749 \\
\hline & \multirow{7}{*}{ PMONDI-8 } & 3 & 7,5 & 0,965 & 0,9849 \\
\hline & & 3 & 12,5 & 0,950 & 0,9913 \\
\hline & & 8 & 5 & 4,570 & 0,9859 \\
\hline & & 8 & 10 & 1,894 & 0,9650 \\
\hline & & 8 & 15 & 1,609 & 0,9944 \\
\hline & & 13 & 7,5 & 4,522 & 0,9910 \\
\hline & & 13 & 12,5 & 3,525 & 0,9888 \\
\hline & \multirow{7}{*}{ PMONDI-16 } & 3 & 7,5 & 1,134 & 0,9688 \\
\hline & & 3 & 12,5 & 0,998 & 0,9690 \\
\hline & & 8 & 5 & 4,142 & 0,9912 \\
\hline & & 8 & 10 & 1,822 & 0,9982 \\
\hline & & 8 & 15 & 1,451 & 0,9884 \\
\hline & & 13 & 7,5 & 5,843 & 0,9847 \\
\hline & & 13 & 12,5 & 3,218 & 0,9799 \\
\hline & \multirow{7}{*}{$16 \% \mathrm{TiO}_{2} / \mathrm{SBA}-15$} & 3 & 7,5 & 1,157 & 0,9905 \\
\hline & & 3 & 12,5 & 0,920 & 0,9914 \\
\hline & & 8 & 5 & 4,149 & 0,9944 \\
\hline & & 8 & 10 & 1,566 & 0,9883 \\
\hline & & 8 & 15 & 0,911 & 0,9687 \\
\hline & & 13 & 7,5 & 3,144 & 0,9900 \\
\hline & & 13 & 12,5 & 3,210 & 0,9892 \\
\hline
\end{tabular}

É possível notar na Tabela 2.7 que a maior constante cinética obtida foi de 5,843 $\times 10^{-2} \mathrm{~min}^{-1}$ no experimento realizado $\mathrm{m}$ presença do fotocatalisador PMONDI-16 nas condições com baixa concentração inicial de $\operatorname{SDZ}\left(C_{0, \mathrm{SDZ}}=7,5 \mathrm{mg} \mathrm{\textrm {L } ^ { - 1 }}\right)$ e alta irradiância $\left(I=13 \mathrm{~mW} \mathrm{~cm}^{-2}\right)$.

Para maior facilidade na comparação entre as constantes cinéticas obtidas, a Figura 2.13 mostra o efeito da variação da irradiância $\left(\mathrm{mW} \mathrm{cm}^{-2}\right)$ para experimentos realizados com soluções de mesma concentração inicial de SDZ $\left(C_{0, \mathrm{SDZ}}\right)$. É possível observar que com o aumento da irradiância de 3 para $13 \mathrm{~mW} \mathrm{~cm} \mathrm{~cm}^{-2}$ a remoção 
fotocatalítica de SDZ apresentou melhor desempenho, tanto para $C_{0, \mathrm{SDZ}}$ de $7,5 \mathrm{mg} \mathrm{L}^{-1}$ (Figura 2.13A) quanto para $C_{0, \mathrm{SDZ}}$ de $12,5 \mathrm{mg} \mathrm{L}^{-1}$ (Figura 2.13B). Os materiais PMONDI apresentaram melhor desempenho que o $16 \% \mathrm{TiO}_{2} / \mathrm{SBA}-15$, particularmente quando os experimentos foram realizados com menor concentração inicial de SDZ (Figura 2.13A). Em contrapartida, quando $C_{0, \mathrm{SDZ}}=12,5 \mathrm{mg} \mathrm{L}^{-1}$ as constantes cinéticas obtidas foram similares para todos materiais fotocatalíticos, para as duas irradiâncias apresentadas (Figura 2.13B).

Figura 2.13 Efeito da irradiância $\left(I=3\right.$ e $\left.13 \mathrm{~mW} \mathrm{~cm}^{-2}\right)$ na fotodegradação catalítica de $\mathrm{SDZ}$. (A) $C_{0, \mathrm{SDZ}}=$ $7,5 \mathrm{mg} \mathrm{L}{ }^{-1}$; (B) $C_{0, \mathrm{SDZ}}=12,5 \mathrm{mg} \mathrm{L}^{-1}$. Nesses experimentos: ( ) fotólise; (\$\&) SBA-15; (EzZ)

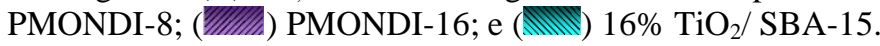
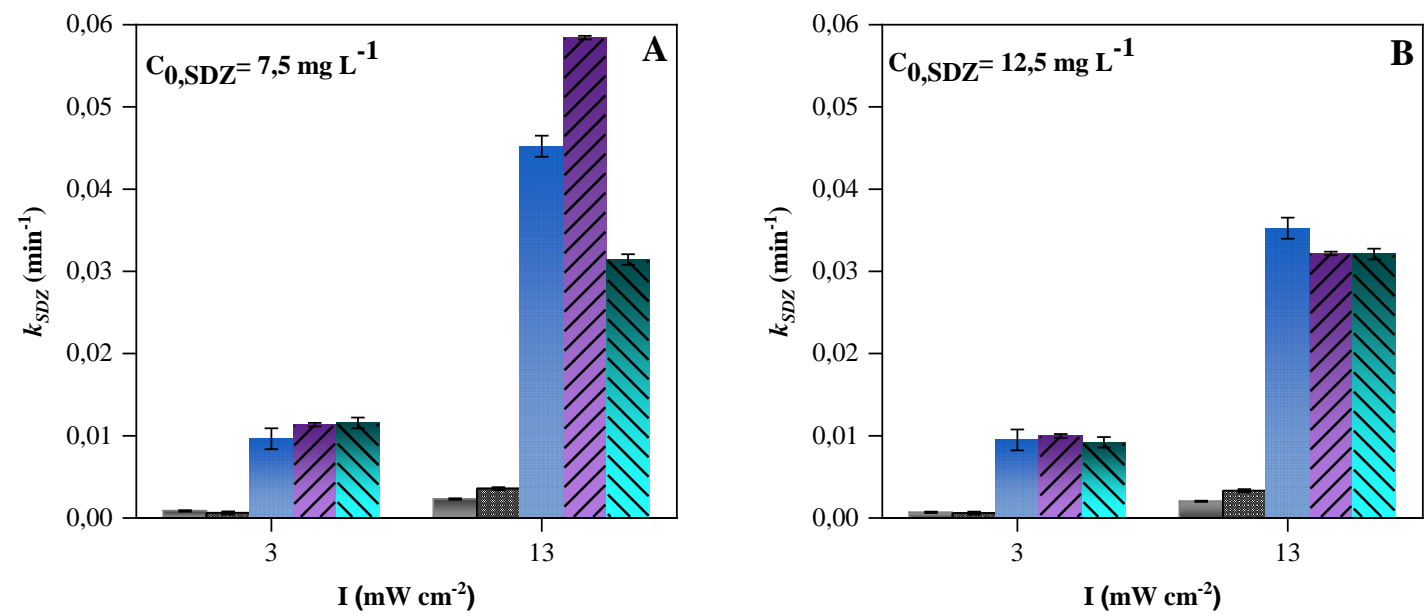

O efeito da variação de concentração inicial de SDZ sobre a constante cinética de pseudo-primeira ordem $\left(k_{\mathrm{SDZ}}\right)$, mantendo a irradiância constante, irradiada em uma pode ser visto na Figura 2.14. Em baixa irradiância $\left(3 \mathrm{~mW} \mathrm{~cm}{ }^{-2}\right)$, as constantes cinéticas foram muito similares, mesmo com variação de concentração inicial de SDZ de 7,5 mg $\mathrm{L}^{-1}$ para $12,5 \mathrm{mg} \mathrm{L}^{-1}$ (Figura 2.14A). Quando se utilizou irradiância de $8 \mathrm{~mW} \mathrm{~cm}^{-2}$, é possível notar que os valores de $k_{\mathrm{SDZ}}$ diminuem aproximadamente pela metade com $\mathrm{o}$ aumento de $C_{0, \mathrm{SDZ}}$ de 5 para $10,0 \mathrm{mg} \mathrm{L}^{-1}$ e se mantêm quando se aumenta para o $C_{0, \mathrm{SDZ}}$ para $15 \mathrm{mg} \mathrm{L}^{-1}$ (Figura 2.14B).

Em $13 \mathrm{~mW} \mathrm{~cm}{ }^{-2}$ os valores de $k_{\mathrm{SDZ}}$ na presença dos fotocatalisadores contendo a imida aromática NDI (PMONDI) sofrem diminuição quando se aumenta a concentração inicial de SDZ de 4,522 × $10^{-2}$ e 5,843 $\times 10^{-2} \min ^{-1}$ para $3,525 \times 10^{-2}$ e $3,218 \times 10^{-2}$ $\min ^{-1}$, para PMONDI-16 e PMONDI-8, respectivamente. Tal efeito não ocorre na 
presença do fotocatalisador $16 \% \mathrm{TiO}_{2} / \mathrm{SBA}-15$ (Figura $2.14 \mathrm{C}$ ), para o qual os valores de $k_{\text {SDZ }}$ permanecem similares em $3,144 \times 10^{-2}$ e $3,210 \times 10^{-2} \min ^{-1}$ para $C_{0, S D Z}$ de 7,5 e $12,5 \mathrm{mg} \mathrm{L}^{-1}$, respectivamente. Este resultado pode ser devido aos diferentes mecanismos de geração de espécies reativas de oxigênio em cada fotocatalisador, que promovem a degradação do contaminante SDZ, bem como sua dependência com a taxa de fótons que o componente fotoativo absorve.

Figura 2.14 Efeito da concentração inicial de $\operatorname{SDZ}\left(C_{0, \mathrm{SDZ}}=7,5 \mathrm{mg} \mathrm{L}^{-1}\right.$ e $\left.12,5 \mathrm{mg} \mathrm{L}^{-1}\right)$ na fotodegradação catalítica de SDZ. (A) $3 \mathrm{~mW} \mathrm{~cm}^{-2}$; (B) $8 \mathrm{~mW} \mathrm{~cm}^{-2}$; (C) $13 \mathrm{~mW} \mathrm{~cm}^{-2}$. Nesses experimentos, ( $\square$ ) fotólise;

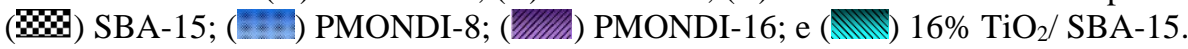
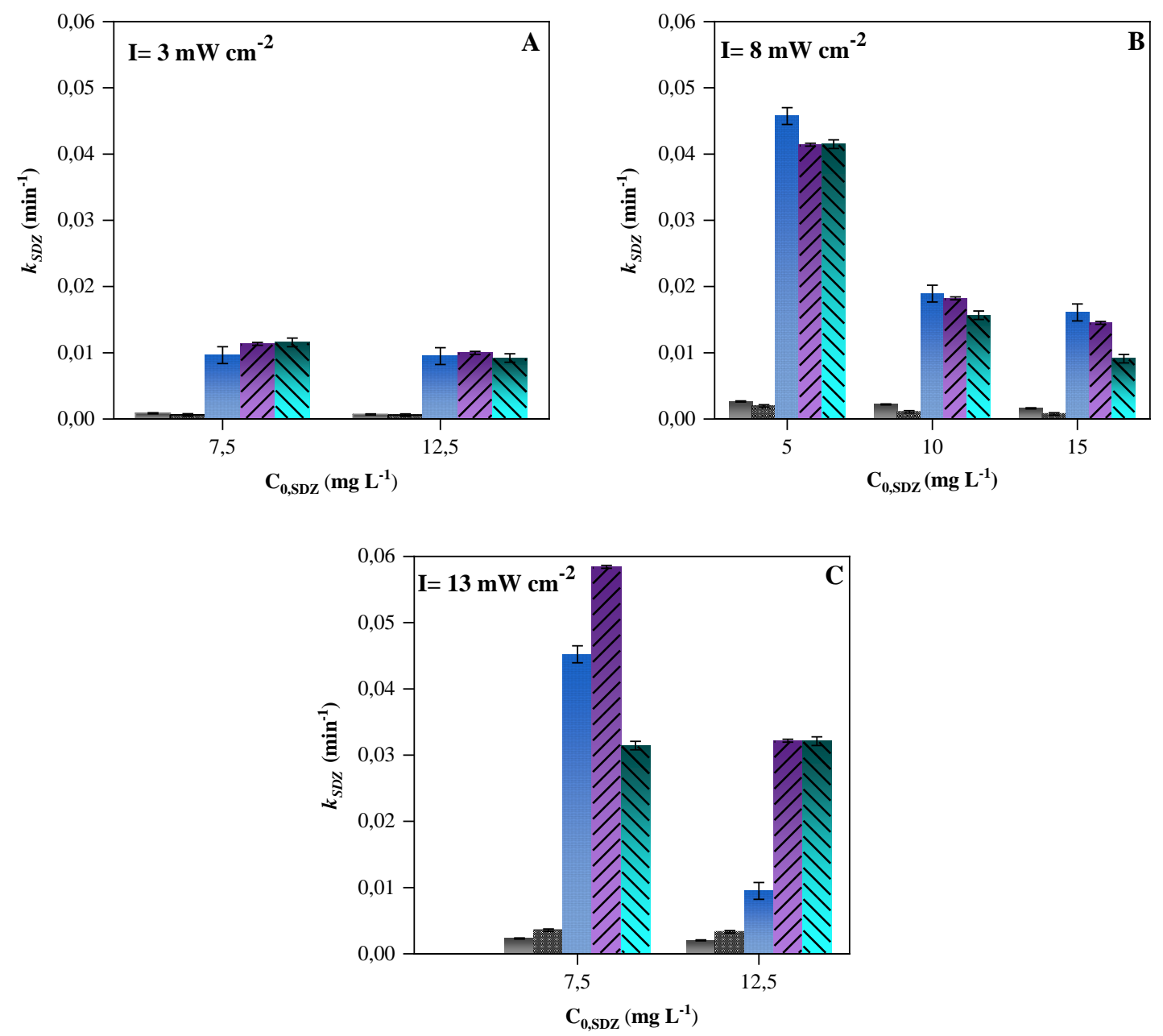

\subsection{Reutilização dos Fotocatalisadores}

Como foi visto, os fotocatalisadores $16 \% \mathrm{TiO}_{2} / \mathrm{SBA}-15$ e PMONDI-16 obtiveram o melhor desempenho para de degradação de SDZ, por este motivo, também foram avaliados quanto ao reuso. Para isso, reutilizou-se cada material em três ciclos distintos 
de fotodegradação de SDZ. Na seleção das condições adotadas para cada experimento, consideram-se maior concentração de $\operatorname{SDZ}\left(C_{0, \mathrm{SDZ}}=12,5 \mathrm{mg} \mathrm{L}^{-1}\right)$ e menor irradiância (I $=3 \mathrm{~mW} \mathrm{~cm}^{-2}$ ), pois é nestas condições que não houve efeito pronunciado de fotólise (Figura 2.12B).

O fotocatalisador PMONDI-16 mostrou desempenho melhor nos experimentos de reutilização quando comparado a $16 \% \mathrm{TiO}_{2} / \mathrm{SBA}-15$, como mostra a Figura 2.15. Este é um indicativo que organosílicas periódicas mesoporosas contendo imidas aromáticas podem ser fortes candidatas para serem aplicadas como fotocatalisadores. Devido à diferença de mecanismo de fotodegradação, a inativação da PMONDI-16 parece ser menor que no caso do material contendo $\mathrm{TiO}_{2}$.

Figura 2.15 Experimentos de reutilização dos fotocatalisadores (-A) PMONDI-16 e (m) $16 \%$ $\mathrm{TiO}_{2} /$ SBA-15 quanto à degradação fotocatalítica de SDZ. Condições: $C_{0, \mathrm{SDZ}}=12,5 \mathrm{mg} \mathrm{L}^{-1} ; \mathrm{I}=3 \mathrm{~mW} \mathrm{~cm}^{-}$ 2; pH natural ; $25^{\circ} \mathrm{C}$.

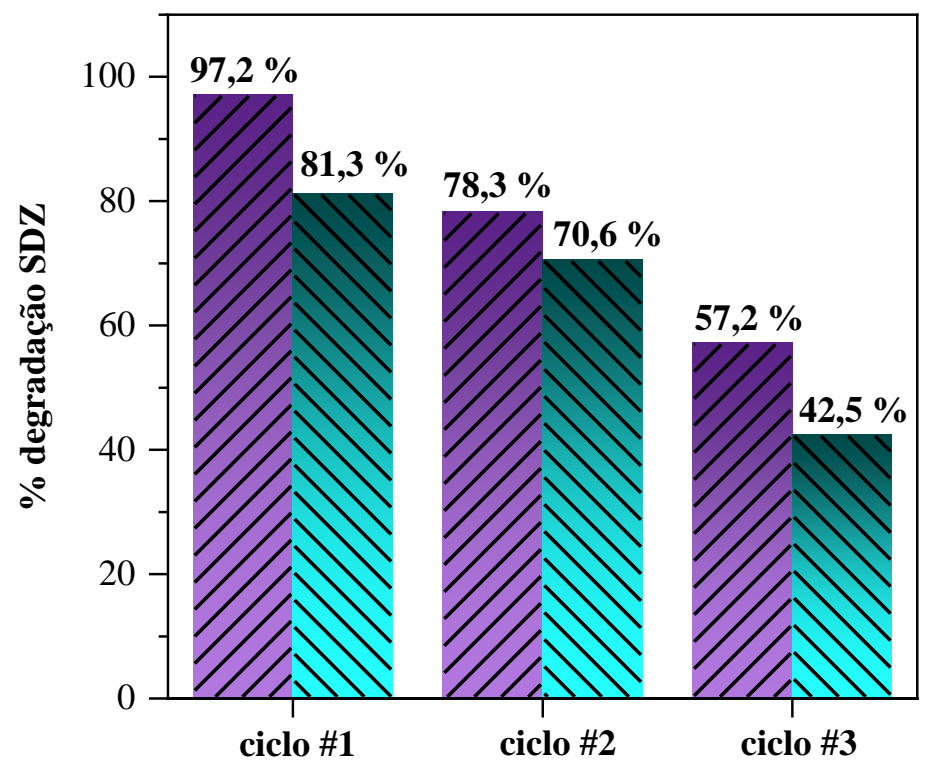

\subsection{Estudo da Geração das Espécies Reativas Fotoinduzidas na Degradação da} SDZ

Para melhor entender os diferentes mecanismos que levam à degradação de SDZ, buscou-se quantificar a geração de espécies reativas de oxigênio (oxigênio singlete, ${ }^{1} \mathrm{O}_{2}$; radicais hidroxila, $\mathrm{HO}^{*}$ ) na presença dos fotocatalisadores $16 \%$ $\mathrm{TiO}_{2} / \mathrm{SBA}-15$, PMONDI-8 e PMONDI-16, como apresentado a seguir. O estudo da geração de espécies fotoinduzidas foi realizado através do uso de compostos-sonda 
(FFA e pCBA, respectivamente), que interagem com essas espécies reativas segundo reações de segunda ordem com constantes de velocidade conhecidas, o que permite a quantificação dessas espécies de forma indireta.

Neste estudo, foram utilizadas as condições do experimento G (Figura 2.12), ou seja, maior concentração de $\operatorname{SDZ}\left(C_{0, \mathrm{SDZ}}=12,5 \mathrm{mg} \mathrm{L}^{-1}\right)$ e maior irradiância $(\mathrm{I}=13 \mathrm{~mW}$ $\mathrm{cm}^{-2}$ ). Estas condições mostraram-se adequadas para quantificação da concentração no estado estacionário das espécies radicalares.

A Figura 2.16 apresenta a degradação do pCBA em meio aquoso contendo o fotocatalisador $16 \% \mathrm{TiO}_{2} / \mathrm{SBA}-15$, na ausência e presença de $\operatorname{SDZ}\left(12,5 \mathrm{mg} \mathrm{L}^{-1}\right)$. A ocorrência da degradação de pCBA em ambos os sistemas indica a formação de radicais hidroxila $\mathrm{HO}^{\bullet}$. É possível notar, na irradiação na presença de SDZ, que após $30 \mathrm{~min}$ uma parte dos radicais formados que degradam o pCBA começam a ser consumidos em uma reação competitiva para a degradação de SDZ.

É importante salientar que os experimentos de controle mostraram que a remoção por adsorção de pCBA na superfície da sílica mesoporosa SBA-15 é pouco importante, garantindo que a degradação observada se deve apenas ao ataque de radicais HO. 
Figura 2.16 Experimentos de fotodegradação de pCBA $\left(C_{0, \mathrm{pCBA}}=22,5 \mu \mathrm{mol} \mathrm{L}{ }^{-1}\right)$ em meio aquoso (50 $\mathrm{mL})$ contendo $16 \% \mathrm{TiO}_{2} \mathrm{SBA}-15\left(0,5 \mathrm{~g} \mathrm{~L}^{-1}\right)$. (- - $)$ ausência de $\mathrm{SDZ}$ e $(-\boldsymbol{-}-)$ com SDZ $\left(C_{0, \mathrm{SDZ}}=12,5\right.$ $\left.\mathrm{mg} \mathrm{L}^{-1}\right)$. Condições: $\mathrm{I}=13 \mathrm{~mW} \mathrm{~cm} \mathrm{~m}^{-2}$; $\mathrm{pH}$ natural; $25^{\circ} \mathrm{C}$.

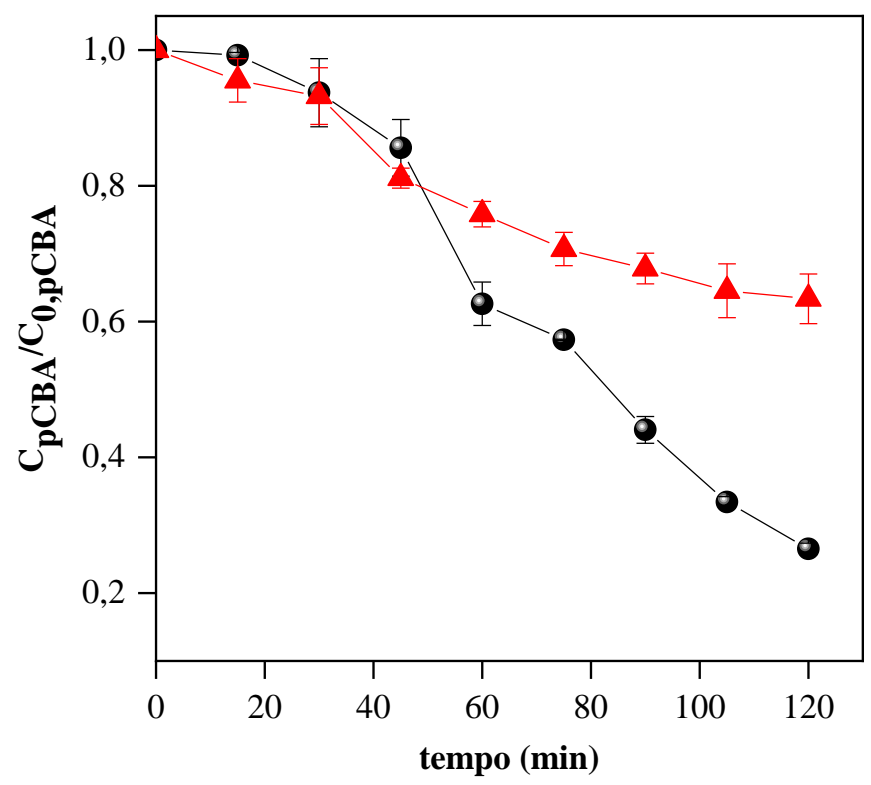

De fato, ao irradiar a solução contendo o composto-sonda FFA na presença de PMONDI-16, este sofre rápida degradação (Figura 2.17), sendo um indicativo de que oxigênio singlete $\left({ }^{1} \mathrm{O}_{2}\right)$ é a espécie reativa predominante neste sistema. Nestes experimentos, a presença de SDZ não gera reação competitiva para a degradação de FFA.

Figura 2.17 Experimentos de fotodegradação de FFA $\left(C_{0, \mathrm{FFA}}=10^{-4} \mathrm{~mol} \mathrm{~L}^{-1}\right)$ em meio aquoso $(50 \mathrm{~mL})$ contendo (A) PMONDI-8 e (B) PMONDI-16 (C) 16\% TiO $/ \mathrm{SBA}^{-15}$, ambos a 0,5 $\mathrm{g} \mathrm{L}^{-1}$. (- - ) ausência de SDZ; e $\left(-\boldsymbol{A}_{-}\right)$com SDZ $\left(C_{0, \mathrm{SDZ}}=12,5 \mathrm{mg} \mathrm{L}^{-1}\right)$. Condições: $\mathrm{I}=13 \mathrm{~mW} \mathrm{~cm}{ }^{-2} ; \mathrm{pH}$ natural; $25{ }^{\circ} \mathrm{C}$.
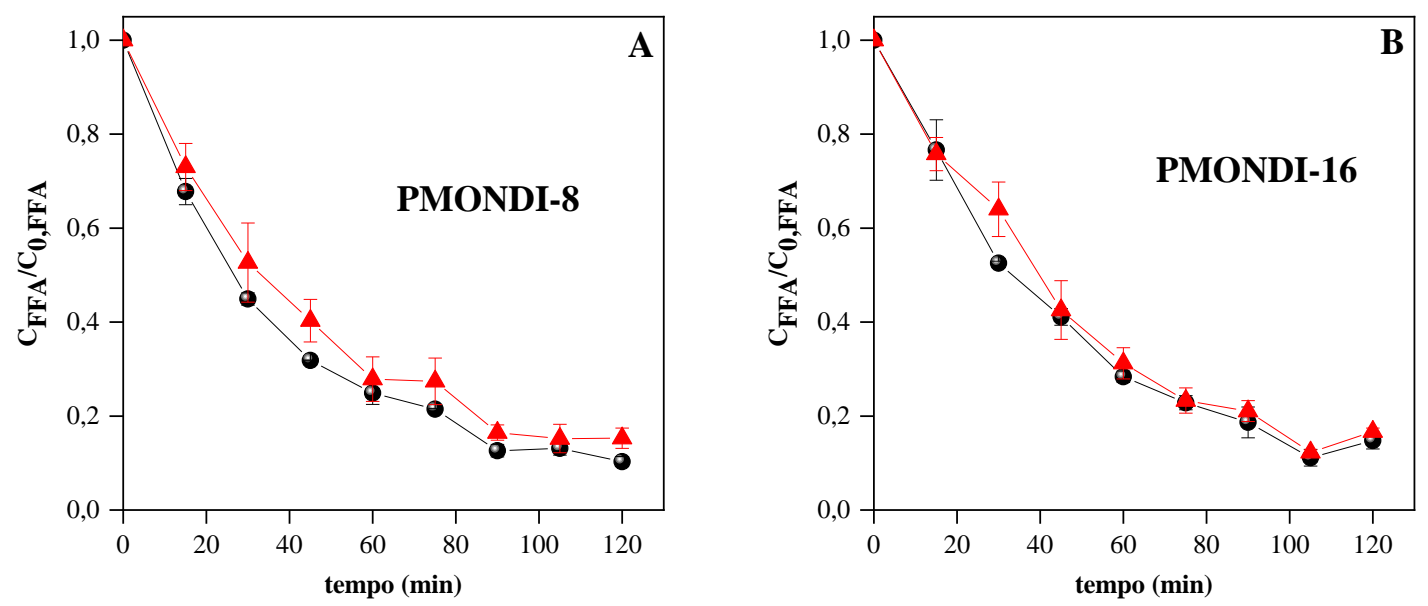
De acordo com as Equações 2.21 e 2.22 (secção 5.2.4) a inclinação da curva de degradação $\left(\ln \left(C_{\mathrm{pCBA}} / C_{0, \mathrm{pCBA}}\right) v s\right.$. tempo) (Figura 2.18) dividida pelo $k_{\mathrm{HO} \cdot \mathrm{pCBA}}$ resultará na concentração de radicais $\mathrm{HO}^{*}$ no estado estacionário ([HO$\left.\left.{ }^{*}\right]_{\mathrm{ss}}\right)$.

E através das Equações 2.24 e 2.25 (secção 5.2.4) a inclinação da curva de degradação $\left(\ln \left(C_{\mathrm{FFA}} / C_{0, \mathrm{FFA}}\right) v s\right.$. tempo) (Figura 2.19) dividida por $k_{102 \text {,FFA resultará na }}$ concentração de estado estacionário de oxigênio singlete $\left(\left[{ }^{1} \mathrm{O}_{2}\right]_{\mathrm{ss}}\right)$. Os resultados de concentrações de estado estacionário das espécies radicalares fotoinduzidas são mostrados na Tabela 2.8 .

Figura 2.18 Ajuste linear de $\ln \left(C_{\mathrm{pCBA}} / \mathrm{C}_{0, \mathrm{pCBA}}\right)$ versus tempo (s) para determinação da quantidade estacionária de radicais hidroxila $\left(\left[\mathrm{HO}^{*}\right]_{\mathrm{ss}}\right)$ na irradiação de solução $(50 \mathrm{~mL})$ contendo pCBA $\left(C_{0, \mathrm{pCBA}}=\right.$ $\left.22,5 \mu \mathrm{mol} \mathrm{L} \mathrm{L}^{-1}\right)$ na presença do fotocatalisador $16 \% \mathrm{TiO}_{2} / \mathrm{SBA}-15\left(0,5 \mathrm{~g} \mathrm{~L}^{-1}\right)$. (A) ausência de SDZ (B); com SDZ $\left(C_{0, \mathrm{SDZ}}=12,5 \mathrm{mg} \mathrm{L}^{-1}\right)$. Condições: $\mathrm{I}=13 \mathrm{~mW} \mathrm{~cm}{ }^{-2} ; \mathrm{pH}$ natural; $25{ }^{\circ} \mathrm{C}$.
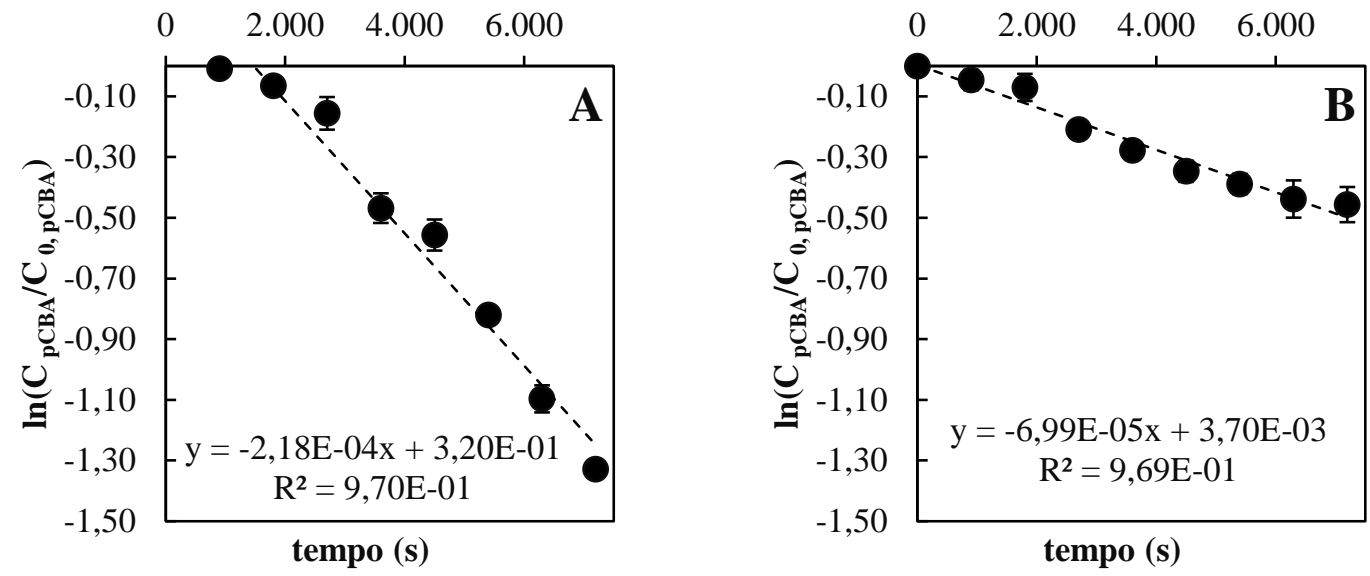
Figura 2.19 Ajuste linear de $\ln \left(C_{\mathrm{FFA}} / C_{0, \mathrm{FFA}}\right)$ versus tempo para determinação da quantidade estacionária de oxigênio singlete $\left(\left[{ }^{1} \mathrm{O}_{2}\right]_{\mathrm{ss}}\right)$ na irradiação de solução $(50 \mathrm{~mL})$ contendo FFA $\left(C_{0, \mathrm{FFA}}=10^{-4} \mathrm{~mol} \mathrm{~L}^{-1}\right)$ na presença do fotocatalisador PMONID-8 $\left(0,5 \mathrm{~g} \mathrm{~L}^{-1}\right)$. (A) ausência de SDZ (B); com SDZ ( $C_{0, \mathrm{SDZ}}=12,5 \mathrm{mg}$ $\left.\mathrm{L}^{-1}\right)$, e PMONDI-16 $\left(0,5 \mathrm{~g} \mathrm{~L}^{-1}\right)$. (C) ausência de SDZ (D); com SDZ $\left(C_{0, \mathrm{SDZ}}=12,5 \mathrm{mg} \mathrm{L}^{-1}\right)$. Condições: I $=13 \mathrm{~mW} \mathrm{~cm}{ }^{-2} ; \mathrm{pH}$ natural; $25^{\circ} \mathrm{C}$.
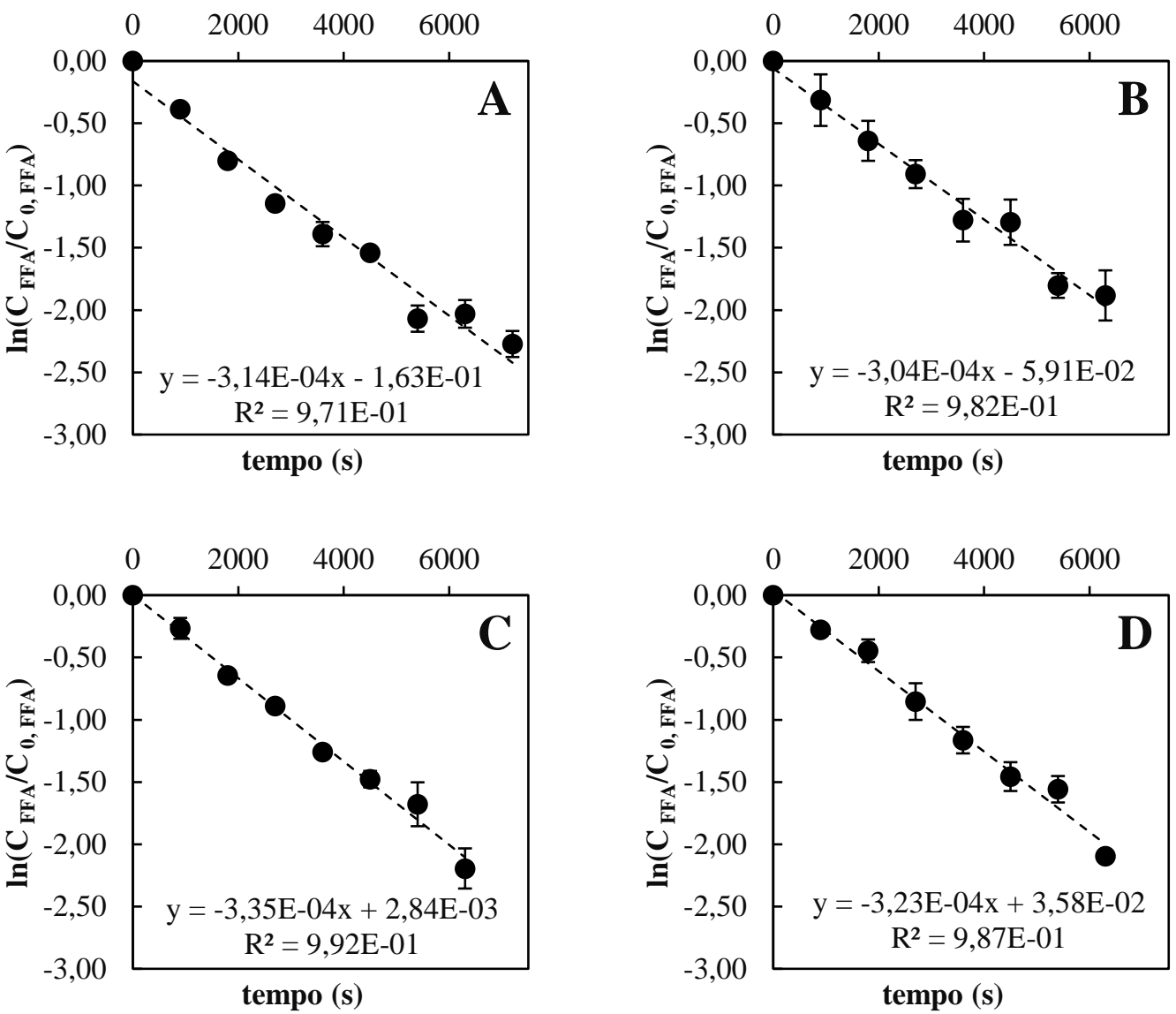

A concentração de radicais $\mathrm{HO}^{\bullet}$ gerados no estado estacionário $\left(4,36 \times 10^{-14} \mathrm{~mol}\right.$ $\mathrm{L}^{-1}$ ) pelas moléculas do semicondutor $\mathrm{TiO}_{2}$ (anatase) ancoradas no substrato SBA-15 está conforme a literatura (CONCEIÇÃO et al., 2017). Devido à reação competitiva na presença de moléculas de SDZ esse valor caiu em três vezes. Como visto na introdução, o mecanismo de formação de radicais $\mathrm{HO}^{\bullet}$ pelo $\mathrm{TiO}_{2}$ é bem conhecido e ocorre através de uma série de reações de oxidação e redução que seguem a formação do par elétronlacuna quando o $\mathrm{TiO}_{2}$ é foto-excitado (Equações 2.1-2.9).

Como moléculas orgânicas fotossensíveis, as NDI presentes nos materiais PMONDI promoveram a geração de ${ }^{1} \mathrm{O}_{2}$ em concentrações estacionárias na ordem de $10^{-12} \mathrm{~mol} \mathrm{~L}{ }^{-1}$, conforme o esperado (SILVA et al., 2015). Tais valores de concentração se mostraram similares, tanto para PMONDI-8 quanto para PMONDI-16, o que pode 
ser um indicativo de que $8 \%$ em massa de NDI na sílica mesoporosa está alcançado o máximo de formação das espécies de ${ }^{1} \mathrm{O}_{2}$.

Tabela 2.8 Resultados da formação das espécies reativas fotoinduzidas: constante cinética de pseudoprimeira ordem observada $\left(k_{\exp }\right)$, coeficiente de determinação $\left(R^{2}\right)$ e concentração no estado estacionário de radicais hidroxila $\left(\left[\mathrm{HO}^{*}\right]_{\mathrm{ss}}\right)$ e de oxigênio singlete $\left(\left[{ }^{1} \mathrm{O}_{2}\right]_{\mathrm{ss}}\right)$.

\begin{tabular}{|c|c|c|c|c|}
\hline \multirow[t]{2}{*}{ Fotocatalisador } & \multirow{2}{*}{$\begin{array}{c}k_{\exp } \\
\left(10^{-4} s^{-1}\right)\end{array}$} & \multirow[t]{2}{*}{$R^{2}$} & \multicolumn{2}{|c|}{$\begin{array}{l}\text { Concentração de espécies reativas } \\
\text { em estado estacionário }\left(\mathrm{mol} \mathrm{L}^{-1}\right)\end{array}$} \\
\hline & & & {$\left[\mathrm{HO}^{\circ}\right]_{\mathrm{ss}}$} & {$\left[{ }^{1} \mathbf{O}_{2}\right]_{\mathrm{ss}}$} \\
\hline $16 \% \mathrm{TiO}_{2} / \mathrm{SBA}-15$ & 2,18 & 0,97 & $4,36 \times 10^{-14}$ & - \\
\hline $16 \% \mathrm{TiO}_{2} / \mathrm{SBA}-15+\mathrm{SDZ}$ & 0,69 & 0,96 & $1,40 \times 10^{-14}$ & - \\
\hline PMONDI-8 & 3,14 & 0,97 & - & $2,62 \times 10^{-12}$ \\
\hline PMONDI-8 +SDZ & 3,04 & 0,98 & - & $2,53 \times 10^{-12}$ \\
\hline PMONDI-16 & 3,35 & 0,99 & - & $2,79 \times 10^{-12}$ \\
\hline PMONDI-16 +SDZ & 3,23 & 0,98 & - & $2,69 \times 10^{-12}$ \\
\hline
\end{tabular}

$\mathrm{O}$ mecanismo de formação de ${ }^{1} \mathrm{O}_{2}$ pelas NDI é devido à grande tendência do estado excitado singlete desta imida ( $\left.{ }^{1} \mathrm{NDI}\right)$, gerado após absorção de fótons, sofrer cruzamento intersistemas (ISC) para o estado excitado triplete $\left({ }^{3} \mathrm{NDI}^{*}\right)$ com $\Phi_{\text {ISC }} \sim 1$ (ROGERS; KELLY, 1999). Dessa forma, a ${ }^{3} \mathrm{NDI}^{*}$ pode interagir com a SDZ pelos mecanismos I e II. No mecanismo I a SDZ pode estar interagindo diretamente com a ${ }^{3} \mathrm{NDI}^{*}$ para formar íons NDI e SDZ ou oxidar a SDZ. No mecanismo tipo II a ${ }^{3} \mathrm{NDI} *$ interage com o oxigênio dissolvido para formar oxigênio singlete ${ }^{1} \mathrm{O}_{2}$, que pode estar degradando a SDZ ou sendo desativado pela água do sistema (LI et al., 2016) (Figura 2.20) 
Figura 2.20 Mecanismos tipo I e tipo II possíveis para a degradação de SDZ induzida pelo sensibilizador orgânico 1,4,5,8-naftalenodiimidas (NDI), em que $h v$ representa a absorção de radiação UV pela NDI; ${ }^{1} \mathrm{NDI}^{*},{ }^{3} \mathrm{NDI} *$ correspondem aos estados excitado singlete e triplete, enquanto ISC corresponde ao cruzamento intersistemas.

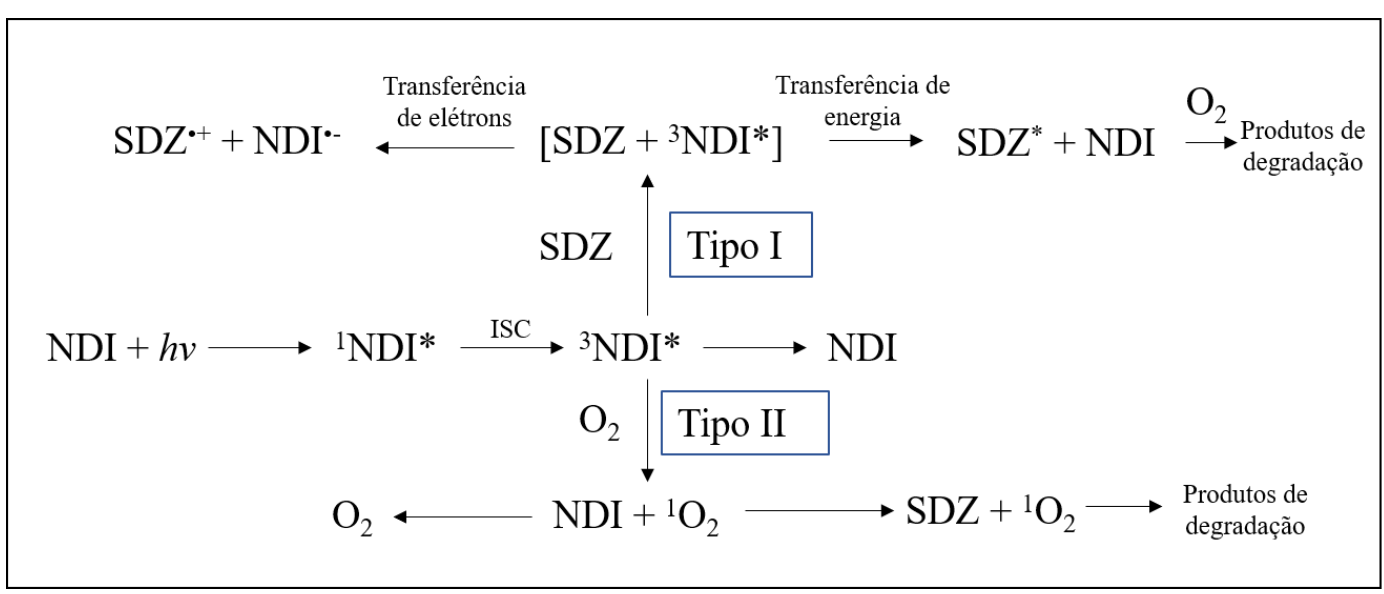

\subsection{Identificação dos Intermediários Formados na Fotodegradação da SDZ}

Para a identificação de intermediários gerados a partir da degradação fotocatalítica da SDZ, foram realizadas análises de cromatografia líquida acoplada a espectrometria de massas (LC-MS) das soluções aquosas coletadas no tempo 0 min e após 180 min de irradiação na presença dos catalisadores $16 \% \quad \mathrm{TiO}_{2} / \mathrm{SBA}-15$ e PMONDI-16. A Figura 2.21 mostra os cromatogramas e os picos mais proeminentes obtidos, nomeados SDZ, P1, P2 e P3. Através do levantamento bibliográfico foi possível identificar a estrutura molecular de cada fragmento obtido (Figura 2.22) e propor as etapas do mecanismo de degradação da SDZ (Figura 2.23). 
Figura 2.21 Cromatogramas (LC-MS) das soluções de SDZ. (A) não irradiada; (B) irradiada por 180 min na presença de $16 \% \mathrm{TiO}_{2} / \mathrm{SBA}-15\left(0,5 \mathrm{~g} \mathrm{~L}^{-1}\right)$; (C) irradiada por $180 \mathrm{~min}$ na presença de PMONDI-16 (0,5 $\left.\mathrm{g} \mathrm{L}^{-1}\right)$. Condições: $C_{0, \mathrm{SDZ}}=12,5 \mathrm{mg} \mathrm{L}^{-1} ; \mathrm{I}=3 \mathrm{~mW} \mathrm{~cm}^{-2}$; $\mathrm{pH}$ natural; $25^{\circ} \mathrm{C}$.
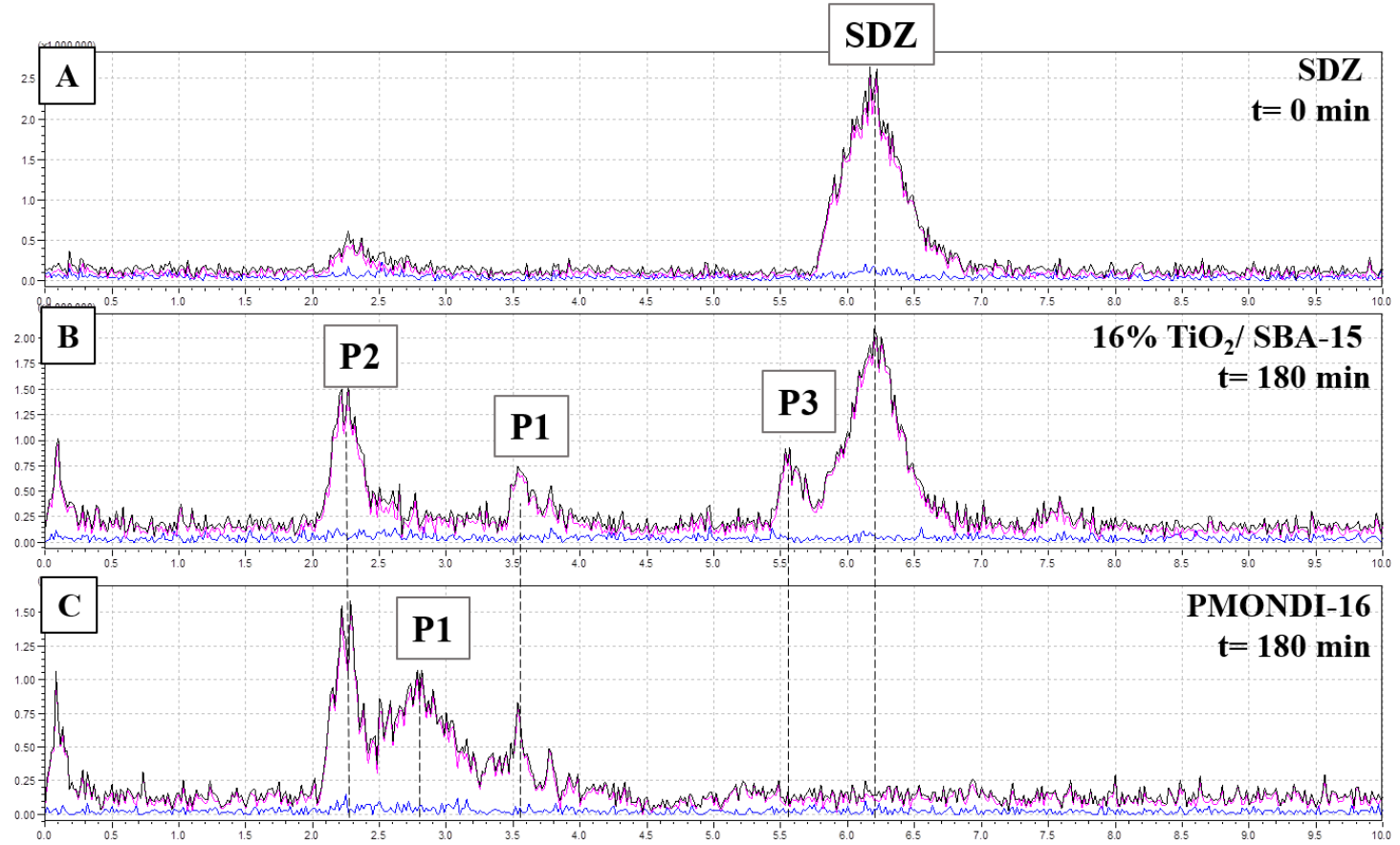

O pico característico da SDZ $[\mathrm{M}+\mathrm{H}]^{+}$apresenta $\mathrm{m} / \mathrm{z}=251$ e corresponde ao pico no tempo de retenção de 6,2 min identificado no cromatograma (Figura 2.21). É possível observar a ausência deste pico quando a SDZ é irradiada com o material PMODNI-16 (Figura 2.21C), sendo um indicativo que toda a SDZ foi degradada e convertida a outros intermediários, resultado que não ocorre quando a irradiação é feita com $16 \% \mathrm{TiO}_{2} / \mathrm{SBA}-15$ (Figura 2.21B). 
Figura 2.22 Relação massa/carga $(\mathrm{m} / \mathrm{z})$ dos fragmentos correspondentes aos picos obtidos pelas análises de cromatografia líquida acoplada à espectrometria de massas das alíquotas de SDZ após 180 min de fotodegradação catalítica.
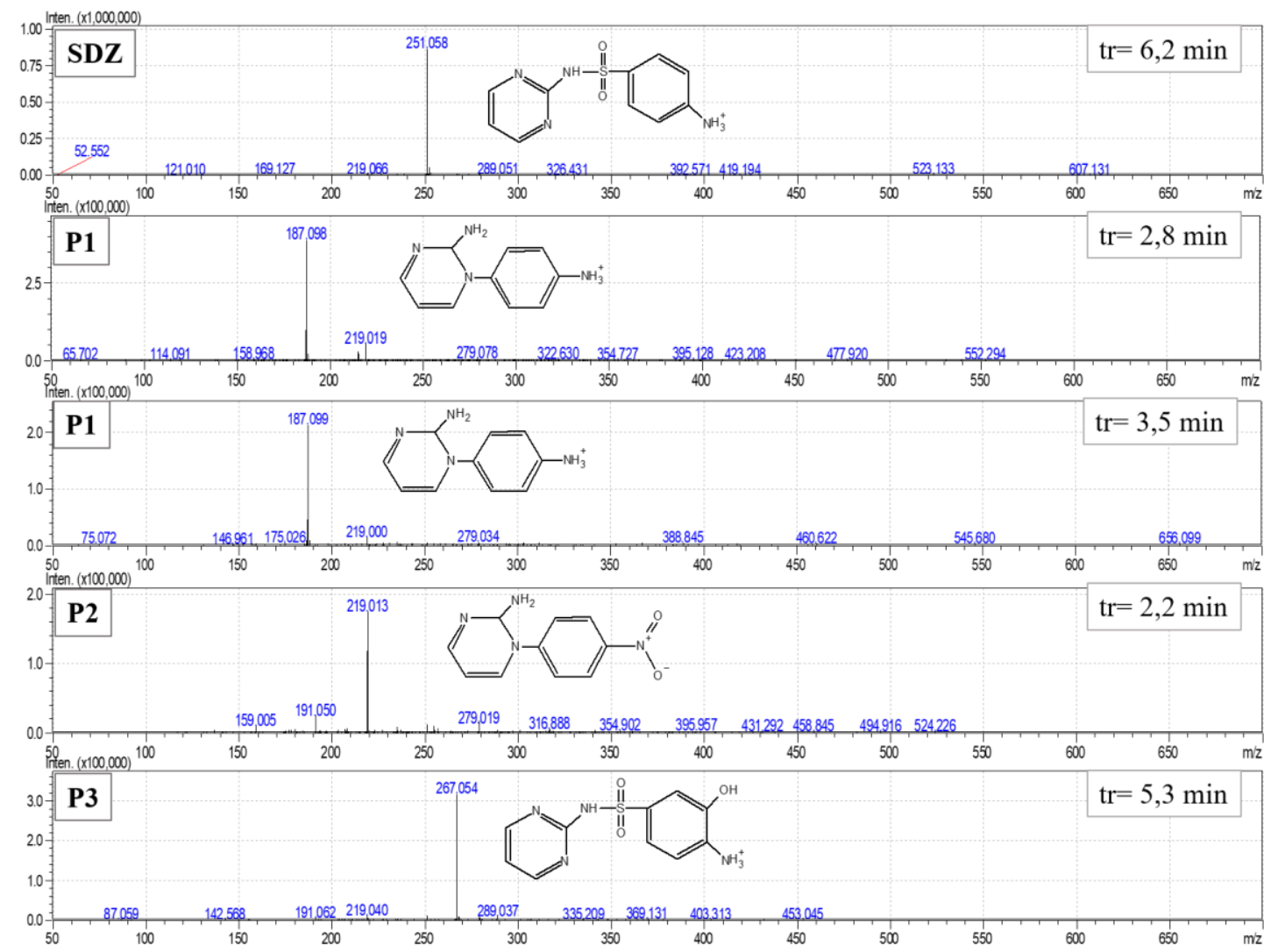

O pico identificado como P1 aparece em dois diferentes tempos de retenção, 2,8 e 3,5 min, e possui a razão $\mathrm{m} / \mathrm{z}=187$ (Figura 2.22). Este valor de $\mathrm{m} / \mathrm{z}$ foi reportado na literatura por diversos autores (BATISTA; PIRES; TEIXEIRA, 2014; BOREEN; ARNOLD; MCNEILL, 2005; JI et al., 2017; LI et al., 2016; PERIŠA et al., 2013), associado a dois diferentes tempos de retenção (GUAN et al., 2020). Este sub-produto corresponde à extrusão de $\mathrm{SO}_{2}$ seguido do rearranjo da molécula de $\mathrm{SDZ}$, formando o 4(2-aminopirimidina-1(2H)-il)-anilina (Figura 2.23).

Os picos correspondentes ao P1 foram mais proeminentes na amostra irradiada na presença da PMONDI-16 (Figura 2.21C). Como visto na Secção 4.2, a formação deste sub-produto ocorre através do mecanismo tipo I (Figura 2.20), segundo o qual há transferência de elétrons entre SDZ e ${ }^{3} \mathrm{NDI}^{*}$ para formar íons radicais $\mathrm{NDI}^{\bullet-}$ e SDZ ${ }^{\circ+}$. Neste caso, a deficiência eletrônica na porção da anilina da $\mathrm{SDZ}^{\cdot+}$ leva ao mecanismo de extrusão do grupo $\mathrm{SO}_{2}$ e rearranjo da molécula de SDZ (BATISTA et al., 2016; JI et al., 2017; LI et al., 2016). 
O produto correspondente ao pico $\mathrm{P} 2$ possui $m / z=219$ (Figura 2.22) e refere-se à oxidação da anilina para nitrobenzeno (Figura 2.23) (JI et al., 2017).

O produto $\mathrm{P} 3$, com razão $\mathrm{m} / \mathrm{z}=267$, corresponde a $\mathrm{SDZ}[\mathrm{M}+\mathrm{H}]^{+}$somada a 17 unidades de massa, indicando hidroxilação da molécula de SDZ (Figura 2.22). A hidroxilação ocorre preferencialmente no anel aromático, sendo menos provável no anel da piridina devido a sua grande densidade de elétrons (JI et al., 2017) (Figura 2.23); a atribuição estrutural de $\mathrm{m} / \mathrm{z}=267$ é comum e já foi relatada por diversos autores (JI $e t$ al., 2017; MA et al., 2015; MAJEWSKY et al., 2014).

Figura 2.23 Mecanismo proposto para a fotodegradação catalítica de SDZ.

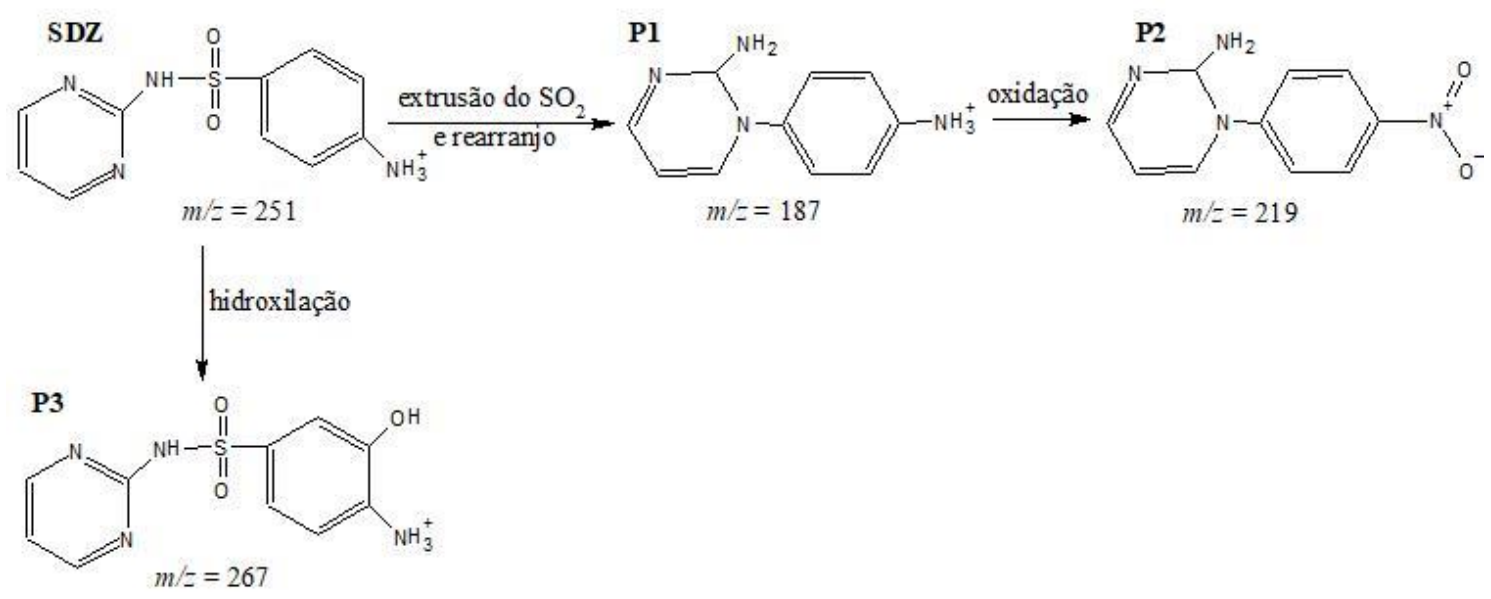

\section{CONCLUSÕES DO CAPÍTULO 2}

Todos os materiais sintetizados se mostraram capazes de degradar com eficiência o contaminante emergente SDZ em reator batelada. Como discutido neste capítulo, a fotocatálise realizada em presença da PMONDI-16 apresentou melhor desempenho quanto à degradação da SDZ no reator tipo batelada, em comparação aos demais materiais utilizados (PMONDI-8 e 16\% $\mathrm{TiO}_{2} / \mathrm{SBA}-15$ ). O melhor sistema fotocatalítico corresponde a amostras irradiadas em menor concentração de SDZ e maior irradiância.

Os mecanismos de fotodegradação de SDZ foram conduzidos diferentemente para cada fotocatalisador. No caso do material $16 \% \mathrm{TiO}_{2} / \mathrm{SBA}-15$, devido à presença do semicondutor $\mathrm{TiO}_{2}$, o radical hidroxila $\left(\mathrm{HO}^{*}\right)$ é a espécie transitória fotogerada com maior relevância. Por outro lado, quando se utiliza os materiais PMONDI, a espécie predominante é o oxigênio singlete $\left({ }^{1} \mathrm{O}_{2}\right)$, como resultado da excitação da imida aromática NDI para um estado singlete ( $\left.{ }^{1} \mathrm{NDI} *\right)$, gerando um estado triplete $\left({ }^{3} \mathrm{NDI} *\right)$ por 
cruzamento intersistemas; as espécies excitadas ${ }^{3} \mathrm{NDI}^{*}$ interagem com o oxigênio por meio de transferência de energia, formando a espécie oxidante ${ }^{1} \mathrm{O}_{2}$, identificada experimentalmente neste trabalho.

Foi possível identificar três intermediários oriundos da fotodegradação catalítica de SDZ. O primeiro intermediário corresponde à extrusão de $\mathrm{SO}_{2}$ seguido de um rearranjo da molécula de SDZ, o segundo refere-se à oxidação do anel da anilina para nitrobenzeno, já o terceiro intermediário corresponde a uma hidroxilação da molécula de SDZ. 


\section{CAPÍTULO 3 APLICAÇÃO DOS MATERIAIS PMONDI EM UM MICRORREATOR DE LEITO EMPACOTADO OPERANDO EM MODO CONTÍNUO PARA A FOTODEGRADAÇÃO CATALÍTICA DE SULFADIAZINA}

"Microreaction technology is a hot topic as it opens completely new possibilities for chemical engineering, combinatorial chemistry, and biotechnology. Small, inexpensive, independent, and versatile devices ensure many reactions achieve maximum selectivity, minimum waste, minimum investment, a better control of the process, safe manufacture and production on demand - to create a more efficient process."

Parte introdutória do livro "Microreactors: New Technology for Modern Chemistry" publicado em junho de 2000 pelos autores Wolfgang Ehrfeld, Volker Hessel e Holger Löwe.

\section{OBJETIVOS}

O principal objetivo do presente capítulo é estudar a degradação fotocatalítica de sulfadiazina (SDZ) em um micro reator de leito empacotado operando em fluxo contínuo. Para isto, foram utilizados como fotocatalisadores os materiais PMONDI preparados e caracterizados conforme descrito no Capítulo 1. O desempenho fotocatalítico foi comparado com o do fotocatalisador comercial $\mathrm{TiO}_{2}$ P25 (Evonik Degussa).

\section{INTENSIFICAÇÃO DO PROCESSO DE FOTOCATÁLISE}

A intensificação do processo de fotocatálise heterogênea através do uso de configurações inovadoras de fotorreatores pode ser uma abordagem interessante para melhorar a transferência de massa e de fótons, e assim a eficiência na fotocatálise. Essa intensificação pode ser alcançada através do acoplamento de processos físicos, químicos, eletroquímicos e fotoquímicos (SUNDAR; KANMANI, 2020).

Com isso, o projeto do reator fotocatalítico possui um papel importante para melhorar o desempenho na fotocatálise, em particular no que se refere à intensificação no contato entre catalisadores fotoativados e reagentes/poluentes e na eficiência na iluminação. Etapa fundamental no processo fotocatalítico é o transporte de fótons para a 
superfície do catalisador e os avanços recentes neste tema estão associados ao estudo do uso de irradiação em micro (GORGES; MEYER; KREISEL, 2004) e nanoescala (GOLE et al., 2005) ou empregando fibras ópticas (WANG; KU, 2003).

As limitações da transferência de massa também devem ser consideradas. Neste sentido, deve ser otimizado o contato entre o catalisador ativado imobilizado em um suporte ou suspenso no meio aquoso e as moléculas de poluente/reagente, bem como a remoção de produtos formados durante a reação para que os sítios catalíticos sejam constantemente renovados.

Reatores que operam com catalisadores em suspensão tendem a ser mais reativos que em forma imobilizada, mas quando se trata de separação pós-processo das partículas de catalisador, os reatores em suspensão são muito mais desafiadores. Reatores fotocatalíticos imobilizados, quando projetados adequadamente, podem funcionar de maneira semelhante ao reator fotocatalítico em suspensão; para tanto, importantes fatores devem cuidadosamente consideradas, tais como, energia de bandgap do catalisador e a espessura do filme fotocatalítico, bem como a configuração do fotorreator levando em consideração o contato efetivo entre a solução e a superfície catalítica, para que se possam reduzir as limitações de transferência de massa; a irradiação adequada da superfície do fotocatalisador também deve ser cuidadosamente considerada (COSTA FILHO et al., 2017).

A fim de superar esses desafios de sistemas imobilizados, grande atenção tem sido dada aos microrreatores. Graças ao seu pequeno diâmetro, os foto-micro reatores permitem maior iluminação da superfície do catalisador imobilizado por unidade de volume de reação, o que leva a uma maior exposição do catalisador à radiação aumentando consideravelmente a eficiência das reações fotocatalíticas (MATSUSHITA et al., 2008). Com base nessas características, no presente capítulo foi estudada a aplicação dos materiais fotocatalíticos (PMONDI) em um fotorreator com micro configuração. Maiores características desse sistema serão vistas a seguir.

\section{MICRO REATOR FOTOCATALÍTICO E FOTOREATOR DE LEITO EMPACOTADO}

Microrreatores têm sido extensivamente estudados em reações fotocatalíticas devido à interessante configuração baseada em micro canais. Tal configuração permite curtas distâncias para a difusão molecular e grandes áreas interfaciais específicas, 
maximizando o contato poluente-reagentes-catalisador e oferecendo maior homogeneidade de iluminação espacial em toda a superfície do catalisador e por toda a superfície e profundidade do reator em comparação com os reatores de grande escala (VAN GERVEN et al., 2007). Outras vantagens no uso desses sistemas destacam-se, particularmente a economia de espaço físico e de energia pelo uso de fontes radiantes menores e mais econômicas.

Em 2004, Gorges e Kreisel (GORGES; MEYER; KREISEL, 2004) testaram pela primeira vez um reator microestruturado em sistema fotocatalítico. O dispositivo utilizado continha 19 microcanais com seção transversal de aproximadamente $300 \mu \mathrm{m} \times$ $200 \mu \mathrm{m}$, onde foi depositado um filme de $5 \mu \mathrm{m}$ de espessura de $\mathrm{TiO}_{2}$ e por onde se passava a solução aquosa contendo o poluente. Acima destes microcanais era acoplada uma placa de LED como fonte luminosa, conforme mostra a Figura 3.1. Neste trabalho, os autores estudaram a degradação fotocatalítica de 4-clorofenol e mostraram que a área superficial específica iluminada de catalisador $\left(\kappa\left[\mathrm{m}^{2} \mathrm{~m}^{-3}\right]\right)$ pode aumentar em um fator de aproximadamente 4 a 400 vezes quando comparadas aos reatores convencionais.

Figura 3.1 Configuração do primeiro micro reator utilizado em fotocatálise em 2004.

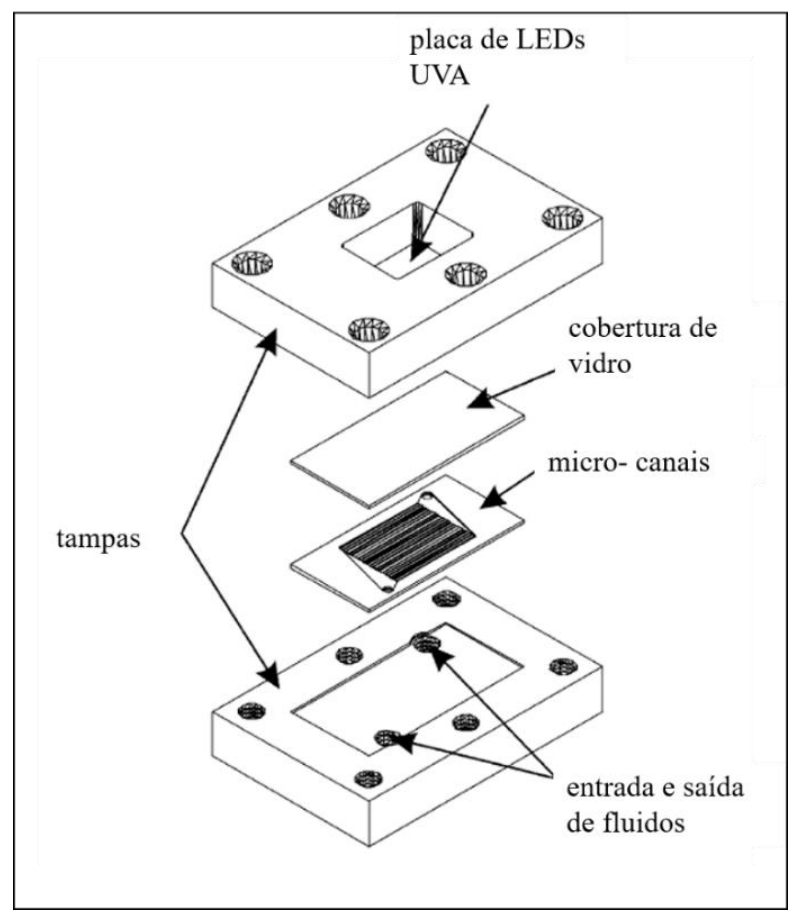

Fonte: Adaptado de GORGES; MEYER; KREISEL, 2004.

Em 2008, Matsushita e colaboradores (MATSUSHITA et al., 2008) investigaram o uso de um microrreatores na fotodegradação e fotorredução de compostos orgânicos. 
O dispositivo utilizado era constituído de quartzo com um microcanal de $500 \mu \mathrm{m}$ de largura, 10-500 $\mu \mathrm{m}$ de profundidade e $50 \mathrm{~mm}$ de comprimento (Figura 3.2). As paredes inferior e lateral do microcanal eram revestidas com uma camada de $\mathrm{TiO}_{2}$ na forma anatase através do processo sol-gel. Neste trabalho, as reações prosseguiram de forma rápida e com grande eficiência fotônica, sugerindo uma grande viabilidade do sistema micro reacional catalítico para fotorreações orgânicas.

Figura 3.2 Fotografia do microrreator fotocatalítico. Por clareza, o microcanal foi preenchido com solução aquosa de azul de metileno.

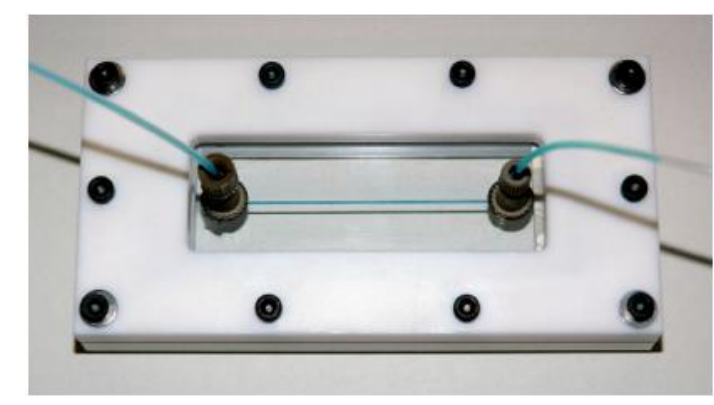

Fonte: (MATSUSHITA et al., 2008).

Krivec e colaboradores reportaram em 2013 (KRIVEC et al., 2013) a fabricação de um novo microrreator fotocatalítico utilizando dupla camada $(10 \mu \mathrm{m})$ de $\mathrm{TiO}_{2}$ na forma anatase imobilizado em uma folha de titânio para a oxidação de cafeína. Os resultados mostram que após seis meses de uso e 3600 ciclos de trabalho, o microrreator ainda exibia $60 \%$ de sua eficiência inicial. Porém, se fez necessário dupla deposição e calcinação para preparar filmes de $\mathrm{TiO}_{2}$ mais homogêneos.

Neste contexto, microrreatores imobilizados têm se mostrado promissores para fotocatálise, porém revestir substratos para imobilização dos catalisadores apresenta certas desvantagens, a exemplo do emprego de técnicas para deposição do catalisador para obtenção dos filmes, que demanda gasto energético e tempo, a não homogeneidade deste revestimento e a possível lixiviação do catalisador devido ao efeito abrasivo do contato contínuo com a solução de reagentes.

Para tentar solucionar tais limitações uma alternativa na configuração de reator fotocatalítico tem chamado atenção. Conhecidos como reatores de leito empacotado (packed bed reactors) (PBR), estes reatores possuem dentro de seus canais ou tubos os catalisadores dispostos de forma empacotada, ou seja, presos a um material sólido 
insolúvel que pode ser uma partícula polimérica ou de material inorgânico (SUNDAR; KANMANI, 2020). Desde seu desenvolvimento, os PBR têm sido largamente empregados (LOSEY; SCHMIDT; JENSEN, 1999; MUNIRATHINAM; HUSKENS; VERBOOM, 2015).

Recentemente, PBR têm sido aplicados com êxito em sistemas fotocatalíticos. Em 2019, Sacco et al. (SACCO; SANNINO; VAIANO, 2019) desenvolveram um reator de leito empacotado para a remoção de diversos poluentes (Figura 3.3). O fotocatalisador empregado era ativo no visível ( $\mathrm{TiO}_{2}$ dopado com nitrogênio) e os autores fizeram uso de LEDs como fonte radiante. Os resultados dos testes fotocatalíticos mostraram descoloração quase total de solução de azul de metileno $\left(C_{0}=10 \mathrm{mg} \mathrm{L}^{-1}\right)$ após 120 minutos de irradiação.

Além disso, o PBR desenvolvido foi eficaz na remoção de ceftriaxona, paracetamol e cafeína com concentração inicial de $5 \mathrm{mg} \mathrm{L}^{-1}$, permitindo atingir degradação quase total destes contaminantes e remoção de carbono orgânico total acima de 80\% após 180 minutos de irradiação em luz visível. A intensidade de luz de LEDs utilizada foi de $78 \mathrm{~mW} \mathrm{~cm}{ }^{-2}$, a vazão do reator foi de $50 \mathrm{~mL} \mathrm{~min}^{-1}$ e o volume total tratado foi de $500 \mathrm{~mL}$.

Figura 3.3 Esquema da configuração do reator de leito empacotado (PBR) trabalhando em modo batelada com recirculação.

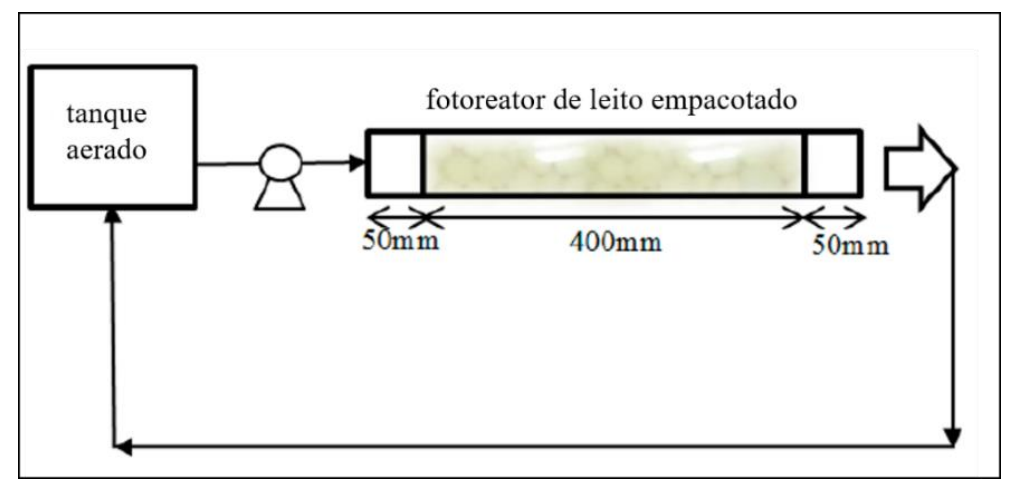

Fonte: Adaptado de SACCO; SANNINO; VAIANO, 2019.

Também em 2019, (RAMOS et al., 2019) investigaram parâmetros estruturais de um PBR fotoquímico e irradiação UV-A externa. Os reatores tubulares foram construídos a partir de tubos de vidro de borossilicato de dois diâmetros externos (20 e $30 \mathrm{~mm})$, embalados com esferas de vidro de três diâmetros médios (1,0, 3,0 e 6,0 mm) e 
esferas de alumina (6,0 $\mathrm{mm}$ de diâmetro) (Figura 3.4). Como modelo de reação fotoquímica homogênea, foi estudada a oxidação de ácido benzóico em meio aquoso via radicais hidroxila $\left(\mathrm{HO}^{*}\right)$, gerados pela irradiação UV-A de íons nitrito.

Figura 3.4 Esquema da configuração do micro reator de leito empacotado (em cima). Posição da fonte de luz em relação ao corpo do reator (em baixo).

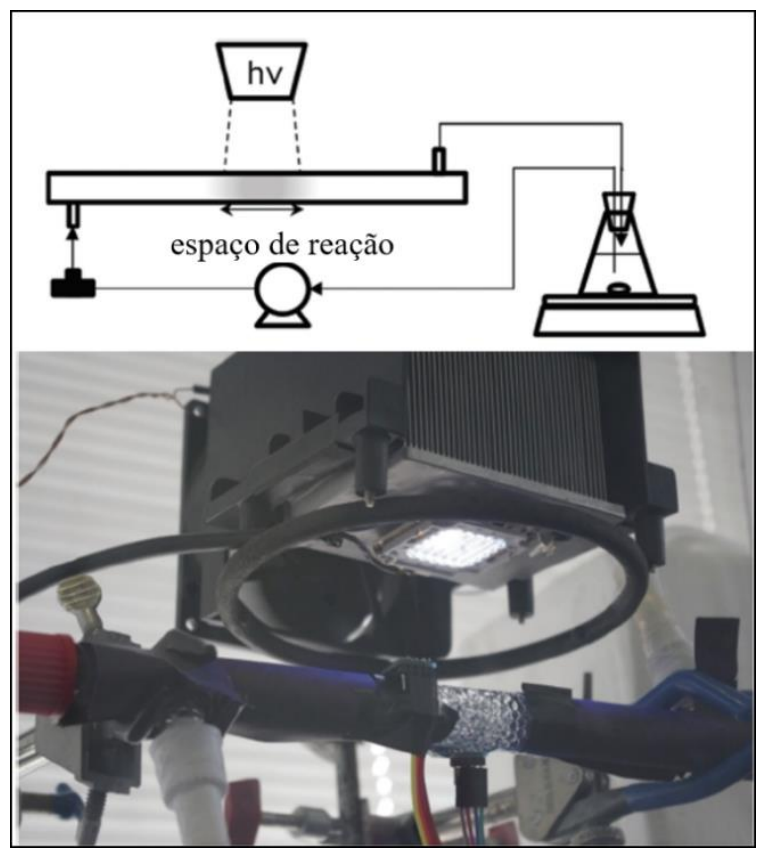

Fonte: Adaptado de RAMOS et al., 2019.

Ramos e colaboradores observaram que o modelo de reator com menor diâmetro levou a maiores rendimentos, sugerindo uma possível intensificação. Mostrou-se também que as esferas de vidro podem ser substituídas por esferas de alumina com pouca perda na eficiência de coleta de luz (cerca de 20\%), indicando um caminho atraente para a fotocatálise solar em leito fixo.

É possível notar que há poucos estudos que abrangem o desenvolvimento e uso de microrreatores fotoquímicos de leito fixo ( $\mu \mathrm{PBR})$ para sistemas heterogêneos. Por este motivo, no presente capítulo, estudou-se a intensificação da degradação fotocatalítica de SDZ utilizando os materiais PMONDI empacotados em um $\mu$ PBR, cujos resultados serão vistos a seguir. 


\section{SEÇÃO EXPERIMENTAL}

\subsection{Materiais}

$\mathrm{TiO}_{2}$ P25 (Evonik Degussa) (55 $\mathrm{m}^{2} \mathrm{~g}^{-1}$ de área superficial) foi adquirido da Evonik. Demais reagentes e catalisadores são equivalentes aos descritos no Capítulo 2.

\subsection{Métodos}

A preparação da solução estoque de $\operatorname{SDZ}\left(C_{0, \mathrm{SDZ}}=30 \mathrm{mg} \mathrm{L}^{-1}\right)$ foi feita através da dissolução de $30 \mathrm{mg}$ do antibiótico em $1 \mathrm{~L}$ de água Milli-Q; a fim de garantir a completa dissolução do fármaco, deixou-se a solução sonicando por 2 h. $\mathrm{O}$ pH natural $(\mathrm{pH}=7)$ não foi alterado e não foi corrigido durante os experimentos fotocatalíticos. A solução estoque de SDZ foi armazenada em um frasco de âmbar na geladeira.

Tubos capilares de $1 \mathrm{~mm}$ de diâmetro foram empregados como microrreatores de leito empacotado (micro-packed bed reactor) ( $\mu \mathrm{PBR}$ ). Para tanto, aproximadamente $2 \mathrm{mg}$ dos materiais PMONDI e SBA-15 foram empacotados nestes tubos capilares conforme mostra a Figura 3.5A. Para evitar que o catalisador fosse arrastado devido ao escoamento da solução aquosa, pequenos pedaços de lã de vidro foram inseridos antes e após o catalisador no capilar. Uma extremidade do reator foi então conectada a uma bomba de êmbolo de alta precisão (Asia Series, Syrris Co.) e a outra extremidade foi conectada por micro-conectores em uma tubulação de Teflon para a coleta de amostras.

A bomba foi ajustada para alimentar o reator com a solução de $\operatorname{SDZ}\left(C_{0, \operatorname{SDZ}}=10\right.$ mg L $\mathrm{L}^{-1}$ ou $0,04 \mathrm{mmol} \mathrm{L}^{-1}$ ) a $20 \mu \mathrm{L} \mathrm{min}{ }^{-1}$ durante 3 horas, para monitoramento da adsorção de SDZ sobre os materiais. Decorrido esse tempo, a placa de LEDs que emite na região do UV-A com potência de $100 \mathrm{~W}$ e $\lambda_{\mathrm{em}}{ }^{\max }=370 \mathrm{~nm}$, foi acionada durante 5 horas para os experimentos fotocatalíticos (Figura 3.5B). Uma ventoinha foi acoplada à placa de LEDs para manter sua temperatura constante; os experimentos foram conduzidos à temperatura ambiente $\left(25^{\circ} \mathrm{C}\right)$. A distância entre os LEDs e o leito fotocatalítico foi mantida fixa em $3 \mathrm{~cm}$. As amostras de SDZ eram coletadas em vials à saída do tudo capilar a cada 15 minutos e armazenadas em geladeira (T $6{ }^{\circ} \mathrm{C}$ ) para posteriormente serem analisadas por cromatografia líquida de alta eficiência (HPLC). A irradiância $\mathrm{I}\left(\mathrm{W} \mathrm{m}^{2}\right)$ foi determinada através do espectroradiômetro Luzchem SPR-02, à mesma posição do microrreator. 
Figura 3.5 (A) Microrreator de leito fixo ( $\mu$ PBR). (B) Fonte de LEDs UV-A e arranjo do $\mu$ PBR.

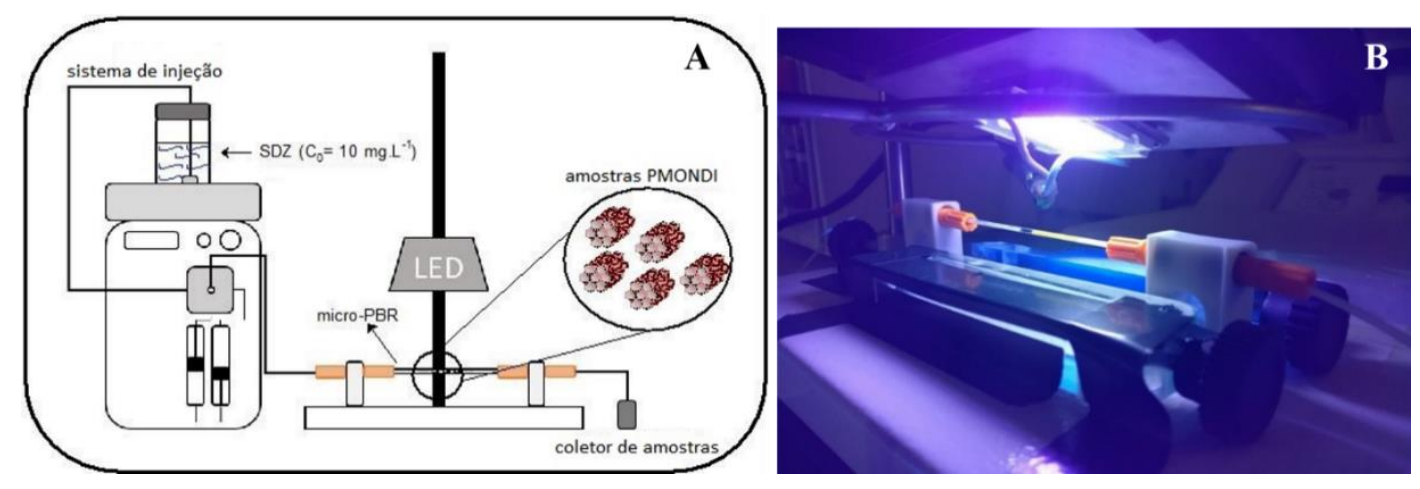

A porcentagem de degradação de $\mathrm{SDZ}\left(X_{\mathrm{SDZ}}\right)$ no estado estacionário para cada catalisador foi determinada através da expressão:

$$
X_{S D Z}=\frac{C_{0, S D Z}-C_{S S, S D Z}}{C_{0, S D Z}} \times 100
$$

A taxa específica $\left(r_{\mathrm{SDZ}}\right)$ de degradação da SDZ em base energética, ou seja, a quantidade de SDZ que sofreu degradação por unidade de energia radiante incidente no leito catalítico, foi determinada de acordo com a expressão:

$$
r_{\mathrm{SDZ}}\left[\frac{\mathrm{mmol}}{h W}\right]=\frac{\left(C_{0}-C_{S S}\right) \times Q_{S D Z}}{W_{\text {in }}}
$$

Em que $Q$ é a vazão da solução aquosa de SDZ alimentada ao reator $\left(20 \mu \mathrm{L} \mathrm{min}^{-}\right.$ ${ }^{1}$ ) em todos os experimentos e $W_{\text {in }}$ corresponde à potência radiante que chega ao leito fotocatalítico (W). Para determinação de $W_{\text {in }}$ utilizou-se a seguinte equação:

$$
W_{\text {in }}[W]=A_{\text {irrad }} \times I
$$

Em que $I$ é a irradiância $\left(\mathrm{W} \mathrm{m}^{-2}\right)$ e $A_{\text {irrad }}$ é a área $\left(\mathrm{m}^{2}\right)$ do leito fotocatalítico exposta à radiação $U V$, calculada por:

$$
A_{\text {irrad }}\left[m^{2}\right]=\pi \times L_{\text {irrad }} \times\left(\frac{d_{\text {reator }}}{2}\right)
$$


Nessa equação, $L_{\text {irrad }}$ é o comprimento do leito fotocatalítico e $d_{\text {reator }}$ é o diâmetro do microrreator capilar $(1 \mathrm{~mm})$. Nessa equação, leva-se em conta que apenas a parte superior do leito fotocatalítico é iluminada pela fonte radiante. É importante salientar que cada leito fotocatalítico continha aproximadamente a mesma quantidade $(2 \mathrm{mg}) \mathrm{de}$ catalisador, com isso os $L_{\text {irrad }}$ obtidos foram de $15,12,15,19$ e $15 \mathrm{~mm}$ para os materiais fotocatalíticos PMONDI-8, PMONDI-16, SBA-15 e $\mathrm{TiO}_{2} \mathrm{P} 25$, respectivamente.

Nos experimentos conduzidos em diferentes vazões, a taxa de degradação da SDZ por unidade de massa de catalisador pode ser aproximada pela expressão:

$$
r_{S D Z}=\frac{\left(C_{0}-C_{S S}\right) \times Q}{m_{c a t}}\left[\frac{\mu m o l}{h \cdot g}\right]
$$

Na qual $Q$ é a vazão da solução aquosa do antibiótico alimentada ao reator $\left(\mathrm{L} \mathrm{h}^{-1}\right)$ e $m_{\text {cat }}$ é a massa de catalisador (g).

\subsection{Técnicas Analíticas}

As concentrações de SDZ foram determinadas por análises de cromatografia líquida de alta eficiência (HPLC) e os intermediários formados durante a fotodegradação de SDZ foram identificados por cromatografia líquida acoplada a um espectrômetro de massa (LCMS-IT-TOF). Os equipamentos e métodos analíticos são os mesmos descritos na Seção 5.3 do Capítulo 2.

\section{RESULTADOS}

A fonte radiante composta por uma placa de LEDs com emissão na região do UVA foi escolhida para excitar os catalisadores nos experimentos de fotocatálise, uma vez que há uma considerável sobreposição do seu espectro de emissão com a absorção dos materiais PMONDI (Figura 3.6). É importante ressaltar que a absorção da SDZ, na concentração empregada nos experimentos de fotocatálise $\left(C_{0, S D Z}=10 \mathrm{mg} \mathrm{L}^{-1}\right)$, não apresenta uma sobreposição significante com a emissão da fonte radiante, não devendo apresentar fotólise expressiva nessa região do espectro. 
Figura 3.6 (a) Espectro de emissão da fonte de LEDs na região do UV-A, sobreposto aos espectros de absorção dos fotocatalisadores (b) PMONDI-16 e (c) PMONDI-8, juntamente com (d) espectro de absorção da solução de $\operatorname{SDZ}\left(C_{0, S D Z}=10 \mathrm{mg} \mathrm{L}^{-1}\right)$.

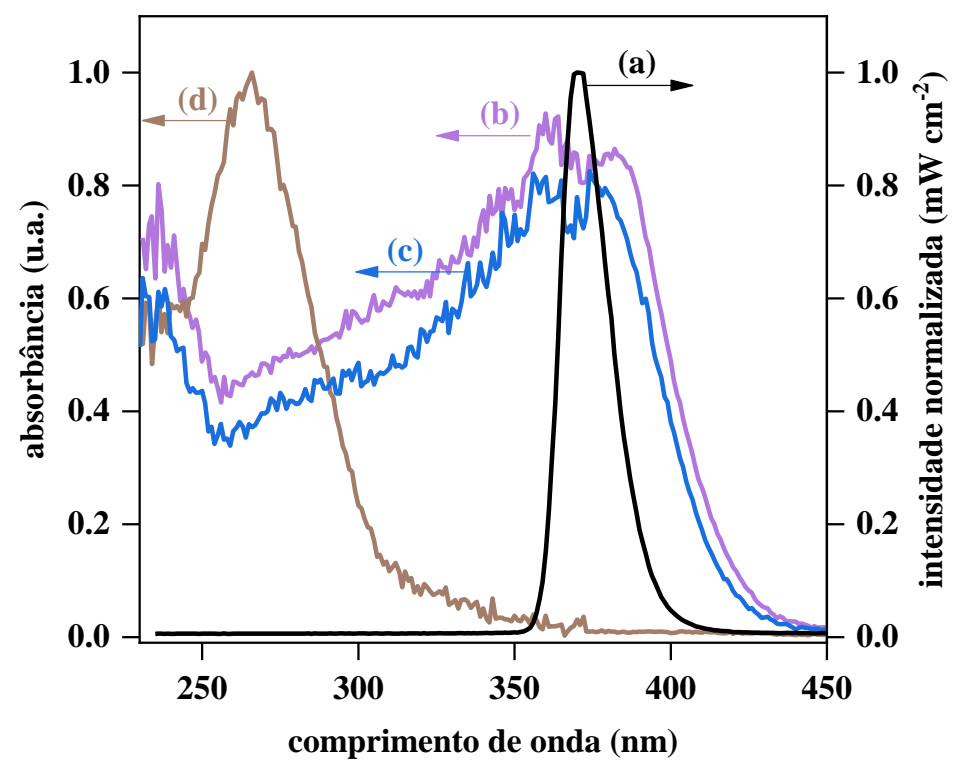

A Figura 3.7 apresenta os resultados de concentração de SDZ à saída do reator capilar, normalizada em relação à concentração na entrada $\left(C_{\mathrm{SDZ}} / C_{0, \mathrm{SDZ}}\right)$, em escoamento contínuo à vazão de $20 \mu \mathrm{L} \mathrm{min}{ }^{-1}$, para os experimentos de fotocatálise heterogênea na presença dos materiais PMONDI-8, PMONDI-16 e TiO 2 P25, além dos experimentos de controle: na presença da sílica mesoporosa SBA-15 e fotólise (na ausência de sólidos).

Nos primeiros 180 minutos, os experimentos foram conduzidos com os LEDs desligados e com isso foi possível acompanhar a adsorção da SDZ em cada material. É possível notar, neste período, uma variação de $C_{\mathrm{SDZ}} / C_{0, \mathrm{SDZ}}$ nos materiais PMONDI, segundo a qual há uma queda nos primeiros 30 min seguida por um aumento de $C_{\mathrm{SDZ}} / C_{0, \mathrm{SDZ}}$. Esse comportamento está associado à adsorção-dessorção do antibiótico nos materiais, até atingir o equilíbrio, alcançado após 150 min (Figura 3.7).

A variação de $C_{\mathrm{SDZ}} / C_{0, \mathrm{SDZ}}$ na sílica $\mathrm{SBA}-15$ e no $\mathrm{TiO}_{2}$ P25 é praticamente desprezível. Tal comportamento pode ser atribuído à baixa interação das moléculas de SDZ com os grupos hidróxido $(-\mathrm{OH})$ presentes nas superfícies destes materiais, pois o pH de trabalho da solução de SDZ foi próximo a 7,0. Com isso, há mistura de espécies de SDZ na forma aniônica e neutra, que não possuem afinidade com os grupos $-\mathrm{OH}$ (POPOVA et al., 2012; VAVSARI, ZIARANI, BADIEI, 2015). No caso das PMONDI, os grupos orgânicos 1,4,5,8-naftalenodiimidas (NDI) estão presentes como parte 
integrante da parede dos poros (como foi visto anteriormente); com isso alguns grupos hidróxidos podem estar expostas na superfície destes materiais.

Figura 3.7 Experimentos de adsorção e fotodegradação da SDZ conduzidos no microrreator empacotado (micro-packed bed reactor) com escoamento contínuo $\left(20 \mu \mathrm{L} \mathrm{min}{ }^{-1}\right)$. Experimentos na presença dos fotocatalisadores PMONDI-8 ( $\Delta$ ), PMONDI-16 ( ) e $\mathrm{TiO}_{2} \mathrm{P} 25$ ( $\bullet$ ) e controles: fotólise $(\square)$ e SBA-15 ( ), utilizando fonte radiante uma placa de LEDs UV-A.

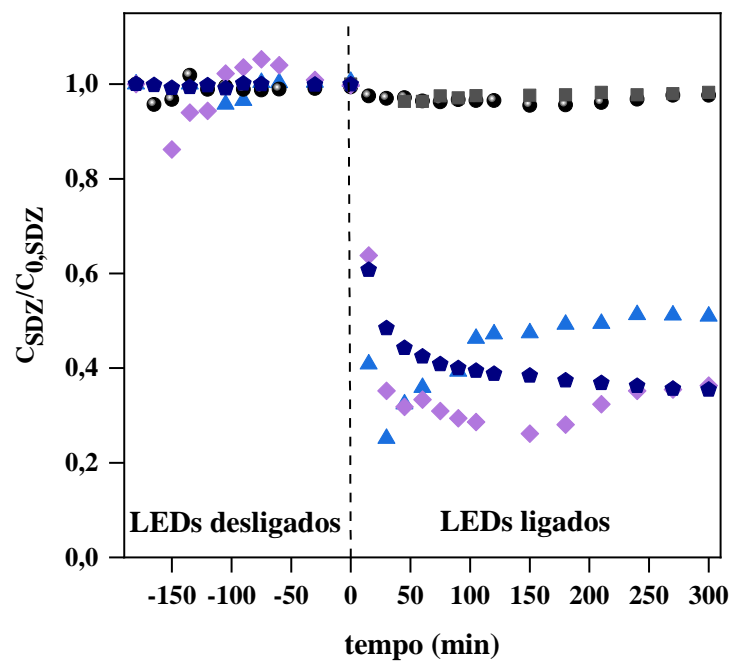

É possível observar na Figura 3.7 o decaimento da concentração de SDZ na saída do reator quando o reator é irradiado, exceto para os experimentos de controle de fotólise e com a sílica não modificada SBA-15. Este resultado comprova que os materiais sintetizados no presente trabalho possuem atividade fotocatalítica. Na Figura 3.7 é possível notar também que nos primeiros 100 min de irradiação os materiais PMONDI permitem degradar maior quantidade de SDZ em comparação ao catalisador comercial $\mathrm{TiO}_{2} \mathrm{P} 25$, embora após esse período haja uma queda na atividade fotocatalítica dos catalisadores PMONDI, a qual é mais pronunciada no caso de PMONDI-8. Este efeito não é constatado quando se utiliza o fotocatalisador comercial $\mathrm{TiO}_{2} \mathrm{P} 25$. De fato, para todos os materiais observa-se a evolução para o estado estacionário da concentração de saída do reator após aproximadamente $250 \mathrm{~min}$, atingindo-se concentrações de estado estacionário à saída do reator idênticas para PMONDI-16 e $\mathrm{TiO}_{2}$ P25, correspondendo a 64\% de remoção de SDZ.

Como mencionado no Capítulo 2 desta Tese, a diferença na atividade fotocatalítica dos materiais está relacionada aos diferentes mecanismos de degradação do contaminante. $\mathrm{O}$ mecanismo de degradação promovido pelo semicondutor $\mathrm{TiO}_{2}$ majoritariamente via radicais hidroxila ( $\left.\mathrm{HO}^{\circ}\right)$ e lacunas positivas, enquanto no caso dos 
materiais PMONDI ocorre via interação entre o poluente e o estado excitado triplete da molécula orgânica, ${ }^{3} \mathrm{NDI} *$ e com espécies ${ }^{1} \mathrm{O}_{2}$. Neste caso, alguma espécie intermediária resultante da degradação da SDZ pode ter sido formada, suprimindo a atividade de fotocatálise. Contudo, é importante ressaltar que mesmo perdendo atividade fotocatalítica, o fotocatalisador PMONDI-16 alcançou o mesmo patamar de degradação que o $\mathrm{TiO}_{2} \mathrm{P} 25$.

A seguir será discutida mais detalhadamente a capacidade dos materiais testados em fotodegradar a SDZ através dos estudos de cinética de fotodegradação catalítica em operação contínua do reator fotocatalítico.

\subsection{Estudos da Cinética de Fotodegradação Catalítica da SDZ em Modo Contínuo}

A concentração de $\mathrm{SDZ}$ no estado estacionário $\left(C_{\mathrm{ss}, \mathrm{SDZ}}\right)$ nos experimentos em escoamento contínuo $\left(20 \mu \mathrm{L} \mathrm{min}^{-1}\right)$ em presença dos catalisadores PMONDI-8 e $\mathrm{TiO}_{2}$ P25 pode ser determinada pela média das concentrações após 180-200 min de irradiação, pois como pode ser visto na Figura 3.8, é a partir desse período que a concentração de saída do poluente se estabiliza. Por outro lado, no caso a irradiação em presença da PMONDI-16 a concentração de saída de SDZ apenas se estabiliza após 240 min de irradiação (Figura 3.8); portanto, nesse experimento a $C_{\mathrm{ss}, \mathrm{SDZ}}$ foi determinada para esse tempo de tratamento.

Figura 3.8 Concentrações de SDZ à saída do reator, normalizadas com relação à concentração de entrada $\left(C_{\mathrm{SDZ}} / \mathrm{C}_{0, \mathrm{SDZ}}\right)$ para os experimentos de fotocatálise conduzidos no microrreator empacotado (micro-packed bed reactor) com escoamento contínuo $\left(20 \mu \mathrm{L} \min ^{-1}\right)$, na presença dos materiais PMONDI-8 $(\boldsymbol{\Delta})$, PMONDI-16 $(\bullet), \mathrm{TiO}_{2} \mathrm{P} 25(\bullet)$ ) e SBA-15 (• ) após 180 min de irradiação.

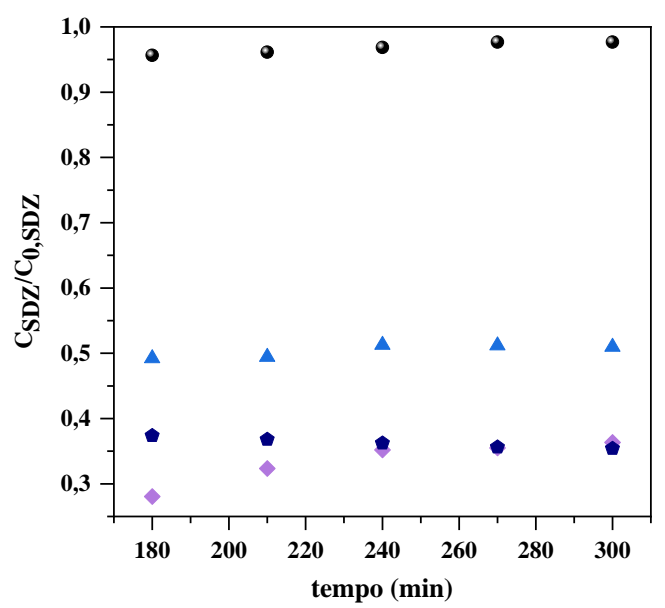


Os valores de concentração na entrada do reator $\left(C_{0, \mathrm{SDZ}}\right)$ e à saída do reator no estado estacionário $\left(C_{\mathrm{ss}, \mathrm{SDZ}}\right)$, bem como os valores de porcentagem de degradação do antibiótico $\left(X_{\mathrm{SDZ}}\right)$, são mostrados na Tabela 3.1. Como já observado, a degradação de SDZ foi de $64 \%$ utilizando a PMONDI-16, valor equivalente ao obtido com o fotocatalisador comercial $\mathrm{TiO}_{2} \mathrm{P} 25$ e de $50 \%$ para a PMONDI-8.

Tabela 3.1 Concentração de entrada $\left(C_{0, \mathrm{SDZ}}\right)$, concentração no estado estacionário à saída do microrreator $\left(C_{\mathrm{ss}, \mathrm{SDZ}}\right)$ e porcentagem de degradação $\left(X_{\mathrm{SDZ}}\right)$ de $\mathrm{SDZ}$ nos experimentos de fotocatálise conduzidos no microrreator empacotado (micro-packed bed reactor) com escoamento contínuo $\left(20 \mu \mathrm{L} \mathrm{min}^{-1}\right)$ para diferentes fotocatalisadores.

\begin{tabular}{|c|c|c|c|}
\hline Catalisador & $C_{0, \mathrm{SDZ}}\left(\mathrm{mmol} \mathrm{\textrm {L } ^ { - 1 } )}\right.$ & $C_{\mathrm{SS}, \mathrm{SDZ}}\left(\mathrm{mmol} \mathrm{L}^{-1}\right) \mathrm{a}$ & $X_{\operatorname{SDZ}}(\%)$ \\
\hline PMONDI-8 & 0,0397 & 0,0199 & 49,0 \\
\hline PMONDI-16 & 0,0403 & 0,0144 & 64,0 \\
\hline SBA-15 & 0,0395 & 0,0385 & 3,0 \\
\hline $\mathrm{TiO}_{2} \mathrm{P} 25$ & 0,0403 & 0,0146 & 64,0 \\
\hline
\end{tabular}

${ }^{a}$ Determinada pela média de $C_{\mathrm{SDZ}}$ após 180 min de irradiação para $\mathrm{SBA}-15, \mathrm{TiO}_{2} \mathrm{P} 25$, PMONDI-15 e PMONDI-8 e em 240 min para PMONDI-16.

Para emprego da Equação 3.2 (Seção 4.2), a irradiância (I) (W $\mathrm{m}^{-2}$ ) foi determinada em relação à distância entre a fonte radiante e o leito fotocatalítico, que se manteve fixa em $3 \mathrm{~cm}$, através da expressão exponencial de calibração dada pela Equação 3.4, como indicado na Figura 3.9. A extrapolação da curva foi utilizada, pois a irradiância da fonte radiante em $3 \mathrm{~cm}$ possui um valor alto que supera a sensibilidade do espectrorradiômetro, impedindo sua medida direta. 
Figura 3.9 Decaimento exponencial da irradiância versus a distância do microrreator em relação à fonte radiante utilizada nos experimentos fotocatalíticos $(x, \mathrm{~cm})$. O ajuste da curva de calibração corresponde a $R^{2}=0,9999$.

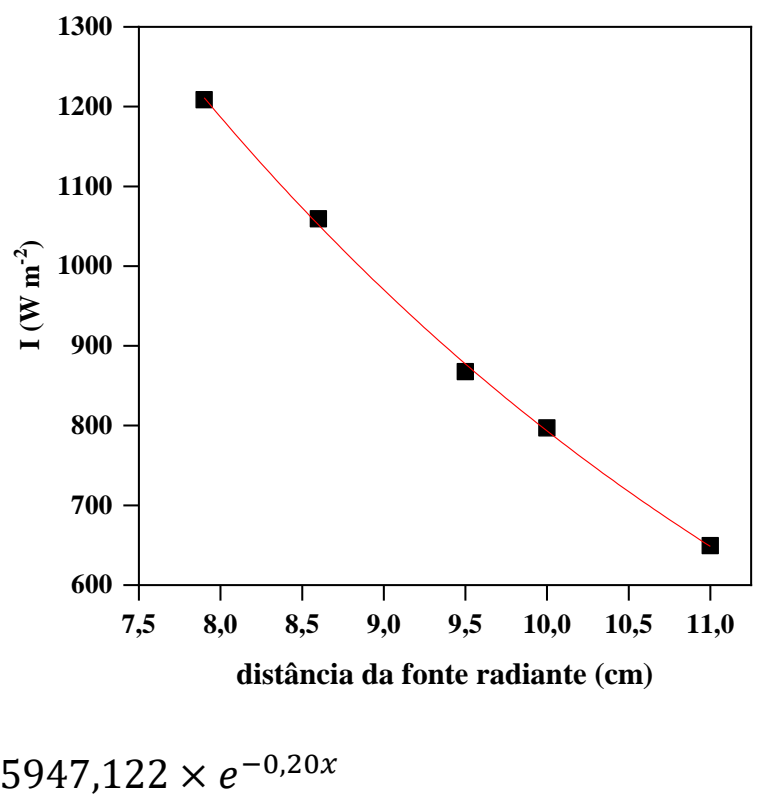

A taxa específica $\left(r_{\mathrm{SDZ}}\right)$ de degradação da SDZ por unidade de energia radiante incidente em estado estacionário, determinada através da Equação 3.2 (Seção 4.2), é um indicador importante para avaliar o desempenho de cada fotocatalisador, uma vez que envolve parâmetros relacionados diretamente ao processo de fotocatálise: potência radiante que chega ao leito fotocatalítico e a distância entre o leito fotocatalítico e a fonte radiante.

Os valores calculados de $r_{S D Z}$ para cada fotocatalisador são mostrados na Figura 3.10. É possível notar que o material PMONDI-16 permitiu obter valor de taxa específica de $0,405 \mu \mathrm{mol} \mathrm{W}^{-1} \mathrm{~h}^{-1}$, equivalente ao obtido para o catalisador comercial $\mathrm{TiO}_{2}$ P25 $\left(0,401 \mu \mathrm{mol} \mathrm{W} \mathrm{W}^{-1} \mathrm{~h}^{-1}\right)$. Este resultado é um indicativo que a efetividade dos materiais PMONDI como fotocatalisadores pode ser comparada à do $\mathrm{TiO}_{2}$. 
Figura 3.10 Taxa especifica de degradação de SDZ $\left(r_{S D Z}\right)$ em estado estacionário e base energética para os

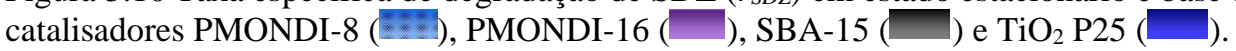

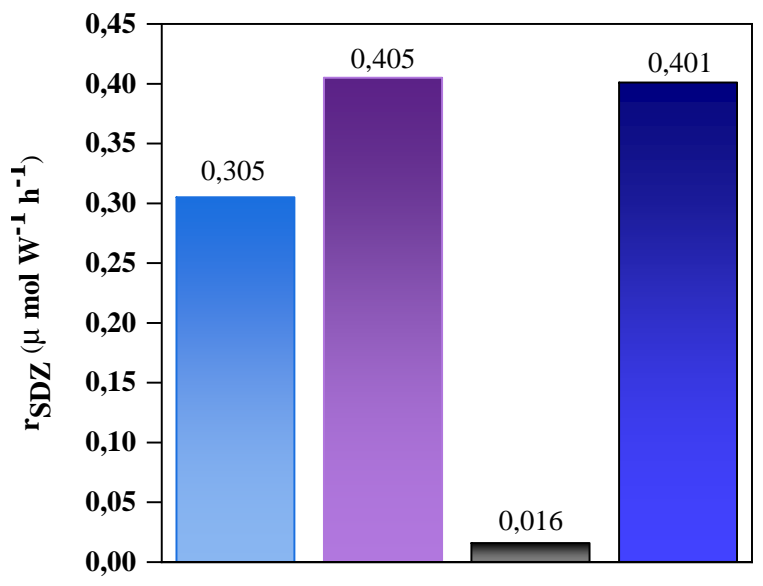

Visto que o fotocatalisador PMONDI-16 resultou em maior degradação porcentual $\left(X_{S D Z}\right)$ e maior taxa específica de degradação da SDZ $\left(r_{S D Z}\right)$, realizou-se um estudo adicional com este material para determinar a taxa de reação no reator fotocatalítico em experimentos conduzidos a diferentes vazões de alimentação. A Figura 3.11 mostra os valores de concentração de SDZ normalizada à saída do reator $\left(C_{\mathrm{SDZ}} / C_{0, \mathrm{SDZ}}\right)$ em função do tempo de adsorção (LEDs desligados) e durante a irradiação, utilizando PMONDI-16 como catalisador nos experimentos para as vazões de alimentação de 20, 25, 30 e $40 \mu \mathrm{L} \mathrm{min}^{-1}$.

É possível observar o efeito de variação da concentração de SDZ durante a adsorção no material PMONDI-16 (antes de $t=0 \mathrm{~min}$ ). Nos primeiros 30 minutos, há diminuição da concentração de SDZ, que se estabiliza logo após este período, como discutido anteriormente. No início da irradiação $(t=0 \mathrm{~min})$ todos os experimentos são iniciados à mesma condição de adsorção, apresentando valores $C / C_{0} \sim 1$, indicativo da ocorrência do equilíbrio de adsorção.

No instante em que a fonte radiante é ligada ocorre a diminuição da concentração inicial de SDZ, conforme esperado. A degradação de SDZ é maior quando a vazão é menor, como resultado do maior tempo espacial no reator. Por outro lado, é possível observar uma inversão quanto ao comportamento da fotodegradação de SDZ após aproximadamente 200 min de irradiação, que pode ser originária da desativação da PMONDI-16. Com o aumento na vazão, os efeitos difusionais dos intermediários 
formados na superfície do material tornam-se mais intensos, daí a desativação do fotocatalisador não ser observada em vazões maiores (30 e $\left.40 \mu \mathrm{L} \mathrm{min}{ }^{-1}\right)$.

Figura 3.11 Experimentos de adsorção e fotodegradação da SDZ conduzidos no microrreator empacotado (micro-packed bed reactor) para vazões $20(\square), 25(\bigcirc), 30(\triangle)$ ) e 40 ( $\lesssim$ ) $\mu \mathrm{L} \mathrm{min}$ ma $^{-1}$ na presença do fotocatalisador PMONDI-16.

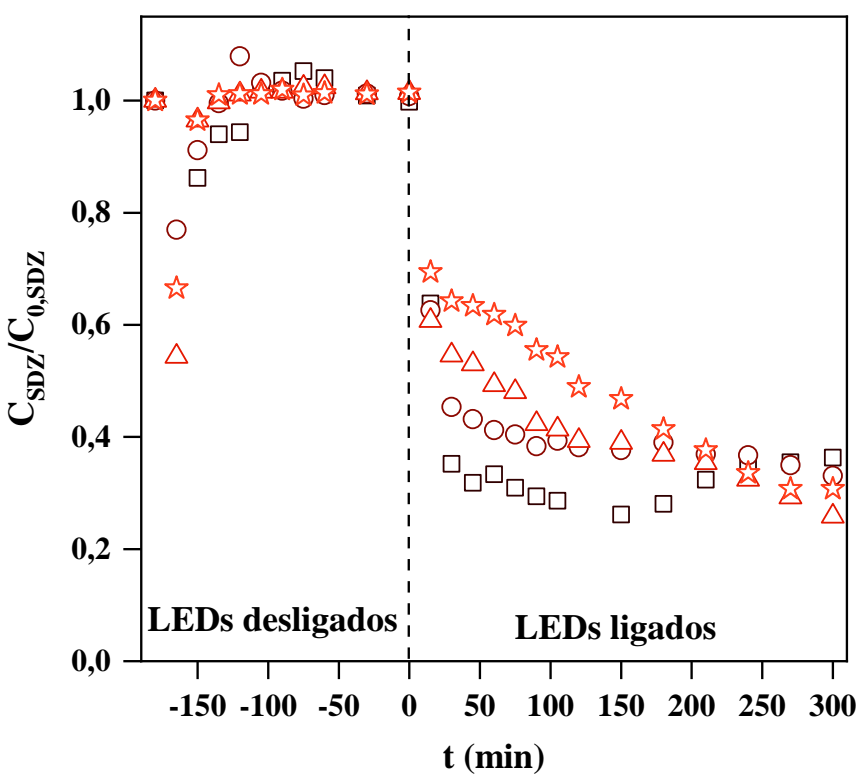

A concentração em estado estacionário $\left(C_{\mathrm{ss}, \mathrm{SDZ}}\right)$, para cada vazão, foi determinada através da média das concentrações após $250 \mathrm{~min}$, uma vez que que é a partir deste tempo que a concentração de saída se estabiliza (Figura 3.11). Nestes experimentos, os valores de $r_{\mathrm{SDZ}}$ foram determinados através da Equação 3.5 (Seção 4.2). Como não houve estabilização da concentração de saída na vazão de $30 \mu \mathrm{L} \mathrm{min}{ }^{-1}$, o valor de $r_{\mathrm{SDZ}}$ não pôde ser determinado nesse caso.

A Tabela 3.2 mostra os valores de $C_{0, \mathrm{SDZ}}, C_{\mathrm{Ss}, \mathrm{SDZ}}, X_{\mathrm{SDZ}}$ e $r_{\mathrm{SDZ}}$ para os experimentos de fotocatálise conduzidos a diferentes vazões com a PMONDI-16. É possível observar que a conversão de estado estacionário ( $\left.X_{\mathrm{SDZ}}\right)$ se mantém praticamente constante nas vazões utilizadas, porém com um pequeno aumento conforme aumenta a vazão de escoamento, passando de $64 \%$ em $20 \mu \mathrm{L} \mathrm{min}^{-1}$ para $70 \%$ na vazão de $40 \mu \mathrm{L} \min ^{-1}$ (Tabela 3.2). A taxa de degradação da SDZ por unidade de massa de catalisador $\left(r_{S D Z}\right)$ também aumenta com o aumento da vazão. Este resultado pode ser um indicativo de que alguns compostos intermediários que inibem a reação podem ter sido dessorvidos com maior facilidade devido à maior velocidade de eluição. 
Tabela 3.2 Concentração de entrada $\left(C_{0, S D Z}\right)$, concentração no estado estacionário $\left(C_{\mathrm{ss}, \mathrm{SDZ}}\right)$, porcentagem de degradação $\left(X_{\mathrm{SDZ}}\right)$ e taxa de reação $\left(r_{\mathrm{SDZ}}\right)$ por unidade de massa de catalisador nos experimentos de fotocatálise conduzidos no microrreator empacotado (micro-packed bed reactor) a diferentes vazões na presença de PMONDI-16.

\begin{tabular}{|c|c|c|c|c|c|}
\hline Catalisador & $\begin{array}{c}\text { Vazão } \\
\left(\mu \mathrm{L} \text { min }^{-1}\right)\end{array}$ & $\begin{array}{c}C_{0, S D Z} \\
\left(\mathbf{m m o l ~ L}^{-1}\right)\end{array}$ & 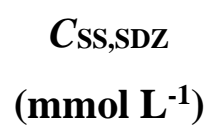 & $\begin{array}{c}X_{\mathrm{SDZ}} \\
(\%)\end{array}$ & $\begin{array}{c}r_{\mathrm{SDZ}} \\
\left(\mu \mathrm{mol} \mathbf{h}^{-1} \mathrm{~g}^{-1}\right)\end{array}$ \\
\hline \multirow{4}{*}{ PMONDI-16 } & 20 & 0,0403 & 0,0105 & 64,0 & 0,22 \\
\hline & 25 & 0,0401 & 0,0131 & 66,0 & 0,31 \\
\hline & $30^{\mathrm{a}}$ & 0,0401 & n.d. & n.d. & n.d. \\
\hline & 40 & 0,0403 & 0,0122 & 70,0 & 0,59 \\
\hline
\end{tabular}

${ }^{\text {a }}$ A $C s s_{, S D Z}$ não pôde ser determinada para a vazão de $30 \mu \mathrm{L} \mathrm{min}{ }^{-1}$, pois a concentração de saída de SDZ não se estabilizou.

A seguir, será discutida a caracterização dos intermediários formados na fotodegradação da SDZ no micro reator de leito empacotado.

\subsection{Caracterização dos Produtos de Fotodegradação da SDZ}

Assim como no sistema em batelada, foram realizadas análises de cromatografia líquida acoplada à espectrometria de massas (LC-MS) para caracterização dos produtos formados pela degradação da SDZ, a partir de amostras coletadas no tempo 0 min e após 300 min de irradiação e em presença dos materiais PMONDI no sistema de microrreator operando de modo contínuo.

Um evento que chamou atenção nestes experimentos foi o aparecimento de um segundo pico nos cromatogramas obtidos através das análises HPLC das soluções de SDZ irradiadas em presença dos materiais PMONDI, resultado que não ocorreu no sistema em batelada e nas soluções irradiadas com o fotocatalisador $\mathrm{TiO}_{2} \mathrm{P} 25$. A Figura 3.12 mostra os cromatogramas das alíquotas analisadas após 300 min de irradiação. É possível observar um pico proeminente em $t_{\mathrm{R}} \sim 4,75 \mathrm{~min}$, que corresponde à molécula de SDZ e um segundo pico em $t_{\mathrm{R}} \sim 2,06$ min nas amostras irradiadas com as PMONDI; este pico se mostra irrelevante para a amostra irradiada com $\mathrm{TiO}_{2} \mathrm{P} 25$. É importante destacar que este segundo pico apenas começa a aparecer nos cromatogramas das amostras coletadas após acionamento da fonte radiante; portanto, trata-se de um produto gerado fotocataliticamente. 
Figura 3.12 Cromatogramas obtidos nas análises de cromatografia líquida de alta eficiência (HPLC) da solução aquosa de $\mathrm{SDZ}\left(C_{0, \mathrm{SDZ}}=10 \mathrm{mg} \mathrm{L}^{-1}\right)$ após $300 \mathrm{~min}$ de irradiação, na presença dos catalisadores PMONDI-8, PMONDI-16 e $\mathrm{TiO}_{2}$ P25.
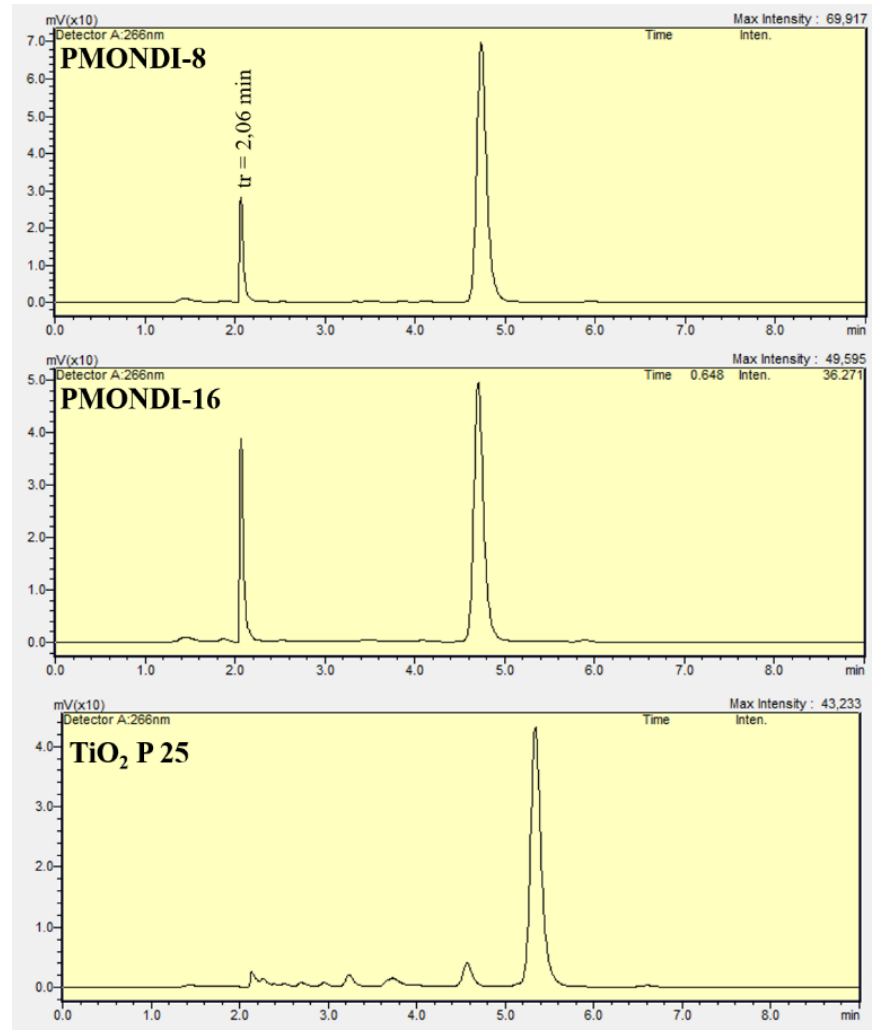

À medida que a fotodegradação evolui há aumento da área deste segundo pico. A razão entre as áreas do pico correspondente à $\mathrm{SDZ}\left(t_{\mathrm{R}} \sim 4,75 \mathrm{~min}\right)$ e do segundo pico $\left(t_{\mathrm{R}}\right.$ 2,06 min), obtidas via HPLC, para cada experimento de fotocatálise com os materiais PMONDI, é mostrada na Figura 3.13. É possível observar que ocorre stabilização na geração deste fotoproduto à medida que há estabilização na fotodegradação da SDZ, ou seja, esses processos são concomitantes.

A Figura 3.13A apresenta a evolução das áreas dos picos correspondentes à SDZ e ao segundo pico utilizando a PMONDI-8. É possível observar que as quantidades geradas do fotoproduto, bem como a degradação de SDZ, se estabilizam concomitantemente após aproximadamente 100 min de irradiação. Na presença do material PMONDI-16 (Figura 3.13B) a estabilização da formação do intermediário (segundo pico) ocorre nos primeiros $25 \mathrm{~min}$ aproximadamente. Porém, neste caso a concentração de saída de SDZ não se estabilizou. Um fato que se mostra curioso é que apesar dos materiais PMONDI perderem a atividade fotocatalítica durante os experimentos, a concentração do intermediário fotogerado não sofre a mesma queda. 
Figura 3.13 Razão entre a área dos picos de $\operatorname{SDZ}\left(t_{\mathrm{R}} \sim 4,75 \mathrm{~min}\right)(-\bullet-)$ e do segundo pico $\left(t_{\mathrm{R}} \sim 2,06 \mathrm{~min}\right)$ $\left(-{ }^{-}\right)$em função do tempo de irradiação nos experimentos fotocatalíticos na presença dos materiais PMONDI-8 (A) e PMONDI-16 (B).
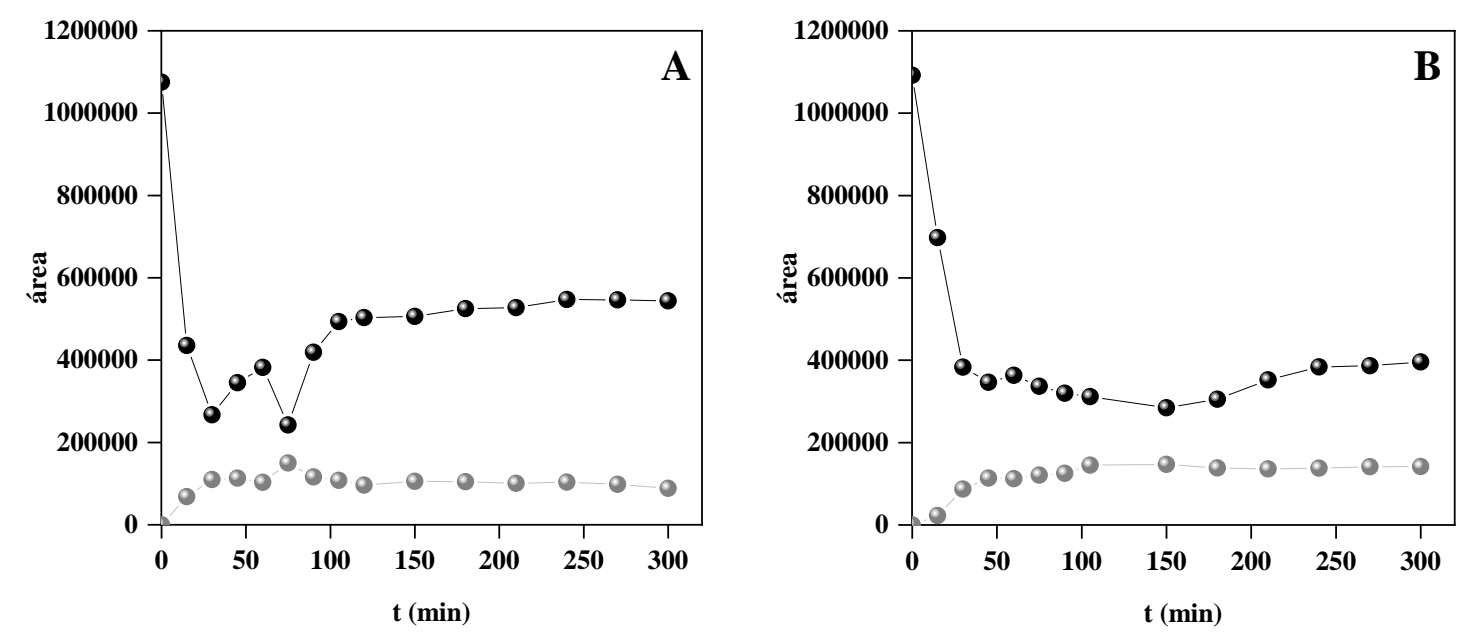

Nas análises de LC-MS (Figura 3.14) é possível observar que os picos que aparecem são semelhantes para ambos os materiais PMONDI, ou seja, possuem relação massa carga $(\mathrm{m} / \mathrm{z})$ análogos; estes picos foram nomeados SDZ, P1, P2 e P3. Contudo, na amostra irradiada com o catalisador PMONDI-16 houve aparecimento de um outro pequeno pico, nomeado por P4 (Figura 3.14). O tempo de retenção e a razão $\mathrm{m} / \mathrm{z}$ dos produtos, SDZ, P1, P2 e P3 são mostrados na Figura 3.15.

Figura 3.14 Picos e relação massa carga $(\mathrm{m} / \mathrm{z})$ obtidos através cromatografia líquida acoplado à espectrometria de massas (LCMS-IT-TOF) para as amostras irradiadas com (A) PMONDI-8 e (B) PMONDI-16 $(t=300 \mathrm{~min})$.

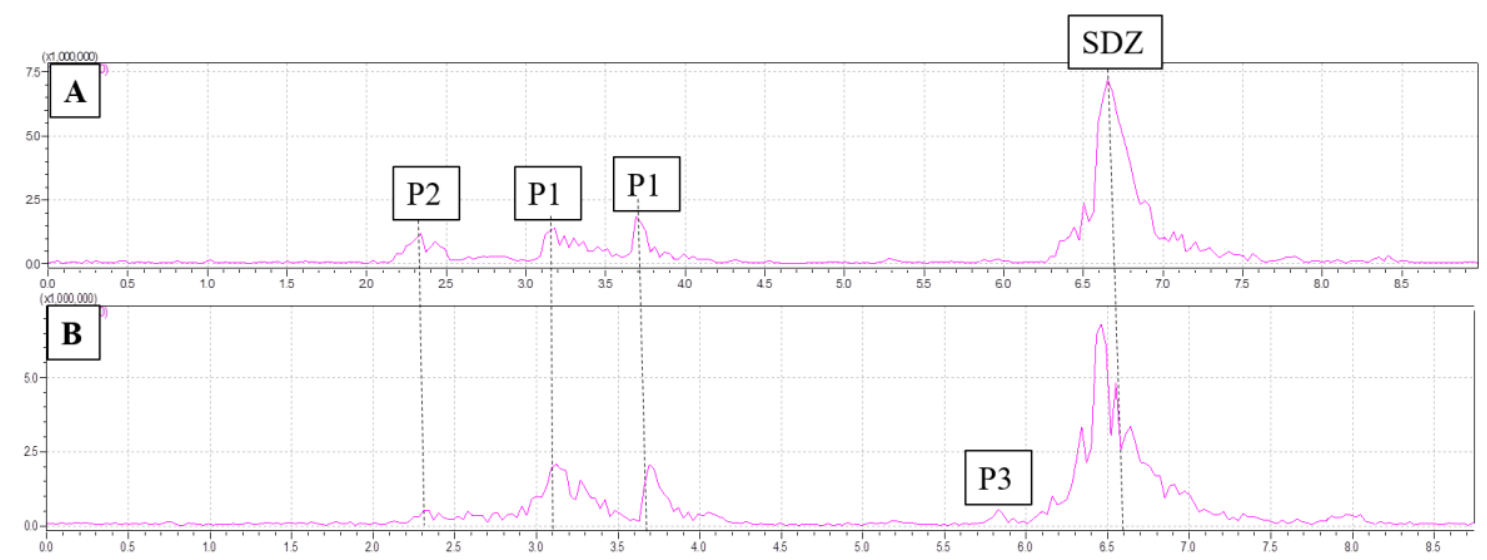


Figura 3.15 Relação massa/carga $(\mathrm{m} / \mathrm{z})$ dos fragmentos correspondentes aos picos obtidos pelas análises de cromatografia líquida acoplada à espectrometria de massas das alíquotas de SDZ após 300 min de fotodegradação catalítica.

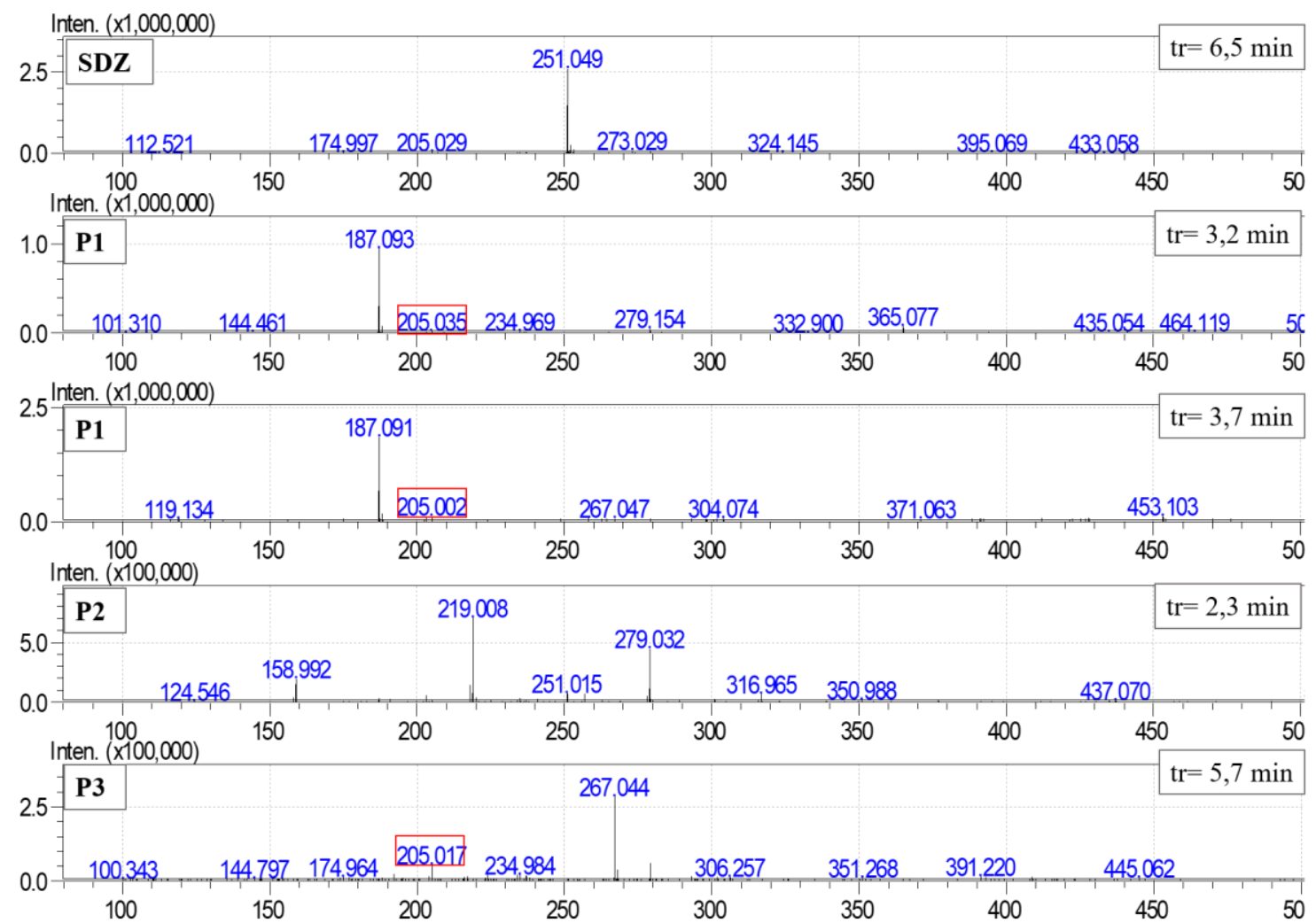

É possível notar que a razão $\mathrm{m} / \mathrm{z}$ e os tempos de retenção dos fragmentos obtidos são análogos aos observados para os sistemas operando em batelada (Figura 2.22 do Capítulo 2). Portanto, pode-se supor que o mecanismo de reações do sistema em microrreator operando em modo contínuo (Figura 3.16) seja semelhante ao apresentado no Capítulo 2 (Figura 2.23).

A SDZ é identificada no tempo de retenção de $6,5 \mathrm{~min} \operatorname{com} \mathrm{m} / \mathrm{z}$ característico de 251. O fragmento P1 que aparece em dois tempos no cromatograma, quais sejam $t_{\mathrm{r}}=$ 3,2 e 3,7 min, corresponde sub-produto formado pela extrusão de $\mathrm{SO}_{2}$ e rearranjo da molécula de SDZ, conhecido por 4-(2-aminopirimidina-1(2H)-il)-anilina), também identificado no Capítulo 2 (Figura 3.16). O fragmento P2, com $\mathrm{m} / \mathrm{z}$ igual a 219, é oriundo da oxidação deste sub-produto.

O foto-intermediário P3 é formado através da hidroxilação da molécula de SDZ (Figura 3.16) $\mathrm{com} \mathrm{m} / \mathrm{z}$ de 267 e $t_{\mathrm{r}}$ de $5,7 \mathrm{~min}$, sendo identificado somente nas amostras obtidas por irradiação na presença de PMONDI-16. 
Foi possível também observar que a ocorrência do segundo pico presente nas análises de HPLC possa sugerir que uma rota de reação seja mais favorecida. Este segundo pico está correlacionado aos picos P1 da espectrometria de massa com tempos de retenção de 3,2 min e 3,7 min, respectivamente, ou seja, a rota de reação favorecida é a formação do foto-intermediário 4-(2-aminopirimidina-1(2H)-il)-anilina).

A formação deste subproduto foi favorecida neste sistema devido à ausência de uma constante oxigenação no vaso de alimentação contendo a solução de SDZ (este vaso era fechado com tampa) e ausência de contato entre a solução de SDZ com o oxigênio do ar no microrreator. Dessa forma, supõe-se que o mecanismo preferencial de degradação de SDZ seja do Tipo I (Figura 2.20, Capítulo 2).

Outro resultado que chamou a atenção foi a ocorrência de pequenos fragmentos com valor de $\mathrm{m} / \mathrm{z}$ de 205 (evidenciados em caixas vermelhas na Figura 3.15). Este fragmento já foi reportado em alguns estudos (CALZA et al., 2004; JI et al., 2017), e surge através da extrusão de $\mathrm{SO}_{2}$ seguido de rearranjo da molécula de $\mathrm{SDZ}$ hidroxilada (P3) (Figura 3.16). Supõe-se que a ocorrência deste fragmento possa ser devido ao favorecimento da rota de mecanismo Tipo I neste sistema.

Figura 3.16 Mecanismo proposto para a fotodegradação catalítica de SDZ no microrreator operando a modo contínuo.

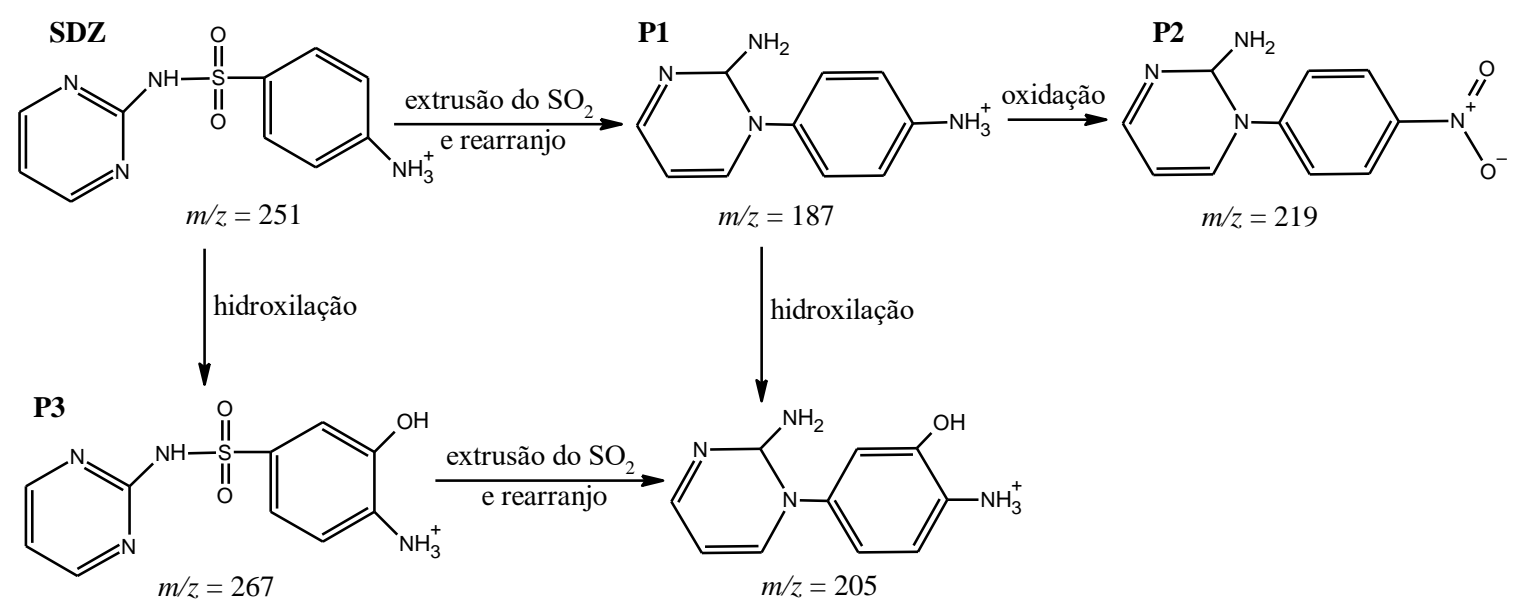

\section{CONCLUSÕES DO CAPÍTULO 3}

No presente capítulo foi possível mostrar a eficiência na aplicação das PMONDI em fotocatálise heterogênea para a degradação de SDZ. As PMONDI permitiram degradar aproximadamente $70 \%$ deste poluente em um micro reator de fluxo contínuo e empacotado (micro-packed bed reactor). O principal intermediário formado 
fotocataliticamente foi 4-(2-aminopirimidina-1(2H)-il)-anilina), originado através do mecanismo de extrusão de $\mathrm{SO}_{2}$ e rearranjo da molécula de SDZ. 


\section{CAPÍtUlO 4 APLICAÇÃO DOS MATERIAIS TIO2/SBA-15 PARA A DEGRADAÇÃO FOTOCATALÍTICA DE SULFADIAZINA NO FOTORREATOR FLUHELIK}

"They say water is life. But water quality is healthy."

Professora Joan Rose, presidente da Homer Nowlin, que realiza pesquisas sobre água na Michigan State University, em seu discurso de laureação do "2016 Stockholm Water Prize Laureate”. O prêmio foi concedido por suas incansáveis contribuições à saúde pública global, em particular por seu trabalho na avaliação de riscos para a saúde humana devido ao consumo de água.

\section{OBJETIVOS}

O presente capítulo tem como objetivo estudar o desempenho dos materiais preparados e caracterizados no primeiro capítulo $\left(\mathrm{TiO}_{2} / \mathrm{SBA}-15\right)$ quanto à fotodegradação catalítica de sulfadiazina em diferentes matrizes (i) água pura (ii) águas residuais urbanas utilizando um robusto fotorreator: o FluHelik.

\section{FOTORREATOR FLUHELIK}

Reatores tubulares anulares têm sido os mais aplicados em processos fotoquímicos para remediação de água e efluentes (PERES et al., 2015, 2019; WRIGHT; HARGREAVES, 2001; XU; ZHAO; RANGAIAH, 2013). Eles são constituídos por uma carcaça cilíndrica equipada com uma ou várias camisas cilíndricas de quartzo internas ou externas contendo lâmpadas UV; o líquido escoa entre a camisa de quartzo e a carcaça do reator (Figura 4.1). Nestes sistemas são possíveis dois diferentes arranjos: (i) com uma ou mais lâmpadas localizadas no centro e paralelo ao eixo do vaso do reator (Figura 4.1A); (ii) com duas ou mais lâmpadas colocados fora do tubo de quartzo, acopladas a refletores (R) (Figura 4.1B) (OPPENLANDER, 2002). 
Figura 4.1 Vista em corte transversal e vista superior de A: Fotorreator tubular de escoamento contínuo com lâmpada em posição coaxial. B: posição externa da lâmpada com refletor $(\mathrm{R})$. RV: vaso do reator; $\mathrm{Q}$ : camisa de quarto para lâmpada.

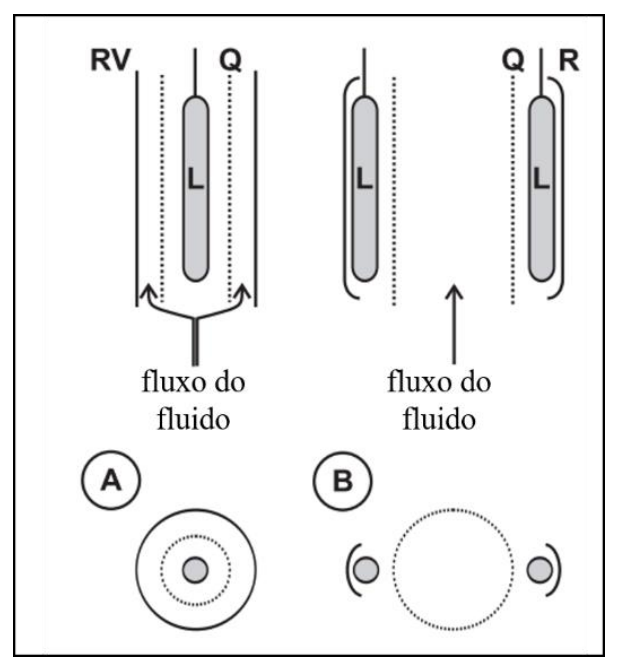

Fonte: (OPPENLANDER, 2002).

Com configuração similar ao reator tubular, o fotorreator FluHelik consiste em um tubo anular com tubos de entrada e saída situados perpendicularmente com lados opostos ao fluxo do fluido e tangencialmente ao tubo do reator. A lâmpada UV cilíndrica fica localizada em uma manga de quartzo concêntrica interna ao reator. A Figura 4.2 apresenta resultados de simulações CFD ilustrando o escoamento obtido no reator.

Figura 4.2 Simulação CFD do movimento helicoidal do fluido no interior do reator FluHelik.

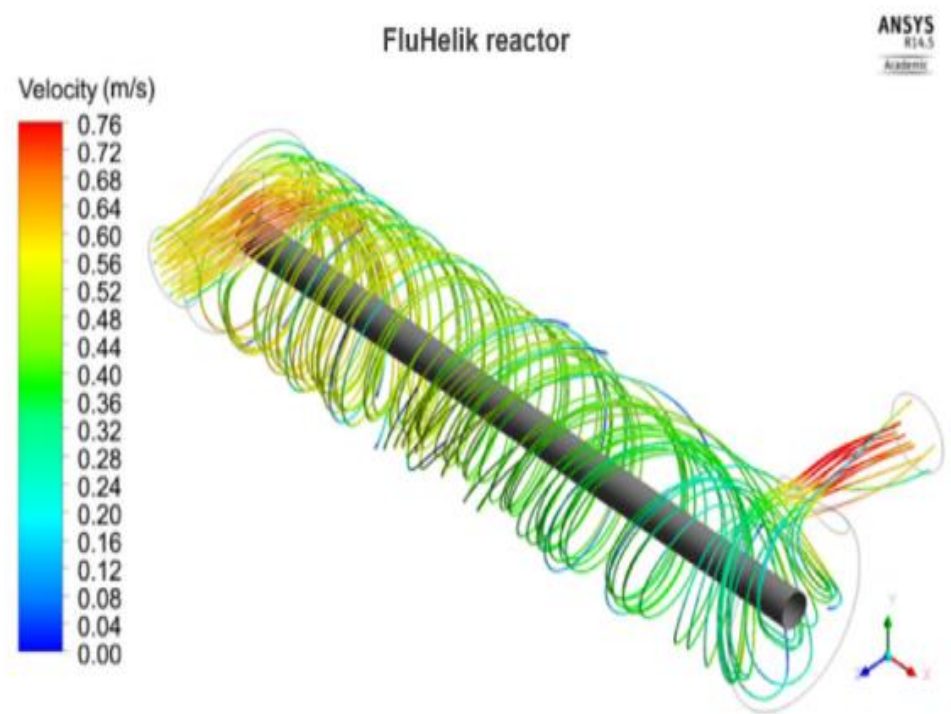

Fonte: (MOREIRA et al., 2019). 
Essa configuração possibilita maior grau de contato entre as partículas de fluido e a radiação UV, aumentando a dinâmica do sistema e a iluminação homogênea no interior do tubo reator devido ao movimento helicoidal do líquido em torno da lâmpada (Figura 4.2). Além disso, o design do reator FluHelik pode favorecer a implementação de vários reatores em série, promovendo sua aplicação em escala industrial. A Figura 4.3 mostra como exemplo uma possível configuração de seis reatores FluHelik posicionados em série.

Neste sentido, Moreira e colaboradores (MOREIRA et al., 2019) fizeram o estudo da implementação de uma instalação FluHelik pré-piloto. O reator era constituído de aço inoxidável com volume iluminado de $8 \mathrm{~L}$ acoplado a um vaso de circulação de 130 L de capacidade, onde foi possível eliminar $100 \%$ do contaminante 3-amino-5-metil isoxazol (AMI) utilizando o sistema UV-C/ $\mathrm{H}_{2} \mathrm{O}_{2}$.

Figura 4.3 Esboço dos reatores FluHelik montados em série.

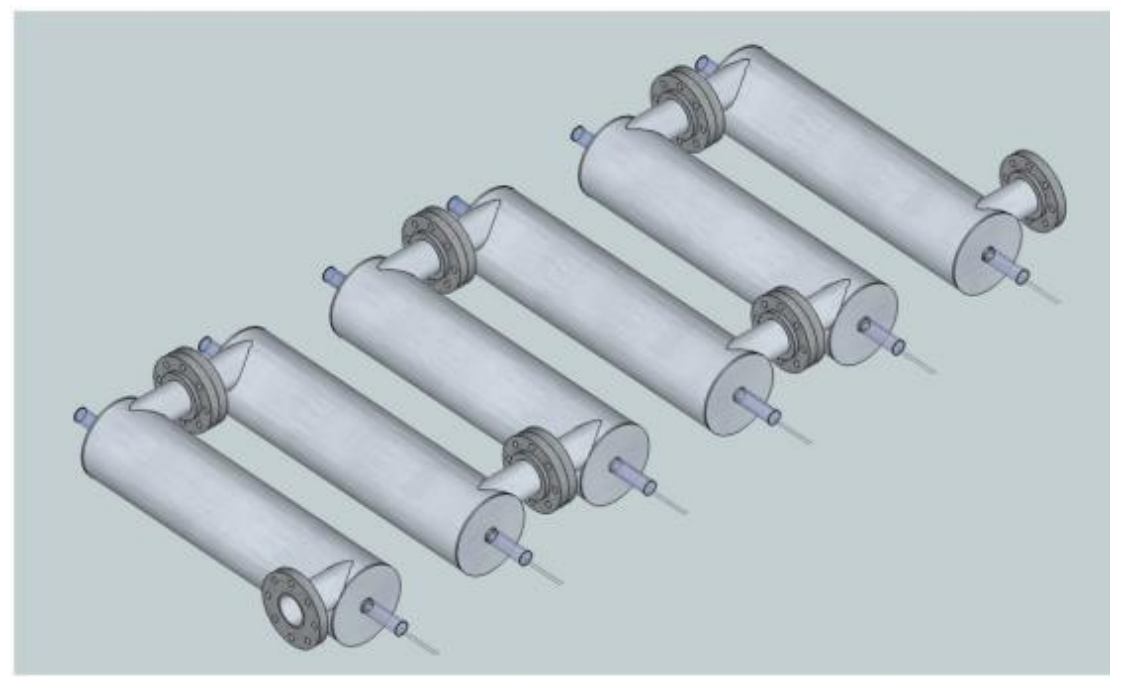

Fonte: (MOREIRA et al., 2019).

Em outro trabalho publicado por Espíndola e colaboradores (ESPÍNDOLA et al., 2019) também se avaliou o desempenho do fotorreator FluHelik em escala laboratorial e pré-piloto para promover a degradação de contaminantes de interesse emergente por processos fotoquímicos $\mathrm{UV}-\mathrm{C} / \mathrm{H}_{2} \mathrm{O}_{2}$. Em escala laboratorial o contaminante-modelo oxitetraciclina (OTC) pôde ser completamente mineralizado em apenas 5 min de reação utilizando lâmpada UV-C de $11 \mathrm{~W}$ e $500 \mathrm{mg} \mathrm{L}^{-1}$ de $\mathrm{H}_{2} \mathrm{O}_{2}$.

Em escala pré-piloto usou-se o mesmo reator FluHelik de $8 \mathrm{~L}$ de capacidade estudado por Moreira e colaboradores (MOREIRA et al., 2019) acoplado a um vaso de 
recirculação de $120 \mathrm{~L}$, onde foi possível diminuir a toxidade de um efluente real urbano (coletado após tratamento secundário) fortificado com onze fármacos diferentes.

Nesta Tese, tal sistema foi utilizado para estudar a fotodegradação de SDZ em água pura e águas residuais urbanas em presença de suspensão do material fotocatalíticos $\mathrm{TiO}_{2} / \mathrm{SBA}-15$, comparado com o fotocatalisador comercial $\mathrm{TiO}_{2} \mathrm{P} 25$. Este trabalho foi realizado durante estágio sanduíche na Universidade do Porto (Portugal) junto ao grupo de pesquisa coordenado pelo Dr. Vitor Vilar no Laboratório de Processos de Separação e Reação-Laboratório de Catálise de Materiais (LSRELCM).

\section{SEÇÃO EXPERIMENTAL}

\subsection{Materiais}

Dióxido de titânio (IV) $\left(\mathrm{TiO}_{2}\right)$ Aeroxide® P25 $\left(55 \mathrm{~m}^{2} \mathrm{~g}^{-1}\right.$ de área superficial específica e $\geq 99,5 \%$ de pureza) foi obtido pela Evonik. Sulfadiazina (99\% de pureza) foi obtida da Sigma-Aldrich. Todas as soluções aquosas foram preparadas com água deionizada. Uma amostra de água residual urbana (ARU), cujas características são apresentadas na Tabela 4.1, foi coletada após tratamento secundário e foi caracterizada por um dos membros do grupo de pesquisa do LCRE-LCM. 
Tabela 4.1 Características físico-químicas da água residual urbana.

\begin{tabular}{|c|c|}
\hline Parâmetros (unidade) & \\
\hline Cor & amarela \\
\hline Odor & n.d $d^{*}$ \\
\hline Turbidez (NTU) & 0,34 \\
\hline $\mathrm{pH}$ & 7,5 \\
\hline Temperatura $\left({ }^{\circ} \mathrm{C}\right)$ & 25 \\
\hline Condutividade $\left(\mathrm{mS} \mathrm{cm}^{-1}\right)$ & 2,4 \\
\hline Carbono total dissolvido $\left(\mathrm{mg} \mathrm{L}^{-1}\right)$ & 43,8 \\
\hline Carbono inorgânico dissolvido $\left(\mathrm{mg} \mathrm{L}^{-1}\right)$ & 29,7 \\
\hline Carbono orgânico dissolvido $\left(\mathrm{mg} \mathrm{L}^{-1}\right)$ & 14,1 \\
\hline Demanda química de oxigênio $\left(\mathrm{mg} \mathrm{L}^{-1}\right)$ & 21,0 \\
\hline Absorbância em 254 nm (AU) & 0,215 \\
\hline Transmitância em 254 nm (\%) & 61 \\
\hline Sólidos suspensos totais $\left(\mathrm{mg} \mathrm{L}^{-1}\right)$ & 20,5 \\
\hline Sólidos suspensos voláteis $\left(\mathrm{mg} \mathrm{L}^{-1}\right)$ & 16,0 \\
\hline Sulfato $-\mathrm{SO}_{4}^{2-}\left(\mathrm{mg} \mathrm{L}^{-1}\right)$ & 339 \\
\hline Nitrito $-\mathrm{NO}_{2}^{-}\left(\mathrm{mg} \mathrm{L}^{-1}\right)$ & $<0,3$ \\
\hline Nitrato $-\mathrm{NO}_{3}^{-}\left(\mathrm{mg} \mathrm{L}^{-1}\right)$ & 28 \\
\hline Nitrogênio total $\left(\mathrm{mg} \mathrm{L}^{-1}\right)$ & 52 \\
\hline Fluoreto $-\mathrm{F}^{-}\left(\mathrm{mg} \mathrm{L}^{-1}\right)$ & $<1$ \\
\hline Cloreto $-\mathrm{Cl}^{-}\left(\mathrm{mg} \mathrm{L}^{-1}\right)$ & 308 \\
\hline Fosfato $-\mathrm{PO}_{4}^{3-}\left(\mathrm{mg} \mathrm{L}^{-1}\right)$ & $<4$ \\
\hline Fósforo total (mg L-1) & 2,0 \\
\hline
\end{tabular}

*não detectado.

\subsection{Métodos}

\subsubsection{Aparato}

Os experimentos foram realizados no reator FluHelik constituído por um tubo de vidro de borossilicato com 196,0 $\mathrm{mm}$ de comprimento, 65,6 $\mathrm{mm}$ de diâmetro interno e $1,8 \mathrm{~mm}$ de espessura. $\mathrm{O}$ reator é equipado com um tubo de entrada e um de saída, localizados tangencialmente ao invólucro e na parte superior em lados opostos, com distância de 3,0 mm das extremidades do reator, 43,0 $\mathrm{mm}$ de comprimento e 7,0 $\mathrm{mm}$ de diâmetro interno. No centro do reator há uma camisa (tubo) de quartzo interno 
concêntrico com 196,0 mm de comprimento, 23,0 mm de diâmetro externo e 1,0 mm de espessura contendo uma lâmpada. A lâmpada empregada foi de luz negra azul UV-A Philips TL $6 \mathrm{~W}$ e potência radiante de 0,62 \pm 0,02 W (WEBLER et al., 2019). O fotorreator FluHelik foi conectado a um recipiente de vidro cilíndrico para recirculação, controlado termostaticamente e agitado magneticamente (Figura 4.4).

Figura 4.4 (A) Diagrama esquemático da configuração experimental (B) Foto do sistema utilizado, em que: (i) fonte de energia para ligar a lâmpada UV-A; (ii) fotorreator FluHelik; (iii) bomba de recirculação; (iv) vaso de recirculação com $2 \mathrm{~L}$ de capacidade; (v) agitador magnético; (vi) medidor de $\mathrm{pH}$.

$\mathbf{A}$

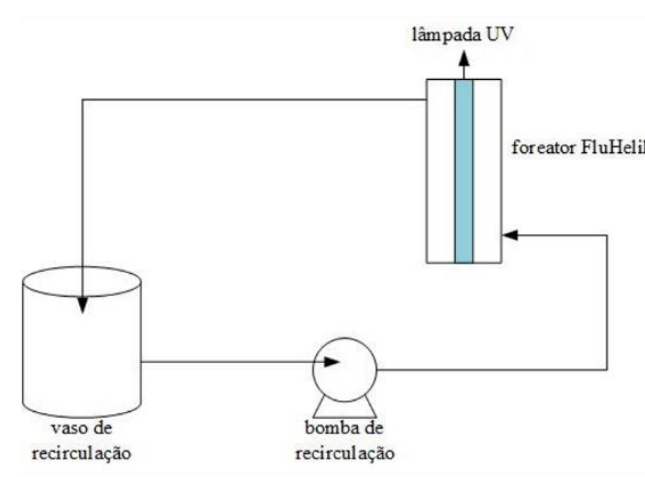

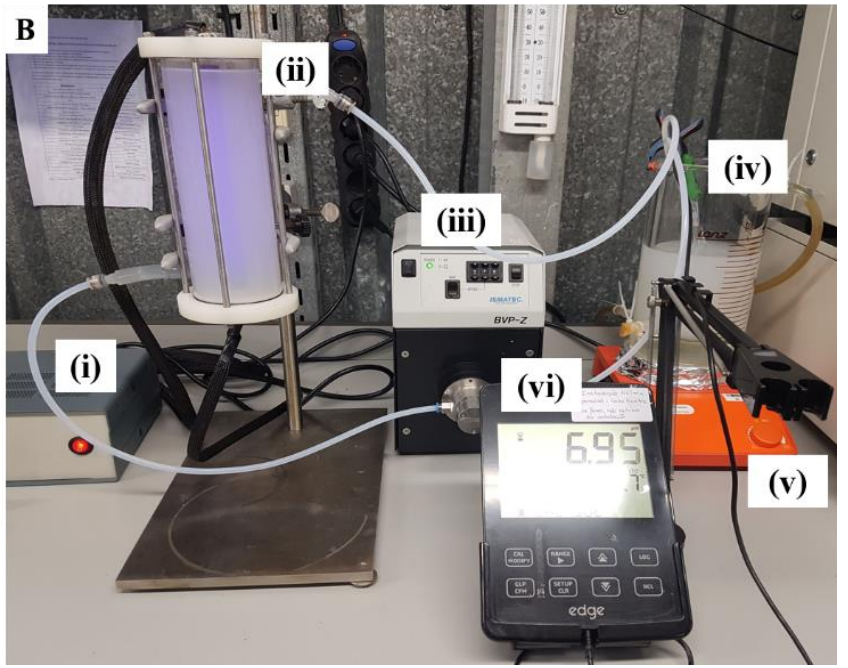

\subsubsection{Procedimentos experimentais}

1,5 L de uma solução aquosa de $\mathrm{SDZ}$ com $\mathrm{C}_{0, \mathrm{SDZ}}=2 \mathrm{mg} \mathrm{L}^{-1}$ foram agitados com quantidades necessárias de fotocatalisador em suspensão durante a noite a $25^{\circ} \mathrm{C}$ para alcançar o equilíbrio de adsorção-dessorção entre moléculas de SDZ e os fotocatalisadores. Esta suspensão foi disposta no vaso de recirculação de vidro do reator, sendo bombeada para o fotorreator FluHelik por meio de uma bomba de recirculação (Ismatec, modelo BVP-Z) à vazão de $75 \mathrm{~L} \mathrm{~h}^{-1}$; esta vazão foi escolhida por ter apresentado melhores resultados para fotodegradação de poluentes no FluHelik em um estudo anterior (ESPÍNDOLA et al., 2019). Em todos os experimentos, o banho termostático foi ajustado para manter a solução a $25{ }^{\circ} \mathrm{C}$ e o pH inicial da solução foi ajustado para 7,0 usando soluções diluídas $(1,0 \mathrm{~N})$ de ácido sulfúrico $\left(\mathrm{H}_{2} \mathrm{SO}_{4}\right)$ e/ou hidróxido de sódio $(\mathrm{NaOH})$; o $\mathrm{pH}$ não foi corrigido ao longo do tempo. Após acionamento da lâmpada, alíquotas de $10 \mathrm{~mL}$ da suspensão aquosa foram coletadas do reator e filtradas através de um filtro de membrana de $0,45 \mu \mathrm{m}$ para remover o 
catalisador sólido para posterior análise em HPLC. Cada experimento foi realizado em duplicata.

O tempo espacial da solução no fotorreator FluHelik foi determinado através da equação:

$$
\tau=\frac{\mathrm{V}}{\mathrm{Q}}
$$

Em que $Q$ é a vazão $75 \mathrm{~L} \mathrm{~h}^{-1}$ e $V$, o volume do reator $(0,680 \mathrm{~L})$. O tempo espacial obtido no reator foi da ordem de 32,6 segundos.

A fotodegradação de sulfadiazina foi avaliada utilizando o modelo cinético de pseudo-primeira ordem ajustado pelo método de regressão não linear. A constante cinética de pseudo-primeira ordem para o decaimento da concentração de SDZ $\left(k_{\mathrm{SDZ}}\right)$ foi determinada pela equação a seguir:

$$
[S D Z]_{t}=[S D Z]_{0} \times e^{-k_{\mathrm{SDZ}} t}
$$

O material que demonstrou o melhor desempenho foi escolhido para estudos complementares de degradação de SDZ, através dos seguintes procedimentos:

\subsubsection{Variação na massa de fotocatalisador}

Os experimentos foram conduzidos utilizando 1,5 L de solução aquosa de SDZ $\left(C_{0, \mathrm{SDZ}}=2 \mathrm{mg} \mathrm{L}^{-1}\right)$ na presença de suspensões de 50, 150, 200, 300, 500 e $600 \mathrm{mg}$ do melhor fotocatalisador.

\subsubsection{Reutilização de fotocatalisador}

Estudos de reutilização do melhor fotocatalisador foram realizados em três ciclos diferentes. Para isso, utilizou-se suspensão da melhor quantidade de fotocatalisador, resultante do experimento anterior, em $1,5 \mathrm{~L}$ de $\mathrm{SDZ} \operatorname{com} C_{0, \mathrm{SDZ}}=2 \mathrm{mg} \mathrm{L}^{-1}$. Ao final de cada experimento, separava-se o fotocatalisador da solução irradiada por filtração, deixava-se secar em estufa $\left(50{ }^{\circ} \mathrm{C}\right)$ por $24 \mathrm{~h}$; uma vez seco o material era reutilizado no tratamento de uma nova solução de SDZ. 


\subsubsection{Estudo da fotodegradação da sulfadiazina em águas residuais urbanas}

As ARU foram fortificadas com $2 \mathrm{mg} \mathrm{L}^{-1}$ de SDZ. A fotodegradação de 1,5 L desta solução foi conduzida na melhor quantidade e com o melhor fotocatalisador empregado. Também foram realizados estudos comparativos com o fotocatalisador comercial $\mathrm{TiO}_{2} \mathrm{P} 25$. Além disso, foram realizados experimentos de adsorção e de degradação, empregando ARU fortificads com SDZ, em concentração mais próxima da realidade (PAÍGA et al., 2019), ou seja, com $C_{0, \mathrm{SDZ}}=40 \mu \mathrm{g} \mathrm{\textrm {L } ^ { - 1 }}$, com o melhor fotocatalisador estudado, à melhor concentração avaliada. A pré-concentração da SDZ foi realizada através de extrações em fase sólida (SPE). Para isso, $200 \mathrm{~mL}$ das amostras foram filtradas em filtros de poliamida de $0,45 \mu \mathrm{m}$ e concentradas gota-a-gota em cartuchos Oasis HLB (Waters) de 500 mg. Após lavagem com metanol e água e secagem de cada cartucho, os analitos foram recuperados em $10 \mathrm{~mL}$ de metanol para realização das análises cromatográficas.

\subsection{Técnicas Analíticas}

A concentração de SDZ foi monitorada por HPLC de fase reversa usando um VWR Hitachi ELITE LaChrom equipado com um detector de matriz de diodos (DAD) e uma coluna Merck LiChrosorb ${ }^{\circledR}$ RP-18 (5 $\left.\mu \mathrm{m}\right)$ LiChroCART $^{\circledR} 125-4$ a $25{ }^{\circ} \mathrm{C}$. Empregou-se eluição isocrática de ácido oxálico 80:20 (v/v) $\left(0,014 \mathrm{~mol} \mathrm{~L}^{-1}\right)$ : acetonitrila, com vazão da fase móvel igual a $0,7 \mathrm{~mL} \mathrm{~min}^{-1}$ durante 5 minutos. Amostras de $20 \mu \mathrm{L}$ foram injetadas e o DAD foi estabelecido em $\lambda$ de $265 \mathrm{~nm}$. O tempo de retenção $\left(t_{\mathrm{r}}\right)$ foi de 3,4 min e os limites de quantificação e detecção foram de 0,18 e 0,05 mg L ${ }^{-1}$ de SDZ, respectivamente.

A determinação da concentração de SDZ e dos demais micropoluentes encontrados na amostra de ARU foi realizada através de cromatografia líquida acoplada por espectrometria de massa em tandem (LC-MS/MS) no Departamento de Química Analítica, Nutrição e Ciências dos Alimentos localizado no Instituto de Análise e Pesquisa de Alimentos (IIAA) na Universidade de Santiago, em Santiago de Compostela, Espanha.

Para tanto, os extratos metanólicos foram injetados no sistema LC-MS/MS (XEVO-TQD, Waters). A separação cromatográfica foi realizada em uma coluna de fusão Synergi RP C18 $100 \mathrm{~mm} \times 2 \mathrm{~mm}$ (Phenomenex) de $4 \mu \mathrm{m}$, com vazão da fase móvel de $0,4 \mathrm{~mL} \min ^{-1}$ e temperatura da coluna ajustada em $35{ }^{\circ} \mathrm{C}$. Foram utilizados 
como fases móveis A: água e B: metanol, ambas contendo $5 \mathrm{mmol} \mathrm{L}^{-1}$ de acetato de amônio. O gradiente começou em 2\% B (0-1 min) e aumentou para 100\% B em 10 minutos, depois permaneceu em $100 \% \mathrm{~B}$ por 5 minutos, retornou às condições iniciais $\mathrm{e}$ manteve esse passo isocrático de $2 \% \mathrm{~B}$ por 5 minutos. A corrida total foi de $20 \mathrm{~min}$. $\mathrm{O}$ nitrogênio foi usado como gás de nebulização, secagem e dissociação induzida por colisão (CID).

O intervalo de varredura foi de $50-1000 \mathrm{~m} / \mathrm{z}$. Uma solução de referência do fabricante foi alimentada continuamente durante cada execução para recalibração permanente do eixo $\mathrm{m} / \mathrm{z}$, de acordo com as instruções do fabricante. As medições em espectrometria de massa em tandem (MS/MS) foram realizadas no modo "autoMSMS" (dependente de dados), portanto, o sistema selecionou continuamente os íons $(\mathrm{m} / \mathrm{z}) \mathrm{com}$ maior abundância e realizou experimentos de MS/MS desses íons em três energias de colisão diferentes (10, 20 e 40 V.). A seleção do precursor foi limitada a 2 íons por ciclo e 3 espectros MS/MS (1 por energia de colisão, com um tempo de liberação de 0,5 min.) Três injeções consecutivas da mesma amostra foram realizadas no "modo iterativo", em que o sistema excluiu automaticamente o precursor de MS/MS já fragmentado nas injeções anteriores da mesma amostra e no mesmo tempo de retenção.

O software MassHunter Qualitative Analysis 10 (Agilent Technologies) foi utilizado para o tratamento dos dados, para isso identificou-se cada composto presente nas amostras de ARU através dos espectros pertencentes a biblioteca de massas que é composta por 3320 compostos químicos. Essa biblioteca foi construída a partir de diversas fontes, tais como Agilent ForTox, Agilent Water Screening, Agilent Metlin e Agilent Pesticides e por injeção direta de padrões. Os níveis de confirmação para cada composto foram estabelecidos de acordo com SCHYMANSKI et al. (2014). Os picos dos compostos provisoriamente identificados foram então integrados a partir do cromatograma de íons extraído de MS simples (EIC) com uma janela configurada para reconstrução do íon $[\mathrm{M}+\mathrm{H}]^{+}$ou $[\mathrm{M}-\mathrm{H}]^{-}$ajustado para $50 \mathrm{ppm}$. As áreas obtidas foram comparadas entre as três condições analisadas, a fim de obter uma estimativa de rendimento da degradação.

O coeficiente de determinação $\left(R^{2}\right)$ foi de $0,9997\left(5-5000 \mu \mathrm{g} \mathrm{L}^{-1}\right)$. O limite instrumental de quantificação (IQL) foi de $5 \mu \mathrm{g} \mathrm{L}^{-1}$. 


\section{RESULTADOS}

\subsection{Avaliação do Fotocatalisador para Degradação da SDZ}

A Figura 4.5 mostra os resultados obtidos na degradação de SDZ utilizando o fotorreator FluHelik para os experimentos de controle: fotólise e com a sílica SBA-15 não funcionalizada, bem como na presença dos fotocatalisadores $10 \% \mathrm{TiO}_{2} / \mathrm{SBA}-15$, $20 \% \mathrm{TiO}_{2} / \mathrm{SBA}-15$ e $30 \% \mathrm{TiO}_{2} / \mathrm{SBA}-15$.

Nestes experimentos é possível notar que não houve degradação de SDZ por fotólise e na presença da sílica inerte SBA-15, na qual ocorreu apenas adsorção/dessorção. Como o pH inicial da solução foi 7,0, 50\% das moléculas de SDZ estão na forma aniônica e os outros $50 \%$ são neutras (cf. Figura 2.3, Capítulo 2). O potencial de carga zero (ZPC) da SBA-15 se encontra em valor de pH próximo a 2,0 (temperatura de $25^{\circ} \mathrm{C}$ ) (MAUČEC et al., 2018) de modo que em $\mathrm{pH}$ 7,0 sua superfície encontra-se com potencial zeta fortemente negativo $(\sim-35 \mathrm{mV})$, podendo ocasionar alguma atração entre as moléculas de SDZ neutras na sua superfície.

No entanto, a remoção por adsorção da SDZ nos materiais $\mathrm{TiO}_{2} / \mathrm{SBA}-15$ pode ser desprezada, pois estes materiais possuem ZPC em pH entre 5,7 e 6,0 (MAUČEC et al., 2018). Em pH 7,0 sua superfície se encontra carregada negativamente, porém com menor potencial zeta $(\sim-20 \mathrm{mV})$ repelindo as moléculas aniônicas e não possuindo poder de atração para as moléculas neutras de SDZ.

$\mathrm{Na}$ Figura 4.5 nota-se uma pronunciada degradação do antibiótico promovida pelos materiais $\mathrm{TiO}_{2} / \mathrm{SBA}-15$. À medida que se aumenta a quantidade de $\mathrm{TiO}_{2}$ na sílica mesoporosa maior é o efeito fotocatalítico para a degradação de SDZ. O fotocatalisador contendo $10 \%$ de $\mathrm{TiO}_{2}$ foi capaz de degradar 31,6\% de SDZ, enquanto 65,2\% de degradação foram obtidos empregando o material com $20 \%$ de $\mathrm{TiO}_{2}$; já o material com $30 \%$ de $\mathrm{TiO}_{2}$ promoveu degradação de 73,2\% de SDZ após 180 min de tratamento (Tabela 4.2).

Neste sistema, os materiais contendo $20 \%$ e $30 \%$ de $\mathrm{TiO}_{2}$ apresentaram resultados similares para a degradação de SDZ, o que pode ser devido aos tamanhos de partículas de $\mathrm{TiO}_{2}$ na superfície desses materiais (cf. Tabela 1.3, Capítulo 1). O material 20\% $\mathrm{TiO}_{2} / \mathrm{SBA}-15$ apresentou tamanho de cristal de $\mathrm{TiO}_{2}$ de $6,62 \mathrm{~nm}$, similar ao observado para o material $30 \% \mathrm{TiO}_{2} / \mathrm{SBA}-15$, que apresentou tamanho de cristal de 6,18 nm. Por sua vez, o fotocatalisador $10 \% \mathrm{TiO}_{2} / \mathrm{SBA}-15$ possui tamanho de cristal de 7,94 nm, 
mostrando maior aglomeração de $\mathrm{TiO}_{2}$ em sua superfície. Conforme já visto na literatura (TSENG et al., 2012; VAN GRIEKEN et al., 2002), os materiais que possuem cristais de $\mathrm{TiO}_{2}$ com tamanho entre 6 e $7 \mathrm{~nm}$ podem estar mais dispersos na superfície da sílica e por isso, apresentam melhor desempenho para a degradação de poluentes orgânicos.

Contudo, o $30 \% \mathrm{TiO}_{2} / \mathrm{SBA}-15$ apresentou uma ligeira melhora em relação ao $20 \%$ $\mathrm{TiO}_{2} / \mathrm{SBA}-15$, este resultado pode ser devido à maior área superficial específica obtida para este fotocatalisador $\left(473 \mathrm{~m}^{2} \mathrm{~g}^{-1}\right)$, proporcionando maior contato entre as moléculas de contaminante e os sítios ativos de sua superfície (LIU et al., 2016a).

Figura 4.5 Experimentos de adsorção e de fotodegradação da sulfadiazina (SDZ) conduzidos no fotorreator FluHelik. Experimentos de controle por fotólise (-A-), adsorção em SBA-15 (-匹-) e fotodegradação na presença dos fotocatalisadores $10 \% \mathrm{TiO}_{2} / \mathrm{SBA} 15(-\downarrow), 20 \% \mathrm{TiO}_{2} / \mathrm{SBA}-15(-\bullet)$, $30 \% \mathrm{TiO}_{2} / \mathrm{SBA}-15\left(-\mathrm{O}-\right.$ ). Condições: $150 \mathrm{mg}$ de fotocatalisador, $V_{\mathrm{sol}}=1,5 \mathrm{~L} ; C_{0, \mathrm{SDZ}}=2 \mathrm{mg} \mathrm{L}^{-1}$; $\mathrm{pH}_{\text {inicial }}=7,0 ; \mathrm{T}=25^{\circ} \mathrm{C}$.

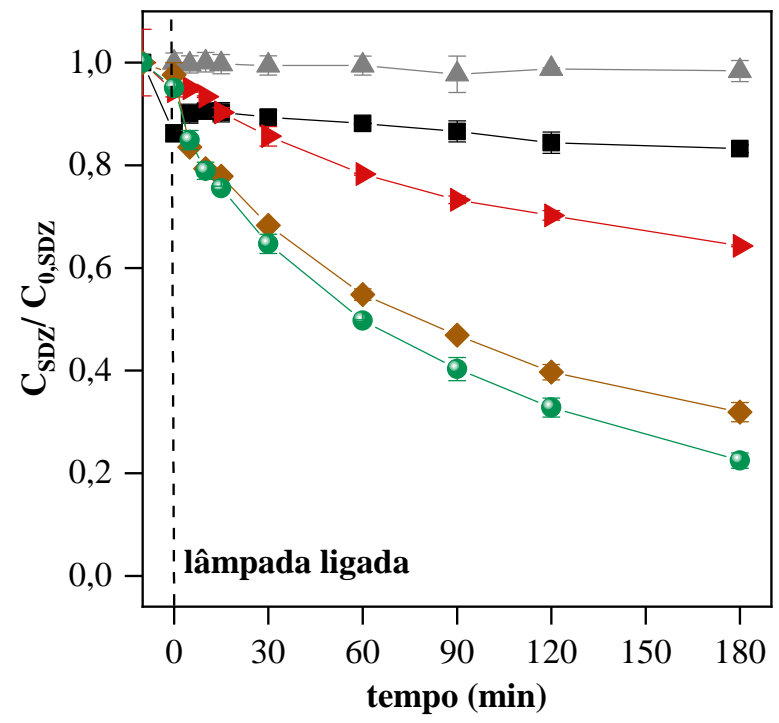

\subsection{Avaliação da Quantidade de Fotocatalisador 30\% $\mathrm{TiO}_{2} / \mathrm{SBA}-15$ para a} Degradação da SDZ

Como o material $30 \% \mathrm{TiO}_{2} / \mathrm{SBA}-15$ mostrou melhor desempenho fotocatalítico frente aos demais (Figura 4.5), este foi escolhido para uso nos demais estudos. A Figura 4.6 mostra os experimentos de degradação de SDZ com variação na massa de fotocatalisador $30 \% \mathrm{TiO}_{2} / \mathrm{SBA}-15$. A massa foi variada conforme a Tabela 4.2, resultando em diferentes concentrações de fotocatalisador no meio reacional.

Como esperado, a degradação de SDZ aumenta com o aumento na quantidade de fotocatalisador, uma vez que isto implica no aumento da quantidade de $\mathrm{TiO}_{2}$ presente no 
meio reacional (Tabela 4.2), promovendo o aumento da fotogeração de espécies oxidantes. É possível observar que a quantidade de $500 \mathrm{mg}\left(C_{\text {catal }}=0,333 \mathrm{~g} \mathrm{~L}^{-1}\right.$ e $C_{\mathrm{TiO} 2}$ $=100 \mathrm{mg} \mathrm{L}^{-1}$ ) apresentou o melhor resultado para degradar a SDZ, alcançando a degradação deste contaminante após 120 minutos de irradiação. Contudo, quando se aumenta a quantidade de fotocatalisador, para $600 \mathrm{mg}$ o efeito fotocatalítico é suprimido, o que se deve a um aumento no espalhamento de luz e menor penetração da radiação no meio, uma vez que a suspensão se tornava visivelmente com aspecto mais esbranquiçado.

Tabela 4.2 Massa e concentração do fotocatalisador $30 \% \mathrm{TiO}_{2} / \mathrm{SBA}-15$ juntamente com a concentração de $\mathrm{TiO}_{2}$ presentes nos testes de variação de massa do fotocatalisador. Condições: $V_{\text {sol }}=1,5 \mathrm{~L} ; C_{0, \mathrm{SDZ}}=2$ $\mathrm{mg} \mathrm{L}^{-1} ; \mathrm{pH}_{0}=7,0$ e $\mathrm{T}=25^{\circ} \mathrm{C}$.

\begin{tabular}{cccc}
\hline Fotocatalisador & $\boldsymbol{m}_{\text {fotocatal }}(\mathbf{m g})$ & $\boldsymbol{C}_{\text {fotocatal }}\left(\mathbf{g ~ L}^{-\mathbf{1}}\right)$ & $\boldsymbol{C}_{\text {TiO2 }}\left(\mathbf{m g ~ L}^{-\mathbf{1}}\right)$ \\
\hline 50 & 0,033 & 10 \\
& 150 & 0,100 & 30 \\
$30 \% \mathrm{TiO}_{2} / \mathrm{SBA}-15$ & 200 & 0,133 & 40 \\
& 300 & 0,200 & 60 \\
& 500 & 0,333 & 100 \\
& 600 & 0,400 & 120 \\
\hline
\end{tabular}

Figura 4.6 Experimentos de fotodegradação de sulfadiazina conduzidos na presença de diferentes quantidades do fotocatalisador $30 \% \mathrm{TiO}_{2} / \mathrm{SBA}-15: 50 \mathrm{mg}(-\mathbf{-}), 150 \mathrm{mg}(-\mathbf{-}-), 200 \mathrm{mg}\left(-\boldsymbol{4}^{-}\right), 300$ $\mathrm{mg}(-\star-), 500 \mathrm{mg}\left(-\bullet_{-}\right)$e $600 \mathrm{mg}\left(-{ }^{-}\right.$). Condições: $1,5 \mathrm{~L}$ de solução de SDZ; $C_{0, \mathrm{SDZ}}=2 \mathrm{mg} \mathrm{L}^{-1}$; $\mathrm{pH}_{0}=7,0 ; \mathrm{T}=25^{\circ} \mathrm{C}$.

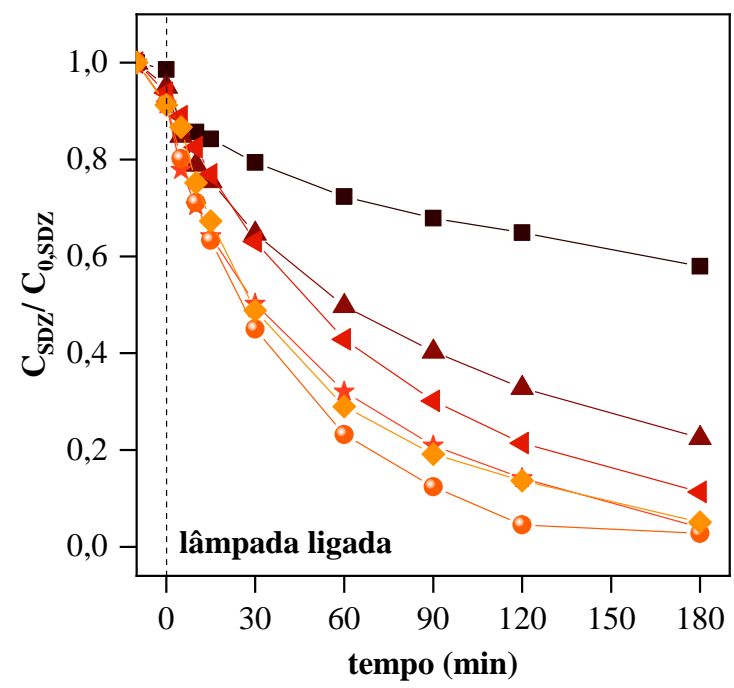




\subsection{Reutilização do Fotocatalisador 30\% $\mathrm{TiO}_{2} / \mathrm{SBA}-15$ para a Degradação da SDZ}

Com esse resultado, a quantidade de $500 \mathrm{mg}\left(C_{\mathrm{TiO} 2}=100 \mathrm{mg} \mathrm{L}^{-1}\right)$ foi selecionada para o estudo de reutilização do fotocatalisador $30 \% \mathrm{TiO}_{2} / \mathrm{SBA}-15$ em 3 ciclos de degradação de SDZ (Figura 4.7). É possível notar que este fotocatalisador perde parcialmente sua atividade fotocatalítica quando reutilizado; no primeiro ciclo, o material foi capaz de praticamente mineralizar a SDZ, enquanto 94\% da SDZ presente inicialmente foram eliminados nos dois últimos ciclos (Tabela 4.3). Este resultado mostra que $\mathrm{TiO}_{2} / \mathrm{SBA}-15$ tem potencial para ser utilizado na descontaminação de matrizes contendo o antibiótico.

Figura 4.7 Experimentos de reutilização do fotocatalisador $30 \% \mathrm{TiO}_{2} / \mathrm{SBA}-15$ para a degradação de SDZ no fotorreator FluHelik. Condições $\mathrm{C}_{\mathrm{TiO} 2}=100 \mathrm{mg} \mathrm{L}^{-1} ; 1,5 \mathrm{~L}$ de solução de $\mathrm{SDZ} ; C_{0, \mathrm{SDZ}}=2 \mathrm{mg} \mathrm{L} \mathrm{L}^{-1} ; \mathrm{pH}_{0}=$ 7,$0 ; \mathrm{T}=25^{\circ} \mathrm{C}$.

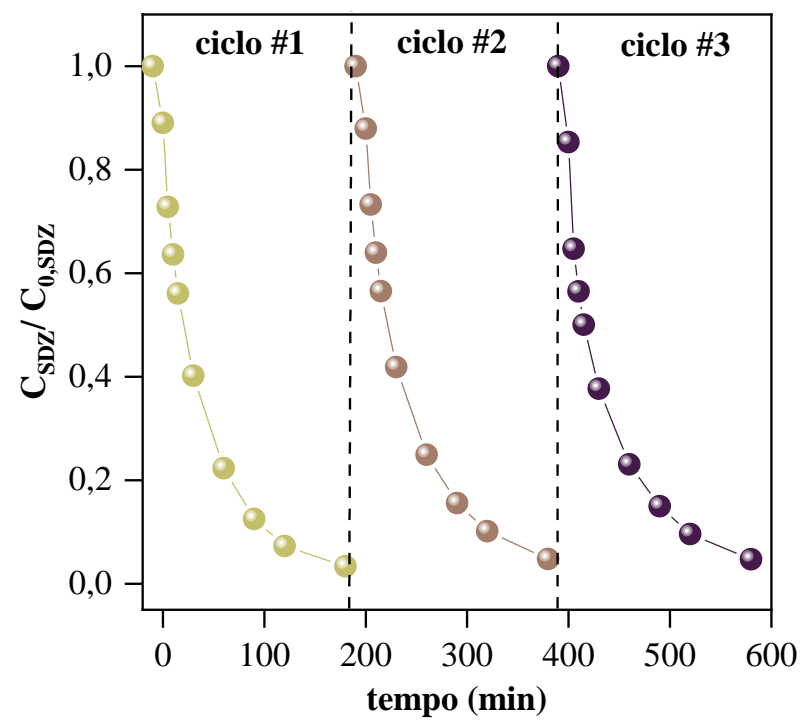

\subsection{Estudo da Fotodegradação da SDZ em ARU}

A degradação de sulfadiazina também foi avaliada empregando como matriz uma amostra de ARU fortificada com $2 \mathrm{mg} \mathrm{L}^{-1}$ deste antibiótico, para isso o desempenho fotocatalítico do $30 \% \mathrm{TiO}_{2} / \mathrm{SBA}-15$ foi comparado com o fotocatalisador utilizado comercialmente o $\mathrm{TiO}_{2} \mathrm{P} 25$.

É possível observar na Figura 4.8A que em água pura, o fotocatalisador $\mathrm{TiO}_{2} \mathrm{P} 25$ apresenta melhor desempenho para a degradação de SDZ quando comparado ao $30 \%$ $\mathrm{TiO}_{2} / \mathrm{SBA}-15$, alcançando a degradação do contaminante em 60 minutos de irradiação.

Contudo, a Figura 4.8B mostra que o fotocatalisador $30 \% \quad \mathrm{TiO}_{2} / \mathrm{SBA}-15$ apresentou melhor desempenho em degradar a SDZ quando a matriz aquosa é o efluente 
real. O material 30\% $\mathrm{TiO}_{2} / \mathrm{SBA}-15$ permitiu degradar 31,6\% de $\mathrm{SDZ}$, enquanto o $\mathrm{TiO}_{2}$ P25 atingiu um máximo de 56,4\% de degradação (Tabela 4.3).

Este resultado pode ser devido a uma maior agregação das partículas de $\mathrm{TiO}_{2} \mathrm{P} 25$ (KONSTANTINOU; ALBANIS, 2004). Como visto, dentre as vantagens do material $\mathrm{TiO}_{2} / \mathrm{SBA}-15$ destaca-se sua rede mesoporosa estável e grande área superficial conferindo boa acessibilidade das moléculas de SDZ facilitando seu acesso aos sítios ativos de $\mathrm{TiO}_{2}$. Destaca-se também que a estrutura mesoporosa da SBA-15 pode bloquear a entrada de espécies maiores presentes na amostra de ARU, tais como os ácidos húmicos, que possuem tamanho na ordem de 600-800nm (KLUČÁKOVÁ, 2018), sendo um fator de seleção para a degradação de pequenas moléculas, tais como as do contaminate SDZ, o que leva a um melhor desempenho deste fotocatalisador mesmo em águas reais (CALZADA et al., 2019; CASTANHEIRA et al., 2017).

Figura 4.8 Experimentos de adsorção e fotodegradação da sulfadiazina (SDZ) em (A) água pura e (B) água residual urbana conduzidos no fotorreator FluHelik. Experimentos na presença dos fotocatalisadores $30 \% \mathrm{TiO}_{2} / \mathrm{SBA}-15(--)$ e $\mathrm{TiO}_{2} \mathrm{P} 25\left({ }^{-}\right)$. Condições: $\left[\mathrm{TiO}_{2}\right]=100 \mathrm{mg} \mathrm{L}{ }^{-1} ; 1,5 \mathrm{~L}$ de água residual fortificada com $\operatorname{SDZ}\left(C_{0, \mathrm{SDZ}}=2 \mathrm{mg} \mathrm{L}^{-1}\right) ; \mathrm{pH}_{0}=7,0 ; \mathrm{T}=25^{\circ} \mathrm{C}$.
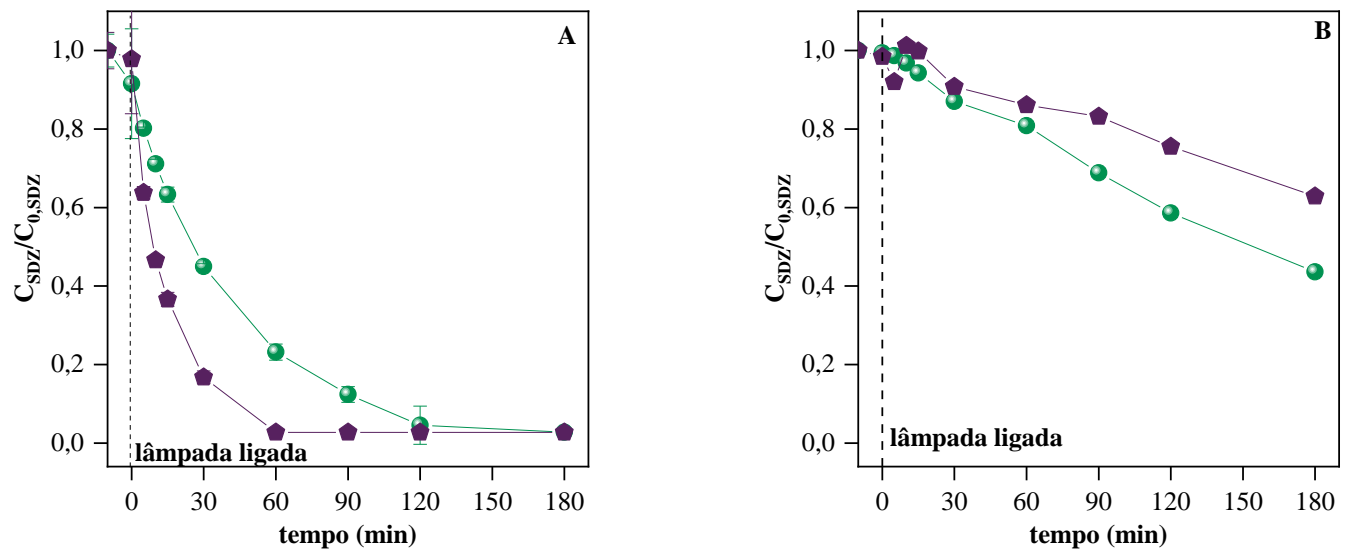

As constantes cinéticas aparentes de pseudo-primeira ordem $\left(k_{\mathrm{SDZ}}\right)$ determinadas através do ajuste não linear do decaimento da concentração de SDZ em função do tempo (Equação 4.2), bem como as porcentagens de adsorção e de degradação e os parâmetros utilizados em todos os experimentos realizados no presente Capítulo são mostrados na Tabela 4.3.

Uma adsorção de aproximadamente 13,8\% de SDZ ocorreu na superfície da sílica SBA-15 não funcionalizada, a presença de $\mathrm{TiO}_{2}$ na superfície da sílica, nas 
diferentes porcentagens, a adsorção de SDZ diminui para valores entre 3 a 6\%. Porém, este resultado não influencia na fotodegradação deste poluente, de modo que, como foi visto, a maior degradação foi em presença de $30 \%$ de $\mathrm{TiO}_{2}$ na sílica apresentando o valor para a constante de reação de pseudo-primeira ordem $\left(k_{S D Z}\right)$ de $0,809 \times 10^{-2} \mathrm{~min}^{-1}$.

Os experimentos que avaliaram a influência na quantidade da suspensão do material 30\% $\mathrm{TiO}_{2} / \mathrm{SBA}-15$, ou seja, aumento na contração de $\mathrm{TiO}_{2}$ no meio reacional, mostram que a adsorção de SDZ aumenta com o aumento da massa de catalisador, alcançando um valor de equilíbrio de aproximadamente $8 \%$ de adsorção de SDZ (Tabela 4.3). $\mathrm{O}$ experimento com concentração de $\mathrm{TiO}_{2}$ de $100 \mathrm{mg} \mathrm{L}^{-1}$ apresentou o maior $k_{\mathrm{SDZ}}$ com valor de $2,36 \times 10^{-2} \mathrm{~min}^{-1} \mathrm{em}$ água pura.

Os experimentos de reutilização do fotocatalisador $30 \% \quad \mathrm{TiO}_{2} / \mathrm{SBA}-15$ apresentaram variação na quantidade de adsorção de SDZ, no primeiro ciclo 9,7\% de SDZ presente inicialmente foi adsorvida, no segundo e terceiro ciclo a adsorção diminui para 2,7 e 3,1\%, respectivamente. Este resultado pode ser um indicativo de que a sulfadiazina remanescente, ou intermediários formados durante a fotodegradação, permanecem na superfície do material fotocatalisador após o final do primeiro ciclo. Contudo, essa diminuição na adsorção de SDZ não influencia no desempenho de sua fotodegradação, apresentando valores similares de $k_{S D Z}$ de $1,874 \times 10^{-2} ; 1,723 \times 10^{-2} \mathrm{e}$ $1,659 \times 10^{-2} \mathrm{~min}^{-1}$ para o primeiro, segundo e terceiro ciclo, respectivamente.

A comparação realizada do material $30 \% \mathrm{TiO}_{2} / \mathrm{SBA}-15$ com o fotocatalisador comercial $\mathrm{TiO}_{2} \mathrm{P} 25$, mostrou que de fato em água pura, o $\mathrm{TiO}_{2} \mathrm{P} 25$ possui uma eficiência superior ao $30 \% \mathrm{TiO}_{2} / \mathrm{SBA}-15$ para a fotodegração de SDZ resultando em um $k_{S D Z}$ de $6,099 \times 10^{-2} \mathrm{~min}^{-1}$. Contudo, quando se muda o substrato de água pura para água residual urbana, o material $30 \% \mathrm{TiO}_{2} / \mathrm{SBA}-15$ apresentou o dobro do valor de $k_{\mathrm{SDZ}}$ $\left(0,427 \times 10^{-2} \mathrm{~min}^{-1}\right)$ quando comparado ao $\mathrm{TiO}_{2} \mathrm{P} 25$ (Degussa) com $k_{\mathrm{SDZ}}=0,253 \times 10^{-2}$ $\min ^{-1}$. Revelando que de fato, o efeito de aglomeração do $\mathrm{TiO}_{2} \mathrm{P} 25$ o limita para a aplicação em degradação de poluentes presentes nos efluentes reais (DONG et al., 2015). 
Tabela 4.3 Porcentagem de adsorção (\%SDZ ads.), porcentagem de fotodegradação (\%SDZ deg.), constante de reação de pseudo-primeira ordem $\left(k_{\mathrm{SDZ}}\right)$, coeficiente de determinação do ajuste não linear $\left(R^{2}\right)$ e os parâmetros empregados nos experimentos de degradação de sulfadiazina no fotorreator FluHelik.

\begin{tabular}{|c|c|c|c|c|c|c|c|c|c|c|c|c|}
\hline Experimento & matriz & fotocatalisador & $\begin{array}{c}{\left[\mathrm{TiO}_{2}\right]} \\
\left(\mathrm{mg} \mathrm{L}^{-1}\right)\end{array}$ & $\begin{array}{c}{[\mathrm{SDZ}]_{0}} \\
\left(\mathrm{mg} \mathrm{L}^{-1}\right)\end{array}$ & $\begin{array}{c}\text { Tempo } \\
\text { irradiação } \\
\text { (min) }\end{array}$ & $\begin{array}{c}\mathbf{Q}^{\mathbf{b}} \\
\left(\mathbf{L} \mathbf{h}^{-1}\right)\end{array}$ & $\begin{array}{c}\text { pH } \\
\text { inicial }\end{array}$ & $\begin{array}{c}\text { pH } \\
\text { final }\end{array}$ & $\begin{array}{c}\% \text { SDZ } \\
\text { ads. }\end{array}$ & $\begin{array}{c}\text { \%SDZ } \\
\text { deg. }\end{array}$ & $\begin{array}{c}k S D Z \\
\left(10^{-2} \min ^{-1}\right)^{\mathrm{c}}\end{array}$ & $R^{2}$ \\
\hline $\begin{array}{c}\text { Homogêneo } \\
\text { (fotólise) }\end{array}$ & $\mathrm{AP}^{\mathrm{a}}$ & - & - & 2 & $0-180$ & 75 & 7,0 & 7,38 & - & 1,6 & - & - \\
\hline \multirow{15}{*}{$\begin{array}{l}\text { Heterogêneo } \\
\text { (fotocatálise) }\end{array}$} & \multicolumn{12}{|c|}{ Influência material fotocatalítico } \\
\hline & AP & SBA-15 & 30 & 2 & $0-180$ & 75 & 7,0 & 7,38 & 13,8 & 3,1 & 0,049 & 0,9693 \\
\hline & $\mathrm{AP}$ & $10 \% \mathrm{TiO}_{2} / \mathrm{SBA}-15$ & 30 & 2 & $0-180$ & 75 & 7,0 & 7,39 & 5,6 & 31,6 & 0,204 & 0,9634 \\
\hline & AP & $20 \% \mathrm{TiO}_{2} / \mathrm{SBA}-15$ & 30 & 2 & $0-180$ & 75 & 7,0 & 7,25 & 2,4 & 65,2 & 0,608 & 0,9855 \\
\hline & AP & $30 \% \mathrm{TiO}_{2} / \mathrm{SBA}-15$ & 30 & 2 & $0-180$ & 75 & 7,0 & 7,37 & 4,9 & 73,2 & 0,809 & 0,9920 \\
\hline & \multicolumn{12}{|c|}{ Influência da massa de fotocatalisador } \\
\hline & $\mathrm{AP}$ & $30 \% \mathrm{TiO}_{2} / \mathrm{SBA}-15$ & 10 & 2 & $0-180$ & 75 & 7,0 & 7,30 & 1,4 & 40,7 & 0,234 & 0,9784 \\
\hline & $\mathrm{AP}$ & $30 \% \mathrm{TiO}_{2} / \mathrm{SBA}-15$ & 40 & 2 & $0-180$ & 75 & 7,0 & 7,01 & 6,2 & 82,5 & 1,265 & 0,9991 \\
\hline & AP & $30 \% \mathrm{TiO}_{2} / \mathrm{SBA}-15$ & 60 & 2 & $0-180$ & 75 & 7,0 & 7,11 & 8,6 & 87,3 & 1,855 & 0,9834 \\
\hline & AP & $30 \% \mathrm{TiO}_{2} / \mathrm{SBA}-15$ & 100 & 2 & $0-180$ & 75 & 7,0 & 7,06 & 8,4 & 88,8 & 2,360 & 0,9990 \\
\hline & AP & $30 \% \mathrm{TiO}_{2} / \mathrm{SBA}-15$ & 120 & 2 & $0-180$ & 75 & 7,0 & 7,26 & 8,7 & 86,2 & 1,851 & 0,9941 \\
\hline & \multicolumn{12}{|c|}{ Reutilização do 30\% $\mathrm{TiO}_{2} / \mathrm{SBA}-15$} \\
\hline & AP & Ciclo \#1 & 100 & 2 & $0-180$ & 75 & 7,0 & 7,15 & 9,7 & 87,3 & 1,874 & 0,9887 \\
\hline & AP & Ciclo \#2 & 100 & 2 & $0-180$ & 75 & 7,0 & 7,13 & 2,7 & 94,5 & 1,723 & 0,9903 \\
\hline & AP & Ciclo \#3 & 100 & 2 & $0-180$ & 75 & 7,0 & 7,27 & 3,1 & 94,0 & 1,659 & 0,9909 \\
\hline
\end{tabular}


Tabela 4.3 (Cont.) Porcentagem de adsorção (\%SDZ ads.), porcentagem de fotodegradação (\%SDZ deg.), constante de reação de pseudo-primeira ordem $\left(k_{\mathrm{SDZ}}\right)$, coeficiente de determinação do ajuste não linear $\left(R^{2}\right)$ e os parâmetros empregados nos experimentos de degradação de sulfadiazina no fotorreator FluHelik.

\begin{tabular}{|c|c|c|c|c|c|c|c|c|c|c|c|c|}
\hline Experimento & matriz & fotocatalisador & $\begin{array}{c}{\left[\mathrm{TiO}_{2}\right]} \\
\left(\mathrm{mg} \mathrm{L}^{-1}\right)\end{array}$ & $\begin{array}{c}{[\mathrm{SDZ}]_{0}} \\
\left(\mathrm{mg} \mathrm{L}^{-1}\right)\end{array}$ & $\begin{array}{c}\text { Tempo } \\
\text { irradiação } \\
(\text { min) }\end{array}$ & $\begin{array}{c}\mathbf{Q}^{\mathbf{b}} \\
\left(\mathbf{L} \mathbf{h}^{-1}\right)\end{array}$ & $\begin{array}{c}\text { pH } \\
\text { inicial }\end{array}$ & $\begin{array}{c}\text { pH } \\
\text { final }\end{array}$ & $\begin{array}{c}\% \mathrm{SDZ} \\
\text { ads. }\end{array}$ & $\begin{array}{c}\% \mathrm{SDZ} \\
\text { deg. }\end{array}$ & $\begin{array}{c}k_{a p p} \\
\left(10^{-2}\right. \\
\left.\min ^{-1}\right)^{\mathbf{c}}\end{array}$ & $R^{2}$ \\
\hline & \multicolumn{12}{|c|}{ Influência da matriz } \\
\hline Heterogêneo & $\mathrm{AP}^{\mathrm{a}}$ & $\mathrm{TiO}_{2} \mathrm{P}-25$ & 100 & 2 & $0-180$ & 75 & 7,0 & 6,57 & 2,2 & 95,0 & 6,099 & 0,9971 \\
\hline \multirow[t]{2}{*}{ (fotocatálise) } & $\mathrm{ARU}^{\mathrm{a}}$ & $\mathrm{TiO}_{2} \mathrm{P}-25$ & 100 & 2 & $0-180$ & 75 & 7,0 & 7,15 & 1,6 & 31,6 & 0,253 & 0,9716 \\
\hline & ARU & $30 \% \mathrm{TiO}_{2} / \mathrm{SBA}-15$ & 100 & 2 & $0-180$ & 75 & 7,0 & 7,55 & 0,6 & 56,4 & 0,427 & 0,9907 \\
\hline
\end{tabular}

a AP: Água pura; ARU. Água Residual Urbana.

b Vazão.

${ }^{\mathrm{c}}$ Constante de pseudo-primeira ordem determinada através de ajusto não linear. 
4.4.1 Estudo da adsorção e fotodegradação de SDZ e dos micropoluentes presentes na $A R U$

Através dos resultados de LC-MS/MS dos experimentos realizados com a matriz ARU fortificada com a SDZ na concentração inicial de $40 \mu \mathrm{g} \mathrm{L}^{-1}$, notou-se que não houve remoção de SDZ através da adsorção, contudo, 90 \% da SDZ pôde ser degradada após 180 min de irradiação devido à presença do fotocatalisador $30 \% \mathrm{TiO}_{2} / \mathrm{SBA}-15$.

Os demais microcontaminantes identificados na ARU totalizaram 65 e estão listados na Tabela 4.4. É possível notar que a grande maioria desses microcontaminantes pertence à família dos fármacos, predominantemente fármacos empregados em medicamentos de uso neurológico. Como é bem conhecido, a presença de compostos de uso farmacêutico em águas residuais urbanas é atribuída ao descarte desses produtos que não foram utilizados ou vencidos, à excreção animal e humana ou lançamentos por parte das indústrias em efluentes gerados nos processos de fabricação e formulação (KÜMMERER, 2009a, 2009b).

A maioria dos microcontaminantes presentes na Tabela 4.4 foi adsorvida após 24 h e degradada após 180 min de irradiação nos experimentos conduzidos na presença do material 30\% $\mathrm{TiO}_{2} / \mathrm{SBA}-15$ (Figura 4.9).

Quase $80 \%$ da concentração inicial dos fármacos utilizados para tratamento de doenças do sistema nervoso foram eliminados (Figura 4.9A).Os fármacos utilizados como anti-infecciosos e antibacterianos, como é o caso do claritromicina (CR), sulfapiridina (SPy), sulfametoxazol (SMX) e o trimetoprim (TMP), assim como a SDZ, não apresentaram afinidade de adsorção na superfície do fotocatalisador, o mesmo ocorreu com os fármacos utilizados no tratamento de doenças cardiovasculares: losartan (LOS), perindopril (PRD), propranolol (PRN), sotalol (STL) e telmisartan (TEL) (Figura 4.9B). Contudo, a concentração desses fármacos diminui quase $100 \%$ após a irradiação, com exceção do SMX.

Os fármacos de uso dermatológico climbazole (CLZ) e fluconazole (II) (FLC) e os contaminantes fipronil (FIP), nitrofenolato (NP), ácido ritalínico (RA), sucralose (SUC), terbutrin (TB) e tolueno 2-sulfonamida (TSN), que não compõem a classe de fármacos, não foram adsorvidos na superfície do material $30 \% \mathrm{TiO}_{2} / \mathrm{SBA}-15$ e também foram parcialmente degradados após a irradiação. No entanto, tiemônio (TI), sitagliptina (SGN), levorpanol (LEV), levofloxacina (LVX), denatonium (DE) e dietiltoluamida (DEET), que são medicamentos utilizados para outros tratamentos, foram 
completamente eliminados após os 180 min de irradiação (Figura 4.9C). Ou seja, 25\% dos 65 microcontaminates inicialmente detectados alcançaram redução de sua concentração inicial superior a $80 \%$.

Figura 4.9 Gráficos de radar das relações de concentração $\left(C / C_{0}\right)$ presentes inicialmente $(-)$ e após a adsorção (-) e irradiação (-) utilizando o fotocatalisador $30 \% \mathrm{TiO}_{2} / \mathrm{SBA}-15$, considerando os microcontaminantes detectados na ARU que são fármacos utilizados em (A) medicamentos de uso neurológico; (B) medicamentos de uso cardiovascular, respiratório e urinário (C) medicamentos de uso dermatológico, outros e substancias não usadas como medicamentos.
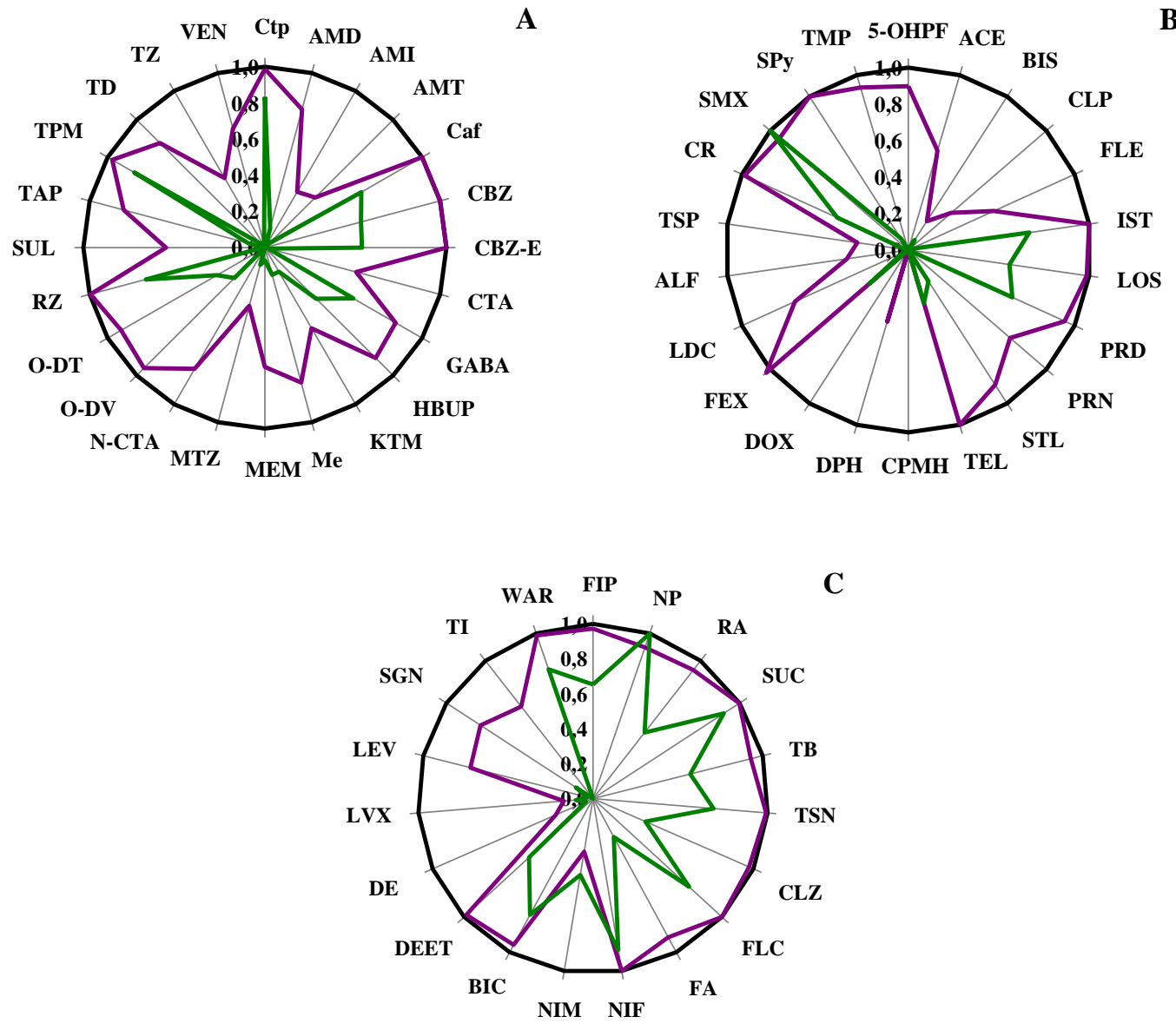

C

B

A 
Tabela 4.4 Nomenclatura, abreviatura, fórmula química, tempo de retenção $(R t)$ e aplicação dos micropoluentes encontrados na ARU coletada após tratamento secundário através de análises LC-MS/MS.

\begin{tabular}{|c|c|c|c|c|c|c|c|}
\hline Contaminante & Abreviatura & $\begin{array}{l}\text { Fórmula } \\
\text { Química }\end{array}$ & $R t$ (min) & Contaminante & Abreviatura & $\begin{array}{l}\text { Fórmula } \\
\text { Química }\end{array}$ & $R t$ (min) \\
\hline \multicolumn{8}{|c|}{ Uso no sistema neurológico } \\
\hline 8-Cloroteofilina & Ctp & $\mathrm{C}_{7} \mathrm{H}_{7} \mathrm{ClN}_{4} \mathrm{O}_{2}$ & 6,204 & Memantine & MEM & $\mathrm{C}_{12} \mathrm{H}_{21} \mathrm{~N}$ & 8,835 \\
\hline Amantadine & AMD & $\mathrm{C}_{10} \mathrm{H}_{17} \mathrm{~N}$ & 4,925 & Mirtazapina & MTZ & $\mathrm{C}_{17} \mathrm{H}_{19} \mathrm{~N}_{3}$ & 6,040 \\
\hline Amisulprida & AMI & $\mathrm{C}_{17} \mathrm{H}_{27} \mathrm{~N}_{3} \mathrm{O}_{4} \mathrm{~S}$ & 5,433 & Norcitalopram & N-CTA & $\mathrm{C}_{19} \mathrm{H}_{19} \mathrm{FN}_{2} \mathrm{O}$ & 9,309 \\
\hline Amitriptilina & $\mathrm{AMT}$ & $\mathrm{C}_{20} \mathrm{H}_{23} \mathrm{~N}$ & 11,294 & Desvenlafaxina & O-DV & $\mathrm{C}_{16} \mathrm{H}_{25} \mathrm{NO}_{2}$ & 5,815 \\
\hline Cafeína & Caf & $\mathrm{C}_{8} \mathrm{H}_{10} \mathrm{~N}_{4} \mathrm{O}_{2}$ & 5,636 & O-desmetiltramadol & O-DT & $\mathrm{C}_{15} \mathrm{H}_{23} \mathrm{NO}_{2}$ & 4,633 \\
\hline Carbamazepina & $\mathrm{CBZ}$ & $\mathrm{C}_{15} \mathrm{H}_{12} \mathrm{~N}_{2} \mathrm{O}$ & 11,502 & Riluzol & RZ & $\mathrm{C}_{8} \mathrm{H}_{5} \mathrm{~F}_{3} \mathrm{~N}_{2} \mathrm{OS}$ & 11,622 \\
\hline $\begin{array}{c}\text { Carbamazepina 10,11- } \\
\text { epóxido }\end{array}$ & CBZ-E & $\mathrm{C}_{15} \mathrm{H}_{12} \mathrm{~N}_{2} \mathrm{O}_{2}$ & 8,985 & Sulpirida & SUL & $\mathrm{C}_{15} \mathrm{H}_{23} \mathrm{~N}_{3} \mathrm{O}_{4} \mathrm{~S}$ & 3,200 \\
\hline Citalopram & CTA & $\mathrm{C}_{20} \mathrm{H}_{21} \mathrm{FN}_{2} \mathrm{O}$ & 9,250 & Tapentadol & TAP & $\mathrm{C}_{14} \mathrm{H}_{23} \mathrm{NO}$ & 6,830 \\
\hline Gabapentina & GABA & $\mathrm{C}_{9} \mathrm{H}_{17} \mathrm{NO}_{2}$ & 3,329 & Topiramato & TPM & $\mathrm{C}_{12} \mathrm{H}_{21} \mathrm{NO}_{8} \mathrm{~S}$ & 9,205 \\
\hline Hidroxibupropiona & HBUP & $\mathrm{C}_{13} \mathrm{H}_{18} \mathrm{ClNO}_{2}$ & 6,526 & Tramadol & TD & $\mathrm{C}_{16} \mathrm{H}_{25} \mathrm{NO}_{2}$ & 6,349 \\
\hline Cetamina & KTM & $\mathrm{C}_{13} \mathrm{H}_{16} \mathrm{ClNO}$ & 5,832 & Trazodona & $\mathrm{TZ}$ & $\mathrm{C}_{19} \mathrm{H}_{22} \mathrm{ClN}_{5} \mathrm{O}$ & 8,003 \\
\hline Melperone & $\mathrm{Me}$ & $\mathrm{C}_{16} \mathrm{H}_{22} \mathrm{FNO}$ & 7,269 & Venlafaxina & VEN & $\mathrm{C}_{17} \mathrm{H}_{27} \mathrm{NO}_{2}$ & 8,304 \\
\hline \multicolumn{8}{|c|}{ Uso no sistema cardiovascular } \\
\hline 5-hidroxipropafenona & $5-\mathrm{OHPF}$ & $\mathrm{C}_{21} \mathrm{H}_{27} \mathrm{NO}_{4}$ & 9,593 & Losartan & LOS & $\mathrm{C}_{22} \mathrm{H}_{23} \mathrm{ClN}_{6} \mathrm{O}$ & 13,279 \\
\hline Acebutolol & $\mathrm{ACE}$ & $\mathrm{C}_{18} \mathrm{H}_{28} \mathrm{~N}_{2} \mathrm{O}_{4}$ & 6,914 & Perindopril & PRD & $\mathrm{C}_{19} \mathrm{H}_{32} \mathrm{~N}_{2} \mathrm{O}_{5}$ & 10,378 \\
\hline Bisoprolol & BIS & $\mathrm{C}_{18} \mathrm{H}_{31} \mathrm{NO}_{4}$ & 8,543 & Propranolol & PRN & $\mathrm{C}_{16} \mathrm{H}_{21} \mathrm{NO}_{2}$ & 8,845 \\
\hline Celiprolol & CLP & $\mathrm{C}_{20} \mathrm{H}_{33} \mathrm{~N}_{3} \mathrm{O}_{4}$ & 8,008 & Sotalol & STL & $\mathrm{C}_{12} \mathrm{H}_{20} \mathrm{~N}_{2} \mathrm{O}_{3} \mathrm{~S}$ & 2,396 \\
\hline Flecainida & FLE & $\mathrm{C}_{17} \mathrm{H}_{20} \mathrm{~F}_{6} \mathrm{~N}_{2} \mathrm{O}_{3}$ & 9,398 & Telmisartan & TEL & $\mathrm{C}_{33} \mathrm{H}_{30} \mathrm{~N}_{4} \mathrm{O}_{2}$ & 13,042 \\
\hline Irbesartan & IST & $\mathrm{C}_{25} \mathrm{H}_{28} \mathrm{~N}_{6} \mathrm{O}$ & 13,546 & & & & \\
\hline
\end{tabular}


Tabela 4.4 (Cont.) Nomenclatura, abreviatura, fórmula química, tempo de retenção $(R t)$ e aplicação dos micropoluentes encontrados na ARU coletada após tratamento secundário através de análises LC-MS/MS.

\begin{tabular}{|c|c|c|c|c|c|c|c|}
\hline Contaminante & Abreviatura & $\begin{array}{l}\text { Fórmula } \\
\text { Química }\end{array}$ & $R t(\min )$ & Contaminante & Abreviatura & $\begin{array}{l}\text { Fórmula } \\
\text { Química }\end{array}$ & $R t$ (min) \\
\hline \multicolumn{8}{|c|}{ Uso no sistema respiratório } \\
\hline Clorfeniramina & $\mathrm{CPMH}$ & $\mathrm{C}_{16} \mathrm{H}_{19} \mathrm{ClN}_{2}$ & 7,21 & Fexofenadina & FEX & $\mathrm{C}_{32} \mathrm{H}_{39} \mathrm{NO}_{4}$ & 11,709 \\
\hline Difenidramina & DPH & $\mathrm{C}_{17} \mathrm{H}_{21} \mathrm{NO}$ & 9,146 & Lidocaina & LDC & $\mathrm{C}_{14} \mathrm{H}_{22} \mathrm{~N}_{2} \mathrm{O}$ & 4,687 \\
\hline Doxilamina & DOX & $\mathrm{C}_{17} \mathrm{H}_{22} \mathrm{~N}_{2} \mathrm{O}$ & 4,707 & & & & \\
\hline \multicolumn{8}{|c|}{ Uso no sistema urinário } \\
\hline \multicolumn{8}{|c|}{ Anti-infecciosos e antibacterianos para uso sistêmico } \\
\hline Claritromicina & CR & $\mathrm{C}_{38} \mathrm{H}_{69} \mathrm{NO}_{13}$ & 11,091 & Sulfapiridina & SPy & $\mathrm{C}_{11} \mathrm{H}_{11} \mathrm{~N}_{3} \mathrm{O}_{2} \mathrm{~S}$ & 4,112 \\
\hline Sulfametoxazol & SMX & $\mathrm{C}_{10} \mathrm{H}_{11} \mathrm{~N}_{3} \mathrm{O}_{3} \mathrm{~S}$ & 6,269 & Trimetoprim & TMP & $\mathrm{C}_{14} \mathrm{H}_{18} \mathrm{~N}_{4} \mathrm{O}_{3}$ & 5,058 \\
\hline \multicolumn{8}{|c|}{ Uso dermatológico } \\
\hline Climbazole & CLZ & $\mathrm{C}_{15} \mathrm{H}_{17} \mathrm{ClN}_{2} \mathrm{O}_{2}$ & 11,118 & Fluconazole(II) & FLC & $\mathrm{C}_{13} \mathrm{H}_{12} \mathrm{~F}_{2} \mathrm{~N}_{6} \mathrm{O}$ & 7,746 \\
\hline Bicalutamida & BIC & $\mathrm{C}_{18} \mathrm{H}_{14} \mathrm{~F}_{4} \mathrm{~N}_{2} \mathrm{O}_{4} \mathrm{~S}$ & 13,426 & Sitagliptina & SGN & $\mathrm{C}_{16} \mathrm{H}_{15} \mathrm{~F}_{6} \mathrm{~N}_{5} \mathrm{O}$ & 6,869 \\
\hline Dietiltoluamida & DEET & $\mathrm{C}_{12} \mathrm{H}_{17} \mathrm{NO}$ & 12,259 & Tiemônio & $\mathrm{TI}$ & $\mathrm{C}_{18} \mathrm{H}_{24} \mathrm{NO}_{2} \mathrm{~S}$ & 6,554 \\
\hline Denatonium & $\mathrm{DE}$ & $\mathrm{C}_{21} \mathrm{H}_{29} \mathrm{~N}_{2} \mathrm{O}$ & 9,267 & Varfarina & WAR & $\mathrm{C}_{19} \mathrm{H}_{16} \mathrm{O}_{4}$ & 13,440 \\
\hline Levofloxacina & LVX & $\mathrm{C}_{18} \mathrm{H}_{20} \mathrm{FN}_{3} \mathrm{O}_{4}$ & 5,640 & & & & \\
\hline
\end{tabular}


Tabela 4.4 (Cont.) Nomenclatura, abreviatura, fórmula química, tempo de retenção $(R t)$ e aplicação dos micropoluentes encontrados na ARU coletada após tratamento secundário através de análises LC-MS/MS.

\begin{tabular}{|c|c|c|c|c|c|c|c|}
\hline Contaminante & Abreviatura & $\begin{array}{l}\text { Fórmula } \\
\text { Química }\end{array}$ & $R t(\min )$ & Contaminante & Abreviatura & $\begin{array}{l}\text { Fórmula } \\
\text { Química }\end{array}$ & $R t(\min )$ \\
\hline \multicolumn{8}{|c|}{ Outras substâncias } \\
\hline Fipronil & FIP & $\mathrm{C}_{12} \mathrm{H}_{4} \mathrm{C}_{12} \mathrm{~F}_{6} \mathrm{~N}_{4} \mathrm{OS}$ & 15,769 & Sucralose & SUC & $\mathrm{C}_{12} \mathrm{H}_{19} \mathrm{C}_{13} \mathrm{O}_{8}$ & 6,055 \\
\hline Nitrofenolato & NP & $\mathrm{C}_{6} \mathrm{H}_{5} \mathrm{NO}_{3}$ & 6,144 & Terbutrin & $\mathrm{TB}$ & $\mathrm{C}_{10} \mathrm{H}_{19} \mathrm{~N}_{5} \mathrm{~S}$ & 12,140 \\
\hline Ácido ritalínico & RA & $\mathrm{C}_{13} \mathrm{H}_{17} \mathrm{NO}_{2}$ & 5,993 & Tolueno-2-sulfonamida & TSN & $\mathrm{C}_{7} \mathrm{H}_{9} \mathrm{NO}_{2} \mathrm{~S}$ & 5,886 \\
\hline Fipronil & FIP & $\mathrm{C}_{12} \mathrm{H}_{4} \mathrm{C}_{12} \mathrm{~F}_{6} \mathrm{~N}_{4} \mathrm{OS}$ & 15,769 & Sucralose & SUC & $\mathrm{C}_{12} \mathrm{H}_{19} \mathrm{C}_{13} \mathrm{O}_{8}$ & 6,055 \\
\hline
\end{tabular}




\section{CONCLUSÕES DO CAPÍTULO 4}

Os materiais $\mathrm{TiO}_{2} / \mathrm{SBA}-15$ mostraram ser capazes de degradar o contaminante emergente SDZ no fotorreator FluHelik. A SBA-15 pura adsorveu mais SDZ que os materiais $\mathrm{TiO}_{2} / \mathrm{SBA}-15$, mas este resultado não interferiu na fotodegradação do fármaco, de modo que o material 30\% $\mathrm{TiO}_{2} / \mathrm{SBA}-15$ apresentou melhor desempenho em porcentagem de degradação em até quatro ciclos de reuso.

A variação na quantidade do catalisador $30 \% \mathrm{TiO}_{2} / \mathrm{SBA}-15$ permitiu melhorar o desempenho quanto à degradação fotocatalítica do fármaco, alcançando o máximo em $C_{\mathrm{TiO} 2}$ de $100 \mathrm{mg} \mathrm{L}^{-1}$. Ao mudar a matriz de água pura para ARU, o material 30\% $\mathrm{TiO}_{2} / \mathrm{SBA}-15$ mostrou melhor desempenho que o fotocatalisador comercial $\mathrm{TiO}_{2} \mathrm{P}-25$.

$\mathrm{Na}$ matriz ARU, os experimentos utilizando a SDZ na concentração de $40 \mu \mathrm{g} \mathrm{L}^{-1}$ mostraram que o fotocatalisador $30 \% \mathrm{TiO}_{2} / \mathrm{SBA}-15$ foi capaz de remover $90 \%$ deste fármaco e eliminar quase completamente os demais fármacos presentes nessa matriz.

Estes resultados indicam que $\mathrm{TiO}_{2} / \mathrm{SBA}-15$ tem potencial para ser aplicado em sistemas heterogêneos para a remediação de águas contaminadas com fármacos e outros microcontaminantes. 


\section{CONCLUSÕES GERAIS}

Nesta Tese de Doutorado, foi possível demonstrar a síntese, caracterização e avaliação do desempenho fotocatalítico dos materiais $\mathrm{TiO}_{2} / \mathrm{SBA}-15$ e PMONDI à base de sílicas mesoporosas para a degradação do contaminante emergente SDZ.

Como pode ser observado, cada sistema fotocatalítico utilizado nos Capítulos 2, 3 e 4 foi bastante distinto, tendo havido variação de concentração inicial e volume da solução de SDZ, do material fotocatalisador e de sua massa, bem como da fonte radiante utilizada, tornando difícil uma efetiva comparação entre os sistemas.

De fato, o intuito do trabalho não era esse tipo de comparação, e sim a avaliação e comparação do desempenho fotocatalítico de cada material preparado e do fotocatalisador comercial $\mathrm{TiO}_{2} \mathrm{P} 25$ (Degussa) em cada sistema. Neste contexto, este estudo possibilitou verificar que as PMONDI podem atingir desempenho superior ao do $\mathrm{TiO}_{2} / \mathrm{SBA}-15$ quando utilizadas em suspensão na solução do contaminante alvo no reator batelada, bem como podem apresentar desempenho equivalente ao do $\mathrm{TiO}_{2}$ P25 (Degussa) quando utilizadas em sistema microrreacional, de modo empacotado e fluxo contínuo da solução que contém o contaminante alvo. Outro resultado importante é que o material $30 \% \mathrm{TiO}_{2} / \mathrm{SBA}-15$ apresentou melhor taxa de remoção de SDZ em comparação ao $\mathrm{TiO}_{2}$ P25 (Degussa) quando a matriz (água pura) foi substituída por águas residuais urbanas. Dessa forma, dependendo do sistema a ser tratado, este novo material pode ser um candidato a ser aplicado em substituição ao fotocatalisador comercial.

\section{PERSPECTIVAS FUTURAS}

Mais experimentos com maior número de variações em cada caso devem ser realizados, tais como, uso de diferentes procedimentos de síntese dos materiais $\mathrm{TiO}_{2} / \mathrm{SBA}-15$ e das PMONDI, a fim de averiguar qual a rota é economicamente e ambientalmente mais viável. Pode-se sugerir também o estudo na degradação de poluentes emergentes de outras naturezas químicas, bem como o emprego de matrizes reais de diferentes fontes. Tais testes podem fornecer resultados mais concretos para aplicação destes novos fotocatalisadores em escala amplicada. Estes estudos abrangem as perspectivas futuras desta Tese. 


\section{REFERÊNCIAS}

ACOSTA-SILVA, Y. J. et al. Methylene blue photodegradation over titania-decorated SBA15. Applied Catalysis B: Environmental, v. 110, p. 108-117, 2011.

AHMAD, R. et al. Photocatalytic systems as an advanced environmental remediation : Recent developments, limitations and new avenues for applications. Journal of environmental chemical engineering, v. 4, n. 4, p. 4143-4164, 2016.

ALEMÁN, J. et al. Definitions of terms relating to the structure and processing of sols, gels, networks, and inorganic-organic hybrid materials (IUPAC recommendations 2007). Pure and Applied Chemistry, v. 79, n. 10, p. 1801-1829, 2007.

ANANDAN, S.; YOON, M. Photocatalytic activities of the nano-sized $\mathrm{TiO}_{2}$-supported Yzeolites. Journal of Photochemistry and Photobiology C: Photochemistry Reviews, v. 4, n. 1, p. 5-18, 2003.

ANDRIC, G. et al. Spectroscopy of naphthalene diimides and their anion radicals. Australian Journal of Chemistry, v. 57, n. 10, p. 1011-1019, 2004.

ASEFA, T. et al. Periodic mesoporous organosilicas with organic groups inside the channel walls. Nature, v. 402, n. December, p. 867-871, 1999.

BALAS, F. et al. Confinement and controlled release of bisphosphonates on ordered mesoporous silica-based materials. Journal of the American Chemical Society, v. 128, n. 25, p. 8116-8117, 2006.

BAO, S. et al. Photocatalytic degradation pathway of sulfadiazine over $\mathrm{Ag}-\mathrm{TiO}_{2}$ under visible light irradiation. Research on Chemical Intermediates, v. 44, n. 10, p. 6137-6149, 2018.

BAPTISTA, M. S. et al. Type I and Type II Photosensitized Oxidation Reactions: Guidelines and Mechanistic Pathways. Photochemistry and Photobiology, v. 93, n. 4, p. 912-919, 2017.

BARAN, W. et al. Photocatalytic degradation of sulfa drugs with $\mathrm{TiO}_{2}, \mathrm{Fe}$ salts and $\mathrm{TiO}_{2} / \mathrm{FeCl}_{3}$ in aquatic environment-Kinetics and degradation pathway. Applied Catalysis B: Environmental, v. 90, n. 3-4, p. 516-525, 2009.

BARAN, W. et al. Effects of the presence of sulfonamides in the environment and their influence on human health. Journal of Hazardous Materials, v. 196, p. 1-15, 2011.

BARAN, W.; SOCHACKA, J.; WARDAS, W. Toxicity and biodegradability of sulfonamides and products of their photocatalytic degradation in aqueous solutions. Chemosphere, v. 65, p. 1295-1299, 2006.

BARRETT, E. P.; JOYNER, L. G.; HALENDA, P. P. The determination of pore volume and area distributions in porous substances. I. Computations from nitrogen isotherms. Journal of the American Chemical Society, v. 73, n. 1, p. 373-380, 1951.

BARROS, T. C. et al. Photophysical characterization of a 1,4,5,8-naphthalenediimide derivative. Journal of Photochemistry and Photobiology A: Chemistry, v. 111, n. 1-3, p. 97-104, 1997. 
BATISTA, A. P. S. et al. Correlating the chemical and spectroscopic characteristics of natural organic matter with the photodegradation of sulfamerazine. Water Research, v. 93, p. 20-29, 2016.

BATISTA, A. P. S.; PIRES, F. C. C.; TEIXEIRA, A. C. S. C. Photochemical degradation of sulfadiazine, sulfamerazine and sulfamethazine: Relevance of concentration and heterocyclic aromatic groups to degradation kinetics. Journal of Photochemistry and Photobiology A: Chemistry, v. 286, p. 40-46, 2014.

BECK, J. S. et al. A new family of mesoporous molecular sieves prepared with liquid crystal templates. J. Am. Chem. Soc., v. 114, n. 14, p. 10834-10843, 1992.

BESANÇON, M. et al. Influence of the porous texture of SBA-15 mesoporous silica on the anatase formation in $\mathrm{TiO}_{2}-\mathrm{SiO}_{2}$ nanocomposites. New Journal of Chemistry, v. 40, n. 5, p. 4386-4397, 2016.

BOER, R. et al. Polarized Absorption Spectra of Some Electron- Donor- Acceptor Cyclophanes. Tetrahedron, v. 34, p. 3225-3232, 1978.

BOREEN, A. L.; ARNOLD, W. A.; MCNEILL, K. Photochemical fate of sulfa drugs in then aquatic environment: Sulfa drugs containing five-membered heterocyclic groups. Environmental Science and Technology, v. 38, n. 14, p. 3933-3940, 2004.

BOREEN, A. L.; ARNOLD, W. A.; MCNEILL, K. Triplet-sensitized photodegradation of sulfa drugs containing six-membered heterocyclic groups: Identification of an $\mathrm{SO}_{2}$ extrusion photoproduct. Environmental Science and Technology, v. 39, n. 10, p. 3630-3638, 2005.

BREEZE, A. J. et al. Polymer- perylene diimide heterojunction solar cells. Applied Physics Letters, v. 81, n. 16, p. 3085-3087, 2002.

BRÜHWILER, D. Postsynthetic functionalization of mesoporous silica. Nanoscale, v. 2, n. 6 , p. 887-892, 2010.

BRUNAUER, S.; EMMETT, P. H.; TELLER, E. Adsorption of gases in multimolecular layers. Journal of the American Chemical Society, v. 60, n. 1, p. 309-319, 1938.

BUSUIOC, A. M. et al. Structural features and photocatalytic behaviour of titania deposited within the pores of SBA-15. Applied Catalysis A: General, v. 312, n. 1-2, p. 153-164, 2006.

CALZA, P. et al. Photocatalytic transformations of sulphonamides on titanium dioxide. Applied Catalysis B: Environmental, v. 53, n. 1, p. 63-69, 2004.

CALZADA, L. A. et al. $\mathrm{TiO}_{2}, \mathrm{SnO}_{2}$ and $\mathrm{ZnO}$ catalysts supported on mesoporous SBA-15 versus unsupported nanopowders in photocatalytic degradation of methylene blue. Microporous and Mesoporous Materials, v. 285, n. February, p. 247-258, 2019.

CALZAFERRI, G. et al. Host-guest antenna materials. Angewandte Chemie - International Edition, v. 42, n. 32, p. 3732-3758, 2003.

CANONICA, S. Oxidation of Aquatic Organic Contaminants Indued by Excited Triplet States. Photochemistry, v. 1, p. 2-5, 2007. 
CASTANHEIRA, B. et al. Dye photodegradation employing mesoporous organosilicas functionalized with 1,8-naphthalimides as heterogeneous catalysts. Journal of Photochemistry and Photobiology A: Chemistry, v. 332, 2017.

CASTANHEIRA, B. et al. Synthesis of Novel Periodic Mesoporous Organosilicas Containing 1,4,5,8-Naphthalenediimides within the Pore Walls and Their Reduction To Generate Wall-Embedded Free Radicals. Langmuir, v. 34, n. 28, p. 8195-8204, 2018.

CASTRO, F. L. et al. Solid state fluorescence of a 3,4,9,10-perylenetetracarboxylic diimide derivative encapsulated in the pores of mesoporous silica MCM-41. Microporous and Mesoporous Materials, v. 102, p. 258-264, 2007.

CHATZITAKIS, A. et al. Photocatalytic degradation and drug activity reduction of Chloramphenicol. Water Research, v. 42, p. 386-394, 2008.

CHEN, G. et al. Photophysical properties of a naphthalimide derivative encapsulated within Si-MCM-41, Ce-MCM-41 and Al-MCM-41. Dyes and Pigments, v. 81, n. 2, p. 119-123, 2009.

CHENG, T. et al. Transition-metal-functionalized ordered mesoporous silicas: An overview of sustainable chiral catalysts for enantioselective transformations. Green Chemistry, v. 17, n. 4, p. 2100-2122, 2015.

$\mathrm{CHO}$, M. et al. Linear correlation between inactivation of $\mathrm{E}$. coli and $\mathrm{OH}$ radical concentration in $\mathrm{TiO}_{2}$ photocatalytic disinfection. v. 38, p. 1069-1077, 2004.

CONCEIÇÃO, D. S. et al. Photochemical insights of $\mathrm{TiO}_{2}$ decorated mesoporous SBA-15 materials and their influence on the photodegradation of organic contaminants. Microporous and Mesoporous Materials, v. 253, p. 203-214, 2017.

CORONADO, J. M. et al. Design of advanced photocatalytic materials for energy and environmental applications. Green Energy and Technology. [s.l: s.n.]. v. 71

COSTA FILHO, B. M. et al. Intensification of heterogeneous $\mathrm{TiO}_{2}$ photocatalysis using an innovative micro-meso-structured-photoreactor for n-decane oxidation at gas phase. Chemical Engineering Journal, v. 310, p. 331-341, 2017.

CYCHOSZ, K. A. et al. Recent advances in the textural characterization of hierarchically structured nanoporous materials. Chem. Soc. Rev., v. 46, n. 2, p. 389-414, 2017.

DA'NA, E. Adsorption of heavy metals on functionalized-mesoporous silica: A review. Microporous and Mesoporous Materials, v. 247, p. 145-157, 2017.

DEWIL, R. et al. New perspectives for Advanced Oxidation Processes. Journal of Environmental Management, v. 195, p. 93-99, 2017.

DMITRIENKO, S. G. et al. Recent advances in sample preparation techniques and methods of sulfonamides detection - A review. Analytica Chimica Acta, v. 850, p. 6-25, 2014.

DONG, H. et al. An overview on limitations of $\mathrm{TiO}_{2}$-based particles for photocatalytic degradation of organic pollutants and the corresponding countermeasures. Water Research, v. 79, p. 128-146, 2015. 
DUAN, Y. et al. Efficient sulfadiazine degradation via in-situ epitaxial grow of Graphitic Carbon Nitride $\left(\mathrm{g}-\mathrm{C}_{3} \mathrm{~N}_{4}\right)$ on carbon dots heterostructures under visible light irradiation: Synthesis, mechanisms and toxicity evaluation. Journal of Colloid and Interface Science, v. 561, p. 696-707, 2020.

ELOVITZ, M. S.; GUNTEN, U. VON. Hydroxyl Radical/ Ozone Ratios During Ozonation Processes . I . The Rct Concept. Ozone: Science \& Engineering, v. 21, n. 1999, 1999.

ESPÍNDOLA, J. C. et al. An innovative photoreactor, FluHelik, to promote UVC/H2O2 photochemical reactions: Tertiary treatment of an urban wastewater. Science of the Total Environment, v. 667, p. 197-207, 2019.

FERNÁNDEZ-CASTRO, P. et al. Insight on the fundamentals of advanced oxidation processes: Role and review of the determination methods of reactive oxygen species. Journal of Chemical Technology and Biotechnology, v. 90, n. 5, p. 796-820, 2015.

FOX, M. A. et al. Heterogeneous Photocatalysis. Chemical Reviews, v. 93, p. 341-357, 1993.

GARCÍA-GALÁN, M. J.; DÍAZ-CRUZ, M. S.; BARCELÓ, D. Determination of 19 sulfonamides in environmental water samples by automated on-line solid-phase extractionliquid chromatography - tandem mass spectrometry ( SPE-LC - MS / MS ). Talanta v. 81, p. $355-366,2010$.

GAYA, U. I.; ABDULLAH, A. H. Heterogeneous photocatalytic degradation of organic contaminants over titanium dioxide: A review of fundamentals, progress and problems. Journal of Photochemistry and Photobiology C: Photochemistry Reviews, v. 9, n. 1, p. 1$12,2008$.

GE, L. et al. The importance of reactive oxygen species on the aqueous phototransformation of sulfonamide antibiotics: kinetics, pathways, and comparisons with direct photolysis. Water Research, v. 149, p. 243-250, 2019.

GLIGOROVSKI, S. et al. Environmental Implications of Hydroxyl Radicals ( • OH ). 2015.

GOLE, J. L. et al. Unusual properties and reactivity at the nanoscale. Journal of Physics and Chemistry of Solids, v. 66, n. 2-4, p. 546-550, 2005.

GORGES, R.; MEYER, S.; KREISEL, G. Photocatalysis in microreactors. Journal of Photochemistry and Photobiology A: Chemistry, v. 167, n. 2-3, p. 95-99, 2004.

GREEN, S.; FOX, M. A. Intramolecular Photoinduced Electron Transfer from Nitroxyl Radicals. The Journal of Physical Chemistry, v. 99, n. 40, p. 14752-14757, 1995.

GREENFIELD, S. R. et al. Multistep photochemical charge separation in rod-like molecules based on aromatic imides and diimides. Journal of the American Chemical Society, v. 118, n. 28, p. 6767-6777, 1996.

GUAN, Z. et al. Fabrication of $\mathrm{Co}_{3} \mathrm{O}_{4}$ and $\mathrm{Au}$ co-modified $\mathrm{BiOBr}$ flower-like microspheres with high photocatalytic efficiency for sulfadiazine degradation. Separation and Purification Technology, v. 234, 2020.

HENCH, L. L.; WEST, J. K. The Sol-Gel Process. Chemical Reviews, v. 90, n. 1, p. 33-72, 1990. 
HENDERSON, M. A. A surface science perspective on $\mathrm{TiO}_{2}$ photocatalysis. Surface Science Reports, v. 66, n. 6-7, p. 185-297, 2011.

HIRSCH, R. et al. Occurrence of antibiotics in the aquatic environment. The Science of the Total Environment, v. 225, p. 109-118, 1999.

HOFFMANN, F.; CORNELIUS, M.; MORELL J.; FROBA, M. Silica-based mesoporous organic-inorganic hybrid materials. Angewandte Chemie - International Edition, v. 45, p. 3216-3251, 2006.

HOFFMANN, F.; FRÖBA, M. Vitalising porous inorganic silica networks with organic functions-PMOs and related hybrid materials. Chem. Soc. Rev., v. 40, n. 2, p. 608-620, 2011.

HOFFMANN, M. R. et al. Environmental applications of semiconductor photocatalysis. Chemical Reviews, v. 95, p. 69-96, 1995.

HOUAS, A. et al. Photocatalytic degradation pathway of methylene blue in water. Applied Catalysis B: Environmental, v. 31, p. 145-157, 2001.

HUANG, X. et al. Mechanistic QSAR models for interpreting degradation rates of sulfonamides in UV-photocatalysis systems. Chemosphere, v. 138, p. 183-189, 2015.

ICHINOSE, I.; SENZU, H.; KUNITAKE, T. A Surface Sol-Gel Process of $\mathrm{TiO}_{2}$ and Other Metal Oxide Films with Molecular Precision. Chemistry of Materials, v. 9, n. 6, p. 12961298, 1997.

INAGAKI, S. et al. Novel mesoporous materials with a uniform distribution of organic groups and inorganic oxide in their frameworks. J. Am. Chem. Soc., v. 121, n. 13, p. $9611-$ 9614, 1999.

JI, Y. et al. Sulfate radical-based oxidation of antibiotics sulfamethazine, sulfapyridine, sulfadiazine, sulfadimethoxine, and sulfachloropyridazine: Formation of $\mathrm{SO}_{2}$ extrusion products and effects of natural organic matter. Science of the Total Environment, v. 593594, n. September, p. 704-712, 2017.

JIANG, J.; ZHOU, Z.; SHARMA, V. K. Occurrence , transportation , monitoring and treatment of emerging micro-pollutants in waste water - A review from global views. Microchemical Journal, v. 110, p. 292-300, 2013.

JUNG, W. Y. et al. Synthesis of $\mathrm{TiO}_{2}$ supported on SBA-15 using different method and their photocatalytic activity. Journal of Nanoscience and Nanotechnology, v. 11, n. 8, p. 74467450, 2011.

KLUČÁKOVÁ, M. Size and charge evaluation of standard humic and fulvic acids as crucial factors to determine their environmental behavior and impact. Frontiers in Chemistry, v. 6, n. JUL, p. 1-8, 2018.

KOBAISI, M. AL et al. Functional naphthalene diimides: synthesis, properties, and applications. Chemical Reviews, v. 116, p. 11685-11796, 2016.

KONG, W. et al. Fabrication of 3D Sponge@ AgBr-AgCl/Ag and Tubular Photoreactor for Continuous Wastewater Purification under Sunlight Irradiation. ACS Sustainable Chemistry and Engineering, v. 7, n. 16, p. 14051-14063, 2019. 
KONSTANTINOU, I. K.; ALBANIS, T. A. TiO 2 -assisted photocatalytic degradation of azo dyes in aqueous solution: Kinetic and mechanistic investigations: A review. Applied Catalysis B: Environmental, v. 49, p. 1-14, 2004.

KRIVEC, M. et al. Highly efficient $\mathrm{TiO}_{2}$-based microreactor for photocatalytic applications. ACS Applied Materials and Interfaces, v. 5, n. 18, p. 9088-9094, 2013.

KRUK, M. et al. Characterization of the porous structure of SBA-15. Chemistry of Materials, v. 12, n. 7, p. 1961-1968, 2000.

KÜMMERER, K. Antibiotics in the aquatic environment - A review - Part I. Chemosphere, v. 75, n. 4, p. 417-434, 2009a.

KÜMMERER, K. Antibiotics in the aquatic environment - A review - Part II. Chemosphere, v. 75, n. 4, p. 435-441, 2009 b.

LACHHEB, H. et al. Photocatalytic degradation of various types of dyes (Alizarin S, Crocein Orange G, Methyl Red, Congo Red, Methylene Blue) in water by UV-irradiated titania. Applied Catalysis B: Environmental, v. 39, p. 75-90, 2002.

LACHHEB, $\mathrm{H}$. et al. Photocatalytic activity of $\mathrm{TiO}_{2}-\mathrm{SBA}-15$ under UV and visible light. Journal of Photochemistry and Photobiology A: Chemistry, v. 226, n. 1, p. 1-8, 2011.

LAKSHMI, S.; RENGANATHAN, R.; FUJITA, S. Study on $\mathrm{TiO}_{2}$-mediated photocatalytic degradation of methylene blue. Journal of Photochemistry and Photobiology A: Chemistry, v. 88, p. 163-167, 1995.

LANGHALS, H. Cyclic carboxylic imide structures as structure elements of high stability. Novel developments in perylene dye chemistry. Heterocycles, v. 40, n. 1, p. 477-500, 1995.

LARSSON, D. G. J.; DE PEDRO, C.; PAXEUS, N. Effluent from drug manufactures contains extremely high levels of pharmaceuticals. Journal of Hazardous Materials, v. 148, n. 3, p. 751-755, 2007.

LASTRE-ACOSTA, A. M. et al. Direct and indirect photolysis of the antibiotic enoxacin: kinetics of oxidation by reactive photo-induced species and simulations. Environmental Science and Pollution Research, v. 26, n. 5, p. 4337-4347, 2018.

LI, G.; ZHAO, X. S. Characterization and photocatalytic properties of titanium-containing mesoporous SBA-15. Industrial and Engineering Chemistry Research, v. 45, n. 10, p. 3569-3573, 2006.

LI, Q. et al. Z-Scheme BiOCl-Au-CdS Heterostructure with Enhanced Sunlight-Driven Photocatalytic Activity in Degrading Water Dyes and Antibiotics. ACS Sustainable Chemistry and Engineering, v. 5, n. 8, p. 6958-6968, 2017.

LI, Y. et al. Grafting of amines on ethanol-extracted SBA-15 for $\mathrm{CO}_{2}$ adsorption. Materials, v. 6, p. 981-999, 2013.

LI, Y. et al. Insights into photolytic mechanism of sulfapyridine induced by triplet-excited dissolved organic matter. Chemosphere, v. 147, n. 3, p. 305-310, 2016.

LIANG, G. et al. A highly selective heterogeneous fluorescent sensor for palladium ions. Anal. Methods, v. 7, n. 12, p. 4877-4880, 2015. 
LIOU, T. H. et al. Direct synthesis of nano titania on highly-ordered mesoporous SBA-15 framework for enhancing adsorption and photocatalytic activity. Journal of Porous Materials, v. 25, n. 5, p. 1337-1347, 2018.

LIU, C. et al. Enhanced photocatalytic performance of mesoporous $\mathrm{TiO}_{2}$ coated SBA-15 nanocomposites fabricated through a novel approach: supercritical deposition aided by liquid-crystal template. Materials Research Bulletin, v. 75, p. 25-34, 2016 a.

LIU, X. et al. Heterogeneous catalysis for water oxidation by an iridium complex immobilized on bipyridine-periodic mesoporous organosilica. Angewandte Chemie International Edition, v. 55, n. 28, p. 7943-7947, 2016 b.

LIU, X. et al. Performance and mechanism into $\mathrm{TiO}_{2} /$ Zeolite composites for sulfadiazine adsorption and photodegradation. Chemical Engineering Journal, v. 350, n. June, p. 131$147,2018$.

LÓPEZ-MUÑOZ, M. J. et al. Role of the support on the activity of silica-supported $\mathrm{TiO}_{2}$ photocatalysts: Structure of the $\mathrm{TiO}_{2} / \mathrm{SBA}-15$ photocatalysts. Catalysis Today, v. 101, n. 3- 4 SPEC. ISS., p. 307-314, 2005.

LOSEY, M. W.; SCHMIDT, M. A.; JENSEN, K. F. A Micro Packed Bed Reactor. $3^{\text {rd }}$ International conference on Micro reaction Technology, 1999.

LUAN, Z.; KEVAN, L. Characterization of titanum-containing mesoporous silica molecular sieve SBA-15 and generation of paramegnetic hole and electron centers. Microporous and Mesoporous Materials, v. 44-45, p. 337-344, 2001.

MA, Y. et al. Oxidation of Sulfonamides in Aqueous Solution by UV-TiO $2-\mathrm{Fe}(\mathrm{VI})$. BioMed Research International, v. 2015, n. Vi, 2015.

MAJEWSKY, M. et al. Antibacterial activity of sulfamethoxazole transformation products (TPs): General relevance for sulfonamide TPs modified at the para position. Chemical Research in Toxicology, v. 27, n. 10, 2014.

MARCON, R. O.; BROCHSZTAIN, S. Highly stable 3,4,9,10-perylenediimide radical anions immobilized in robust zirconium phosphonate self-assembled films. Langmuir, v. 23, n. 24, p. 11972-11976, 2007.

MARTINEZ, J. L. Environmental pollution by antibiotics and by antibiotic resistance determinants. Environmental Pollution, v. 157, n. 11, p. 2893-2902, 2009.

MATSUSHITA, Y. et al. Photocatalytic reactions in microreactors. Chemical Engineering Journal, v. 135, n. SUPPL. 1, p. 303-308, 2008.

MAUČEC, D. et al. Titania versus zinc oxide nanoparticles on mesoporous silica supports as photocatalysts for removal of dyes from wastewater at neutral $\mathrm{pH}$. Catalysis Today, v. 310, n. February 2017, p. 32-41, 2018.

MCNEILL, K.; CANONICA, S. Triplet state dissolved organic matter in aquatic photochemistry: Reaction mechanisms, substrate scope, and photophysical properties. Environmental Science: Processes and Impacts, v. 18, n. 11, p. 1381-1399, 2016.

MEHRABADI, B. A. T. et al. A Review of Preparation Methods for Supported Metal Catalysts. [s.l: s.n.]. v. 61 
MEHTA, A. et al. Effect of silica/titania ratio on enhanced photooxidation of industrial hazardous materials by microwave treated mesoporous $\mathrm{SBA}^{-15} / \mathrm{TiO}_{2}$ nanocomposites. Journal of Nanoparticle Research, v. 18, n. 7, p. 1-9, 2016.

MELDE, B. J. et al. Mesoporous sieves with unified hybrid inorganic/ organic frameworks. Chem. Mater., v. 11, n. 18, p. 3302-3308, 1999.

MELÉNDEZ-ORTIZ, H. I. et al. Synthesis of spherical SBA-15 mesoporous silica. Influence of reaction conditions on the structural order and stability. Ceramics International, p. 1-7, 2015.

MENG, Q. et al. Multifunctional mesoporous silica material used for detection and adsorption of $\mathrm{Cu}^{2+}$ in aqueous solution and biological applications in vitro and in vivo. Advanced Functional Materials, v. 20, n. 12, p. 1903-1909, 2010.

MILLER, L. L.; MANN, K. R. $\pi$-Dimers and $\pi$-Stacks in Solution and in Conducting Polymers. Accounts of Chemical Research, v. 4842, n. c, p. 417-423, 1996.

MIZOSHITA, N. et al. Energy and electron transfer from fluorescent mesostructured organosilica framework to guest dyes. Langmuir, v. 28, n. 8, p. 3987-3994, 2012a.

MIZOSHITA, N. et al. Mesoporous organosilica hybrids consisting of silica-wrapped $\pi-\pi$ Stacking columns. Angewandte Chemie - International Edition, v. 51, n. 5, p. 1156-1160, $2012 b$.

MIZOSHITA, N.; TANI, T.; INAGAKI, S. Syntheses, properties and applications of periodic mesoporous organosilicas prepared from bridged organosilane precursors. Chemical Society reviews, v. 40, n. 2, p. 789-800, 2011.

MOREIRA, F. C. et al. Selecting the best piping arrangement for scaling-up an annular channel reactor: An experimental and computational fluid dynamics study. Science of the Total Environment, v. 667, p. 821-832, 2019.

MOSTAFA, S.; ROSARIO-ORTIZ, F. L. Singlet oxygen formation from wastewater organic matter. Environmental science \& technology, v. 47, n. 15, p. 8179-86, 2013.

MUNIRATHINAM, R.; HUSKENS, J.; VERBOOM, W. Supported catalysis in continuousflow microreactors. Advanced Synthesis and Catalysis, v. 357, n. 6, p. 1093-1123, 2015.

OPPENLANDER, T. Photochemical purification of water and air. [s.l: s.n.].

PAÍGA, P. et al. Assessment of 83 pharmaceuticals in WWTP influent and effluent samples by UHPLC-MS/MS: Hourly variation. Science of the Total Environment, v. 648, p. 582$600,2019$.

PARAMBADATH, S. et al. Periodic mesoporous organosilica ( PMO ) containing bridged succinamic acid groups as a nanocarrier for sulfamerazine, sulfadiazine and famotidine: Adsorption and release study. Microporous and Mesoporous Materials, v. 225, p. 174-184, 2016.

PERATHONER, S. et al. Use of mesoporous SBA-15 for nanostructuring titania for photocatalytic applications. Microporous and Mesoporous Materials, v. 90, n. 1-3, p. 347361, 2006. 
PERES, J. C. G. et al. Study of an Annular Photoreactor with Tangential Inlet and Outlet: I.Fluid Dynamics. Chemical Engineering and Technology, v. 38, n. 2, p. 311-318, 2015.

PERES, J. C. G. et al. Study of an Annular Photoreactor with Tangential Inlet and Outlet. II. The UV/H2O2 Reactive Flow. Chemical Engineering and Technology, v. 42, n. 2, p. 316$326,2019$.

PERIŠA, M. et al. Photodegradation of sulfonamides and their N4-acetylated metabolites in water by simulated sunlight irradiation: Kinetics and identification of photoproducts. Environmental Science and Pollution Research, v. 20, n. 12, p. 8934-8946, 2013.

PETRIE, B. et al. Multi-residue analysis of 90 emerging contaminants in liquid and solid environmental matrices by ultra-high-performance liquid chromatography tandem mass spectrometry. Journal of Chromatography A, v. 1431, p. 64-78, 2016.

POPOVA, M. D. et al. Carboxylic modified spherical mesoporous silicas s drug delivery carriers. International Journal of Pharmaceutics, v. 436, n. 1-2, p. 778-785, 2012.

RAMOS, B. et al. Micro-structured packed bed reactors for solar photocatalysis: impacts of packing size and material on light harnessing. Photochemical and Photobiological Sciences, v. 18 , n. 2 , p. $577-582,2019$.

RIBEIRO, A. R. et al. An overview on the advanced oxidation processes applied for the treatment of water pollutants defined in the recently launched Directive 2013/39/EU. Environment international, v. 75, p. 33-51, 2015.

RIZZO, L. et al. Consolidated vs new advanced treatment methods for the removal of contaminants of emerging concern from urban wastewater. Science of the Total Environment, v. 655, p. 986-1008, 2019.

ROGERS, J. E.; KELLY, L. A. Nucleic acid oxidation mediated by naphthalene and benzophenone imide and diimide derivatives: Consequences for DNA redox chemistry. Journal of the American Chemical Society, v. 121, n. 16, p. 3854-3861, 1999.

ROGERS, J. E.; WEISS, S. J.; KELLY, L. A. Photoprocesses of naphthalene imide and diimide derivatives in aqueous solutions of DNA. Journal of the American Chemical Society, v. 122, n. 3, p. 427-436, 2000.

SACCO, O.; SANNINO, D.; VAIANO, V. Packed bed photoreactor for the removal of water pollutants using visible light emitting diodes. Applied Sciences (Switzerland), v. 9, n. 3, 2019.

SCARPELLI, F. et al. Mesoporous $\mathrm{TiO}_{2}$ Thin Films: State of the Art. In: Titanium Dioxide Material for a Sustainable Environment. [s.l: s.n.]. p. 57-80.

SCHYMANSKI, E. L. et al. Identifying small molecules via high resolution mass spectrometry: Communicating confidence. Environmental Science and Technology, v. 48, n. 4, p. 2097-2098, 2014.

SHANDILYA, M.; RAI, R.; SINGH, J. Review: Hydrothermal technology for smart materials. Advances in Applied Ceramics, v. 115, n. 6, p. 354-376, 2016. 
SILVA, M. P. et al. Photochemical fate of amicarbazone in aqueous media: laboratory measurement and simulations. Environmental Engineering Science, v. 32, n. 8, p. 1-11, 2015 .

SING, K. S. W. et al. International union of pure and applied chemistry(IUPAC). Pure Appl. Chem., v. 57, p. 603-619, 1985.

SOON, A. N.; HAMEED, B. H. Heterogeneous catalytic treatment of synthetic dyes in aqueous media using Fenton and photo-assisted Fenton process. Desalination, v. 269, n. 1-3, p. 1-16, 2011.

STARLING, M. C. V. M.; AMORIM, C. C.; LEÃO, M. M. D. Occurrence, control and fate of contaminants of emerging concern in environmental compartments in Brazil. Journal of Hazardous Materials, v. 372, n. April 2018, p. 17-36, 2019.

SUNDAR, K. P.; KANMANI, S. Progression of Photocatalytic reactors and it's comparison: A Review. Chemical Engineering Research and Design, v. 154, p. 135-150, 2020.

TIAN, H. et al. One-pot sustainable synthesis of magnetic MIL-100(Fe) with novel Fe3O4 morphology and its application in heterogeneous degradation. Dalton Transactions, v. 47, $\mathrm{n}$. 10, p. 3417-3424, 2018.

TIJANI, J. O. et al. Pharmaceuticals, endocrine disruptors, personal care products, nanomaterials and perfluorinated pollutants: a review. Environmental Chemistry Letters, p. $1-3,2015$.

TRANG, T. N. H.; ALI, Z.; KANG, D. J. Mesoporous $\mathrm{TiO}_{2}$ Spheres Interconnected by Multiwalled Carbon Nanotubes as an Anode for High-Performance Lithium Ion Batteries. ACS Applied Materials \& Interfaces, v. 7, p. 3676-3683, 2015.

TRINDADE, F. D. J. et al. Color- tunable fluorescence and white light emission from mesoporous organosilicas based on energy transfer from 1,8-naphthalimide hosts to perylenediimide guests. The Journal of Physical Chemistry C, v. 119, p. 26989-26998, 2015.

TRINDADE, F. J. et al. Covalent attachment of 3,4,9,10-perylenediimides onto the walls of mesoporous molecular sieves MCM-41 and SBA-15. Microporous and Mesoporous Materials, v. 113, n. 1-3, p. 463-471, 2008.

TRINDADE, F. J.; REY, J. F. Q.; BROCHSZTAIN, S. Modification of molecular sieves MCM-41 and SBA-15 with covalently grafted pyromellitimide and 1,4,5,8naphthalenediimide. Journal of Colloid and Interface Science, v. 368, n. 1, p. 34-40, 2012.

TRINDADE, F.; QUEIRUGA REY, J. F.; BROCHSZTAIN, S. Covalent attachment of 4amino-1,8-naphthalimides onto the walls of mesoporous molecular sieves MCM-41 and SBA15. Dyes and Pigments, v. 89, n. 2, p. 97-104, 2011.

TSENG, H. H. et al. Synthesis of $\mathrm{TiO}_{2} / \mathrm{SBA}-15$ photocatalyst for the azo dye decolorization through the polyol method. Chemical Engineering Journal, v. 210, p. 529-538, 2012.

VAN GERVEN, T. et al. A review of intensification of photocatalytic processes. Chemical Engineering and Processing: Process Intensification, v. 46, n. 9 SPEC. ISS., p. 781-789, 2007. 
VAN GRIEKEN, R. et al. Synthesis of size-controlled silica-supported $\mathrm{TiO}_{2}$ photocatalysts. Journal of Photochemistry and Photobiology A: Chemistry, v. 148, n. 1-3, p. 315-322, 2002.

VAVSARI, V. F.; ZIARANI, M.G.; BADIEI, A. The role of SBA-15 in drug delivery. RSC Adv., v. 5, n. 111, p. 91686-91707, 2015.

VIEHBECK, A. Electrochemical Properties of Polyimides and Related Imide Compounds. Journal of The Electrochemical Society, v. 137, n. 5, p. 1460, 1990.

WAHAB, M. A.; HUSSAIN, H.; HE, C. Photoactive perylenediimide-bridged silsesquioxane functionalized periodic mesoporous organosilica thin films (PMO-SBA15): Synthesis, selfassembly, and photoluminescent and enhanced mechanical properties. Langmuir, v. 25, n. 8, p. 4743-4750, 2009.

WANG, W.; KU, Y. The light transmission and distribution in an optical fiber coated with TiO2 particles. Chemosphere, v. 50, n. 8, p. 999-1006, 2003.

WANG, X. et al. Direct synthesis and catalytic applications of ordered large pore aminopropyl-functionalized SBA-15 mesoporous materials. Journal of Physical Chemistry B, v. 109, n. 5, p. 1763-1769, 2005.

WEBLER, A. D. et al. Development of an integrated treatment strategy for a leather tannery landfill leachate. Waste Management, v. 89, p. 114-128, 2019.

WRIGHT, N. G.; HARGREAVES, D. M. The use of CFD in the evaluation of UV treatment systems. Journal of Hydroinformatics, v. 3, n. 2, p. 59-70, 2001.

WU, Y. et al. Adsorption of tetracycline and sulfonamide antibiotics on amorphous nanocarbon. Desalination and Water Treatment, v. 3994, n. November, p. 1-13, 2016.

XU, C.; ZHAO, X. S.; RANGAIAH, G. P. Performance analysis of ultraviolet water disinfection reactors using computational fluid dynamics simulation. Chemical Engineering Journal, v. 221, p. 398-406, 2013.

XU, M. M.; ZHAO, Y.; YAN, Q. Efficient visible-light photocatalytic degradation of sulfadiazine sodium with hierarchical $\mathrm{Bi}_{7} \mathrm{O}_{9} \mathrm{I}_{3}$ under solar irradiation. Water Science and Technology, v. 72, n. 12, p. 2122-2131, 2015.

$\mathrm{XU}$, X. et al. $\mathrm{Bi}$ spheres SPR-coupled $\mathrm{Cu}_{2} \mathrm{O} / \mathrm{Bi}_{2} \mathrm{MoO}_{6}$ with hollow spheres forming Z-scheme $\mathrm{Cu}_{2} \mathrm{O} / \mathrm{Bi} / \mathrm{Bi}_{2} \mathrm{MoO}_{6}$ heterostructure for simultaneous photocatalytic decontamination of sulfadiazine and Ni(II). Journal of Hazardous Materials, v. 381, n. May 2019, p. 120953, 2020.

YAN, W. et al. Surface sol-gel modification of mesoporous silica materials with $\mathrm{TiO}_{2}$ for the assembly of ultrasmall gold nanoparticles. Journal of Physical Chemistry B, v. 108, n. 9, p. 2793-2796, 2004.

YANG, J. et al. Synthesis of nano titania particles embedded in mesoporous SBA-15: Characterization and photocatalytic activity. Journal of Hazardous Materials, v. 137, n. 2, p. 952-958, 2006. 
YUAN, S. et al. Recent advances of SBA-15-based composites as the heterogeneous catalysts in water decontamination: A mini-review. Journal of Environmental Management, v. 254, 2020.

ZARFL, C.; MATTHIES, M.; KLASMEIER, J. A mechanistical model for the uptake of sulfonamides by bacteria. Chemosphere, v. 70, n. 5, p. 753-760, 2008.

ZHAN, X. et al. Rylene and related diimides for organic electronics. Advanced Materials, v. 23, n. 2, p. 268-284, 2011.

ZHANG, D.; YAN, S.; SONG, W. Photochemically induced formation of reactive oxygen species (ROS) from effluent organic matter. Environmental Science and Technology, v. 48, n. 21, p. 12645-12653, 2014.

ZHANG, T.; DING, Y.; TANG, H. Generation of singlet oxygen over $\mathrm{Bi}(\mathrm{V}) / \mathrm{Bi}(\mathrm{III})$ composite and its use for oxidative degradation of organic pollutants. Chemical Engineering Journal, v. 264, p. 681-689, 2015.

ZHANG, Z. et al. Thermal detemplation of SBA-15 mesophases. Effect of the activation protocol on the framework contraction. Microporous and Mesoporous Materials, v. 176, p. 103-111, 2013.

ZHAO, D. et al. Triblock Copolymer Syntheses of Mesoporous Silica with Periodic 50 to 300 Angstrom Pores. Science, v. 279, n. 1998, p. 548-552, 1998.

ZHAO, D. et al. Rapid and facile synthesis of Ti-MCM-48 mesoporous material and the photocatalytic performance for hydrogen evolution. International Journal of Hydrogen Energy, v. 35, n. 11, p. 5276-5283, 2010. 
ANEXOS 